Universidade de Brasília

Faculdade de Ciências da Saúde

Programa de Pós-Graduação em Enfermagem

CARLA ANDRÉIA ARAÚJO

IMPLICAÇÕES DA ESTOMIA URINÁRIA CONTINENTE NA
QUALIDADE DE VIDA DE PESSOAS COM LESÃO MEDULAR

BRASÍLIA 
UNIVERSIDADE DE BRASÍLIA

FACULDADE DE CIÊNCIAS DA SAÚDE

PROGRAMA DE PÓS-GRADUAÇÃO EM ENFERMAGEM

\author{
CARLA ANDRÉIA ARAÚJO
}

\title{
IMPLICAÇÕES DA ESTOMIA URINÁRIA CONTINENTE NA QUALIDADE DE VIDA DE PESSOAS COM LESÃO MEDULAR
}

Dissertação apresentada como requisito parcial para a obtenção do título de Mestre em Enfermagem pelo Programa de Pós-Graduação em Enfermagem, da Universidade de Brasília. Área de Concentração: Políticas, práticas e cuidado em saúde e enfermagem.

Linha de pesquisa: Processo de cuidar em Saúde e Enfermagem.

Orientadora: $\operatorname{Prof}^{\mathrm{a}} \operatorname{Dr}^{\mathrm{a}}$ Dirce Bellezi Guilhem

BRASÍLIA 
Ficha catalográfica elaborada pela Biblioteca Central da Universidade de Brasília. Acervo 1019331.

Araújo, Carla Andréia.

A663i Implicações da estamia urinária continente na qual idade de vida de pessoas cam lesão medular / Carla Andréia Araújo. -- 2014.

$182 \mathrm{f}$ : il : $30 \mathrm{~cm}$

Dissertação (mestrado) - Universidade de Brasília, Faculdade de Ciências da Saúde, Programa de Pós-Graduação en Enfermagem, 2014.

Or ientação: Di rce Bell ize Gui Ihem.

Inclui bibliografia.

1. Qual idade de vida. 2. Medula espinhal - Fer imentos e Iesões. 3. Estamia. 4. Reabilitação. 5. Bexiga - Doenças I. Guilhem, Dirce. II. Título. 


\title{
IMPLICAÇÕES DA ESTOMIA URINÁRIA CONTINENTE NA QUALIDADE DE VIDA DE PESSOAS COM LESÃO MEDULAR
}

Dissertação apresentada como requisito parcial para a obtenção do título de Mestre em Enfermagem pelo Programa de Pós-Graduação em Enfermagem, da Universidade de Brasília.

Aprovado em 18 de dezembro de 2014.

\author{
BANCA EXAMINADORA
}

Professora Doutora Dirce Guilhem - Presidente da Banca

Universidade de Brasília

\begin{abstract}
Professora Doutora Ana Lúcia da Silva - Membro Efetivo - externo ao Programa Universidade de Brasília
\end{abstract}

Professora Doutora Leila Bernarda Donato Gottems - Membro Efetivo Universidade de Brasília

Professora Doutora Leides Barroso de Azevedo Moura- Membro Suplente Universidade de Brasília 
Dedico este trabalho às pessoas portadoras de lesão medular e estomia urinária continente, que fazem parte do Programa oferecido pelo Hospital Sarah-Brasília, Distrito Federal, que prontamente se disponibilizaram em participar deste estudo, de forma a torná-lo possível. 


\section{AGRADECIMENTOS}

À Professora Dra. Dirce Bellezi Guilhem, que me orientou com conhecimento, dedicação, presteza, tolerância e de forma acolhedora; sua proficiência é motivo de orgulho para a Enfermagem e inspiração para a formação profissional.

Aos demais professores do Programa de Pós-Graduação em Enfermagem, da Universidade de Brasília, por aguçarem o interesse no conhecimento; especialmente, à professora Ivone Kamada, que me recebeu na condição de Aluna Especial do curso de Mestrado, na disciplina Assistência Integralizada ao Estomizado.

À colega Enfermeira Geila M. Meneguessi, por acreditar e me incentivar na pretensão de me candidatar a uma vaga do Programa de Pós-Graduação em Enfermagem, bem como pelas orientações transmitidas quando precisei.

Ao Hospital Sarah-Brasília, por me permitir realizar este estudo, promovendo a acessibilidade a informações, a recursos didáticos, estrutura física e apoio profissional de excelência.

À Enfermeira Mauren Alexandra Sampaio, pela sua contribuição na análise qualitativa dos dados e sugestões para contextualização.

Ao Centro Nacional de Controle de Qualidade, na pessoa dos estatísticos Eleonora Maria de Jesus Oliveira e Sandro Barbosa de Oliveira, que contribuíram com orientações e sugestões na avaliação dos dados descritivos do estudo.

Agradeço, com grande apreço, à bibliotecária Cristine Sardinha Schneider Lopes, pela atenção a mim dispensada, juntamente com a equipe técnica da biblioteca do Hospital SarahBrasília, que sempre esteve pronta a atender as minhas solicitações de artigos, livros, teses e outras necessidades envolvidas.

Às professoras doutoras que compuseram a minha banca Dirce Guilhem, Ana Lúcia da Silva, Leila Bernarda Donato Gottems e Leides Barroso de Azevedo Moura.

À Dra. Renata Santinoni Vera, por ter disponibilizado artigos relevantes que vieram a enriquecer a minha pesquisa, no que se refere ao foco na Qualidade de Vida e Lesão Medular.

À minha irmã Mariles Araújo Brandão Machado e à minha amiga Lisabel Tabari, pela convivência, conversas e compartilhamento das vivências desse período do mestrado.

Aos meus filhos, Pablo Guillermo, Luís Henrique e Gustavo Andrés, por aceitarem as minhas ausências, mesmo não as compreendendo.

Aos meus familiares e amigos, por compreenderem meus momentos de dedicação exclusiva a este estudo.

À Ermelina Paula (Lina), pela inestimável colaboração ao se dedicar à adequação do trabalho às normas técnicas.

A Deus, que nos instrumentaliza com o potencial do aprendizado. 
Assim brilhe a luz de vocês diante dos homens, para que vejam as suas boas obras e glorifiquem ao Pai de vocês, que estás nos céus.

Mateus 5:16 


\section{RESUMO}

Araújo Carla Andréia. Implicações da Estomia Urinária Continente na qualidade de vida de pessoas com lesão medular. 2014. 182fls. Dissertação (Mestrado) - Departamento de Enfermagem, Faculdade de Ciências da Saúde, Universidade de Brasília, Brasília, DF, 2014.

\section{RESUMO}

A derivação urinária continente é um conduto confeccionado cirurgicamente com partes do intestino na parede inferior do abdome com o objetivo de tornar possível o esvaziamento vesical naquelas pessoas em que o cateterismo intermitente limpo (CIL) não é viável pela uretra. A lesão medular é um evento catastrófico na vida das pessoas e compromete o controle da micção, uma vez que o funcionamento da bexiga está alterado: bexiga neurogênica. Nesses casos, o manejo para o esvaziamento da bexiga acontece pelo autocateterismo intermitente limpo; no entanto, para algumas pessoas com lesão medular e alto grau de comprometimento físico-funcional faz-se necessária a assistência de uma pessoa para os cuidados de vida diária, entre eles, o CIL assistido, comprometendo a autonomia e a privacidade dessas pessoas. Este estudo, uma pesquisa qualitativa fenomenológica, teve como objetivo avaliar a implicação da estomia urinária continente na qualidade de vida das pessoas com lesão medular. A amostra deste estudo se constituiu de 15 pessoas com lesão medular de etiologia traumática ou congênita (tetraplegia, paraplegia e mielomeningocele) com dificuldade de autocateterização por meio da uretra nativa ou por situações de dificuldades apresentadas pelo cuidador em realizar o CIL. Os procedimentos para a coleta dos dados foram: a) a aplicação de questionário específico para se conhecer os dados sociodemográficos e clínicos e a percepção sobre qualidade de vida e a estomia urinária continente; b) a realização de entrevista virtual ou presencial, semiestruturada; e c) revisão em prontuário eletrônico. Foi efetuada estatística descritiva e Análise de Conteúdo conforme proposição de Bardin, para análise das verbalizações dos participantes. Os resultados demonstraram que houve predominância de pessoas do sexo feminino, na faixa etária entre 16 e 48 anos, com baixa escolaridade. O subgrupo mais representativo de injúrias medulares foi o de pessoas com tetraplegia, seguido de mielomeningocele. A maioria dos participantes tornou-se independente para o manejo do esvaziamento vesical, e o número de infecções urinárias após a confecção da derivação e ampliação vesical diminuiu. Pode-se inferir que a maioria dos respondentes (14) se sente satisfeita com a derivação urinária e que, com relação à melhoria da qualidade de vida, 12 participantes fizeram correlação de forte intensidade (boa e muito boa) com a qualidade de vida. A Análise de Conteúdo de Bardin apontou dez categorias teóricas: "eu tenho mais independência"; "não ficar perdendo xixi"; "minha lesão"; "qualidade de vida pra mim é..."; "falta acessibilidade"; "eu tinha uma vida muito ativa"; "não ligo pra estética"; "não entendem sobre isso"; "um pouco a reclamar"; e "o sexo diminuiu". Na série de casos estudada, confirmou-se que existem implicações positivas da estomia urinária continente na qualidade de vida das pessoas com lesão medular e alto grau de comprometimento físico-funcional, bem como naquelas com inviabilidade de CIL pela uretra nativa.

Descritores: Qualidade de vida. Traumatismos da medula espinhal. Bexiga urinária neurogênica. Coletores de urina. Enfermagem em Reabilitação. 


\begin{abstract}
Continent urinary diversion is a tube surgically designed with parts of the bowel in the lower wall of the abdomen with the aim of making possible the vesical emptying in people whose clean intermittent catheterization (CIC) is not feasible through the urethra. Spinal cord injury is a catastrophic event in people's lives and compromises urination control, since the bladder functioning is altered: neurogenic bladder. In these cases, bladder emptying management happens by clean intermittent self-catheterization; however, for some people with spinal cord injury and high degree of physical-functional compromise, it is necessary the help of a person for daily life care, among them the assisted CIC, which ends up compromising these people's autonomy and privacy. This study, a phenomenological qualitative research, aimed at evaluating the effect of continent urinary stoma in the quality of life of subjects with spinal cord injury. The sampling of this study was composed of 15 subjects with spinal cord injury of traumatic or congenital etiology (tetraplegia, paraplegia or myelomeningocele), with difficulties of self-catheterization through the native urethra or difficulty situations presented by the caregiver when performing the CIC. Procedures for data collection were: a) use of a specific questionnaire to find what are the sociodemographic and clinical data and the perception about quality of life and continent urinary stoma; b) performance of online or present semi-structured interviews; and c) electronic record review. Descriptive statistics and content analysis were carried out according to Bardin's proposal in order to analyze the participants' verbalizations. Results showed predominance of the female gender, from 16 to 48 years old, with low educational level. The most representative subgroup of spinal cord injury was of tetraplegia subjects, followed by myelomeningocele ones. Most participants became independent for management of vesical emptying, and the number of urinary infections after the vesical diversion and amplification confection decreased. We can state that most respondents (14) is satisfied with urinary diversion and that, according to quality of life improvement, 12 participants made a strong correlation (good and very good) with the quality of life. Bardin's content analysis pointed out ten theoretical categories: "I am more independent"; "I don't lose my willingness to pee"; "my lesion"; "quality of life for me is...", "lack of accessibility"; "I had a very active life"; "I don't care about esthetics"; "do not understand this"; "a little to complain" and "sex decreased". In the cases studied, positive implication of continent urinary stoma in the quality of life of subjects with spinal cord injury and high degree of physical-functional compromise were confirmed, as well as CIC impracticability due to native urethra.
\end{abstract}

Descriptors: Quality of life. Spinal cord injuries. Urinary bladder neurogenic. Continent urinary reservoirs. Rehabilitation nursing. 


\section{RESUMEN}

Derivación urinaria continente es un conducto hecho por medio de cirugía con partes del intestino en la pared más baja del abdomen, con el objetivo de tornar posible el vaciamiento vesical en las personas en las cuales el cateterismo intermitente limpio (CIL) no es viable por la uretra. La lesión medular es un evento catastrófico en la vida de personas y compromete el control de micción, ya que el funcionamiento de vejiga es alterado: vejiga neurógena. En esos casos, el manejo para el vaciamiento de la vejiga ocurre por el auto-cateterismo intermitente limpio; aunque para algunas personas con lesión medular y alto grado de comprometimiento físico-funcional, es necesaria la asistencia de un cuidador para los tratamientos de vida diaria como el CIL asistido, lo que compromete la autonomía y privacidad de esos individuos. El presente estudio, una investigación cualitativa fenomenológica, tuvo como objetivo la evaluación de la implicación de ostomía urinaria continente en la calidad de vida de personas con lesión medular. El muestreo de eso estudio se constituyó de 15 sujetos con lesión medular de etiología traumática o congénita (tetraplejía, paraplejía y mielomeningocele) con dificultad de auto-cateterismo por medio de la uretra nativa o por situaciones de dificultades presentadas por el cuidador al realizar el CIL. Los procedimientos para la coleta de datos fueron: a) la aplicación de un cuestionario específico para conocerse los datos sociodemográficos y clínicos y la percepción a respeto de calidad de vida y ostomía urinaria continente; b) la realización de entrevistas semiestructuradas virtuales o presenciales; y c) la revisión en prontuario electrónico. Fueron conducidos estadística descriptiva y análisis de contenido siguiendo la proposición de Bardin para análisis de verbalizaciones de los participantes. Los resultados mostraron que hubo predominancia del género femenino, entre 16 y 48 años de edad, con bajo nivel educacional. El subgrupo más representativo de lesiones medulares fue lo de personas con tetraplejía, seguido del mielomeningocele. La mayoría de los participantes se tornaron independientes para el manejo del vaciamiento vesical, y la cantidad de infecciones urinarias después de la confección de derivación y amplificación vesical se disminuyó. Es posible inferir que la mayoría de los respondientes (14) están satisfechos con la derivación urinaria y que con relación a la mejoría de la calidad de vida, 12 participantes hicieron una fuerte correlación (buena y muy buena) con la calidad de vida. El análisis de contenido de Bardin apuntó diez categorías teóricas: "Yo tengo más independencia"; "no dejo de hacer pipí"; "mi lesión"; "cualidad de vida para mi es..."; "no hay accesibilidad"; "yo tenía una vida muy activa"; "no me importo con estética"; "no entienden de eso"; "un poco a reclamar"; y "el sexo disminuyó". En los casos estudiados, se confirmó que hay una implicación positiva del ostomía urinaria continente en la calidad de vida de personas con lesión medular y alto grado de comprometimiento físico-funcional, así como en las personas con inviabilidad de CIL por la uretra nativa.

Descriptores: Calidad de vida. Traumatismos de la médula espinal. Vejiga urinaria neurogénica. Reservorios urinarios continentes. Enfermería en Rehabilitación. 


\section{LISTA DE FIGURAS}

Figura 1 - Qualidade de vida após a derivação urinária continente................................61

Figura 2 - Avaliação da satisfação com a derivação urinária continente. ........................61 


\section{LISTA DE TABELAS}

Tabela 1 - Características sociodemográficas e clínicas dos entrevistados, no período de agosto de 2003 a setembro de 2013. Brasília, DF.

Tabela 2 - Indicações cirúrgicas e complicações informadas sobre a derivação urinária continente, no período de agosto de 2003 a setembro de 2013. Brasília, DF

Tabela 3 - Manejo da bexiga neurogênica e controle da atividade detrusora com medicação, após a derivação urinária, no período de agosto de 2003 a setembro de 2013. Brasília, DF. 58

Tabela 4 - Tipo de bexiga antes e após a derivação urinária, capacidade vesical após a ampliação vesical e derivação urinária e uso de medicação após a derivação urinária - no período de agosto de 2003 a setembro de 2013. Brasília, DF. 59

Tabela 5 - Distribuição dos episódios de infecção urinária antes e após a derivação urinária com e sem ampliação vesical, no período de agosto de 2003 a setembro de 2013. Brasília, DF.

Tabela 6 - Aspectos que melhoraram após a derivação urinária, no período de agosto de 2003 a setembro de 2013. Brasília, DF. 


\section{LISTA DE ABREVIATURA E SIGLAS}

CIL

Cateterismo Intermitente Limpo

QV

Qualidade de Vida

OMS

Organização Mundial de Saúde

IDH

Índice de Desenvolvimento Humano

IQV

Índice de Qualidade de Vida

QALY

Quality-adjusted life-years

DALY

Disability-adjusted life-years

AVCI

Anos de Vida Corrigidos pela Incapacidade

QVRS

Qualidade de Vida Relacionada à Saúde

WHOQOL

World Health Organization Quality of Life

WHOQOL-100

The World Health Organization Quality of Life-100

WHOQOL-brief

The World Heart Organization Quality of life brief

LM

Lesão medular

IBGE

Instituto Brasileiro de Geografia e Estatística

AIS

American Impairment Scale

APS

Associação das Pioneiras Sociais

CNS

Conselho Nacional de Saúde

MS

Ministério da Saúde

CEP

Comitê de Ética em Pesquisa

TCLE

Termo de Consentimento Livre e Esclarecido

$\mathrm{DF}$

Distrito Federal 


\section{SUMÁRIO}

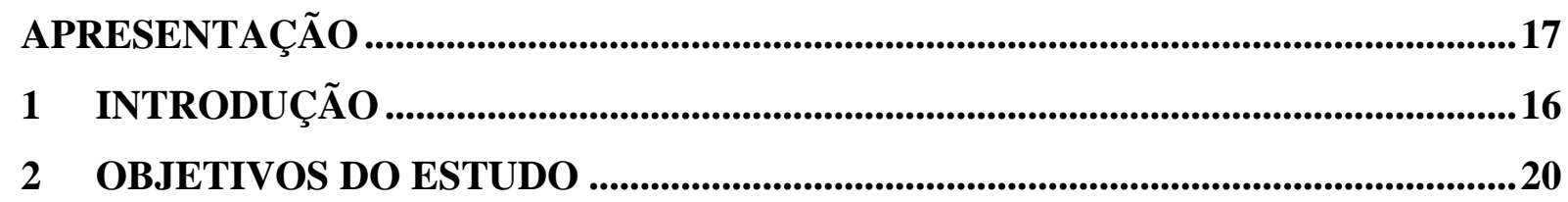

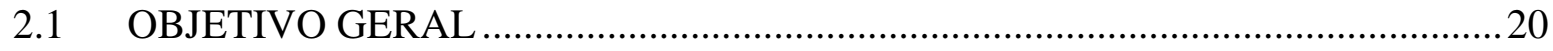

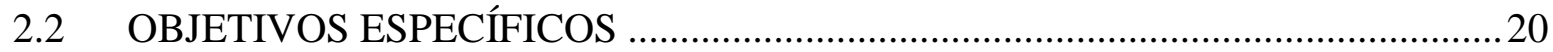

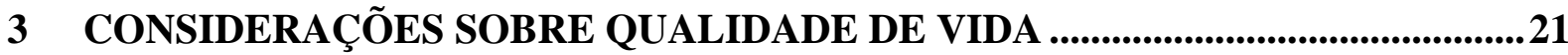

3.1 CONSIDERAÇÕES HISTÓRICAS, FATORES FORMADORES DO CONSTRUCTO QUALIDADE DE VIDA E DEFINIÇÕES ......................................... 21

3.1.1 Classificação da qualidade de vida: global, componente, focal e composta ......22

3.1.2 Índices de qualidade de vida e a compreensão da subjetividade do construto ...23

4 QUALIDADE DE VIDA RELACIONADA À SAÚDE ..........................................24

4.1 A CONTRIBUIÇÃO DAS INTER-RELAÇÕES NA EXPRESSÃO DA QUALIDADE DE VIDA RELACIONADA À SAÚDE .............................................24

4.1.1 Compreensão da qualidade de vida na visão do estudo e da Organização

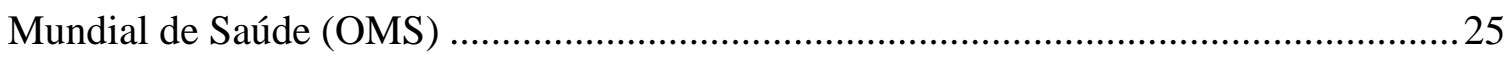

4.1.2 Instrumentos de qualidade de vida da OMS ..................................................26

4.1.3 Relevância dos instrumentos de pesquisa...........................................................2

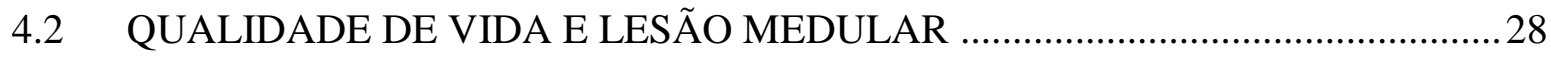

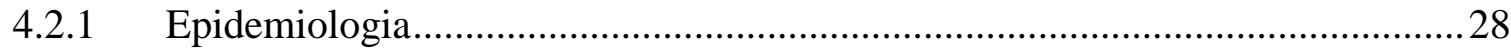

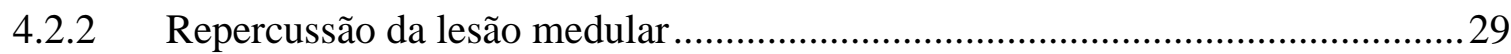

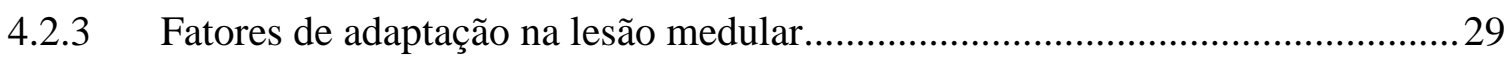

4.2.4 Evidências que influenciam a percepção da qualidade de vida.......................... 31

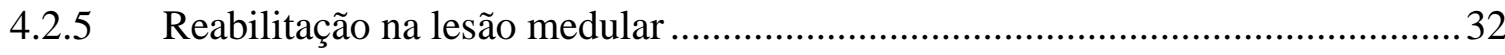

4.3 QUALIDADE DE VIDA E SUA CORRELAÇÃO COM A BEXIGA NEUROGÊNICA E A ESTOMIA URINÁRIA CONTINENTE (DERIVAÇÃO

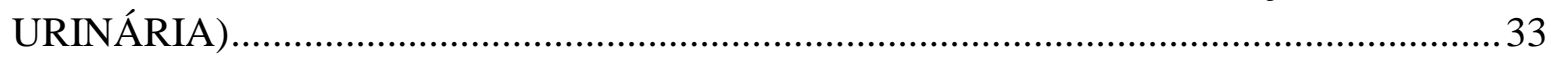

4.3.1 Bexiga neurogênica: fisiologia e manejo ...................................................... 33

4.3.2 Fatores que inviabilizam o autocateterismo e o cateterismo intermitente limpo

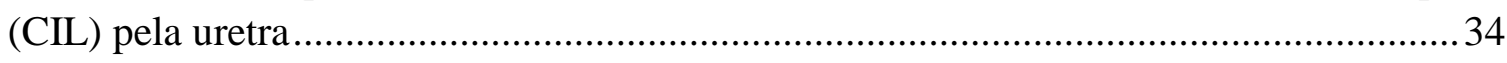

4.3.3 Estomia urinária continente (cistostomia, vesicostomia ou derivação continente) ..... 34

4.3.4 Estomia urinária continente e qualidade de vida ............................................. 35

4.3.4.1 Fatores Determinantes na Indicação da Cirurgia .......................................... 36

4.3.4.2 Complicações com a Derivação Urinária ........................................................... 36 
4.3.4.3 Pontos Positivos da Derivação Urinária Continente 37

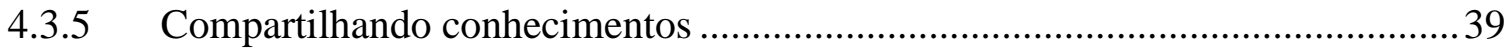

\section{A ENFERMAGEM NO PROCESSO DE REABILITAÇÃO EM PESSOAS COM} LESÃO MEDULAR E ESTOMIA URINÁRIA CONTINENTE ...................................40

5.1 REABILITAÇÃO EM LESÃO MEDULAR .................................................. 40

5.2 O PAPEL DO ENFERMEIRO NA REABILITAÇÃO ........................................... 40

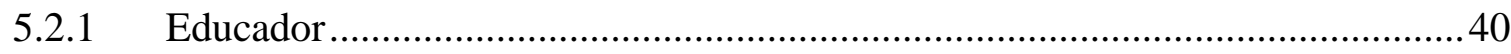

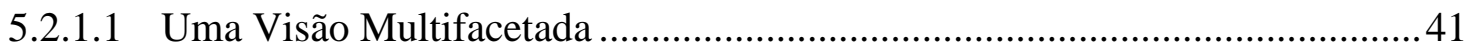

5.2.1.2 Gestão, Trabalho em Equipe Multiprofissional e Cuidados Diretos às Pessoas

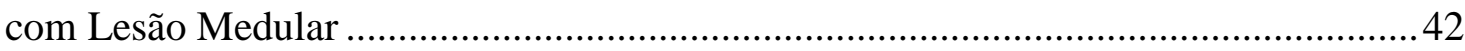

5.2.1.3 Cuidados Pré-Operatórios em Derivação Urinária Continente ....................... 43

5.2.1.4 Cuidados Pós-operatórios e CIL pela Derivação Urinária............................... 44

5.3 AS IMPLICAÇÕES DA DERIVAÇÃO URINÁRIA CONTINENTE ...................45

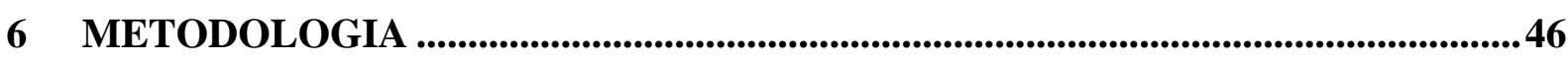

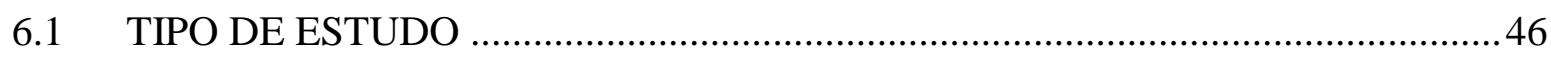

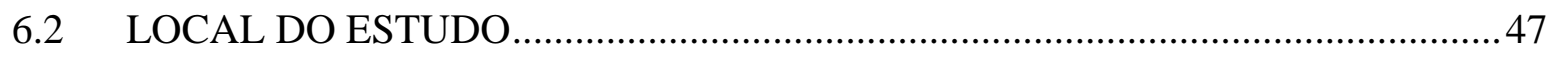

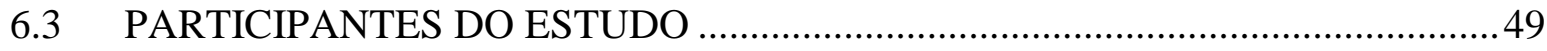

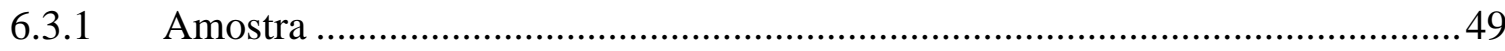

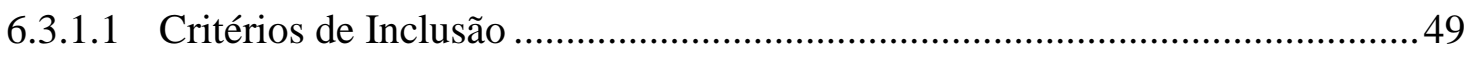

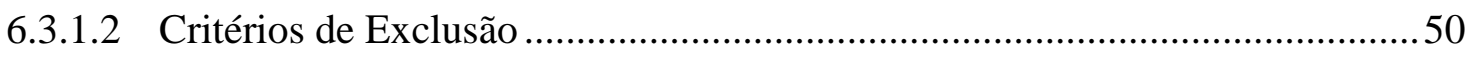

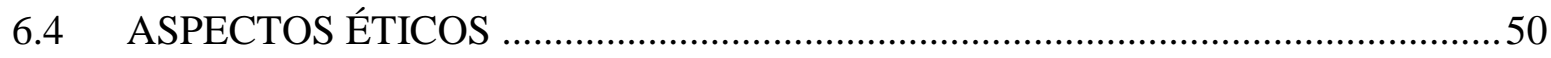

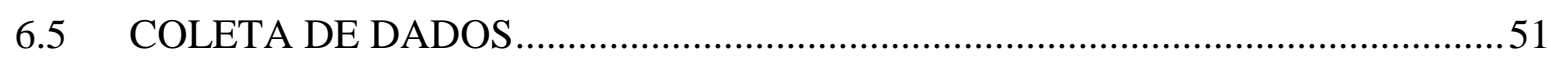

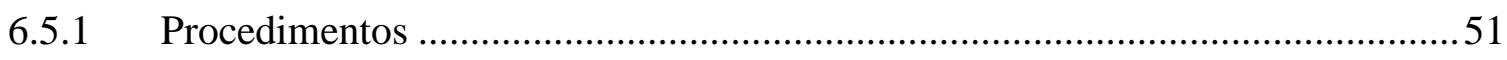

6.5.1.1 Instrumento de Coleta de Dados ................................................................. 51

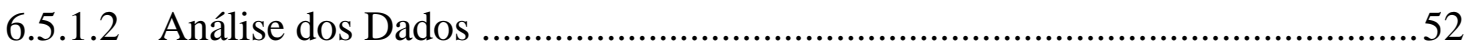

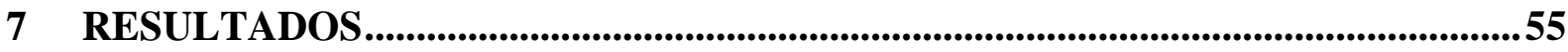

7.1 CARACTERÍSTICAS SOCIODEMOGRÁFICAS E CLÍNICAS ...........................55

7.2 AVALIAÇÃO DA QUALIDADE DE VIDA DOS PARTICIPANTES COM

LESÃO MEDULAR E SUBMETIDOS À DERIVAÇÃO URINÁRIA CONTINENTE....60

7.3 CATEGORIAS TEÓRICAS QUE EMERGIRAM A PARTIR DAS

VERBALIZAÇÕES DOS ENTREVISTADOS: DERIVAÇÃO URINÁRIA E QUALIDADE DE VIDA DA PESSOA COM LESÃO MEDULAR

8 DISCUSSÃ O............................................................................................................8 82

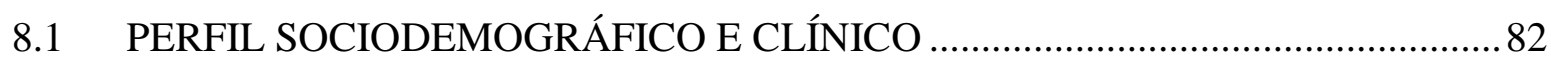


8.2 AVALIAÇÃO DA QUALIDADE DE VIDA DE PESSOAS COM DERIVAÇÃO URINÁRIA E LESÃO MEDULAR: ANÁLISE QUALITATIVA ...................................... 88

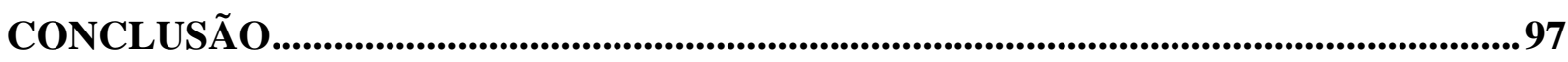

REFERÊNCIAS BIBLIOGRÁFICAS ..................................................................................99

APÊNDICE A - Termo de Consentimento Livre e Esclarecido ........................................ 105

APÊNDICE B - Termo de Assentimento ...............................................................................108

APÊNDICE C - Termo de Cessão do Uso de Imagem .............................................................110

APÊNDICE D - Questionário para Coleta de Dados Sociodemográfico e Clínico ........111

APÊNDICE E - Entrevista com os participantes (transcrição ipsis verbis)....................115

APÊNDICE F - Entrevista com os participantes (tratamento do material) ...................146

APÊNDICE G - Fotos..........................................................................................................177

ANEXO A - Parecer consubstanciado do CEP/SARAH-Brasília ...................................181 


\section{APRESENTAÇÃO}

Na condição de enfermeira de reabilitação em um programa que atende, exclusivamente, pessoas com lesão medular, me deparei com as mais diversificadas mudanças de vida, tanto pessoal e social quanto físico-funcional, por que passam essas pessoas.

A lesão medular atinge não só a mobilidade e locomoção, mas também todos os órgãos abaixo do nível do acometimento medular. Pude observar que nesse tipo de agravo é comum a alteração do controle do esvaziamento da bexiga, mas que, na maioria dessas pessoas, a reeducação vesical é alcançada através do cateterismo intermitente limpo (CIL), o que lhes proporciona maior autonomia. Contudo, existem pessoas com bexiga neurogênica que não conseguem fazer o CIL devido à lesão medular e ao grau de comprometimento da motricidade. Portanto, a minha curiosidade foi estimulada quando percebi que pessoas com tetraplegia submetiam-se a uma cirurgia para confecção de um estoma no abdome e alcançavam a independência para esvaziar a bexiga. Esse fato gerou surpresa e admiração, fazendo nascer em mim o interesse em saber o quê significava para as pessoas com lesão medular, impossibilitadas de realizar o autocateterismo, poder passar a fazê-lo, e conhecer o quê mudava em suas vidas.

Então, a partir do interesse pelo tema e de realizar a pós-graduação em enfermagem comecei a me preparar para dar início aos estudos relativos ao conhecimento científico, de forma a me aprofundar a respeito do assunto, ainda tão pouco conhecido entre profissionais de saúde e da população alvo de interesse.

Acredito que o conhecimento das implicações da estomia urinária continente na vida de uma pessoa com lesão medular possa contribuir com informações relevantes para o processo de cuidar concernente ao enfermeiro: quando se detém o conhecimento, pode-se, previamente, planejar ações individuais e coletivas, a fim de alcançar os melhores resultados de atenção ao cuidado. O domínio do conhecimento científico pode trazer maior visibilidade ao papel do enfermeiro de reabilitação em lesão medular, o que refletirá na qualidade do serviço prestado a essa população e, especialmente, na qualidade de vida dessas pessoas. 


\section{INTRODUÇÃO'}

O manejo da bexiga neurogênica é uma das principais questões que envolvem a pessoa com lesão medular. Há quatro décadas foi preconizado o uso do cateterismo intermitente limpo (CIL) como procedimento standard para o esvaziamento da bexiga, o que contribuiu para o incremento da sobrevivência (AKKOÇ et al., 2012). Nem todas as pessoas com lesão medular são capazes de realizar o autocateterismo ou têm a possibilidade de realizá-lo pela uretra (KARSENTY et al., 2008). O CIL, através da estomia urinária continente ou derivação urinária continente, é um dos métodos com repercussões positivas na qualidade de vida $(\mathrm{QV})$ e pode contribuir para maior independência e facilidade no esvaziamento da bexiga neurogênica (TOUMA et al., 2007; PAZZOKI et al., 2006).

A qualidade de vida é um aspecto preocupante na população com lesão medular, uma vez que esse grupo social sofre desvantagens em relação à população em geral. As desvantagens vão desde a acessibilidade física, estigma, dificuldades de inclusão social e gestão do viver (BAMPI; GUILHEM; LIMA, 2008; MENEGUESSI, 2012). QV é um construto pluralista e subjetivo (SEIDL; ZANNON, 2004) que vai além da avaliação do estado de saúde; é uma forma de valorizar as percepções individuais do viver (BAMPI, GUILHEM; LIMA, 2008).

No Brasil e nos Estados Unidos, o número de pessoas com lesão medular é crescente, cerca de mais de 10.000 novos casos por ano. As causas são diversificadas e dependem do contexto social, político e econômico. Os motivos mais significativos, os que mais contribuem para esse tipo de lesão, são os acidentes automobilísticos (36,5\% nos EUA) e a violência urbana (14,3\%) (REDE SARAH, 2013a). As complicações urológicas, no início da década de 1970, eram responsáveis por parcela importante dos óbitos; com o avanço do tratamento e cuidados específicos na gestão dos cuidados urológicos esse cenário mudou (THE NATIONAL SI STATISTICAL CENTER, 2013).

As condições de incontinência urinária, complicações clínicas, percepção de pouco controle sobre suas vidas, dependência de outras pessoas para o esvaziamento da bexiga correlacionam-se negativamente com a qualidade de vida das pessoas com lesão medular. Em contrapartida, situações adaptativas que favoreçam a independência e o autocuidado, a exemplo do CIL pela derivação urinária, repercutem positivamente na qualidade de vida com

\footnotetext{
1 Neste trabalho, para a expressão "estomia urinária continente" também foram usados como sinônimos os termos "derivação urinária continente", "conduto continente", "cistostomia continente" ou "vesicostomia continente".
} 
melhora da autoestima, senso de autossuficiência, possibilitando maior inclusão e interação social (AKKOÇ et al., 2012; BARONE; WATERS, 2012).

$\mathrm{O}$ interesse em realizar este estudo surgiu do acompanhamento da pesquisadora a algumas pessoas seguidas no pré e no pós-operatório da confecção da derivação urinária continente do serviço de neuroreabilitação em lesão medular do Hospital Sarah Kubitschek, localizado em Brasília, Distrito Federal. A hipótese é que a confecção do estoma facilita o cateterismo e melhora a qualidade de vida preservando a imagem corporal desses indivíduos.

Desde a criação da estomia urinária continente utilizando segmento intestinal preconizada por Mitrofanoff em 1980, muitas técnicas foram criadas sendo que não existe na literatura evidência de que uma técnica se sobressaia à outra (GERHARZ, 2007). O que se percebe é que pessoas com lesão medular cervical, mas com alguma habilidade de extremidades superiores ou com alteração uretral, se beneficiam com o procedimento (VAN DER AA et al., 2009; KU, 2006).

De fato, não existe um protocolo preestabelecido para a indicação da estomia urinária continente, mas características a exemplo de nível do dano medular, a destreza manual, equilíbrio do tronco, força motora, a falta de habilidades para mudar de posição, despir ou vestir-se são condições consideradas na triagem das pessoas que foram submetidas ao procedimento (KHAVARI et al., 2012; AKHAVAN et al., 2007). Instrumentos que avaliam a habilidade funcional das extremidades superiores, juntamente com avaliação clínica, podem ser recursos que favoreçam a indicação adequada para realizar o procedimento (AKHAVAN et al., 2007).

A reabilitação de pessoas com lesão medular é complexa, contínua, dependente de que a equipe multiprofissional seja altamente qualificada, pois o êxito de uma reabilitação consiste, em parte, da capacidade, conhecimento e de habilidades próprias dessa equipe. Os profissionais são importantes fontes de conhecimento e suporte para as pessoas com deficiência motora e suas famílias (HAMMELL, 2004). São vários profissionais engajados no processo de reabilitação: médicos, enfermeiros, nutricionistas, educadores, fisioterapeutas, psicólogos, assistente social, fonoaudiólogos e vários outros envolvidos direta e indiretamente (RUNDQUIST et al., 2011).

A reabilitação, portanto, consiste em um processo educativo e assistencial que exige conhecimento científico, habilidades técnicas e pessoais. $\mathrm{O}$ enfermeiro tem papel essencial nesse processo sua ação como educador em saúde é de suma relevância, pois proporciona às pessoas com lesão medular conhecimentos e habilidades que irão impactar positivamente em 
suas vidas; entre esses cuidados, pode-se citar a gestão do esvaziamento da bexiga neurogênica pela estomia urinária continente (RUNDQUIST et al., 2011; DIXON; WASSON; JOHNSON, 2001).

$\mathrm{Na}$ literatura e na prática profissional observa-se número reduzido de pessoas submetidas à derivação urinária. A amostra desta pesquisa constituiu-se de 15 pessoas que atenderam aos critérios de inclusão; trata-se de um grupo heterogêneo de acometimentos medulares: tetraplegia, mielomeningocele e paraplegia. Os resultados encontrados demonstraram que a implicação da estomia urinária continente na qualidade de vida tem uma correlação positiva obtida em 14 participantes, sendo que dez estavam muito satisfeitos e quatro satisfeitos com a derivação urinária; 12 dos participantes consideraram ter qualidade de vida, sendo essa correlação de forte intensidade (boa e muito boa). Para se chegar a esses resultados foi elaborado um instrumento semiestruturado com questões interpretativas do participante, associadas a duas questões do tipo Likert sobre o tema: O que significa para você ter qualidade de vida? A derivação urinária melhorou a sua qualidade de vida? Como você avalia a sua qualidade de vida? (muito ruim, ruim, nem ruim nem boa, boa e muito boa) Você está satisfeito com a sua derivação urinária? (insatisfeito, pouco satisfeito, satisfeito, muito satisfeito). Questões objetivas que complementam o tema também fazem parte do instrumento.

Então, em busca de respostas para esses questionamentos e para alcançar os objetivos propostos desenvolveu-se esta pesquisa.

Este trabalho se inicia com uma apresentação, na qual a autora expõe de que forma surgiu o interesse em pesquisar o tema, que faz parte de seu cotidiano profissional. A partir daí, está composto de nove capítulos, a contar da introdução até a conclusão e recomendações.

O capítulo 1 é a introdução do estudo, onde se apresentam os principais aspectos que envolvem o tema: derivação urinária, qualidade de vida, incontinência urinária, manejo da bexiga neurogênica, lesão medular, reabilitação, papel do enfermeiro, bem como breve exposição da metodologia empregada na condução do estudo. Os quantitativos de satisfação com a derivação urinária e com a qualidade de vida, parte integrante dos resultados encontrados na pesquisa, também constam dessa parte do trabalho, além da justificativa para a realização do estudo.

O capítulo 2 apresenta os objetivos do estudo a partir de um objetivo geral com desdobramento em objetivos específicos.

No capítulo 3 - referencial teórico - aborda-se globalmente a qualidade de vida: histórico, a compreensão do construto, exemplos de indicadores de qualidade de vida, um tipo de classificação do construto e definições. 
O capítulo 4 encerra substancialmente os aspectos teóricos relevantes ao tema proposto pela dissertação. Apresenta conceitos sobre qualidade de vida relacionada à saúde, aspectos que influenciam a expressão de qualidade de vida, conceito de qualidade de vida pela Organização Mundial de Saúde (OMS), instrumentos criados para medir qualidade de vida, a importância dos instrumentos na pesquisa, lesão medular, bexiga neurogênica, manejo da bexiga neurogênica, estomia urinária continente ou derivação urinária continente correlacionando com a qualidade de vida. Para fundamentar a descrição, são abordados estudos que tratam dos temas mencionados.

O capítulo 5 discorre a respeito do papel do enfermeiro na reabilitação da pessoa com lesão medular e, sobretudo, na reabilitação da pessoa com bexiga neurogênica submetida à derivação urinária continente e a implicação na qualidade de vida.

A metodologia se encontra no capítulo 6, e tem a finalidade de descrever os passos utilizados para a construção do estudo. Nesse capítulo é apresentado o tipo de estudo, o ambiente onde foi realizado, a amostra e os critérios de inclusão e exclusão, os instrumentos utilizados na coleta e análise dos dados, além dos aspectos éticos adotados.

No capítulo 7 estão descritos os resultados obtidos com a aplicação do instrumento de investigação.

Na sequência, no capítulo 8, apresenta-se a discussão dos resultados, tanto dos resultados da análise descritiva dos dados sociodemográficos e clínicos quanto resultados da análise de conteúdo.

Com referência à conclusão, observa-se que o objetivo geral foi devidamente contemplado com base nos dados e resultados da pesquisa, ratificando as limitações, implicações e recomendações de estudos futuros. 


\section{OBJETIVOS DO ESTUDO}

\subsection{OBJETIVO GERAL}

Analisar a implicação da estomia urinária continente na qualidade de vida da pessoa com lesão medular.

\subsection{OBJETIVOS ESPECÍFICOS}

- Identificar as características sociodemográficas e o perfil clínico dos participantes.

- Conhecer a percepção dos participantes no que diz respeito à qualidade de vida das pessoas com lesão medular e estomia urinária continente.

- Verificar a ocorrência de infecção urinária e complicações antes e após a derivação urinária continente.

- Comparar os parâmetros dos exames urológicos antes e após a intervenção cirúrgica. 


\section{CONSIDERAÇÕES SOBRE QUALIDADE DE VIDA}

\subsection{CONSIDERAÇÕES HISTÓRICAS, FATORES FORMADORES DO CONSTRUCTO QUALIDADE DE VIDA E DEFINIÇÕES}

O termo qualidade de vida (QV) foi, inicialmente, discutido entre sociólogos, filósofos e políticos; primeiramente, foi mencionado na obra de Pigou, de 1920, relativa à economia e bem-estar social, sob o foco do suporte governamental às classes sociais menos favorecidas e as repercussões na vida desses, bem como ao orçamento do Estado; entretanto, o termo não se firmou nesse momento (WOOD-DAUPHINEE, 1999). Vários autores consideram o marco referencial para o termo QV o discurso proferido em 1964 pelo presidente da república dos Estados Unidos em exercício, Lyndon Johnson (1964 apud FLECK et. al., 1999), ao afirmar que "[...] os objetivos não podem ser medidos através do balanço dos bancos. Eles só podem ser medidos através da qualidade de vida que proporcionam às pessoas".

Qualidade de vida é um construto de grande plasticidade que faz parte das várias dimensões do viver do ser humano no ambiente que o cerca. Conscientemente ou não, o homem busca meios que melhoram a sua percepção acerca do viver, de acordo com parâmetros próprios ou socialmente construídos.

As sociedades, nas suas mais diversas formas de organização cultural, política, social, religiosa e econômica têm predisposição para indicar padrões mínimos que possam resultar em maior ou menor chance de se ter qualidade de vida. A percepção de QV irá depender da realidade social, econômica, cultural na qual o indivíduo está inserido, sendo que o meio é determinante nos anseios e na forma de julgamento.

O senso comum, a mídia e os interesses mercantis induzem a associação entre a posse de bens de consumo e QV; quando se fala em QV, faz-se associação direta com os determinantes sociais de saúde e o desenvolvimento humano, correlacionando a expressão com poder econômico e social, em sua compreensão está inserida a ideia de condições de vida, estilo de vida, poder de consumo, conforto e bem-estar. Os indicadores de saúde: morbimortalidade, alfabetização, saneamento básico, habitação, cultura, lazer e políticas públicas são meios que irão refletir a qualidade vida. São partes integrantes de um sistema complexo que influencia e é influenciado, mas insuficientes para saturar a significância do termo (BUSS, 2000; ALMEIDA; GUTIERREZ; MARQUEZ, 2012). 
Há relação de proporcionalidade que quanto maior for o desenvolvimento políticosocial e econômico de um povo, maior será sua democracia e as repercussões positivas na sua qualidade de vida (MINAYO; HARTZ; BUSS, 2000; SEIDL; ZANNON, 2004).

Portanto, QV se apresenta como uma abordagem generalista de associação com o poder de consumo de bens materiais: aparelhos eletrônicos, casa, carro e outros que o poder de compra pode oferecer. Amplia-se como sinônimo do desenvolvimento econômico e social de um país e, atualmente, relaciona-se com satisfação, bem-estar, realização pessoal, felicidade e liberdade (MINAYO; HARTZ; BUSS 2000).

Alguns autores (CAMPOLINA; CICONELLI, 2006; FARQUHAR, 1995; MINAYO; HARTZ; BUSS, 2000; SEIDL; ZANNON, 2004) afirmam que não há um consenso com relação ao significado de qualidade vida. No entanto, são categóricos ao afirmar que é um constructo multidimensional, pluralista, que viabiliza a interface da interdisciplinaridade e pode ser percebido de forma objetiva, subjetiva, individual e coletiva.

\subsubsection{Classificação da qualidade de vida: global, componente, focal e composta}

A imprecisão na definição do construto QV dificulta a avaliação dos trabalhos científicos, as comparações e o uso em outras pesquisas pela falta de consenso que operacionalize a definição (FARQUHAR, 1995; PEREIRA; TEIXEIRA; SANTOS, 2012).

O estudo feito por Farquhar (1995) sobre as definições de QV aponta para os três principais tipos de definições que existem na literatura científica: definições gerais ou globais (tipo I); definições que decodificam o conceito em dimensões (tipo II) e definições focalizadas (tipo III). Segundo a autora, a definição global é abrangente e não traduz com clareza os componentes da qualidade de vida que são operacionais. As definições componentes são aquelas que decodificam o construto em partes componentes ou dimensões, podendo identificar características relevantes em qualquer avaliação de qualidade de vida. As definições focalizadas referem-se a um ou a um número mínimo de componentes de qualidade de vida. Há subdivisões nos tipos II e III. A autora menciona um tipo IV que trata da combinação entre a definição do tipo I e do tipo II - que tem características globais, mas também componentes específicos. A conclusão do trabalho é que não há consenso a respeito do termo QV, mas se faz necessário debater o tema tanto por experts quanto por leigos em uma tentativa de buscar uniformidade, a fim de operacionalizar o construto. 


\subsection{2 Índices de qualidade de vida e a compreensão da subjetividade do construto}

Qualidade de vida pode ser então, resultado tanto de uma construção individual abstrata, subjetiva quanto de uma construção coletiva podendo ser identificada e mensurada nas formas mais positivistas e estatísticas possíveis. Alguns exemplos são o Índice de Desenvolvimento Humano (IDH), o Índice de Qualidade de Vida (IQV), o Quality-adjusted life-years (QALY), o Disability-adjusted life-years (DALY) ou Anos de Vida Corrigidos pela Incapacidade (AVCI), entre outros. Com a utilização desses instrumentos é possível estabelecer os perfis de morbimortalidade, socioeconômicos, de sobrevida após agravo à saúde e desenvolver políticas que viabilizem ações que diminuam ou modifiquem os aspectos que comprometem negativamente uma população (ALMEIDA; GUTIERREZ; M ARQUEZ, 2012; PEREIRA; TEIXEIRA; SANTOS, 2012; SEIDL; ZANNON, 2004).

A QV objetiva, quantificável, evidenciada pela aplicabilidade de instrumentos específicos permite construir uma visão geral da realidade, a ideia de bens de consumo concretos a que determinado grupo tem acesso. No entanto, os pormenores, as particularidades da representação simbólica dada pelo indivíduo, no contexto cultural e político, são praticamente impossíveis de captar (ALMEIDA; GUTIERREZ; MARQUEZ, 2012).

Como afirma Minayo et al. (2000, p. 8):

Qualidade de vida é uma noção eminentemente humana, que tem sido aproximada ao grau de satisfação encontrado na vida familiar, amorosa, social e ambiental e à própria estética existencial. Pressupõe a capacidade de efetuar uma síntese cultural de todos os elementos que determinada sociedade considera seu padrão de conforto e bem-estar. O termo abrange muitos significados, que refletem conhecimentos, experiências e valores de indivíduos e coletividades que a ele se reportam em variadas épocas, espaços e histórias diferentes, sendo, portanto, uma construção social com a marca da relatividade cultural.

A partir do momento em que as pessoas compreendem que viver é mais do que o simples fato de existir, que a satisfação com a vida é uma construção pessoal e social, elas se tornam capazes de referir, identificar e buscar o que é mais salutar para o bem viver, para a sua qualidade de vida.

A QV tem uma abrangência ampla e suas peculiaridades irão depender do foco da abordagem; outra vertente do emprego do construto é na saúde e será o próximo tópico a ser abordado. 


\section{QUALIDADE DE VIDA RELACIONADA À SAÚDE}

\subsection{A CONTRIBUIÇÃO DAS INTER-RELAÇÕES NA EXPRESSÃO DA QUALIDADE DE VIDA RELACIONADA À SAÚDE}

O desenvolvimento global influencia os vários contextos de uma sociedade: o pensamento, a expressão artística, a política, as agendas do Governo, o estilo de vida, a organização social, como também as modificações do perfil de morbimortalidade. Hoje, convive-se com doenças e agravos à saúde próprios desse momento, tanto as nações desenvolvidas quanto as em desenvolvimento. Aumentaram não apenas as tecnologias, mas, também, as estatísticas das doenças crônico-degenerativas. Na atualidade, vive-se mais, e essa sobrevida tem relação com a qualidade de vida (SEIDL; ZANNON, 2004).

Qualidade de vida relacionada à saúde (QVRS) seria, então, o resultado do processo saúde-doença que envolve o tratamento dos agravos à função orgânica e à sobrevivência, sendo esse um processo que afeta o bem-estar psicológico, social e econômico, bem como a integridade biológica dos indivíduos (FALLOWFIELD, 1990).

Segundo Paschoal (2000), durante décadas, a avaliação que se fez da QV estava relacionada com a doença e as intervenções terapêuticas, sendo o acompanhamento médico direcionado para o diagnóstico e tratamento e os resultados avaliados de acordo com indicadores objetivos: morbidade e mortalidade. Nas últimas décadas, houve mudança na forma de se avaliar QVRS; há uma tendência em considerar aspectos subjetivos de QV percebidos pela pessoa.

A qualidade de vida relacionada à saúde, em uma percepção externa ao indivíduo, é percebida como resultado da busca pela promoção da saúde pelos vários atores sociais, por meio de determinadas condições passíveis de mensuração - sobrevida após agravos à saúde, longevidade, envolvimento com atividades físicas e satisfação com o trabalho. Os índices apresentados se traduzem em ações modificadoras da realidade vigente; programas são criados ou desfeitos; ações são implementadas; financiamentos são acordados; parcerias são (des)feitas.

Os indicadores de qualidade de vida relacionada à saúde são decisivos, mas sua presença não garante a existência de percepção e sensação de qualidade de vida pela pessoa. Não se pode negligenciá-los, mas, ao pensar na qualidade de vida de forma pontual, há o risco de descuidar-se de outros aspectos que influenciam sua identificação e percepção. 
A evolução história e tecnológica das sociedades criam tanto benefícios quanto malefícios. Na saúde, os benefícios são sentidos pelos recursos tecnológicos, cada vez mais eficientes para diagnóstico e tratamento. Tanto os equipamentos quanto o acesso aos recursos farmacêuticos, imunológicos e de conhecimento científico especializado favorecem, e muito, a sobrevida humana em situações de agravos complexos. Os malefícios são sentidos pelo aumento da violência social, urbana, aumento dos comprometimentos crônico-degenerativos e suas sequelas, gerando a cada dia um desafio em se viver com qualidade (MIGLIORINI; NEW; TONGE, 2010).

Muitas vezes, veiculam-se mensagens responsabilizando exclusivamente o indivíduo por sua saúde e qualidade de vida, eximindo os governantes de ações ou omissões políticas. Saúde e QV dependerão da íntima relação das ações e interações do ser individual, coletivo e político de um grupo (ALMEIDA; GUTIERREZ; MARQUEZ, 2012).

Concordando com Minayo et al. (2000), qualidade de vida pode ser compreendida como resultante híbrida das condições mentais, sociais, culturais e com acréscimo da construção política. A qualidade de vida relacionada à saúde está focada na capacidade de viver sem doenças ou a capacidade de superação dos agravos à saúde. O profissional de saúde age de forma intervencionista, no sentido de contribuir com o indivíduo para o enfrentamento e manejo de determinada situação.

O paradigma de qualidade de vida em saúde como prevenção de doenças e promoção de saúde é essencial.

\subsubsection{Compreensão da qualidade de vida na visão do estudo e da Organização Mundial de Saúde (OMS)}

Neste estudo, qualidade de vida é compreendida como um sistema de retroalimentação e modificações contínuas, a depender dos vários agentes, meios, circunstâncias políticas, sociais e econômicas, produções, cognição e enfrentamentos, podendo ser coletivo, mas, sobretudo, a partir de perspectiva do indivíduo. Portanto, o termo qualidade de vida é resultante de vários aspectos do viver e da organização político-social, econômica, cultural e religiosa de uma sociedade. É a síntese entendida coletiva e individualmente acerca de conceitos das diversas ciências, podendo ser direcionada conforme os interesses das questões analisadas ou emergentes. À medida que há preocupação quanto às políticas públicas em verter desenvolvimento social e econômico, direta ou indiretamente, os indicadores de vida irão se alterar. A qualidade de vida em saúde pode ser avaliada de diversas formas; para isso, 
foram criados recursos direcionados para uma avaliação tanto quantitativa quanto para uma avaliação qualitativa.

Os autores Paschoal (2000) e Seidl e Zannon (2004) apontam a existência de um salto diferencial dado após a conceitualização e criação do instrumento genérico de qualidade de vida pelo grupo de especialistas em Qualidade de Vida, da Organização Mundial de Saúde (WHOQOL/OMS). O construto sobre QV adotado pela OMS inclui um sujeito ativo, sensível às condições internas e externas a ele. Para o The WHOQOL Group (1995, p. 41-60), qualidade de vida: “[...] é a percepção do indivíduo de sua posição na vida, no contexto da cultura e do sistema de valores em que vive e em relação aos seus objetivos, expectativas, padrões e preocupações".

A qualidade de vida relacionada à saúde medida por instrumentos que avaliam apenas o contexto de morbidade e mortalidade não traduz a totalidade da interação da pessoa com o mundo. Quando se quer avaliar qualidade de vida deve-se considerar a opinião dos envolvidos.

\subsubsection{Instrumentos de qualidade de vida da OMS}

Segundo Fleck (2000), a necessidade de avaliar a QV de forma abrangente, em um contexto internacional e com a pessoa como sujeito agente, levou a OMS a criar um grupo responsável pelo estudo acerca de qualidade de vida e, também, pela elaboração de um instrumento capaz de ser utilizado por diversos países em um contexto de validade transcultural e com medidas de valores iguais. O instrumento World Health Organization Quality of Life-100 (WHOQOL-100) é uma criação multicêntrica e foi elaborado em etapas; definiu o conceito de qualidade de vida e os domínios que constituiriam o instrumento por estudiosos de vários países, de forma que a equivalência e a padronização fossem garantidas. O trabalho permitiu a interação dos principais interessados nas suas várias etapas: os participantes, profissionais e comunidade influenciando durante todo o processo de elaboração. O instrumento WHOQOL-100 é composto por cem perguntas referentes a seis domínios: físico, psicológico, nível de independência, relações sociais, meio ambiente e espiritualidade/religiosidade/crenças pessoais. As respostas aos itens que compõem os domínios são do tipo Likert, com uma escala de intensidade (nada-extremamente), capacidade (nada-completamente), frequência (nunca-sempre) e avaliação (muito insatisfeito-muito satisfeito; muito ruim-muito bom). 
A versão em português do instrumento WHOQOL-100 foi validada por um grupo interdisciplinar de profissionais da Universidade Federal do Rio Grande do Sul, por meio da aplicação de testes, retradução, busca da equivalência semântica dos termos em quatro grupos focais formados por seis a oito pessoas, cada um. Esses grupos foram constituídos por voluntários, comunidade, profissionais da saúde, e foi realizada a gestão estatística dos dados até a apuração fidedigna da equivalência do instrumento para o português (FLECK et al., 1999).

O WOHQOL-100 é um instrumento de avaliação da QV em uma abordagem generalista e tem sua versão abreviada - o World Health Organization Quality of Life-Bref (WOHQOL-bref), que garante o mesmo padrão de abrangência, concisão e fidedignidade em um tempo mais curto de resposta. Consiste de 26 questões, sendo duas questões gerais e 24 questões correspondentes as 24 facetas do instrumento original (WOHQOL-100); o que difere é que as 24 facetas eram compostas por quatro questões, cada uma, e no WOHQOL-bref apenas por uma questão que mais se correlacionasse com o escore total. O WHOQOL-bref é composto por quatro domínios: Físico, Psicológico, Relações Sociais e Meio ambiente. Essa é uma versão prática de ser usada em estudos epidemiológicos de grandes populações (FLECK et al., 2000). Existem também instrumentos específicos de grande utilidade científica.

A utilização desses instrumentos permitiu que estudos bem conduzidos fossem feitos abordando não apenas os indicadores de saúde, mas considerando também a subjetividade dos envolvidos com QV relacionada à saúde.

\subsubsection{Relevância dos instrumentos de pesquisa}

Wood-Dauphinee (1999) afirma que mesmo com os avanços metodológicos e analíticos é necessário mais trabalho no sentido de favorecer o emprego de instrumentos operacionais que possam ser cada vez mais utilizados na prática clínica, como parâmetros de ensaios clínicos em grande escala ou de forma adicional nas importantes bases de dados.

Os instrumentos específicos são direcionados a determinadas situações de interesse, têm maior sensibilidade clínica, conferindo singularidade e personalizando aspectos específicos que se quer elucidar. Apresentam como desvantagem a dificuldade de validação psicométrica, de compreensão do fenômeno, de comparações entre patologias e se restringem ao aspecto a ser avaliado (CAMPOLINA; CICONELLI, 2006; DANTAS; SAWADA; MALERBO, 2003).

Vera (2012, p. 63) afirma que os instrumentos em saúde são "valiosos coadjuvantes". Direcionam a triagem de aspectos do processo saúde-doença que poderiam não ser tão prontamente identificados, podendo mesmo ser desconsiderados. Permitem identificar o que é 
relevante para a pessoa, sistematiza os dados encontrados de forma a contribuir com a pesquisa e é um facilitador da comunicação direta com o entrevistado e favorece a comunicação interprofissional.

A QV relacionada à saúde se traduz na interpretação estatística dos aspectos socioeconômicos e demográficos com a realidade intrínseca de cada um em uma tentativa de personalização do indivíduo, de forma que possa exercer suas potencialidades de maneira mais positiva e favorável.

\subsection{QUALIDADE DE VIDA E LESÃO MEDULAR}

\subsubsection{Epidemiologia}

Tanto nos Estados Unidos quanto no Brasil os acidentes de trânsito são a causa mais comum de Lesão Medular (LM); por ano, são aproximadamente mais de 10.000 novos casos nos dois países. Em alguns estados e cidades brasileiras, a exemplo do estado de São Paulo, os ferimentos por arma de fogo são mais significativos devido ao aumento da violência urbana. Os dados estatítiscos de 2013, do Hospital Sarah Kubitschek, em Brasília, DF importante centro de reabilitação em LM -, demonstram que a maioria dos casos ocorre com pessoas do sexo masculino, e a idade está em torno da $3^{\underline{a}}$ e $4^{\text {a }}$ década de vida; dados esses semelhantes aos encontrados nos Estados Unidos (BLANES; CARMAGNANI; FERREIRA, 2009; REDE SARAH, 2013b; THE NATIONAL SI STATISTICAL CENTER, 2013; AKKOÇ et al., 2012). Nesse cenário, percebe-se que as pessoas acometidas pertencem à população de adultos com perspectiva alta de sobrevida e com necessidade de garantia de viver com qualidade.

Os dados estatísticos do The National SCI Database (2013) demostram que nos Estados Unidos $57,1 \%$ das pessoas portadoras de lesão medular estavam empregadas no momento da lesão, e que após 20 anos decorridos do trauma essa porcentagem cai para 34,9\%. As principais causas de morte em portadores de lesão medular estiveram, durante muitos anos, relacionadas à pneumonia, septicemia e, mais recentemente, aos agravos urológicos. No entanto, essa realidade tem se modificado devido à melhora na gestão do tratamento e dos cuidados urológicos. Os dados estatísticos brasileiros referentes especificamente à lesão medular são escassos; o Instituto Brasileiro de Geografia e Estatística (IBGE, 2010) realizou uma avaliação geral da população com deficiência motora, sendo que no censo de 2010 correspondia a 5,7\% do total de distribuição da população por sexo e idade (16 a 
64 anos). Esse censo trouxe informações gerais sobre as taxas de ocupação e de rendimentos da população com mais de dez anos com deficiência, 39,3\% dos homens e 25,2\% das mulheres com deficiência motora, não especificamente lesão medular, tinham uma ocupação e os rendimentos com maiores índices percentuais eram de um a três salários mínimos.

Os dados oferecidos não retratam com fidelidade a realidade dos portadores de lesão medular no Brasil; carecem de maior especificidade.

\subsubsection{Repercussão da lesão medular}

A lesão medular (LM) interfere de forma aguda e crônica na vida de uma pessoa. O indivíduo acometido por esse agravo lida com sequelas e dificuldades de inclusão social. As alterações não se limitam à função motora, abaixo do nível da lesão também ocorrem alterações no intestino, bexiga e espasticidade que podem levar a constrangimentos e dificuldades de relacionamento social, interferindo negativamente na sua qualidade de vida, o que é apercebido pelos que estão diretamente envolvidos no contexto (CHEN; BOORE, 2007; BAMPI; GUILHEM; LIMA, 2008; FONTE, 2008; MENEGUESSI, 2012).

Na maioria das vezes, as pessoas são pegas de supresa em relação à lesão medular. Nesse momento, é importante contar com a assistênca de uma equipe de saúde qualificada e com conhecimentos acerca de lesão medular, de forma que possa minimizar potenciais efeitos deletérios.

As alterações sofridas no contexto psicológico, físico e social são permanentes e acompanhadas por verdadeira luta pessoal, subjetiva de processar e criar mecanismos de enfrentamento que irá depender tanto do interesse quanto da motivação pessoal, implicando respostas com repercussão no afeto, cognição e comportamento do indivíduo e família (VERA, 2012). O estigma de que o indivíduo com lesão medular é incapaz, associado à falta de condições mínimas de vida, podem levar à diminuição de sua qualidade de vida. A sociedade, muitas vezes, não está preparada para incluir essa pessoa, seja nas relações interpessoais ou nos aspectos relacionados à acessibilidade (BAMPI; GUILHEM; LIMA, 2008; VERA, 2012).

\subsubsection{Fatores de adaptação na lesão medular}

Como afirma Hammell (2004), a avaliação da QV após a lesão medular é dificultada pela multidimensionalidade e subjetividade do construto. Segundo o autor, a QV é utilizada 
na literatura médica como as condições de vida que são mesuráveis quanto às experiências de vida significativas. Estudos, a exemplo do de Vera (2012), apontam para melhor desempenho adaptativo quando os portadores de lesão medular lidam com o fato de forma desmistificada da questão religiosa, tem autoestima e senso de autoeficiência com domínio da sua gestão do viver, inclusive servindo de influência positiva para seus pares.

A revisão sistemática feita por Leeuwen et al. (2012) encontrou como fatores determinantes de maior consistência para a QV maior grau de percepção sobre o controle da vida pessoal, o sentido de coerência, fatores positivos - esperança e propósito na vida -, sentimentos de autoestima e autoeficiência e afeto positivo, todas estes fatores estão altamente relacionados com a concepção de elevada QV. Além dessas, a espiritualidade existencial e a extroversão mostraram estreita relação com maior qualidade de vida; no entanto, com a recomendação de estudos mais aprofundados a respeito do tema.

A relevância dessas informações consiste na possibilidade de assistir melhor as pessoas com lesão medular, uma vez que podem ser efetuadas intervenções pela equipe multidisciplinar que favoreçam o autocuidado, não apenas em seus aspectos funcionais, como também quanto à perspectiva de vida. A aquisição de comportamentos que propiciem esses fatores pode ser estimulada por profissionais qualificados e aptos, contribuindo para que a pessoa com lesão medular tenha apropriação do manejo da sua vida, explorando as possibilidades que o cercam.

Embora a revisão sistemática feita por Leeuwen et al. (2012) tenha encontrado uma correlação fraca entre enfrentamento das condições impostas pela lesão medular e QV, outros estudos demonstram que estratégias de enfrentamento podem influenciar positiva e negativamente na adaptação psicossocial da pessoa com lesão medular (BARONE; WATERS, 2012; VERA; ARAÚJO, 2011). A fuga e a esquiva, enfretamentos focados na emoção, citadas em um dos estudos, por exemplo, são estratégias que podem ser úteis por período curto no trauma. Porém, a utilização dessas estratégias de forma crônica pode levar as pessoas a adotarem comportamentos e atitudes autodestrutivas - a exemplo do uso do fumo, da bebida - e displicência com os cuidados e reabilitação.

Segundo a pesquisa feita por Barone e Waters (2012), há uma relação inversa entre a idade e a adaptação psicossocial. Portadores de lesão medular jovens têm maior senso de autocontrole e utilizam poucas estratégias de fuga, esquiva e confronto; adotam estratégias de enfrentamento, de reavaliação positiva, apresentando melhor adaptação geral. Essa informação é relevante, uma vez que pode redirecionar as metas de um programa de reabilitação, levando em consideração cada indivíduo. Há evidência, tanto nesse estudo 
quanto na revisão feita por Leeuwen et al. (2012), que quanto maior a capacidade da pessoa de sentir-se responsável pelo controle de sua vida e tiver o sentimento de autoeficiência, melhores serão os resultados adaptativos e a percepção de melhor qualidade de vida. As experiências por meio da ação diminuem o sentimento de impotência.

\subsubsection{Evidências que influenciam a percepção da qualidade de vida}

Estudo transversal e multicêntrico conduzido por Gey et al. (2012) - que por meio de itens do questionário da OMS, o WHOQOL-BREF, avaliou os fatores que influenciavam a qualidade de vida de 243 pessoas com lesão medular - concluiu que os sujeitos da pesquisa com maior tempo de lesão e que estavam vinculados ao trabalho remunerado relataram melhor QV, independentemente do país. O sentimento de ter o controle do viver proveniente do trabalho vai além da questão financeira; envolve a realização pessoal, autoestima, saúde e melhor integração social. O estudo também apresentou diferenças estatísticas significantes entre viver nos Estados Unidos versus Brasil e Israel; relacionou melhor QV para os sujeitos que residiam nos Estados Unidos do que para aqueles que residiam no Brasil ou em Israel. O estudo não esmiuçou os fatores envolvidos nesse resultado. Os autores consideraram que houve limitação na sua amostragem, bem como alguns dados: participação, suporte social e autoeficiência não foram avaliados, e também os itens utilizados do WHOQOL-BREF não forneciam informações sobre os domínios da vida com a qual a pessoa com lesão medular poderia ser mais ou menos satisfeita, por exemplo.

Hammell (2004) identificou que uma quantidade substancial de pesquisas não encontrou correlação entre QV, satisfação de vida e nível de lesão medular; seja pelo comprometimento da funcionalidade ou pela independência física apresentada. Por outro lado, nos trabalhos avaliados pelo autor, verificou-se correlação negativa entre QV e altas taxas de reinternações por complicações de etiologias diversas, como as doenças cardiovasculares, pneumonias, lesões de pele, complicações urinárias de menor ou maior gravidade.

Estudo transversal realizado por Blanes, Carmagnani e Ferreira (2009), na cidade de São Paulo, incluindo mais de 60 voluntários com lesão medular do tipo paraplegia, apontou que as alterações funcionais, o uso de uma cadeira de rodas, a falta de acessibilidade pública e privada, a falta de inclusão social têm impacto negativo sobre a QV e a autoestima dos participantes. Além disso, a mudança abrupta é acompanhada, em um primeiro momento, por perdas não apenas funcionais; mas perda de emprego e das representações sociais, quer dizer, de alguns papéis exercidos pela pessoa na sociedade - provedor familiar, por exemplo. 
Alguns suportes - de caráter financeiro, social e de cuidados, por exemplo - são necessários por períodos mais curtos e outros de forma contínua e permanente.

Estudos como o de Chen e Boore (2007) afirmam que para minimizar essas complicações é necessário acercar o indivíduo e sua família de conhecimento, vivência e técnicas que possam auxiliá-los na reestruturação de suas vidas. Esses estudos também apontam que há correlação significativa entre tempo de lesão, a gravidade da lesão e rede social de apoio no processo de adaptação da pessoa portadora de lesão medular na realidade que se apresenta.

\subsubsection{Reabilitação na lesão medular}

Um programa de reabilitação que aborda o indivíduo de forma integral e respeita suas possibilidades funcionais e psicossociais tende a ter maior adesão e ser mais efetivo do que aqueles que não fazem uso desse recurso. Seria improdutivo insistir em um conjunto de ações que não desperta o interesse e a participação da pessoa envolvida (VERA, 2012).

O sucesso de um programa de reabilitação é um meio de medir a qualidade de vida, pois, após a reabilitação, espera-se diminuição das taxas de internações por complicações clínicas, a exemplo de úlceras de pressão, infecções urinárias, manejo inadequado da bexiga e intestino neurogênicos; todos factíveis de cuidados que são trabalhados pela equipe multidisciplinar, entre eles, o enfermeiro, durante a reabilitação.

As atividades desenvolvidas no programa de reabilitação devem ir ao encontro dos interesses e necessidades da pessoa diretamente envolvida. A personalização da assistência e o intercâmbio entre equipe multidisciplinar e o indivíduo é fundamental para a obtenção de resultados exitosos.

Contudo, para resultados efetivos e duradouros referente à QV em lesão medular é necessário promover a inclusão social. Uma sociedade deve estar preparada para compartilhar os direitos de todos os cidadãos, não desconsiderando as implicações decorrentes dos diferentes agravos de saúde. Os profissionais de saúde, principalmente aqueles envolvidos diretamente na reabilitação, devem desenvolver atividades que influenciem as políticas públicas e o planejamento social (HAMMELL, 2004). 


\subsection{QUALIDADE DE VIDA E SUA CORRELAÇÃO COM A BEXIGA NEUROGÊNICA E A ESTOMIA URINÁRIA CONTINENTE (DERIVAÇÃO URINÁRIA)}

\subsubsection{Bexiga neurogênica: fisiologia e manejo}

A inervação do músculo detrusor e dos esfíncteres está comprometida após uma lesão medular, resultando em uma bexiga classificada como neurogênica - termo utilizado para descrever disfunções vesico-esfincterianas. Indivíduos com bexiga neurogênica podem ter alterações do padrão miccional nas fases de enchimento vesical/reservatório e na de esvaziamento vesical (ROCHA; GOMES, 2010).

O grau e a extensão do dano à medula espinhal determinam a dimensão e a severidade dos déficits sensoriais, motores, autonômico, principalmente, no sistema urinário. A bexiga neurogênica se manifesta por meio de ampla forma de sintomas, características e repercussões no trato urinário superior e inferior como, por exemplo, a diminuição da capacidade de armazenamento, perda da complacência vesical, hiperatividade detrusora, dissinergia detrusor-esfincteriana, refluxo, hidronefrose. A combinação desses efeitos resulta incontinência urinária, esvaziamento incompleto da bexiga, pressões vesicais elevadas e, de forma mais grave, a perda da função renal. O manejo da bexiga neurogênica exige intervenções medicamentosas - antimuscarínicos, toxina botulínica, cirurgias e o cateterismo intermitente limpo (CIL). No entanto, quando o tratamento conservador falha faz-se necessária abordagem cirúrgica mais radical, como a ampliação vesical ou a derivação urinária (FONTE, 2008; MACEDO JR.; DAMÁZIO; OTONNI, 2010; KHAVARI et al., 2012; KU, 2006; NEWMAN; WILLSON, 2011).

O manejo da bexiga neurogênica com a finalidade de preservar o trato urinário superior se faz de várias maneiras, como o uso de cateter uretral de longa permanência, uso de cateter vesical suprapúbico, desvios urinários e pelo CIL. Todos suscetíveis de complicações (NEWMAN; WILLSON, 2011).

A perda do controle neurológico do esvaziamento vesical pode ser contornada na prática diária dos indivíduos pelo cateterismo intermitente limpo, seja ele realizado pela própria pessoa - autocateterismo - ou pelo cuidador, denominado cateterismo assistido. $\mathrm{O}$ cateterismo intermitente limpo é o regime standard no manejo da bexiga neurogênica (KARSENTY, 2008; PAZOOKI et al., 2006).

$\mathrm{Na}$ escolha do melhor método de esvaziamento da bexiga, vários fatores devem ser levados em consideração, entre eles: a limitação causada pela lesão medular, ou seja, nível da 
lesão e classificação pela American Impairment Scale (AIS), as condições socioculturais, se recebe ou não assistência para os cuidados. O método ideal pode variar no decorrer do tempo e poderá depender das circunstâncias que envolvem a pessoa, tanto física, emocional ou socialmente (AKKOÇ et al. 2012).

\subsubsection{Fatores que inviabilizam o autocateterismo e o cateterismo intermitente limpo (CIL) pela uretra}

Pessoas com deficiência motora podem apresentar, além da bexiga neurogênica, dificuldade para o CIL ou inviabilidade do uso da uretra para a cateterização. São vários os motivos que inviabilizam a utilização da uretra para o cateterismo convencional, entre eles, em pessoas com lesão medular, por exemplo, o comprometimento da funcionalidade das mãos, a dificuldade de posicionamento e o equilíbrio do tronco, dificuldade para acessar e visualizar a genitália e alterações anatômicas da própria uretra. As situações acima descritas e outras, como a necessidade de proteção do trato urinário superior, incontinência, falha do tratamento conservador com drogas anticolinérgicas, a maior independência, a melhora da autoestima e da qualidade de vida fazem com que alguns indivíduos tenham indicação da confecção de um estoma continente (KHAVARI et al., 2012; PAZOOKI et al., 2006; TOUMA et al., 2007; VAN DER AA et al., 2009).

\subsubsection{Estomia urinária continente (cistostomia, vesicostomia ou derivação continente)}

O cirurgião Mitrofanoff (1980) foi o pioneiro na criação de um conduto cateterizável em crianças, nas quais o CIL não foi suficientemente eficaz. Esse cirurgião criou uma cistostomia através do apêndice cecal como conduto continente.

A estomia urinária continente também é conhecida por outras terminologias: derivação urinária continente, vesicostomia continente, cistostomia continente ou conduto continente. É um procedimento cirúrgico que utiliza partes do intestino para a criação de um túnel que liga a bexiga à parede externa do abdome por um orifício externo que se denomina estoma. $\mathrm{O}$ estoma pode localizar-se no quadrante inferior direito ou na cicatriz umbilical, com o objetivo de passar um cateter vesical para o esvaziamento da bexiga, nos casos onde a via natural não é possível. São várias as técnicas cirúrgicas descritas na literatura e que utilizam parte do intestino para confeccionar o conduto, podendo ser provenientes do íleo, cécum, apêndice e mesmo do próprio colo da bexiga (KHAVARI et al., 2012; TOUMA et al., 2007; LIARD et al., 2001). 
Segundo estudo feito por Gerharz (2007), não há na literatura médica uma técnica que se sobressaia à outra. A produção científica a respeito do tema é bastante limitada e se associa à falta de apropriação do conhecimento, tanto por parte de profissionais de saúde quanto das pessoas que poderiam se beneficiar com a criação da estomia urinária continente. O estudo apresentou dados do Conselho de Credenciamento de Residência Médica em Urologia, dos Estados Unidos, de 2000 a 2004, que demonstraram que as técnicas mais complexas de derivação urinária são pouco vivenciadas por cirurgiões urológicos em sua formação.

As derivações urinárias podem ser classificadas de maneiras distintas - pelo segmento intestinal utilizado ou se proporciona continência, entre outras formas de classificação.

A pessoa que se submete a um procedimento para confecção de estomia urinária continente (derivação urinária), geralmente, já realiza ou realizou o cateterismo intermitente limpo pela uretra e faz parte de um grupo bem seletivo devido a sua indicação.

O estudo de Touma et al. (2007) confirmou número reduzido de pessoas com lesão medular submetidas à confecção de uma estomia urinária continente. Para os autores, a derivação urinária continente ideal é aquela que seja funcional: fisicamente acessível, de fácil visualização, que tenha estética aceitável.

A delimitação da localização do estoma é um cuidado relevante para o enfermeiro, juntamente com o cirurgião e o indivíduo na avaliação pré-operatória. Esse é um cuidado imprescindível, pois a repercussão na satisfação da pessoa com estomia urinária continente pode estar relacionada à possibilidade de sua independência para a autocateterização.

\subsubsection{Estomia urinária continente e qualidade de vida}

A continência urinária é uma expectativa social e individual na vida de uma pessoa com lesão medular. O comprometimento do padrão urinário socialmente aceito pode interferir na qualidade de vida do ser. Pessoas com comprometimento da uretra ou que não conseguem realizar a passagem do cateter pela uretra requerem o uso de dispositivos externos ou a manipulação dos seus órgãos genitais por um cuidador; as mulheres, principalmente, necessitam de um local em que possam mudar da posição assentada para horizontalizada, de forma a possibilitar o acesso ao meato uretral. $\mathrm{O}$ uso de dispositivos

externos, como bolsas, cateteres podem causar constrangimentos que interferem na integração social desse indivíduo. A disfunção vesical interfere negativamente na qualidade de vida, principalmente naqueles indivíduos que o cateterismo intermitente limpo é feito por 
outras pessoas, além de interferir nas relações sociais e ter efeitos emocionais negativos (AKKOÇ et al., 2012; MENEGUESSI, 2012).

O estudo realizado por Meneguessi (2012) demonstrou que a incontinência urinária devido à bexiga neurogênica influencia negativamente a $\mathrm{QV}$ de pessoas portadoras de lesão medular. Sugeriu a avaliação da qualidade de vida desses indivíduos como recurso para planejar a assistência e a inclusão no convívio social e produtivo, sendo que a incontinência urinária repercute, também, no afeto e nos comportamentos.

\subsubsection{Fatores Determinantes na Indicação da Cirurgia}

Geralmente, para se indicar o procedimento, é feita uma triagem na qual se consideram alguns fatores como relevantes e determinantes de uma cirurgia, como necessidade de manter a integridade funcional dos rins, a continência, e viabilizar a independência para o autocateterismo. No entanto, não existem diretrizes bem estabelecidas para identificação dessas pessoas (AKHAVAN et al., 2007; ZOMMICK et al., 2003).

Segundo Chaviano (2000) e Merenda (2007) o cateterismo uretral pode ser dificultado por alterações do tipo: função limitada das mãos, obesidade, dificuldade de visualização do meato urinário, dificuldade de despir-se e espasticidade de membros inferiores.

Para Karsenty et al. (2008), os critérios de seleção para a confecção de uma estomia urinária continente incluem o esvaziamento precário da bexiga, a dissinergia detrusoresfincteriana ou a contratilidade da bexiga, incapacidade de realizar o autocateterismo através da uretra nativa, bem como a motivação e habilidade de realizar o cateterismo através de um estoma no abdome.

\subsubsection{Complicações com a Derivação Urinária}

A derivação urinária é uma cirurgia com potencial para complicações, tais como íleo paralítico, deiscências, infecções, estenose da derivação urinária e, mesmo, a incontinência.

O estudo feito por Khavari et al. (2012) trouxe uma taxa de $17,6 \%$ e $44,1 \%$ de complicações imediatas e tardias, respectivamente, na cirurgia de ampliação vesical e estomia urinária continente; taxas percentuais aceitáveis e condizentes com a literatura, conforme elucidaram os autores. Percebe-se nos resultados apresentados nesse estudo, e em outros, melhoria na QV das pessoas com algum tipo de dificuldade para cateterização através da derivação urinária. Houve maior eficiência na gestão do autocateterismo e esvaziamento da 
bexiga, um acondicionamento da urina com baixa pressão, continência urinária, diminuição nas taxas de infecção urinária, satisfação e maior independência social, menor exposição e manipulação do corpo por outras pessoas. A maioria dos participantes que não fazia CIL antes da derivação urinária passou a realizá-lo.

O estudo de Van der AA et al. (2009) compreendeu o acompanhamento de 35 pessoas submetidas à derivação urinária continente, com ou sem ampliação vesical, e cujo comprometimento do trato urinário era, por diversas causas, neurogênico ou não neurogênico, durante período de 60 meses. Nesse estudo, os autores buscaram identificar as principais complicações do grupo submetido à derivação urinária. As complicações imediatas identificadas compreenderam infecção da ferida operatória, hérnia incisional, vazamento de urina pelo estoma ou problemas para a cateterização do conduto - estenoses, falso trajeto e granuloma. As taxas de complicações imediatas e tardias encontradas foram de $17 \%$ com necessidade de pequenas revisões e de $11 \%$ com necessidade cirurgias urológicas de grande porte. A taxa de incontinência pela derivação, nesse grupo, foi de $20 \%$. Os autores pontuaram que quanto maior o tempo de acompanhamento, maiores são as de taxas de complicações. Contudo, concluíram que $75 \%$ dos sujeitos da sua pesquisa alcançaram a continência urinária e facilidade para a cateterização da bexiga e $43 \%$ não necessitaram de nenhuma revisão ou cirurgia adicional.

O estudo feito por Liard et al. (2001) consistiu no acompanhamento dos primeiros sujeitos submetidos ao procedimento de cistostomia com a derivação urinária continente criada por Mitrofanoff (1980) com um acompanhamento mínimo de quinze anos; esses autores concluíram que as complicações relacionadas à derivação urinária são mais comuns nos primeiros anos após o procedimento; contudo, podem ocorrer em qualquer momento. Nessa série de casos, algumas das complicações encontradas foram: refluxo vesico-ureteral, litíase vesical e estenose do conduto; embora com essas ocorrências apresentadas os autores concluíram que a cistostomia continente é um procedimento bastante eficiente.

\subsubsection{Pontos Positivos da Derivação Urinária Continente}

Segundo Zommick et al. (2003, p. 2.184) "a eliminação de aparelhos de coleta de urina pode permitir uma maior qualidade de vida, aumento da autoestima e um maior senso de independência devido à capacidade do indivíduo para a autogestão da bexiga por meio do cateterismo intermitente". 
A série de casos avaliada por Pazooki et al. (2006) apresentou como resultados taxa de satisfação e relato positivo, influenciando a qualidade de vida dos sujeitos semelhantes ao do estudo de Zommick et al. (2003), que foi de $80 \%$ com a derivação urinária continente. O estudo de Pazooki et al. (2006) demonstrou melhora substancial na performance, ao realizar atividades de vida diária, atividades de lazer, e na qualidade de vida.

Estudo feito por Akhavan et al. (2007) com um grupo de cinco pessoas com lesão medular e nível de comprometimento cervical, C4 a C6, apresentou resultados bem expressivos quanto à implicação da derivação urinária continente na qualidade de vida desses sujeitos. $\mathrm{O}$ estudo também explorou o uso de um questionário adaptado para avaliar a autopercepção das habilidades com os membros superiores para realizar movimentos semelhantes ao manuseio do cateter utilizado para esvaziar a bexiga, a fim de predizer se aqueles sujeitos detinham habilidades físicas capazes de favorecer a realização do procedimento. Os escores funcionais foram avaliados de forma concomitante e tinham correlação com o nível da lesão, bem como associação com a habilidade de autocateterização antes e depois da derivação urinária. Os resultados apresentados nessa amostra, após a estomia urinária continente, foram: diminuição significativa do tempo de cateterização, diminuição dos episódios de incontinência, diminuição das infecções do trato urinário inferior e aumento do número de pessoas capazes de realizar o autocateterismo. O estudo apontou que todos os sujeitos estavam muito satisfeitos com os resultados alcançados. Todos contavam com uma rede familiar e também com suporte social. Contudo, os autores ressalvam que a habilidade para autocateterizar-se não dever ser exclusivamente considerada na avaliação para o procedimento.

O estudo de Touma et al. (2007) investigou a implicação de um tipo específico de estomia urinária continente - Casale Spiral Monti - na qualidade de vida. A amostra constou de 12 sujeitos com lesão medular e bexiga neurogênica com dificuldades para o esvaziamento vesical pelo CIL pela via convencional; o instrumento de pesquisa utilizado para avaliar QV foi o Medical Outcomes Study 36-item short-form. Todos os sujeitos participantes da pesquisa afirmaram estar muito satisfeitos com o procedimento. Foi relatada uma taxa de continência de $100 \%$, só ocorrendo vazamentos em três pessoas quando excediam o tempo para esvaziar a bexiga; houve um decréscimo na incidência de infecções urinárias na maioria dos participantes da amostra: de nove acometidos para quatro; e mesmo aqueles sujeitos que necessitaram de um cuidador para realizar o procedimento referiram benefícios graças à facilidade de acesso ao estoma para realizar o cateterismo. Os escores relacionados à avaliação do bem-estar emocional e dos aspectos sociais foram de $90 \%$ e $81 \%$, 
respectivamente, demonstrando a influência positiva da estomia urinária continente na qualidade de vida dessas pessoas.

Os estudos que serviram de paradigma para elucidar o tema foram unânimes no que se refere aos aspectos positivos da estomia urinária continente, influenciando a QV de pessoas com lesão medular; mas todos relataram complicações em maior ou menor grau de gravidade.

Então, pode-se dizer que até o momento os estudos mostram que os benefícios justificam os riscos do procedimento; mas isso não exclui a avaliação clínica e a opinião do candidato ao procedimento.

\subsubsection{Compartilhando conhecimentos}

As disfunções do organismo em pessoas com lesão medular são, na maioria das vezes, apercebidas por elas. O conhecimento técnico-científico deve ser compartilhado entre profissional versus indivíduo de forma esclarecedora e objetiva. As pessoas com lesão medular e bexiga neurogênica, submetidas ao procedimento de derivação urinária no Hospital Sarah Kubitschek, têm informações prévias, por meio de atividades educativas e reuniões de esclarecimentos, dos significados conceituais e possíveis repercussões das circunstâncias que os envolve. A equipe multiprofissional e interdisciplinar está disponível para esclarecer dúvidas que possam surgir antes, durante e depois da confecção da derivação urinária continente, bem como para assegurar o acompanhamento clínico e os cuidados adequados. 


\section{A ENFERMAGEM NO PROCESSO DE REABILITAÇÃO EM PESSOAS COM LESÃO MEDULAR E ESTOMIA URINÁRIA CONTINENTE}

\subsection{REABILITAÇÃO EM LESÃO MEDULAR}

Reabilitar consiste em trabalhar as potencialidades da pessoa que tem lesão medular traumática, patológica ou congênita, objetivando alcançar resultados, na maioria das vezes, positivos, com maior eficácia funcional, social e psicológica, proporcionando segurança e facilidade para o viver com qualidade de vida. A inclusão social da pessoa com deficiência motora irá depender de fatores próprios e adaptativos, bem como das condições culturais da sociedade e da valorização de políticas que favoreçam sua reintegração. São várias as pessoas envolvidas na reabilitação: o indivíduo com a lesão medular, a família, o cuidador e os profissionais de saúde (FARIAS; BUCHALLA, 2005).

A reabilitação em lesão medular é feita por uma equipe multiprofissional e interdisciplinar composta por enfermeiros, médicos, nutricionista, assistente social, psicólogo, professores, fonoaudiólogos e fisioterapeutas.

\subsection{O PAPEL DO ENFERMEIRO NA REABILITAÇÃO}

\subsubsection{Educador}

O papel de educador em saúde exercido pelo enfermeiro na reabilitação da pessoa com lesão medular sobressai entre os diversos cuidados assistenciais, e tem o poder de influenciar positivamente o viver dessas pessoas. A lesão medular é precursora de várias alterações fisiológicas, psicológicas e sociais nas quais o enfermeiro atua de maneira a oferecer conhecimento e educação de ações que serão úteis para a realização do autocuidado ou o treinamento do familiar/cuidador que prestará os cuidados contínuos.

Estudo realizado por Vera (2012) aponta que 94,33\% das pessoas com lesão medular apresentam demanda quanto a informações específicas para lidar com os comprometimentos físicos e psicológicos advindos da lesão medular. Portanto, o enfermeiro, além de conhecimentos próprios à enfermagem, necessita de conhecimentos que atendam a demandas específicas das pessoas com deficiências motoras.

O êxito no desempenho do seu papel irá depender, também, de atitudes que envolvam resolutividade, senso crítico, planejamento, flexibilidade, poder de comunicação e persuasão. 
O enfermeiro é responsável, na maioria das vezes, por viabilizar uma estrutura física e humana necessária ao desenrolar do processo de reabilitação, muitas vezes, servindo de ponte entre os envolvidos no processo.

O estudo multicêntrico feito por Rundquist et al. (2011) nos Estados Unidos, durante cinco anos, focado no processo de reabilitação de pessoas com lesão medular, descreveu o tempo gasto pelos enfermeiros com os pesquisados, em termos de educação e de gestão dos cuidados, considerando características pessoais e da lesão, como o nível e o grau, segundo a $A I S$; não consideraram os cuidados diretos - administração de medicação, higiene e outros. Os resultados encontrados por esses autores foram de que o suporte psicossocial demandou $50 \%$ do tempo gasto na gestão dos cuidados, sendo que esse domínio não é considerado no planejamento da assistência ou documentado. Os cuidados com o manejo da bexiga comprometeram $17 \%$ do tempo do enfermeiro, seguido por cuidados com o intestino e a pele, com 14\% cada; educação sobre medicação e dor envolveu 13\% do tempo em cada ação, todos relacionados ao tempo total, que correspondeu a uma média de 31 horas, 55 dias e uma carga horária de 264 minutos semanais. Variáveis relacionadas à pessoa como: nível e grau de lesão, ser estudante, raça; bem como a variável relacionada ao enfermeiro de ter elevada experiência clínica, interferiram no tempo gasto junto à pessoa na educação e gestão dos cuidados. Esses autores consideraram o enfermeiro um profissional indispensável pelo seu conhecimento e ações, haja vista que são requisitados, muitas vezes, em primeira instância, por outros profissionais que compõem a equipe multiprofissional; esse profissional constitui-se de fonte de informações mais relevantes, assumindo papel central na educação das pessoas com lesão medular, seus cuidadores e família.

\subsubsection{Uma Visão Multifacetada}

A revisão da literatura feita por Andrade et al. (2010) buscou identificar o papel do enfermeiro na reabilitação de pessoas com lesão medular e apontou três categorias predominantes: o cuidado terapêutico, o trabalho em equipe e o de advogado. $\mathrm{O}$ trabalho do enfermeiro considerado terapêutico foi enfocado como sendo de pouco valor no processo de reabilitação, de acordo com algumas literaturas revisadas, por se tratar de cuidados básicos de higiene, mobilização e aferição dos sinais vitais; mas outras literaturas valorizam o cuidado, considerando as atividades do enfermeiro independentes de outras profissões como: a educação para o autocuidado, o treino de habilidades técnicas para realizar atividades da vida diária, educação em saúde, entre outras que proporcionem o bem-estar 
físico, psicológico e social, repercutindo na qualidade de vida dessas pessoas. No trabalho em equipe, o papel desempenhado pelo enfermeiro é apontado no estudo por Andrade et al. (2010) como duas vertentes: uma ambígua, carecendo de maior apropriação e especificidade, ao mesmo tempo indispensável e fundamental. A outra vertente considera-o como o profissional ideal; aquele que está sempre presente, contribuindo com ações multiprofissionais, além das de sua competência, a exemplo da gestão do trabalho multiprofissional e também a assistência direta e indireta à pessoa com lesão medular. $\mathrm{O}$ estudo de Schoeller et al. (2012) aponta que os cuidados prestados pelo enfermeiro para o binômio individuo-família têm potencial terapêutico, no sentido de favorecer o alcance do melhor bem-estar.

O papel do enfermeiro tido como advogado salientou a necessidade de aliar o seu conhecimento sobre as pessoas com lesão medular na luta por direitos sociais cabíveis às necessidades de inclusão da pessoa com deficiência.

O enfermeiro de reabilitação exerce, precocemente, o seu papel como defensor da pessoa com deficiência motora ao acreditar e ao investir esforços, de forma crítica, nas potencialidades funcionais, psicológicas e sociais, contribuindo com a integração social da pessoa com deficiência.

\subsubsection{Gestão, Trabalho em Equipe Multiprofissional e Cuidados Diretos às Pessoas com Lesão Medular}

O papel do enfermeiro nos cuidados da pessoa com lesão medular e submetidos à derivação urinária tramita entre a gestão de um programa de reabilitação, o trabalho em equipe multiprofissional, cuidados diretos à pessoa submetida ao procedimento de estomia urinária continente e, sobretudo, o seu papel como educador. A gama de ações e interrelações exercidas pelo profissional enfermeiro requer conhecimento científico, habilidades técnicas e pessoais. Baseada na experiência profissional em um programa de reabilitação em lesão medular, bem como na literatura pesquisada - a exemplo das obras de Dixon, Wasson e Johnson (2001) e Newman e Wilson (2011) -, a autora deste estudo apresenta os cuidados envolvidos diretamente com o indivíduo submetido ao procedimento de estomia urinária continente, considerando aspectos clínicos, de autocuidado e de inserção social.

A educação no manejo da bexiga neurogênica é um dos pontos mais relevantes na reabilitação da pessoa com lesão medular e é feito pelo enfermeiro. A estomia urinária é um 
meio alternativo em que há dificuldade de manipulação dos órgãos genitais por diversas causas, fazendo imprescindível o seu manejo adequado.

O CIL, por si, requer conhecimento e suporte; é importante para a equipe de saúde identificar junto ao indivíduo e à família a existência ou não de apoio social. $\mathrm{O}$ apoio de pessoas com vínculos afetivos ou afinidades podem fortalecer estratégias de enfrentamentos, contribuindo com resultados positivos para a pessoa (MARCON et al., 2009).

A fase inicial da cateterização de um estoma urinário na parede abdominal pode, inicialmente, causar estranheza à pessoa, família ou cuidador. Para dar assistência à pessoa que será submetida ou que já tenha uma estomia urinária continente recente faz-se necessário conhecimento e sensibilidade; conhecimento sobre lesão medular e suas implicações, bexiga neurogênica, tratamentos e, sobretudo, conhecimentos do cuidar. Sensibilidade para compreender, colocar-se no lugar do outro, criar uma relação propícia à aquisição de conhecimentos e habilidades que contribuirão para o bem viver em etapas futuras.

O enfermeiro líder do programa, juntamente com o cirurgião, enfermeiros dos setores de internação e centro cirúrgico definem a melhor data para a admissão do indivíduo que irá submeter-se ao procedimento. Frequentemente, a opção pela cirurgia acontece no nível ambulatorial entre o urologista e a pessoa a ser submetida à derivação urinária e/ou os familiares. O procedimento pode ser exclusivamente a confecção da estomia urinária continente ou a ampliação vesical mais a derivação urinária.

\subsubsection{Cuidados Pré-Operatórios em Derivação Urinária Continente}

Os cuidados de enfermagem pré-operatórios envolvem os aspectos fisiológicos, emocionais e de compreensão do contexto. Na admissão dessa pessoa, é possível apreender informações relevantes quanto à necessidade da cirurgia apercebida por ela, sua rede social e de apoio, habilidades manuais e conhecimentos prévios, bem como disponibilidade para a realização do procedimento.

O enfermeiro é capaz de dar o suporte psicossocial requerido ao indivíduo e família/cuidador na maioria das vezes; em situações específicas, o enfermeiro direciona o atendimento aos outros profissionais. A avaliação e cuidados fisiológicos se dão pela monitorização da estabilidade hemodinâmica através dos sinais vitais, condições clínicas e acompanhamento dos resultados dos exames laboratoriais e uroradiológicos, discussões em equipe, da administração de medicações - antimicrobianos, antiparasitários, do preparo 
intestinal, degermação da pele, verificação da marcação do sítio cirúrgico e sanando dúvidas que a pessoa possa apresentar.

\subsubsection{Cuidados Pós-operatórios e CIL pela Derivação Urinária}

Os cuidados pós-operatórios irão depender do tipo de procedimento realizado. No caso específico da derivação urinária compete: monitorização e realização do balanço hidroeletrolítico, monitorização de drenos, cateteres gástricos e vesicais garantindo a livre drenagem, avaliação dos fluídos eliminados, curativos dos locais cirúrgicos - ferida operatória e estoma, controle da dor, identificação de possíveis complicações, como adinamia intestinal, sinais e sintomas de infecção, etc. -, e tomada de decisões pertinentes à responsabilidade profissional. O momento ideal para a educação no manejo do cateter para esvaziamento da bexiga pelo estoma se inicia com a convalescença da pessoa e a retirada gradativa dos cateteres. $\mathrm{O}$ cateter de policloreto de vinil número 12 permanece na estomia por cerca de duas semanas até a maturação da derivação urinária. Após a avaliação urológica e liberação para o CIL pelo estoma começa a educação para o manejo do cateter no local. O cateterismo é feito a cada três horas. A irrigação é ensinada nas situações que se faz necessária devido ao muco produzido pela parte do intestino utilizada.

Em um primeiro momento, a técnica é feita pelo enfermeiro, que orienta o indivíduo e ou familiar/cuidador quanto às etapas, de forma objetiva e clara, de acordo com o protocolo da instituição. Em um segundo momento, a pessoa é convidada a fazer o autocateterismo, momento em que lhe é repassada a sequência dos passos, sob a supervisão do enfermeiro; às vezes é necessário repetir o ensinamento. A destreza para autocateterizar-se demanda período de treino, que dependerá de cada um. Depois do aprendizado, tanto a pessoa submetida à confecção de derivação urinária quanto seus familiares/cuidadores saem de alta hospitalar em condições adequadas para a realização da técnica.

Ao longo da internação é feita a educação relacionada às possíveis complicações da derivação urinária, cuidados com o estoma, que envolve limpeza e proteção, cuidados com a bexiga - controle hídrico, presença de muco, esvaziamentos em intervalos regulares - e instruções sobre os sinais e sintomas de infecção urinária. Durante todo esse processo, o enfermeiro avalia a disposição e a motivação da pessoa e do familiar/cuidador para o aprendizado, bem como identifica e sugere adaptações que possam ser úteis, de modo a facilitar o aprendizado e o desempenho no esvaziamento da bexiga pela derivação urinária. 


\subsection{AS IMPLICAÇÕES DA DERIVAÇÃO URINÁRIA CONTINENTE}

A presença da derivação urinária pode facilitar o esvaziamento vesical, diminuindo os riscos de altas pressões vesicais, falência da função renal e incontinência. $\mathrm{O}$ acesso fácil ao abdome permite o esvaziamento da bexiga na posição assentada; por isso, pode ser realizado em qualquer lugar reservado. Naquelas pessoas com lesão medular, onde o acesso à genitália para o esvaziamento da bexiga é o principal problema, a barreira fica extinta, reduzindo a ansiedade relacionada ao controle da micção, podendo facilitar a integração social e, consequentemente, a qualidade de vida. 


\section{METODOLOGIA}

\subsection{TIPO DE ESTUDO}

Para atender o objetivo deste estudo - destinado a analisar a implicação da estomia urinária continente na qualidade de vida da pessoa com lesão medular -, foi delineado um estudo exploratório e descritivo por meio de investigação multidimensional em uma concepção pragmática, tendo como base a utilização dos métodos mistos.

Segundo Sampiere, Collado e Lucio (2006, p. 100), “[...] estudos exploratórios servem para nos familiarizarmos com fenômenos relativamente desconhecidos, para obter informações sobre a possibilidade de realizar uma pesquisa mais completa sobre um contexto particular [...]". Já os estudos descritivos, buscam detalhar as características de determinado fenômeno mediante a mensuração ou coleta de informações, possibilitando previsões ou relações causais. Embora iniciado como um estudo exploratório houve a necessidade, em etapas posteriores, de descrever o fenômeno e suas correlações.

A abordagem de métodos mistos aplicada neste estudo iniciou-se a partir da segunda metade do século XX com a psicologia, de forma a dar maior vigor aos resultados das pesquisas em detrimento da utilização individualizada das metodologias qualitativa e quantitativa; esse sinergismo possibilita que as metodologias se complementem e favorece maior compreensão do problema estudado (CRESWELL; PLANO CLARK, 2007).

Creswell (2014, p. 4) define métodos mistos como:

[...] is an approach to inquiry involving collectin both quantitative and qualitative data, integrating the two forms of data, and using distinct designs that may involve philosophical assumptions and theoretical frameworks. The core assumption of this form of inquiry is that the combination of qualitative and quantitative approaches provides a more complete understanding of a research problem than either approach alone.

Esse tipo de abordagem possibilitou trabalhar com estratégias distintas e concomitantes, qualitativa e quantitativa designadas pela representação: [Qual+quan] para o tema em foco. Os dados quantitativos foram utilizados de forma secundária, com o intuito de complementar a investigação, aumentando a gama de observações sobre o tema.

Segundo Driessinack, Sousa e Mendes (2007, p. 1049):

Os métodos mistos ou múltiplos prometem novos insight e perspectiva de entendimento dos fenômenos na pesquisa de enfermagem. O uso de mais de um 
método oferece o potencial de entendimento mais profundo dos problemas complexos da saúde frequentemente enfrentados pela disciplina de enfermagem.

Para Creswell (2012), um dos objetivos do método misto é o Convergent Parallel Design, também conhecido como triangulação, estudo paralelo, modelo convergente ou triangulação concorrente, que é quando o pesquisador coleta e analisa dados de um mesmo fenômeno, tanto qualitativos quanto quantitativos, na mesma etapa da investigação, com posterior junção dos resultados em uma interpretação ampla. Essa estratégia possibilitou, além do diálogo entre os métodos, combinar fontes variadas de coleta de dados - questionário semiestruturado, entrevista, dados do prontuário da pessoa, observação -, bem como utilizar métodos de análise distintos - análise descritiva e análise de conteúdo.

As vantagens do Convergent Parallel Design encontram-se no fato da coleta de dados e/ ou informações ocorrer ao mesmo tempo, como também cada tipo de dado, qualitativo e quantitativo, poder ser analisado separadamente e de forma independente, empregando as técnicas pertinentes a cada tipo de estudo. O sinergismo entre os métodos favorece o equilíbrio do estudo compensando as fragilidades existentes em abordagens individuais.

\subsection{LOCAL DO ESTUDO}

O estudo foi realizado em um importante e renomado centro de reabilitação do aparelho locomotor, denominado SARAH-Brasília - da Rede Sarah de Hospitais de Reabilitação, cuja instituição gestora é a Associação das Pioneiras Sociais (APS). É uma rede conhecida não só no Brasil como também internacionalmente. A unidade SARAH-Brasília acumula as funções de Hospital, Centro de Administração e de Gestão Hospitalar, Centro de Ensino e Pesquisas, Centro de Pesquisas em Educação e Prevenção, Centro de Controle de Qualidade e Centro de Formação de Recursos Humanos (REDE SARAH, 2013b). A rede de hospitais está presente em oito capitais brasileiras: Belém, Belo Horizonte, Brasília, Fortaleza,

Macapá, Rio de Janeiro, Salvador e São Luís. É uma instituição com gestão autônoma, sem fins lucrativos e integra a rede pública.

As pessoas envolvidas neste estudo são aquelas que, independentemente da etiologia do agravo envolvendo a funcionalidade do aparelho locomotor, podem se beneficiar com a proposta de reabilitação oferecida. Para exemplificar os agravos à saúde atendidos no hospital, pode-se citar: as lesões medulares por causas traumáticas ou patológicas, as lesões neurológicas por causas traumáticas ou metabólicas, gama de alterações ortopédicas e 
neoplasias; existe um universo de alterações e possibilidades que envolvem o processo de reabilitação e inclusão.

O serviço é organizado de forma a assistir pessoas nas suas demandas físicofuncionais, psicológicas e sociais mediante as situações de agravos a que vivenciam. A organização do serviço se dá por meio de programas, de forma a direcionar o acompanhamento do individuo e família. São seis programas, a saber: pediatria, ortopedia, neuroreabilitação neurológica, neuroreabilitação medular, oncologia e $1^{\underline{0}}$ estágio (unidade de alto risco). Conta com uma equipe de saúde multiprofissional e interdisciplinar composta por enfermeiros, médicos, auxiliares de enfermagem, técnicos em enfermagem, psicólogos, nutricionistas, assistente social, educadores físicos, fisioterapeutas, professores, biólogos, farmacêuticos, fonoaudiólogos, técnicos em radiologia, técnicos em laboratório, técnicos em gesso, técnicos da oficina ortopédica, além de várias outras categorias de trabalhadores em serviços imprescindíveis no ambiente hospitalar.

A pesquisa foi desenvolvida no programa de neuroreabilitação medular; o período que compreende o processo de reabilitação é de cerca de quatro a seis semanas, com flexibilizações a depender da necessidade de cada pessoa; no entanto, o vínculo que se forma entre a pessoa e a instituição é contínuo, pois o processo de reabilitação acompanha o indivíduo em sua trajetória de vida nas situações que demandam novas adaptações e/ou assistência. Logo que se dá a internação, a pessoa, a família e/ou cuidador são acolhidos e orientados de forma objetiva a respeito da dinâmica funcional do programa, dos objetivos e da participação.

O programa consta de atividades fixas, aulas que abordam os temas: lesão medular, cuidados com a pele, nutrição, reeducação intestinal, reeducação vesical e grupo de acolhimento, e também de atividades que irão depender das possibilidades individuais, das quais se podem citar: treino de banho, vestuário, transferências, autocateterismo, reeducação intestinal, hidroginástica, esportes, culinária, fisioterapia, condicionamento físico, habilidades com cadeira de rodas, treino de marcha, treino de escrita, orientação sexual, aconselhamento social, atendimento psicológico e várias outras. O objetivo é preparar as pessoas para o autocuidado, estimulando o conhecimento sobre a lesão medular, situações subjacentes, a independência e a autogestão de suas vidas. $\mathrm{O}$ indivíduo desenvolve habilidades que o torna adaptado à condição de pessoa com lesão medular consciente dos seus direitos como cidadão. Quando a limitação física imposta pela lesão medular impede uma pessoa de se autocuidar, então é realizado o treino familiar, de forma que o familiar e/ou cuidador participa da reabilitação juntamente com o principal envolvido, a fim de apreender e desenvolver conhecimento e habilidades para o cuidado. 
Portanto, nessa fase da reabilitação são trabalhados recursos básicos e imprescindíveis para favorecer boa qualidade de vida para a pessoa com lesão medular. Acompanhando diretamente todo esse processo está presente uma equipe multiprofissional e interdisciplinar competente e qualificada.

O processo de reabilitar é contínuo e a bagagem de conhecimento e habilidades desenvolvidos nesse primeiro momento irá acompanhá-los, favorecendo o desejo de superação e a busca pela inclusão social.

\subsection{PARTICIPANTES DO ESTUDO}

O contato com os participantes da pesquisa ocorreu no programa de neuroreabilitação em lesão medular da unidade SARAH-Brasília. A pesquisadora é enfermeira assistencial nesse programa e a desenvoltura apresentada pelas pessoas com derivação urinária ou a facilidade para o CIL vivenciada pelo cuidador logo no pós-operatório recente de derivação urinária continente despertou o interesse em conhecer melhor sua implicação na qualidade de vida dessas pessoas.

\subsubsection{Amostra}

A amostra constituiu-se de pessoas com lesão medular de etiologia traumática e não traumática, com dificuldade de autocateterização da uretra nativa, seja pela dificuldade de habilidades com as mãos, dificuldades de posicionamento, alteração anatômica da uretra ou por situações que dificultem o cuidador de realizar o cateterismo intermitente limpo, a exemplo de pessoas com sobrepeso e lesão medular cervical.

A princípio, após a definição do objeto de estudo da pesquisa, realizou-se, no mês de fevereiro de 2013, o levantamento do quantitativo de pessoas submetidas à cirurgia de derivação urinária registrado no setor de controle e qualidade do hospital SARAH-Brasília.

$\mathrm{Na}$ oportunidade, observou-se que a população do estudo correspondia a 22 pessoas, potenciais participantes da pesquisa na ocasião do levantamento das informações. Desse total, 15 atendiam aos critérios de inclusão e exclusão.

\subsubsection{Critérios de Inclusão}

Os critérios utilizados para inclusão dos participantes foram os seguintes: 
- pessoas de ambos os sexos, maiores de 16 anos, atendidos no hospital SARAHBrasília, no período de agosto de 2003 a setembro de 2013;

- pessoas com lesã o medular de causas traumáticas e não traumáticas, de todos os níveis neurológicos;

- bexiga neurogênica;

- inabilidade e/ou inviabilidade para utilizar a uretra nativa na cateterização vesical;

- conhecimento acerca de suas condições disfuncionais;

- pessoas submetidas à confecção de estomia urinária continente com ou sem ampliação vesical.

\subsubsection{Critérios de Exclusão}

Os critérios utilizados para exclusão dos participantes foram os seguintes:

- crianças menores de 16 anos;

- pessoas que o contato pessoal ou via virtual não foi possível;

- aqueles que se negaram a participar da pesquisa;

- óbito após a realização do procedimento.

Os 15 participantes eleitos para a pesquisa aceitaram participar do estudo. Uma participante, menor de idade, assentiu e foi autorizada pela mãe a participar.

\subsection{ASPECTOS ÉTICOS}

Esta pesquisa obedeceu ao disposto na Resolução n. 466/2012 - do Conselho Nacional de Saúde, do Ministério da Saúde do Brasil -, que aprova as diretrizes e normas regulamentadores de pesquisas envolvendo seres humanos (BRASIL, 2013). O projeto de pesquisa foi submetido para revisão ao Comitê de Ética e Pesquisa (CEP) do Hospital SARAH-Brasília, em 17 de agosto de 2013, com do cadastro CAAE: 16932713.1.0000.0022. A pesquisa iniciou-se após a aprovação por parte do CEP/SARAH-Brasília, sob o parecer consubstanciado número 405.685 (ANEXO A), na data de 12 de setembro de 2013, disponibilizado na Plataforma Brasil no dia 25 de setembro de 2013.

O primeiro contato com os participantes do estudo ocorreu de forma virtual telefônica (Skype) gravada, momento em que a pesquisadora se identificava e explicava o motivo do contato; após a compreensão e aceitação em participar da pesquisa eram fornecidas as explicações a respeito da pesquisa, objetivo, implicações, leitura do Termo de 
Consentimento Livre e Esclarecido (TCLE) (APÊNDICE A) e a respectiva autorização do participante ou responsável. Os documentos impressos foram assinados durante as entrevistas, em situações que o contato pessoal aconteceu, e os consentimentos foram gravados nas circunstâncias em que o contato ocorreu, exclusivamente, por forma virtual. Após a autorização, em que o entrevistado ou responsável aceitava sua participação na pesquisa, dava-se continuidade à aplicação da entrevista.

\subsection{COLETA DE DADOS}

\subsubsection{Procedimentos}

Os dados foram coletados de fontes primárias (entrevistas) e secundárias (prontuário dos participantes).

\subsubsection{Instrumento de Coleta de Dados}

Elaborou-se como instrumento um questionário semiestruturado para a coleta de dados sociodemográficos e clínicos (APÊNDICE D) - que foram coletados em prontuário eletrônico, por entrevista virtual, ou juntamente com o participante no momento de seu retorno ao Hospital SARAH-Brasília ou durante a entrevista no domicílio, se o local da residência fosse o Distrito Federal.

Nos casos em que o participante residia no DF, foi combinado um horário e a pesquisadora foi até a residência. Sendo assim, a leitura e as respostas do formulário de pesquisa foram realizadas pelo participante e, quando necessário, auxiliado com esclarecimentos. Apenas uma participante foi abordada em consulta de retorno para exames no SARAH-Brasília. Dos 15 participantes, quatro residem no DF e 11 em outros estados da Federação.

Os dados sociodemográficos e clínicos incluíram as seguintes variáveis: sexo, idade, grau de escolaridade, nível neurológico, tipo de lesão de acordo com a classificação neurológica American Spinal Injury Association, esvaziamento da bexiga, frequência de esvaziamento, motivo para realizar o procedimento, complicações na derivação urinária continente, tipo de procedimento realizado, apenas derivação urinária ou derivação urinária e ampliação vesical, uso de medicação anticolinérgica, graduação de aspectos melhorados com a derivação urinária, comparação entre exames uroradiológicos e satisfação tanto com a qualidade de vida quanto com a derivação urinária. 
Duas perguntas abertas abordavam a qualidade de vida; a primeira se referia a aspecto geral, a segunda, específica acerca da qualidade de vida e derivação urinária. As perguntas abertas foram as seguintes:

- O que significa para você ter qualidade de vida?

- A derivação urinária melhorou sua qualidade de vida?

As perguntas abertas foram seguidas de duas questões com itens do tipo Likert para mensurar a opinião acerca de qualidade de vida e de estomia urinária continente. Os itens 1 e 2 de cada questão tipo Likert demonstram correlação fraca com o questionamento; os itens 3 e 4 demonstram correlação forte. Fez-se a pergunta aberta seguida da questão com itens tipo Likert que se aproximavam em sentido. As questões com itens tipo Likert para escolha são:

- Como você avalia sua qualidade de vida? (Muito ruim, ruim, nem ruim e nem boa, boa e muita boa).

- Você está satisfeito com a sua derivação urinária? (Insatisfeito, pouco satisfeito, satisfeito ou muito satisfeito).

As duas questões abertas, tanto no contato presencial quanto no virtual, foram gravadas e transcritas para posterior análise. Todos os instrumentos de pesquisa foram aplicados pela pesquisadora para garantir a confidencialidade da origem das informações.

\subsubsection{Análise dos Dados}

Os dados quantitativos (sociodemográficos e clínicos) foram analisados por meio de estatística descritiva, no intuito de avaliar um pequeno grupo dentro de uma população maior; contudo, sem fazer inferências e generalizações para um grupo populacional maior. A estatística descritiva sintetiza os dados de mesma natureza de forma a facilitar a sua descrição, dispõem de recursos como gráficos, tabelas e medidas a fim de resumir as informações.

Os dados obtidos foram organizados em planilha eletrônica utilizando a ferramenta Microsoft Office Excel $^{\circledR}$ e analisados por meio do sistema informatizado que realizou estatística descritiva (média, mediana e desvio-padrão). Posteriormente, os dados foram dispostos em tabela da ferramenta Microsoft Word $^{\circledR}$.

As verbalizações provenientes das duas perguntas abertas foram analisadas por meio de análise de conteúdo segundo Bardin (2001). Esse método surgiu no final do século XX, nos Estados Unidos, como um contraponto ao positivismo hegemônico. Com ênfase no rigor metodológico obedecendo a critérios sistematizados para a análise do material, no entanto, é um método mutante e adaptável aos conteúdos propostos. Na atualidade, é utilizada em uma 
diversificada gama de temas. Um dos recursos utilizados para se analisar o conteúdo é a inferência; mas isso depende do conhecimento do método, perspicácia do pesquisador e leituras exaustivas das entrevistas transcritas, de forma que as categorias teóricas surjam ao final da análise. A análise do conteúdo obedeceu às estratégias a seguir, de acordo com Bardin (2001):

- transcrição das entrevistas ipsis verbis (APÊNDICE E);

- leitura e releituras exaustivas;

- fragmentação do conteúdo extraindo as partes que apresentam maior significado;

- decodificação dos significados em unidades de contexto ou enunciados de valor; Exploração do material emergido de forma crítica para compreender o significado latente e, assim, realizar a categorização;

- tratamento dos resultados, inferência e interpretação.

O objetivo foi obter informações da percepção individual de pessoas com estomia urinária continente a respeito da sua qualidade de vida traduzidas em sentimentos, pensamentos e no viver.

A análise de conteúdo de Bardin (2001) tem como característica a forma sistematizada para o tratamento dos dados. Utilizou-se uma matriz com a estrutura descrita para organizar os dados (APÊNDICE F).

Em OBSERVAÇÕES foram anotados os significados incidentes; suposições a respeito do contexto que permitiu codificar temas em uma base latente. Algumas observações se referem a mais de uma sequência e unidade textual.

As SEQUÊNCIAS foram enumeradas de acordo com as perguntas realizadas pela pesquisadora, de forma crescente e não necessariamente ordinal; no entanto, são sequências que pertencem ao mesmo tema.

As UNIDADES TEXTUAIS BÁSICAS DE ANÁLISE são as respostas, fatos da linguagem e expressões transcritas ipsis verbis, pontuadas com aspas e reticências. Quando unidades textuais com mesmo sentido e em sequência se repetiam, então, omitia-se a transcrição.

Todo o texto das entrevistas foi enumerado de forma ordinal, inclusive o texto da pesquisadora, para facilitar a identificação e localização das unidades textuais básicas na entrevista.

As TEMÁTICAS foram os tópicos ou temas que se repetiram nas unidades textuais básicas ou que tinham alta frequência de ocorrência e que estavam latentes, cuja constância, semelhança e regularidade foram analisadas. Em algumas análises, uma mesma temática exprime a ideia de mais de uma unidade textual básica. 
Nas OBSERVAÇÕES CONCLUSIVAS tem-se a síntese da interpretação feita pela pesquisadora das unidades textuais básicas.

Em seguida, procedeu-se ao refinamento com a classificação das temáticas emergidas em: CATEGORIAS EMPÍRICAS, que analisadas em relação à semelhança de significados foram sistematizadas em CATEGORIAS TEÓRICAS definidas conforme o delineamento apresentado pelo indivíduo e inferidas pela pesquisadora. As categorias emergidas foram validadas por dois avaliadores distintos, que consta da autora da pesquisa e de uma pesquisadora enfermeira com expertise nesse tipo de abordagem e utilizando os mesmos recursos de avaliação.

As questões do tipo Likert foram avaliadas de forma concomitante; também foram levantados os fatores que interferiam negativamente na qualidade de vida relacionados ao período anterior à derivação urinária de cada participante para facilitar a avaliação e definição das categorias teóricas. 


\section{RESULTADOS}

Este capítulo demonstra os resultados da pesquisa efetuada de acordo com a metodologia proposta. São apresentados o perfil sociodemográfico e clínico dos participantes por meio da análise descritiva e, na sequência, a avaliação qualitativa, realizada de acordo com o método de Bardin (2001), onde se apresentam as categorias teóricas que emergiram após a análise do conteúdo das entrevistas.

A pesquisa incluiu 15 participantes que atenderam aos critérios de inclusão do estudo; 14 responderam todas as questões propostas e um absteve-se de responder duas questões. Cabe destacar que, devido à ansiedade em participar do estudo, duas das entrevistas foram intermediadas pelas mães das participantes - que se encontravam presentes no momento.

\subsection{CARACTERÍSTICAS SOCIODEMOGRÁFICAS E CLÍNICAS}

Dos quinze entrevistados, nove eram do sexo feminino e seis do sexo masculino. A faixa etária dos participantes situava-se entre 16 anos e 48 anos. A maioria dos participantes era de adultos, com a idade entre 21 a 40 anos, com média de idade de 31,2 anos (DP \pm 10,5).

Com relação à escolaridade, sete participantes concluíram o ensino fundamental, cinco possuíam ensino médio e três participantes completaram o ensino superior.

Quanto à lesão medular, a idade média foi de 13,9 anos (DP $\pm 6,6$ ); com relação ao tempo de cirurgia, a média foi de 33,1 meses ( $\mathrm{DP} \pm 24,9$ ).

Dessas 15 pessoas, dez submeteram-se à confecção de derivação urinária continente com ampliação vesical e apenas cinco à derivação urinária continente. A distribuição do acometimento medular foi na maioria dos casos tetraplegia $(\mathrm{N}=7)$, seguido por mielomeningocele $(\mathrm{N}=5)$ e paraplegia $(\mathrm{N}=3)$. Dados sumarizados na Tabela 1 , a seguir. 
Tabela 1 - Características sociodemográficas e clínicas dos entrevistados, no período de agosto de 2003 a setembro de 2013. Brasília, DF.

\begin{tabular}{|c|c|}
\hline Características & Frequência $(\mathbf{N})$ \\
\hline Número de participantes & 15 \\
\hline \multicolumn{2}{|l|}{ Faixa etária (em anos) } \\
\hline Até 20 & 3 \\
\hline $21-30$ & 4 \\
\hline $31-40$ & 5 \\
\hline $41-50$ & 3 \\
\hline \multicolumn{2}{|l|}{ Sexo } \\
\hline Masculino & 6 \\
\hline Feminino & 9 \\
\hline \multicolumn{2}{|l|}{ Escolaridade } \\
\hline Fundamental & 7 \\
\hline Médio & 5 \\
\hline Superior & 3 \\
\hline \multicolumn{2}{|l|}{ Tipo de lesão medular } \\
\hline Paraplegia & 3 \\
\hline Tetraplegia & 7 \\
\hline Mielomeningocele & 5 \\
\hline \multicolumn{2}{|l|}{ Cirurgia } \\
\hline Derivação (estomia) urinária continente & 5 \\
\hline Derivação urinária continente e ampliação vesical & 10 \\
\hline
\end{tabular}

Fonte: dados da pesquisa.

Conforme ilustrado na Tabela 2, a indicação cirúrgica predominante foi dificuldade de acesso à genitália $(\mathrm{N}=6)$, seguida por outros motivos $(\mathrm{N}=4)$; entre eles foram apontados: deficiência esfincteriana, busca pela independência e questões cirúrgicas. As outras indicações foram: dificuldade de posicionamento/equilíbrio do tronco $(\mathrm{N}=3)$ e dificuldade anatômica $(\mathrm{N}=3)$.

Dos 15 entrevistados, sete tiveram complicações (imediatas e tardias) registradas em prontuário e apenas cinco dessas pessoas informaram complicações. As complicações que diferiam das relatadas em prontuário eram: incontinência pela derivação e perfuração. Já íleo adinâmico e granuloma, complicações apresentadas em um participante, constava em prontuário e não foram informadas pelo entrevistado. As complicações informadas pelos participantes assumiram $(\mathrm{N}=1)$ e as registradas em prontuário tiveram uma frequência maior: estenose do estoma $(\mathrm{N}=2)$, vascularização do estoma $(\mathrm{N}=3)$, íleo adinâmico e granuloma $(\mathrm{N}=1)$ e deiscência $(\mathrm{N}=1)$. 
Tabela 2 - Indicações cirúrgicas e complicações informadas sobre a derivação urinária continente, no período de agosto de 2003 a setembro de 2013. Brasília, DF

\begin{tabular}{lc}
\hline \multicolumn{1}{c}{ Características } & Frequência (N) \\
\hline Número de participantes & 15 \\
Indicação cirúrgica & \\
Alteração anatômica uretral & 3 \\
Dificuldade de posicionamento/Equilíbrio do tronco & 3 \\
Dificuldade de acesso a genitália & 6 \\
Outro(s) motivo(s) & 4 \\
& \\
Complicações relatadas pelo participante & \\
Incontinência pela derivação urinária & 1 \\
Estenose do conduto & 1 \\
Vascularização do estoma (sangramento) & 1 \\
Deiscência & 1 \\
Perfuração & 1 \\
Complicações registradas em prontuário & \\
Estenose & \\
Vascularização do estoma (mucosa pálida/necrose/sangramento) & 3 \\
Íleo adinâmico e granuloma & 1 \\
Deiscência & 1 \\
\hline
\end{tabular}

Fonte: dados da pesquisa.

O manejo da bexiga para o esvaziamento e o controle da atividade detrusora, bem como das perdas urinárias, após a derivação urinária, se dá por CIL. Dos 15 participantes da amostra, 14 faziam CIL pela estomia e um não obteve sucesso com a derivação urinária, e fazia o CIL assistido pela uretra. Estão independentes para o CIL 11 participantes da pesquisa; três fazem o CIL assistido, sendo que desses um o realiza de forma intermitente, autocateterismo ou cateterismo assistido. A maioria utiliza medicação anticolinérgica devido à atividade detrusora $(\mathrm{N}=9)$. Os intervalos de esvaziamento da bexiga são variados, mas há maior ocorrência no intervalo de quatro em quatro horas, durante o dia, e de seis em seis horas durante a noite $(\mathrm{N}=7)$, conforme ilustrado na Tabela 3 a seguir. 
Tabela 3 - Manejo da bexiga neurogênica e controle da atividade detrusora com medicação, após a derivação urinária, no período de agosto de 2003 a setembro de 2013. Brasília, DF.

\begin{tabular}{lc}
\hline \multicolumn{1}{c}{ Características } & Frequência \\
\hline Número de participantes & 15 \\
Cateterismo Intermitente limpo (CIL) pela derivação urinária & $* 14$ \\
Autocateterismo & 11 \\
Cateterismo assistido & 3 \\
Usa medicamentos & \\
Sim & 9 \\
Não & 6 \\
Frequência de cateterismo & \\
6/6 horas & \\
4/4 horas & 1 \\
4/4 horas dia e 6/6 horas noite & 5 \\
Irregular & 7 \\
\hline *Um participante realiza cateterismo intermitente limpo pela uretra. & 2 \\
Fonte: dados da pesquisa. &
\end{tabular}

Do total da amostra, apenas nove dos entrevistados com derivação urinária continente realizaram exames uroradiológicos pré e pós-operatórios. Desses, apenas um desenvolveu litíase após a derivação urinária com ampliação vesical.

Dois entrevistados apresentaram refluxo antes e após o procedimento, sendo que um desses não apresentou mais refluxo após a cirurgia de derivação e ampliação vesical. Um não tinha refluxo prévio à cirurgia de derivação e ampliação vesical e passou a apresentar após o procedimento cirúrgico.

No estudo urodinâmico foram avaliadas as seguintes características: comportamento da musculatura detrusora (arreflexia ou hiperatividade) e uso da medicação para inibir a atividade detrusora; comportamento da musculatura detrusora e capacidade vesical relacionada à ampliação ou não da bexiga. A interpretação dos dados foi realizada mediante o cruzamento das informações resultantes, conforme se observa na Tabela 4. 
Tabela 4 - Tipo de bexiga antes e após a derivação urinária, capacidade vesical após a ampliação vesical e derivação urinária e uso de medicação após a derivação urinária - no período de agosto de 2003 a setembro de 2013. Brasília, DF.

\begin{tabular}{|c|c|c|c|c|c|c|c|c|c|c|}
\hline \multirow{2}{*}{$\begin{array}{l}\text { Tipo de } \\
\text { bexiga }\end{array}$} & \multicolumn{3}{|c|}{$\begin{array}{l}\text { Antes e após } \\
\text { a derivação urinária }\end{array}$} & \multicolumn{4}{|c|}{$\begin{array}{c}\text { Ampliação vesical e derivação } \\
\text { urinária }\end{array}$} & \multicolumn{3}{|c|}{$\begin{array}{l}\text { Medicação após a } \\
\text { derivação vesical }\end{array}$} \\
\hline & $\mathbf{S}$ & $\mathbf{N}$ & Total & $\begin{array}{l}\text { Capacidade } \\
\text { vesical }\end{array}$ & $\mathbf{S}$ & $\mathbf{N}$ & Total & $\mathbf{S}$ & $\mathbf{N}$ & Total \\
\hline \multirow[t]{2}{*}{ Arreflexa } & 4 & 1 & 5 & Manteve & 1 & 1 & 2 & 3 & 2 & 5 \\
\hline & & & & Aumentou & 3 & 0 & 3 & & & \\
\hline \multirow[t]{2}{*}{ Hiperativa } & 4 & 0 & 4 & Manteve & 1 & 1 & 2 & 2 & 2 & 4 \\
\hline & & & & Aumentou & 2 & 0 & 2 & & & \\
\hline Total & 8 & 1 & 9 & Total & 7 & 2 & 9 & 5 & 4 & 9 \\
\hline
\end{tabular}

Legenda: S (SIM)

$\mathrm{N}(\mathrm{NÃO})$

Fonte: dados da pesquisa.

No estudo urodinâmico, cinco participantes apresentaram bexiga do tipo arreflexa após a derivação urinária. Desses, quatro se submeteram à ampliação vesical, três melhoraram a capacidade vesical e um manteve a capacidade vesical. Quanto ao uso da medicação anticolinérgica, nos participantes com arreflexia, três utilizaram medicação, sendo que dois desses tinham se submetido à ampliação vesical, um melhorou a capacidade e um manteve. Uma pessoa com bexiga arreflexa, sem ampliação, em uso de anticolinérgico para a bexiga, manteve boa sua capacidade vesical. As outras duas pessoas que não utilizaram anticolinérgico, e tinham ampliação, melhoraram a capacidade vesical.

Entre nove participantes, quatro apresentaram atividade detrusora, tanto antes quanto depois da derivação urinária. Desses quatro, três foram submetidos à ampliação vesical. Desses três, dois aumentaram e um manteve a capacidade vesical. Um deles não fez ampliação e manteve boa capacidade reservatória. Quanto ao uso da medicação anticolinérgica, dois utilizaram, sendo que um foi submetido à ampliação vesical com melhora da capacidade reservatória e o outro não se submeteu à ampliação vesical e manteve boa capacidade vesical.

Considerando-se os 15 participantes, quanto ao relato de infecção urinária no último ano ou após a derivação urinária com ou sem ampliação, observou-se que dobrou o número de pessoas sem episódios de infecção urinária e que aumentou o número das pessoas com apenas um episódio em detrimento da redução daqueles acometidos de um a três e com mais de três episódios de infecção urinária, conforme dados apresentados na Tabela 5. 
Tabela 5 - Distribuição dos episódios de infecção urinária antes e após a derivação urinária com e sem ampliação vesical, no período de agosto de 2003 a setembro de 2013. Brasília, DF.

Distribuição dos episódios de infecção urinária/Participantes com ou sem ampliação vesical e derivação urinária

\begin{tabular}{lcclcc}
\hline & $\begin{array}{c}\text { Antes da } \\
\text { derivação }\end{array}$ & $\begin{array}{c}\text { Depois da } \\
\text { derivação }\end{array}$ & & $\begin{array}{c}\text { Com } \\
\text { ampliação } \\
\text { vesical }\end{array}$ & $\begin{array}{c}\text { Sem } \\
\text { ampliação } \\
\text { vesical }\end{array}$ \\
\hline Nenhum & 2 & 4 & Aumentou & 1 & 0 \\
Apenas 1 & 1 & 4 & Diminuiu & 6 & 1 \\
De 1 a 3 & 8 & 5 & Manteve & 3 & 4 \\
Mais de 3 & 4 & 2 & Total & 10 & 5 \\
\hline
\end{tabular}

Fonte: dados da pesquisa.

Estratificando esses dados nas pessoas que fizeram derivação urinária com ampliação vesical $(\mathrm{N}=10)$ e aqueles que fizeram somente a derivação urinária $(\mathrm{N}=5)$, observou-se que os episódios de infecção em pessoas com derivação urinária e ampliação diminuíram em seis dos participantes; apenas um teve aumento na incidência e três mantiveram o mesmo padrão anterior aos procedimentos cirúrgicos. Nos cinco participantes submetidos somente à derivação urinária notou-se que episódio de infecção urinária diminuiu apenas em um e os outros quatro mantiveram o mesmo padrão anterior à confecção de derivação urinária, conforme ilustrado na Tabela 5.

\subsection{AVALIAÇÃO DA QUALIDADE DE VIDA DOS PARTICIPANTES COM LESÃO MEDULAR E SUBMETIDOS À DERIVAÇÃO URINÁRIA CONTINENTE}

A satisfação com a qualidade de vida foi avaliada por meio de duas questões subjetivas, corroboradas por duas questões do tipo Likert: -"Como você avalia a sua qualidade de vida após a derivação urinária?"; "Você está satisfeito com a sua derivação urinária?” Os resultados estão ilustrados nas Figuras 1 e 2 a seguir. 


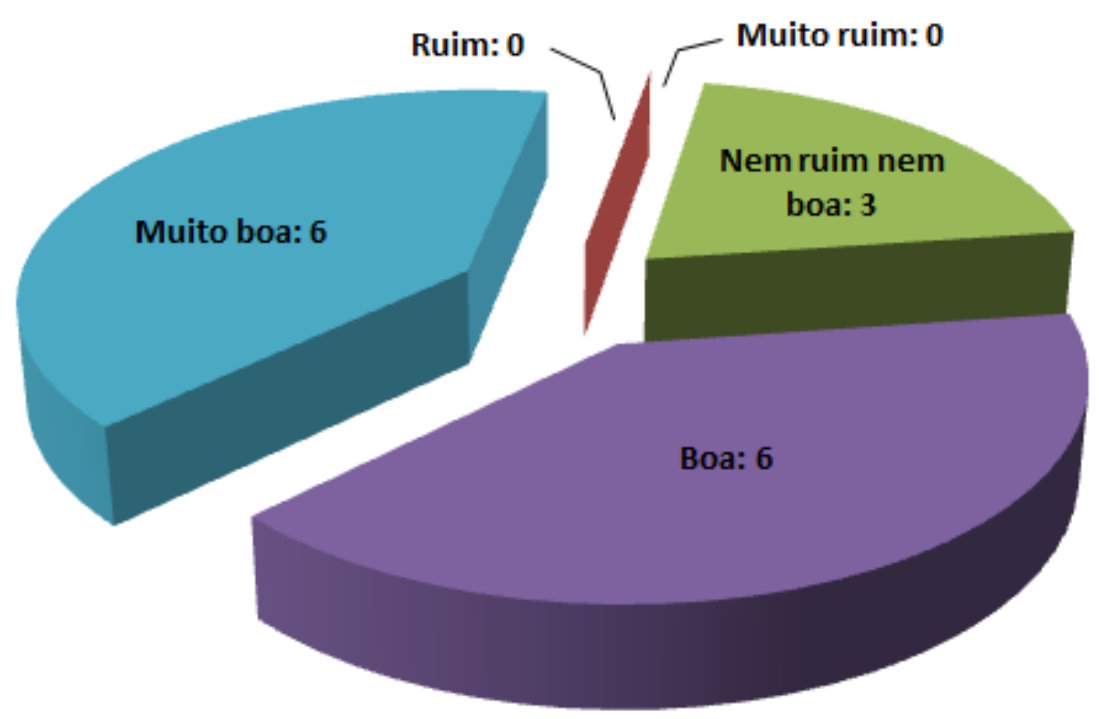

Figura 1 - Qualidade de vida após a derivação urinária continente.

Fonte: dados da pesquisa.

Conforme se depreende da Figura 1, para a pergunta "Como você avalia a sua qualidade de vida após a derivação urinária?”, seis dos respondentes manifestaram considerar muito boa e também seis consideraram boa; três responderam considerar nem ruim, nem boa. Pode-se inferir, portanto, que a maioria dos participantes considera positivamente a sua qualidade de vida depois da derivação urinária.

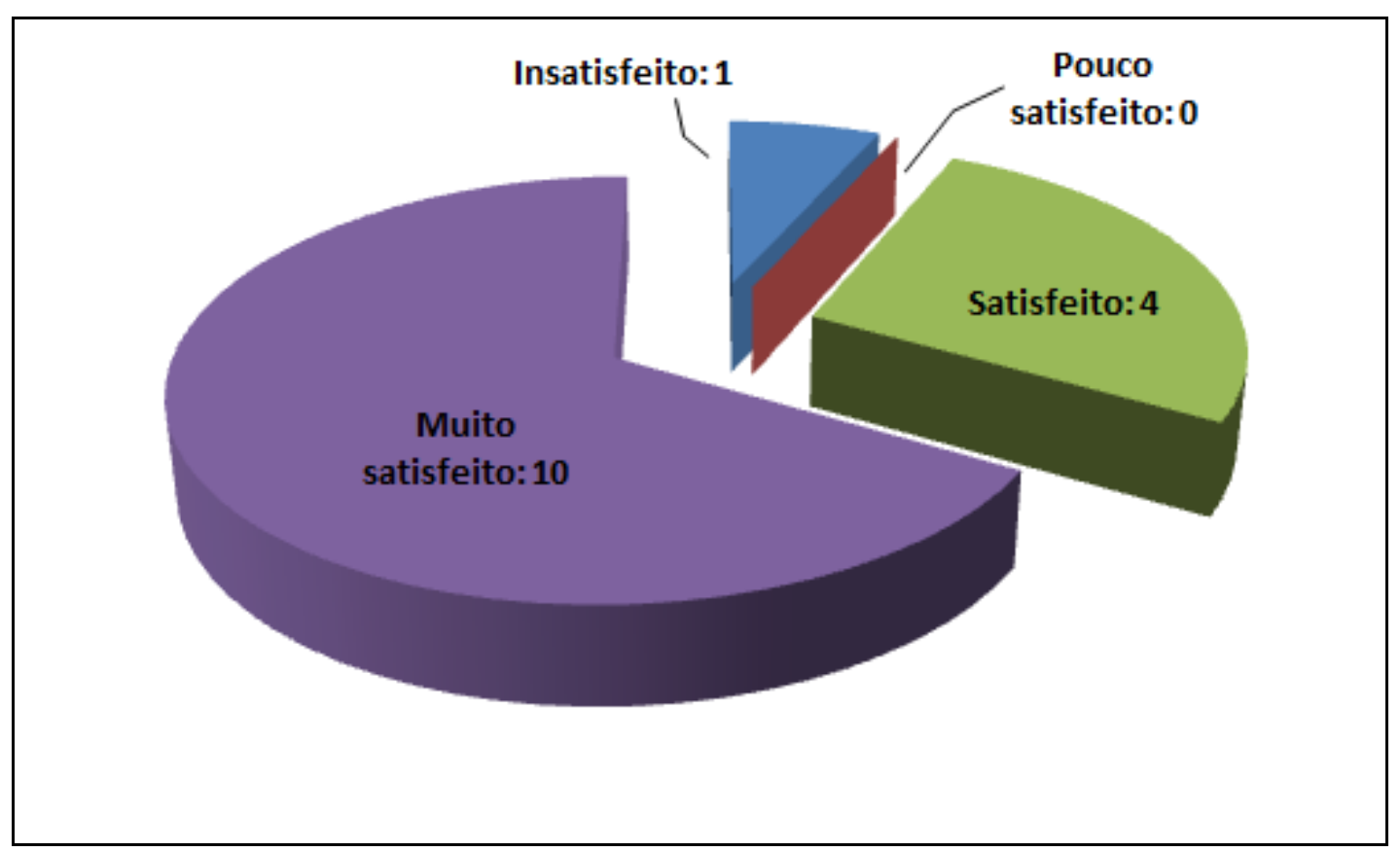

Figura 2 - Avaliação da satisfação com a derivação urinária continente.

Fonte: dados da pesquisa. 
Com relação à pergunta "Você está satisfeito com a sua derivação urinária?", observase na Figura 2 que dez participantes (a maioria) responderam se sentir muito satisfeitos com a derivação urinária feita e quatro responderam se sentir satisfeitos. Portanto, do total da amostra, 14 dos participantes alcançaram satisfação com a derivação urinária continente.

Quatorze participantes enumeraram oito itens relacionados à segunda pergunta aberta: “A derivação urinária melhorou a sua qualidade de vida?" Os itens independência, sexo, economia, estar com outras pessoas, viajar e sair, estudar, trabalhar e sono foram escolhidos pelos participantes, individualmente, em ordem de intensidade que mais sofreram modificações, de forma a interferir na sua qualidade de vida. Um participante não obteve sucesso com a derivação urinária continente e não respondeu a questão. Na enquete, os itens mais relevantes $\left(1^{o}, 2^{\underline{o}}\right.$ e $3^{\underline{o}}$ lugares, respectivamente) foram: independência - escolhida por nove pessoas -; viajar e sair - selecionados por cinco pessoas -; e estar com outras pessoas - escolhido por quatro pessoas. A Tabela 6 ilustra a distribuição das categorias (posição vertical da tabela) versus classificação de cada item (posição horizontal da tabela).

Tabela 6 - Aspectos que melhoraram após a derivação urinária, no período de agosto de 2003 a setembro de 2013. Brasília, DF.

\begin{tabular}{l|cccccccc}
\hline \multicolumn{1}{c|}{ Classificação } & $\mathbf{1}^{\mathbf{0}}$ & $\mathbf{2}^{\mathbf{0}}$ & $\mathbf{3}^{\mathbf{0}}$ & $\mathbf{4}^{\mathbf{0}}$ & $\mathbf{5}^{\mathbf{0}}$ & $\mathbf{6}^{\mathbf{0}}$ & $\mathbf{7}^{\mathbf{0}}$ & $\mathbf{8}^{\mathbf{0}}$ \\
\hline Independência & 9 & 1 & 1 & & & & & 3 \\
Sexo & 1 & 1 & & 2 & 2 & 1 & 3 & 4 \\
Economia & & & 1 & 2 & 1 & 6 & 2 & 2 \\
Estar com outras pessoas & 2 & 3 & 4 & 3 & 2 & & & \\
Viajar e sair & 1 & 5 & 1 & 4 & 1 & 1 & 1 & \\
Estudar & 1 & 2 & 2 & 2 & 2 & & 1 & 3 \\
Trabalhar & & 1 & 2 & & 2 & 5 & 4 & 1 \\
Sono & & 1 & 3 & 1 & 4 & 1 & 3 & 1 \\
\hline Total & 14 & 14 & 14 & 14 & 14 & 14 & 14 & 14 \\
\hline
\end{tabular}

Nota: um participante não obteve sucesso com a derivação urinária e não respondeu. Fonte: dados da pesquisa. 


\subsection{CATEGORIAS TEÓRICAS QUE EMERGIRAM A PARTIR DAS VERBALIZAÇÕES DOS ENTREVISTADOS: DERIVAÇÃO URINÁRIA E QUALIDADE DE VIDA DA PESSOA COM LESÃO MEDULAR}

A avaliação sistemática das entrevistas, de acordo com o método proposto por Bardin (2001), denotou a percepção de cada participante a respeito do significado para a sua qualidade de vida por ter se submetido ao procedimento cirúrgico de confecção da estomia urinária continente.

A partir do tratamento dos dados provenientes das entrevistas emergiram dez categorias, as chamadas Categorias Teóricas: "Eu tenho mais independência"; "Não ficar perdendo xixi”; "Minha lesão"; “Qualidade de vida pra mim é...”; "Falta acessibilidade"; "Eu tinha uma vida muito ativa"; "Não ligo pra estética"; "Não entendem sobre isso"; "Um pouco a reclamar"; e "o sexo diminuiu". A seguir, apresentam-se os dados categorizados.

\section{* Categoria 1 - "Eu tenho mais independência"}

Esta primeira categoria representa os benefícios que a derivação urinária trouxe para as vivências diárias da pessoa. A independência para o cateterismo refletiu na gestão do viver, da mobilidade social, favorecendo atividades a exemplo de lazer, trabalho e socialização, demonstrando a sua importância na inclusão social.

\section{Definição}

Associação feita à autonomia pela modificação do corpo através da derivação urinária. A passagem do cateter vesical pelo estoma foi considerada mais prática, sem necessidade de despir ou exigência de força e destreza manual para limpeza da genitália, principalmente para as mulheres. O controle e a autonomia para o esvaziamento da bexiga, na percepção dos entrevistados, amplificam-se em liberdade e independência pessoal. Significa não depender de outras pessoas para fazer o cateterismo vesical, sentimento de autossuficiência, regularidade na rotina diária, oportunidades de trabalho e qualificação profissional, pois podem ausentar-se de casa por longos períodos e fazê-lo onde estiver. Propicia maior mobilidade social (sair de casa) com possibilidades de lazer, estudo e trabalho.

Ter mais independência, também foi uma suposição/constatação das pessoas em que o cateterismo continuou sendo feito de forma assistida ou parcialmente assistida. A gestão do viver relacionou-se estreitamente com a autonomia para o cateterismo vesical pela derivação urinária.

\begin{tabular}{lcll}
\hline Classificação temática & $\begin{array}{c}\text { Frequência de } \\
\text { unidades de registro } \\
(\mathbf{N = 1 5})\end{array}$ & Categorias empíricas & Inferências \\
\hline Independência pessoal & 8 & $\begin{array}{l}\text { Independência para o } \\
\text { cateterismo }\end{array}$ & $\begin{array}{l}\text { Dá autonomia para o } \\
\text { cateterismo }\end{array}$ \\
$\begin{array}{l}\text { Praticidade para o } \\
\text { cateterismo }\end{array}$ & 5 & $\begin{array}{l}\text { Liberdade de ir e vir (sair de } \\
\text { casa) }\end{array}$
\end{tabular}


Categoria 1 - "Eu tenho mais independência" - continuação

\begin{tabular}{|c|c|c|c|}
\hline Classificação temática & $\begin{array}{c}\text { Frequência de } \\
\text { unidades de registro } \\
(\mathrm{N}=15)\end{array}$ & Categorias empíricas & Inferências \\
\hline \multirow[t]{2}{*}{$\begin{array}{l}\text { Independência para o } \\
\text { autocateterismo }\end{array}$} & 4 & Melhoria da independência & Possibilita o lazer \\
\hline & & & Gestão do viver \\
\hline \multirow[t]{6}{*}{$\begin{array}{l}\text { Independência } \\
\text { profissional }\end{array}$} & 1 & Autogestão no esvaziamento & $\begin{array}{l}\text { Possibilita a permanência no } \\
\text { emprego }\end{array}$ \\
\hline & & & Facilita o cateterismo \\
\hline & & & Promove a independência \\
\hline & & & $\begin{array}{l}\text { Propicia uma independência } \\
\text { relativa }\end{array}$ \\
\hline & & & $\begin{array}{l}\text { Pode passar o dia todo fora } \\
\text { de casa }\end{array}$ \\
\hline & & & $\begin{array}{l}\text { Possibilita Capacitação } \\
\text { profissional }\end{array}$ \\
\hline
\end{tabular}

Os resultados apresentados podem ser identificados nas unidades textuais de análise retiradas das entrevistas transcritas e apresentadas a seguir. O código expresso ao final da transcrição refere-se à pessoa entrevistada.

A independência alcançada pelos entrevistados com derivação urinária pode ser inferida pelas expressões de liberdade, autonomia em relação ao cateterismo vesical e autogestão do viver.

Eu ter uma vida mais... uma vida mais livre, né?! Podendo sair pra qualquer... pra qualquer local, né?! A qualquer momento [...]. (P2)

[...] conseguir organizar sua rotina, ter seus momentos de lazer, tudo sem ter maiores complicações. (P2)

Às vezes, a necessidade de cateterismos vesicais frequentes carecia da presença de um cuidador/família; de outra forma, impossibilitava estabelecer uma rotina que demandasse a presença, como no ambiente de trabalho ou na realização dos estudos.

[...] eu pude tá me capacitando mais no meu trabalho, fazendo os cursos porque eram cursos que eram o dia inteiro [...]. (P6)

[...] ela sempre fala assim pra mim que se tivesse dado certo essa cirurgia, era muito bom pra independência dela [...]. (P7) 
A dificuldade ou inviabilidade de acesso à uretra e a necessidade de cuidador/família para fazer o cateterismo vesical limitava a mobilidade social (sair de casa), restringindo, muitas vezes, a pessoa ao ambiente doméstico e favorecendo o isolamento social.

A localização da estomia urinária continente na parede abdominal eliminou e/ou reduziu barreiras impostas pelas alterações motoras para a realização do cateterismo vesical.

[...] ficou muito mais fácil d'eu realizar o cateterismo [...]. (P2)

[...] tá sendo muito mais fácil agora que... um ano, dois anos atrás que eu fiz essa operação, por que... fica mais prático [...]. (P3)

$[\ldots]$ eu me tornei uma pessoa mais independente [...]. (P15)

[...] até mesmo sentada na cadeira eu posso fazer a minha derivação [...]. (P8)

Alguns entrevistados relataram maior facilidade em sair de casa; relacionaram que antes da derivação urinária havia tensão pela necessidade de tempo programado para voltar com o objetivo de esvaziar a bexiga, pois na maioria das vezes não dispunham de um leito ou banheiro apropriado.

[...] autonomia de poder ir e vir sem depender dos outros de passar a sonda. (P6)

[...] ir à igreja... ah! poder viajar [...]. (P12)

Por causa da facilidade... da praticidade de fazer o cateterismo[...]. (P5)

Em situações em que a derivação urinária foi funcional, mas com impossibilidade de se fazer o autocateterismo vesical, bem como em situações de independência relativa, a valorização da confecção da derivação urinária foi observada.

[...] facilitou fazer o cateterismo mesmo dependendo de outras pessoas [...]. (P11)

Melhorou porque agora eu posso passar a sonda, praticamente, sozinha [...]. (P4)

\section{* Categoria 2 - "Não ficar perdendo xixi"}

Na categoria 2, identificou-se quão significativa e comprometedora para a qualidade de vida é a incontinência urinária, e como a derivação urinária contribuiu para restaurar o equilíbrio psicológico, físico e social. Percebe-se que a autonomia para o manejo da bexiga vivifica sentimentos de autossuficiência e controle da vida, de forma que a pessoa passa a assumir atitudes positivas para si. 


\section{Definição}

Controle da micção através do cateterismo intermitente limpo pela derivação urinária, em intervalos regulares, de forma a propiciar continência urinária, além de contribuir com a continência social: proporciona e favorece a inclusão social por não apresentar perdas urinárias. Algumas pessoas consideraram como "deixar de ser cadeirante", o que demonstra que a incontinência urinária é fator limitante no viver das pessoas com lesão medular. Sentimentos negativos relacionados à incontinência urinária e limitadores da vida pessoal - a exemplo de constrangimento, vergonha, ser desditoso, pudor por expor partes íntimas do corpo e a dependência de outra pessoa para fazer o CIL - deixaram de ocorrer após a derivação urinária, nos entrevistados, e foram substituídos pela satisfação e autoestima, por não usar dispositivos urinários externos: bolsas urinárias, cateteres urinários contínuos e fraldas, ou por não perder urina nas roupas. Os participantes consideraram que convivência social, confiança para interagir e mobilidade social (sair de casa) foram asseguradas pelo controle da micção pela derivação urinária, uma vez que as perdas urinárias antecipavam o retorno para casa. Anterior à derivação urinária, a mobilidade social era restrita e condicionada a ambientes/locais apropriados; comumente, necessitavam de um leito, principalmente as mulheres, para o CIL ou troca de fraldas. Mudança de atitude e estilo de vida emergiram na fala dos entrevistados, a exemplo do emagrecimento, uso de roupas "normais" (calcinha, jeans e vestidos) e deixar outra pessoa, que não a mãe, fazer o CIL. Melhoraram, também, as complicações pelo uso das fraldas, como as dermatites da área das fraldas.

A perda fecal, apresentada por uma entrevistada, foi incluída nessa categoria pela aproximação e representatividade das características definidoras com a incontinência urinária. Foi considerada pela pessoa a situação mais negativa entre outras que envolvem a lesão medular.

\begin{tabular}{cccc}
\hline Classificação temática & $\begin{array}{c}\text { Frequência de } \\
\text { unidades de registro } \\
(\mathbf{N = 1 5})\end{array}$ & Categorias empíricas & Inferências \\
\hline Perdas urinárias & 6 & Melhoria da autoestima & $\begin{array}{c}\text { Alcançou a independência } \\
\text { para o CIL }\end{array}$ \\
Vergonha & 4 & Melhoria incontinência & urinária \\
& & Conseguiu a continência \\
& & Urinária nos intervalos do \\
CIL
\end{tabular}


Categoria 2 - "Não ficar perdendo xixi” - continuação

\begin{tabular}{|c|c|c|c|}
\hline Classificação temática & $\begin{array}{c}\text { Frequência de } \\
\text { unidades de registro } \\
(\mathbf{N}=\mathbf{1 5})\end{array}$ & Categorias empíricas & Inferências \\
\hline Controle da micção & 3 & Comportamento & $\begin{array}{c}\text { Evita, pelo controle da } \\
\text { micção, disrreflexia e perdas }\end{array}$ \\
\hline Deixar de ser cadeirante & 2 & Sofrimento psicológico & urinárias \\
\hline Autoestima & 2 & $\begin{array}{l}\text { Deixar de usar dispositivos } \\
\text { urinários externos }\end{array}$ & $\begin{array}{c}\text { Não necessita de } \\
\text { dispositivos urinários } \\
\text { externos ou fraldas }\end{array}$ \\
\hline Dispositivos urinários & 2 & Incontinência fecal & $\begin{array}{c}\text { Não apresenta dermatites da } \\
\text { área de fraldas }\end{array}$ \\
\hline externos & 1 & & $\begin{array}{l}\text { Pode usar roupas normais } \\
\text { (calcinha, jeans e vestido) }\end{array}$ \\
\hline Comportamento & 1 & & $\begin{array}{c}\text { Procedeu com modificação } \\
\text { de sentimentos, atitudes e } \\
\text { estilo de vida }\end{array}$ \\
\hline \multirow[t]{8}{*}{ Incontinência fecal } & 1 & & $\begin{array}{c}\text { Exibe regularidade para o } \\
\text { CIL }\end{array}$ \\
\hline & & & $\begin{array}{l}\text { Possibilitou a inclusão e } \\
\text { socialização (ter amigos e } \\
\text { emprego) }\end{array}$ \\
\hline & & & $\begin{array}{c}\text { Apresenta aumento da } \\
\text { autoestima (segurança, } \\
\text { satisfação e maior interação } \\
\text { social) }\end{array}$ \\
\hline & & & $\begin{array}{l}\text { Amenizou a timidez e o } \\
\text { medo das perdas urinárias }\end{array}$ \\
\hline & & & $\begin{array}{c}\text { Facilita a assistência do } \\
\text { cuidador }\end{array}$ \\
\hline & & & $\begin{array}{c}\text { Desnecessária a exposição } \\
\text { de partes íntimas para fazer } \\
\text { o CIL }\end{array}$ \\
\hline & & & A continência é positiva \\
\hline & & & $\begin{array}{l}\text { Controla o horário de } \\
\text { esvaziar a bexiga }\end{array}$ \\
\hline
\end{tabular}

A incontinência urinária é uma das alterações mais limitantes no contexto de vida da pessoa com lesão medular. É uma condição que dificulta a participação social, o envolvimento em atividades laborativas, de estudo e lazer. Pode levar a pessoa a ter sentimentos que diminuem a autoestima e favorecem a reclusão social. Seguem alguns trechos das entrevistas que confirmam a categoria "Não ficar perdendo xixi": 
Era constrangedor né?! Você ficar mijada! (P6)

[...] constrangimentos poderiam acontecer a qualquer momento, porque eu perdia né?! (P10)

Antes era mais perturbante, às vezes, a gente preocupava mais... até por sair por causa da urina. (P14)

$[\ldots]$ antes eu não tinha paz com essa urina vazando [...]. (P14)

Alguns dos participantes usavam dispositivos urinários externos - coletores descartáveis, cateter vesical de demora com drenagem contínua de urina ou fraldas. Esses dispositivos podem ficar expostos, despertando a curiosidade de outras pessoas, evidenciando a disfunção urinária. Esses fatores são importantes desencadeadores de constrangimentos, vergonha e isolamento social. $\mathrm{O}$ acúmulo de urina libera odores desagradáveis, além do risco de derrames acidentais ou, no caso das fraldas, mantém o usuário em contato com a umidade contínua e irritante da urina, causando dermatites ou contribuindo para o rompimento da integridade da pele.

[...] Antes da derivação eu usava fraldas [...]. (P8)

Antes dela eu tinha muitos problemas [...] muitos problemas com aquela bolsa [...]. (P9)

[...] ficava apreensiva antes por causa da fralda, às vezes, eu tinha que sair antes dos lugares porque molhava [...]. (P13)

[...] porque antes eu tinha uma cistostomia, a sonda ficava direto [...]. (P14)

$[\ldots]$ não preciso estar carregando bolsa [...]. (P14)

O controle da micção repercutiu em comportamentos e atitudes pessoais que trouxeram resultados positivos por alguns participantes - satisfação com a vida, aumento da autoestima, participação social e convivência -, comparada como uma condição de "normalidade" anterior à lesão medular.

[...] é! parece que eu acho que eu nem sou mais cadeirante de tão bom que foi [...]. (P1)

[...] a sensação que eu tenho é como se... quando eu não era cadeirante [...]. (P12)

A necessidade de roupas confortáveis e práticas para realizar o CIL pela uretra ou acomodar os dispositivos urinários contrapunham-se a um padrão menos estético para o conceito feminino, ficando a vaidade feminina em segundo plano. A derivação urinária influenciou nessa questão.

[...] eu posso comprar calcinha [...] antes eu nem pensava em comprar [...] então, eu posso usar uma calça jeans apertada, eu posso usar roupa normal [...]. (P1)

Emagreci! [...] 17 quilos! Fiz uma dieta! (P1) 
A continência social é uma das principais vantagens da derivação urinária, percebida e expressada pela maioria das pessoas com derivação urinária desta pesquisa.

[...] a principal vantagem dela pra mim foi a questão dos vazamentos, que eu não tenho mais, então, eu não passo mais nenhum constrangimento em relação a nada! (P2)

É, conviver, né?! Com as pessoas, com [...] Ter, fazer mais amizades, né?! (P2)

[...] a condição de vida melhorou outro lado assim de... timidez, esse lado assim de... ficar perto das pessoas, né?! (P3)

Eu fico mais liberal, né? Até eu faço o cate aqui perto do meu tio e ele fica arrepiado [...]. (P3)

[...] não me sinto muito envergonhado [...]. (P5)

Em relação a tá com outras pessoas, a não ficar perdendo xixi [...]. (P9)

[...] minha autoestima melhorou [...]. (P13)

O controle do esvaziamento vesical permitiu o planejamento da vida pessoal e profissional, diminuindo a apreensão quanto às dificuldades de encontrar locais com acessibilidade.

[...] eu não ficava mais preso a esta questão de toda hora ter que ficar fazendo o cateter, né?! (P2)

[...] saber qual o horário de esvaziar ou não [...]. (P9)

[...] cada vez que eu precisar fazer o xixi é só ter um banheiro [...]. (P10)

Minha bexiga enche, eu tenho aquela necessidade de fazer o esvaziamento e uma vez que faço eu sinto alívio [...]. (P12)

Embora não tenha sido abordada a incontinência fecal nesta pesquisa, uma das entrevistadas trouxe a perda fecal como fator de maior repercussão negativa em sua vida. A incontinência fecal tem algumas similaridades com a incontinência urinária - há relato de constrangimentos, necessidade de ambiente adequado para se trocar, necessidade de fraldas ou dispositivos externos (em pessoas estomizadas); no entanto, não é possível fazer inferências quanto à questão. Observa-se o que disse a entrevistada:

[...] às vezes, acontece de ter diarreia, sabe? [...] O meu mundo cai. (P10)

\section{* Categoria 3 - "Minha lesão"}

A terceira categoria aborda a repercussão da lesão medular na vida de uma pessoa. Os participantes da pesquisa afirmaram ser um acometimento difícil, que gera necessidades especiais e enfrentamentos. 


\section{Definição}

É uma mudança abrupta, física, funcional, emocional, social e familiar, com necessidade de readaptações, vivenciada como uma experiência difícil que suscita situações de desamparo, desestruturação e/ou reestruturação pessoal e/ou familiar, observadas nas pessoas com lesão medular traumática. Nas pessoas com lesões congênitas (mielomeningocele), observam-se características semelhantes; embora não seja uma condição aguda, nem por isso, menos significativa. A adaptação a essa condição depende das características individuais e de como são enfrentadas as dificuldades que se apresentam, a exemplo da superação do medo de manipular a derivação urinária, dependência do cuidador/familiar para o autocateterismo ou a falta de uma pessoa que pudesse colaborar na vida doméstica.

\begin{tabular}{lcll} 
Classificação temática & $\begin{array}{c}\text { Frequência de } \\
\text { unidades de registro } \\
(\mathbf{N = 1 5})\end{array}$ & Categorias empíricas & Inferências \\
\hline Resiliência & 1 & Lesão medular & $\begin{array}{l}\text { Aceita as condições de } \\
\text { uma pessoa com lesão } \\
\text { medular }\end{array}$ \\
Enfrentamento & 1 & $\begin{array}{l}\text { Adaptação ao cateterismo } \\
\text { pela derivação }\end{array}$ & $\begin{array}{l}\text { A lesão medular trouxe } \\
\text { dificuldades }\end{array}$ \\
Desamparo & 1 & Medo da manipulação do \\
corpo & $\begin{array}{l}\text { Sente falta de ajuda } \\
\text { Mutoafirmação }\end{array}$ & 1 & $\begin{array}{l}\text { Desejo de superar o medo } \\
\text { em manipular a derivação }\end{array}$ \\
\end{tabular}

A lesão medular é um evento que abarca modificações profundas na vida de uma pessoa e o modo de vivenciá-la irá depender tanto de características individuais quanto sociais e coletivas. A percepção e as respostas de pessoas diferentes a uma mesma condição podem não ser iguais.

[...] tá bem comigo mesma me aceitando do jeito que eu sou não é?! Do jeito que eu estou [...]. (P12)

[...] eu tive na minha lesão, eu tive dificuldades sim [...]. (P8)

[...] se eu olhar pra traz eu também tive ganhos [...]. (P8)

Mesmo priorizando a autonomia, algumas pessoas com lesão medular, com elevado grau de comprometimento funcional, veem como positiva a colaboração de outras pessoas na vida diária. 
Enfrentamentos com respostas positivas geram comportamentos adaptativos, por isso, devem ser estimulados. No caso do medo de manipulação da derivação urinária, enfermeiros e familiares podem contribuir nesse procedimento.

Eu tenho que passar a sonda, eu tenho que tirar esse medo [ .... . (P4)

[...] eu tenho um pouco de medo de passar, de me machucar! (P4)

[...] eu vou conseguir passar sonda, eu vou tirar esse medo de mim! (P4)

\section{* Categoria 4 - "Qualidade de vida pra mim é..."}

A quarta categoria teórica traz uma abordagem geral das mudanças de vida ocorridas após a derivação urinária - uma comparação realizada pelos entrevistados entre o antes e o depois, o que demonstra que essas mudanças contribuíram para melhorar a sua qualidade de vida. Aspectos como ingestão de água, usar roupas femininas, necessidade do cuidador/família, saúde, estilo de vida, determinantes sociais, satisfação com a vida e outros são abordados nessa categoria.

\section{Definição}

É um padrão, condição ou estado considerado ótimo, vivenciado ou passível de ser alcançado na interpretação de cada um. A qualidade de vida da pessoa com lesão medular relaciona-se com a vivência de enfrentamentos, a resiliência e adaptações que, nesse grupo, podem ser traduzidas de duas formas: uma direcionada para a saúde e indicadores sociais - ausência de complicações clínicas, a exemplo as infecções urinárias frequentes, boa saúde, dieta equilibrada, ingerir maior quantidade de água, atividade física, autossuficiência financeira e moradia. Outra, relacionada a aspectos pessoais e à percepção das mudanças positivas no viver, ocorridas após a derivação urinária - satisfação com a vida, estar bem consigo, ter autonomia e independência para o cateterismo, requerer menos a assistência de um cuidador, permanecer longos períodos fora de casa e, com isso, ter a oportunidade de maior convívio e participação social, acessibilidade de locais/ambientes para fazer o cateterismo, quer dizer: aspectos que comparados com o antes e o depois da derivação urinária tiveram mudanças significativas. 
Categoria 4 - "Qualidade de vida pra mim é..." - continuação

\begin{tabular}{|c|c|c|c|}
\hline Classificação temática & $\begin{array}{c}\text { Frequência de } \\
\text { unidades de registro } \\
(\mathrm{N}=15)\end{array}$ & Categorias empíricas & Inferências \\
\hline Mudança de vida & 8 & Mudança de vida & $\begin{array}{l}\text { Qualidade de vida é estar } \\
\text { com a família e amigos }\end{array}$ \\
\hline Infecção urinária & 5 & $\begin{array}{l}\text { Melhoria das } \\
\text { complicações urinárias }\end{array}$ & $\begin{array}{l}\text { Apresenta infecções de urina } \\
\text { recorrentes }\end{array}$ \\
\hline & & Saúde e estilo de vida & \\
\hline $\begin{array}{l}\text { Determinantes sociais de } \\
\text { qualidade de vida }\end{array}$ & 2 & $\begin{array}{l}\text { Determinantes sociais de } \\
\text { qualidade de vida }\end{array}$ & Sentir bem-estar psicológico \\
\hline Sofrimento & 2 & $\begin{array}{l}\text { Melhoria dos sintomas } \\
\text { físicos }\end{array}$ & $\begin{array}{l}\text { Apresenta percepção de } \\
\text { melhoria da autoestima }\end{array}$ \\
\hline Viver bem & 1 & $\begin{array}{l}\text { Melhoria dos sintomas } \\
\text { físicos e psicológicos }\end{array}$ & $\begin{array}{l}\text { Acredita que a prática de } \\
\text { atividade física traz qualidade } \\
\text { de vida }\end{array}$ \\
\hline Rede de apoio & 1 & Autoestima & \\
\hline Satisfação & 1 & Rede de apoio & \\
\hline Não ir ao pronto socorro & 1 & Satisfação com o viver & \\
\hline
\end{tabular}


Categoria 4 - "Qualidade de vida pra mim é..." - continuação

\begin{tabular}{|c|c|c|c|}
\hline Classificação temática & $\begin{array}{c}\text { Frequência de } \\
\text { unidades de registro } \\
(\mathrm{N}=15)\end{array}$ & Categorias empíricas & Inferências \\
\hline \multirow[t]{10}{*}{ Confiança } & 1 & & $\begin{array}{l}\text { Associa boa alimentação com } \\
\text { alimentação saudável e } \\
\text { qualidade de vida }\end{array}$ \\
\hline & & & $\begin{array}{l}\text { Permanece longos períodos } \\
\text { fora de casa }\end{array}$ \\
\hline & & & $\begin{array}{l}\text { Alcançou maior } \\
\text { independência se comparado à } \\
\text { condição anterior à derivação }\end{array}$ \\
\hline & & & $\begin{array}{l}\text { Diminui o grau de } \\
\text { dependência dos cuidados da } \\
\text { mãe }\end{array}$ \\
\hline & & & $\begin{array}{l}\text { Diminuíram as intercorrências } \\
\text { clínicas }\end{array}$ \\
\hline & & & $\begin{array}{l}\text { Percebe melhoria na sua } \\
\text { qualidade de vida }\end{array}$ \\
\hline & & & $\begin{array}{l}\text { Apresenta mais energia e } \\
\text { meta para viver }\end{array}$ \\
\hline & & & $\begin{array}{l}\text { Alcançou maior mobilidade } \\
\text { social ( sair de casa) }\end{array}$ \\
\hline & & & $\begin{array}{l}\text { Diminuíram os episódios de } \\
\text { infecção urinária }\end{array}$ \\
\hline & & & $\begin{array}{l}\text { Possibilidade de ter um } \\
\text { emprego }\end{array}$ \\
\hline
\end{tabular}


Categoria 4 - "Qualidade de vida pra mim é..." - continuação

\begin{tabular}{|c|c|c|c|}
\hline Classificação temática & $\begin{array}{c}\text { Frequência de } \\
\text { unidades de registro } \\
(\mathrm{N}=15)\end{array}$ & Categorias empíricas & Inferências \\
\hline & & & $\begin{array}{l}\text { Apresenta condições de ter } \\
\text { uma moradia }\end{array}$ \\
\hline & & & $\begin{array}{l}\text { É agradecido aos benefícios } \\
\text { da derivação urinária }\end{array}$ \\
\hline & & & $\begin{array}{l}\text { Faz o CIL pela derivação sem } \\
\text { dor }\end{array}$ \\
\hline & & & $\begin{array}{l}\text { Não usa fraldas logo não se } \\
\text { sente constrangida e não passa } \\
\text { mal pela plenitude vesical }\end{array}$ \\
\hline & & & $\begin{array}{l}\text { Ingere mais água, pois não } \\
\text { perde mais urina }\end{array}$ \\
\hline & & & $\begin{array}{l}\text { Alcançou mais habilidade na } \\
\text { limpeza para o CIL pela } \\
\text { derivação (por ser mais } \\
\text { acessível) }\end{array}$ \\
\hline & & & $\begin{array}{l}\text { Diminuíram as idas ao pronto- } \\
\text { socorro }\end{array}$ \\
\hline & & & $\begin{array}{l}\text { Permite outras pessoas, que } \\
\text { não a mãe, fazerem o CIL pela } \\
\text { derivação }\end{array}$ \\
\hline
\end{tabular}

Nos relatos dos entrevistados é possível identificar fatores determinantes ou que interferem na percepção acerca de qualidade de vida, muitas vezes, relacionados às mudanças ocorridas após a derivação urinária, como pode ser observado nos relatos a seguir:

[...] eu posso tomar bastante água, pra mim qualidade de vida... eu tinha muita vontade de tomar água, mas não podia porque a minha bexiga não segurava [...]. (P1)

[...] antes da cirurgia eu ficava muito com infecção urinária [...]. (P4)

[...] depois da cirurgia eu não tenho mais a necessidade de ficar limitando em beber água, né?! É... a qualquer momento eu mesmo passo a sonda e aí eu não preciso ficar dependendo de algum local que tenha algum banheiro [...]. (P6)

[...] depois da derivação eu posso ir ao shopping, passear, eu posso ir pra casa de amigos [...]. (P8)

[...] a qualidade de vida não era muito boa antes da derivação [...]. (P9)

[...] eu até saia antes da derivação; eu já tinha cadeira motorizada, mas eu tinha um prazo pra voltar [...]. (P10)

[...] antes eu tinha receio de sair, ficava até difícil de ir a um lugar, era tudo aquele tempo certinho [...]. (P12) 
As complicações clínicas relacionadas à bexiga neurogênica são muito comuns na lesão medular e também motivos de atendimentos de emergência. Um dos principais aspectos citados pelos participantes da pesquisa, e que interfere na qualidade de vida, é a infecção urinária. Seguem-se alguns trechos:

[...] eu não sinto mais dor [...]. (P2)

[...] eu não tô tendo mais febre, nem infecção, melhorou minha qualidade de vida [...]. (P4)

Eu passei a ter menos infecção urinária [...]. (P8)

[...] esse negócio de passando sonda... isso aí, dois, três meses aí, infecçãozinha de urina $[\ldots] .(\mathrm{P} 14)$

A qualidade de vida foi relacionada, também, à saúde, estilo de vida e fatores psicossociais.

[...] ter, sei lá, minha moradia, meu emprego [...]. (P6)

[...] ter uma vida saudável é... no seu dia a dia, fazer exercícios [...]. (P6)

Se alimentar bem, ela falou, fazer exercícios [...]. (P7)

Qualidade de vida pra mim é manter a saúde em dia, manter boa alimentação, fazer exercícios [...]. (P9)

[...] ter uma boa saúde [...]. (P12)

[...] ter condições de suprir necessidades de forma a viver bem, englobando todos os aspectos assim é... psicológicos, físico e mental. (P13)

[...] minha autoestima melhorou [...]. (P13)

[...] estar bem comigo mesmo [...]. [...] é estar bem de saúde [...]. (P14)

A qualidade de vida dos participantes desta pesquisa está relacionada à autonomia e gestão do viver proporcionadas pela confecção da derivação urinária continente, conforme se observa nas declarações a seguir:

Mudou muito a minha vida, eu sou outra pessoa [...]. (P1)

[...] eu posso passar o dia todo dentro de casa sozinha [...]. (P8)

[...] tive mais disposição, mais, mais foco... na vida! (P9)

[...] minha mãe vem pra cá todos os dias me ajudar na minha casa, aí assim, antes eu precisava que ela ficasse aqui um tempo muito maior do que ela fica hoje. (P10)

$[\ldots]$ se eu tiver que sair, se eu tiver que demorar, não tem problema! (P10)

Outros aspectos estão envolvidos na qualidade de vida dos pesquisados, a exemplo as redes sociais e o apoio social propiciado por essas redes.

Só de poder estar com família, com os amigos é ... todos os meus irmãos e ter uma vida boa [...]. (P15) 
* Categoria 5 - "Falta acessibilidade"

A quinta categoria, aborda uma situação conhecida e vivenciada todos os dias por pessoas com lesão medular: a falta de acessibilidade. Os entrevistados apontaram as dificuldades arquitetônicas, de mobilidade urbana como limitantes da sua participação social. A derivação urinária não exime a necessidade da implementação de políticas públicas que viabilizam a acessibilidade, mas minimiza o déficit de acessibilidade para as pessoas com derivação urinária ao possibilitar a utilização de ambientes comuns para a realização do CIL.

\section{Definição}

São as dificuldades de mobilidade urbana e acesso a espaços físicos e ambientes que sejam apropriados para pessoas com necessidades especiais, a exemplo do uso de cadeira de rodas. A falta de estrutura adaptada barreiras arquitetônicas - às pessoas que usam cadeira de rodas impede a locomoção pelas ruas, ambientes comerciais e domésticos. A falta de acessibilidade é fator limitante para a participação social e retrocesso na autonomia da pessoa com lesão medular, uma vez que para sair necessita estar acompanhada ou, algumas vezes, requerer automóvel. A derivação urinária, por ser na parede do abdome, não suscita constrangimentos ou necessidade de ambientes adaptados aos entrevistados. O esvaziamento da bexiga, pela derivação urinária continente pode ser feito na própria cadeira de rodas em local de interesse da pessoa.

\begin{tabular}{|c|c|c|c|}
\hline Classificação temática & $\begin{array}{c}\text { Frequência de unidades } \\
\text { de registro } \\
(\mathbf{N}=15)\end{array}$ & Categorias empíricas & Inferências \\
\hline \multirow[t]{5}{*}{ Local/Ambiente } & \multirow[t]{5}{*}{5} & \multirow[t]{5}{*}{$\begin{array}{l}\text { Aumento das } \\
\text { oportunidades de locais } \\
\text { para o cateterismo }\end{array}$} & $\begin{array}{l}\text { Depende de automóvel } \\
\text { Falta acessibilidade nos } \\
\text { ambientes físicos }\end{array}$ \\
\hline & & & $\begin{array}{l}\text { Os cadeirantes tem } \\
\text { dificuldade } \\
\text { acessibilidade em ambientes } \\
\text { físicos }\end{array}$ \\
\hline & & & Qualquer espaço físico \\
\hline & & & $\begin{array}{l}\text { Encontra com facilidade } \\
\text { locais possíveis para o CIL } \\
\text { pela derivação }\end{array}$ \\
\hline & & & $\begin{array}{l}\text { Ambiente/espaço } \\
\text { comum }\end{array}$ \\
\hline
\end{tabular}

A falta de acessibilidade restringe as possibilidades de autonomia da pessoa com lesão medular e está associada com a qualidade de vida.

[...] falta pra mim é a acessibilidade [...]. (P8)

[...] ter acessibilidade. (P12)

Na minha cidade, por exemplo, é muito difícil sair aqui, não tem... é difícil chegar numa loja, ir ao banco, não tem acessibilidade[...]. (P12)

[...] se tivesse mais acesso eu mesma poderia ir sozinha, qualquer horário. (P12) 
A praticidade oferecida pela derivação urinária viabilizou o acesso a banheiros ou ambientes comuns, não adaptados; no entanto, não exclui a necessidade de acessibilidade.

[...] eu consigo fazer ele em qualquer local, né?! (P2)

[...] eu posso fazer em qualquer lugar [...]. (P3)

[...] posso fazer num cantinho de parede, posso fazer no banheiro, eu posso fazer dentro do carro [...]. (P3)

Eu posso fazer na rua, tipo no banheiro do shopping [...]. (P4)

\section{* Categoria 6 - "Eu tinha uma vida muito ativa"}

Essa categoria aponta para a alteração na percepção e desempenho dos papéis sociais enfrentados pelas pessoas com lesão medular. A derivação urinária, por favorecer a autonomia, na maioria das vezes, contribuiu positivamente para a pessoa apoderar-se do seu papel social.

\section{Definição}

Significa a interrupção súbita de papéis sociais exercidos comumente por uma pessoa na sociedade, seja como trabalhador, mãe, esposa, cidadã e outros. A pessoa com lesão medular tem uma desfiguração dos seus papéis sociais, seja por suas crenças ou pelo estigma, de boa parte da sociedade, às pessoas com lesão medular considerando-as, incapazes de tomar decisões e de serem incluídas socialmente.

\begin{tabular}{lcll}
\hline Classificação temática & $\begin{array}{c}\text { Frequência de unidades } \\
\text { de registro } \\
(\mathbf{N = 1 5 )}\end{array}$ & Categorias empíricas & \multicolumn{1}{c}{ Inferências } \\
\hline Papéis sociais & 1 & Papéis sociais & $\begin{array}{l}\text { Reassumiu a identidade dos } \\
\text { vários papéis sociais, o que foi } \\
\text { favorecido pela autonomia e } \\
\text { gestão do esvaziamento da } \\
\text { bexiga por meio da derivação } \\
\text { urinária continente }\end{array}$ \\
\hline
\end{tabular}

A pessoa com lesão medular traumática se vê, principalmente nos momentos iniciais da lesão medular, em situação de desaceleração de todas as suas atividades, repercutindo de forma negativa na percepção de bem-estar psicológico.

[...] eu trabalhava, eu tinha uma vida muito ativa antes da lesão, eu trabalhava, eu tinha dois filhos pequenos, casada, saia, fazia um monte de coisa e de repente tudo isso parou [...]. (P10) 


\section{- Categoria 7 - "Nem ligo pra estética"}

Essa categoria apresenta como a alteração intencional na anatomia corporal interferiu na qualidade de vida dos entrevistados. A percepção da alteração da imagem foi pouco expressiva, os benefícios foram considerados mais significativos do que a estética.

\section{Definição}

A interpretação, pessoal ou de outras pessoas, dada à modificação do corpo pela presença de um pequeno orifício - estoma -, presente na parede abdominal. A pessoa considera o benefício da derivação urinária superior à alteração na imagem corporal e não se incomoda com a modificação. A percepção pode ser de outra pessoa relacionada à alteração da imagem corporal e a depender do grau de intimidade pode influenciar a autopercepção, a exemplo da crítica da estética feita pelo esposo. Observa-se que mesmo nessa condição há uma justificativa pessoal para a aceitação quanto à estética.

\begin{tabular}{|c|c|c|c|}
\hline Classificação temática & $\begin{array}{c}\text { Frequência de unidades } \\
\text { de registro } \\
(\mathrm{N}=15)\end{array}$ & Categorias empíricas & Inferências \\
\hline $\begin{array}{l}\text { Alteração da imagem } \\
\text { corporal }\end{array}$ & 2 & $\begin{array}{l}\text { Autopercepção do corpo } \\
\text { Percepção pelo outro da } \\
\text { imagem corporal }\end{array}$ & $\begin{array}{l}\text { Percebe a estomia urinária } \\
\text { tão benéfica que não se } \\
\text { incomoda com a estética } \\
\text { (pequeno óstio no abdome } \\
\text { direito) }\end{array}$ \\
\hline
\end{tabular}

A imagem corporal modificada pode ser fator relevante que interfere na qualidade de vida das pessoas com estomia de modo geral. Nesta pesquisa, dois participantes elucidaram a questão, conforme se depreende das declarações a seguir:

[...] meu marido fica incomodado um pouco... aí ele pediu até... ' Ah! Amor, faz uma cirurgia plástica"’[...]. (P1)

Ele não reclamou mais também não né?! É tão bom, né?! Que não dá nem pra reclamar. (P1)

[...] eu nem ligo pra estética! Tem gente que fala: 'oh! É estranho, é esquisito!' Sinceramente, eu não me incomodo! (P12)

Pra mim o benefício foi tanto que pra mim é tranquilo. (P12)

\section{* Categoria 8 - "Não entendem sobre isso"}

$\mathrm{Na}$ oitava categoria, identifica-se na fala do entrevistado o despreparo de profissionais de saúde, de instituições gerais, em lidar com as especificidades de pessoas com lesão medular. 


\section{Definição}

Trata-se do desconhecimento da equipe de saúde em atender a pessoa com lesão medular e condições urológicas específicas, podendo contribuir para complicações graves, com risco de morte.

\begin{tabular}{lcll}
\hline Classificação temática & $\begin{array}{c}\text { Frequência de unidades } \\
\text { de registro } \\
(\mathbf{N = 1 5 )}\end{array}$ & Categorias empíricas & \multicolumn{1}{c}{ Inferências } \\
\hline Desconhecimento & 1 & $\begin{array}{l}\text { Qualificação } \\
\text { profissional }\end{array}$ & A sonda obstruiu por muco \\
& $\begin{array}{l}\text { Desconhecimento us urológicas } \\
\text { condições } \\
\text { específicas da pessoa }\end{array}$ \\
\hline
\end{tabular}

Nota: trata-se de um participante traqueostomizado; no primeiro dia de oclusão da cânula para decanulação apresentava-se ofegante pelo exercício da fala.

A maioria dos participantes da pesquisa submeteu-se, além da derivação urinária, à ampliação vesical; normalmente, usam-se partes do intestino e as células continuam sua produção de muco podendo, como na situação referida pelo participante, levar à obstrução do cateter vesical contínuo e rompimento da bexiga por distensão. $\mathrm{O}$ desconhecimento das condições urológicas da pessoa com lesão medular é susceptível às iatrogenias.

[...] tem muitos médicos aqui que não entendem sobre isso [...]. (P5)

[...] a sonda que eles colocaram entupiu, então eles não entendeu aí eles pensou que era outra... aí teve que me abri, eles não entendeu... aí foi na hora que abriu que viu que tinha perdido... abriu a bexiga e tinha muita urina perdida porque ela não pode encher muito. (P5)

[...] toda vez que põe aquela sonda permanente tem que tomar cuidado que ela entope, se ela entupir tem que desentupir [...]. (P5)

\section{* Categoria 9 - "Um pouco a reclamar"}

A nona categoria aborda o insucesso e a insatisfação quanto à funcionalidade da derivação urinária para o CIL. O insucesso foi percebido como a impossibilidade para o autocateterismo vesical e por inviabilidade do conduto urinário no esvaziamento da bexiga. Essas condições foram contrárias às expectativas prévias: autocateterismo e independência; no entanto, um dos entrevistados considerou a derivação urinária como um fator positivo na sua qualidade de vida, pois liberou a mãe da exclusividade para o CIL. 


\section{Definição}

Caracteriza o insucesso da derivação urinária continente. O conduto urinário não foi viável para o autocateterismo vesical pela posição do estoma na parede abdominal: estava inacessível à manipulação para o esvaziamento da bexiga ou o conduto urinário foi disfuncional devido à complicação pós-cirúrgica. Ocorrência de frustração das expectativas quanto à independência para o CIL pela derivação urinária. Relaciona sintomas de disrreflexia com a confecção da estomia urinária continente.

\begin{tabular}{lcll}
\hline Classificação temática & $\begin{array}{c}\text { Frequência de } \\
\text { unidades de registro } \\
(\mathbf{N = 1 5})\end{array}$ & Categorias empíricas & Inferências \\
\hline $\begin{array}{l}\text { Insatisfação com a } \\
\text { derivação urinária }\end{array}$ & 2 & $\begin{array}{l}\text { Insatisfação com a } \\
\text { derivação urinária } \\
\text { Impossibilidade de } \\
\text { cateterização do estoma }\end{array}$ & $\begin{array}{l}\text { Insucesso com a derivação } \\
\text { A posição do estoma ficou } \\
\text { inadequada }\end{array}$ \\
& $\begin{array}{l}\text { Deseja reclamar } \\
\text { derivação }\end{array}$ \\
sobre & Apresenta cefaleia e arrepios \\
\hline
\end{tabular}

A independência para o CIL por meio da derivação urinária continente gera expectativas na maioria das pessoas com lesão medular impossibilitadas da autocateterização pela uretra.

[...] aquela expectativa que vai ser um sucesso e agora aí a gente faz e [...]. (P7)

[...] ela sempre fala assim pra mim que se tivesse dado certo essa cirurgia [...]. (P7)

Mesmo quando a cirurgia não atendeu ao intento se observa as idealizações positivas nas verbalizações dos participantes:

[...] Acesso a mais coisas, podia passear mais, ter a independência [...]. (P7)

[...] se a derivação tivesse num posicionamento melhor poderia estar te ajudando mais não é? (P11)

O posicionamento do estoma urinário, juntamente com habilidades de manuseio do cateter vesical na parede abdominal, é um dos principais fatores a ser considerados na indicação da confecção da derivação urinária. O sucesso da derivação urinária está relacionado à sua funcionalidade, conforme se observa nos trechos das entrevistas a seguir transcritos: 
[...] onde ficou é impossível. (P11)

[...] ficou como na dobra da barriga! Digamos, se eu engordar muito é como se a barriga fosse tampar ela. (P11)

[...] até sentado eu já tenho um pouco de dificuldade de fazer, outra pessoa fazer. (P11)

A disrreflexia autonômica pode ser desencadeada por inúmeros fatores - distensão vesical ou intestinal, posicionamento inadequado, úlceras pressão, entre outros. Não é possível afirmar a relação encontrada na fala do entrevistado.

Eu não tinha dor de cabeça e nem arrepios antes da cirurgia! Depois que eu fiz, nossa! Isso me atrapalha e muito! (P11)

\section{* Categoria 10 - "O sexo diminuiu"}

A décima categoria teórica retrata a correlação feita pelo entrevistado de que a derivação urinária comprometeu o seu desempenho sexual.

\section{Definição}

Disfunção sexual (crença que a piora do desempenho sexual advém com a derivação).

\begin{tabular}{|c|c|c|c|}
\hline Classificação temática & $\begin{array}{l}\text { Frequência de unidades } \\
\text { de registro } \\
(\mathrm{N}=15)\end{array}$ & Categorias empíricas & Inferências \\
\hline \multirow[t]{2}{*}{ Sexo } & 1 & Atividade sexual & $\begin{array}{l}\text { Correlaciona a disfunção } \\
\text { sexual com a derivação } \\
\text { urinária }\end{array}$ \\
\hline & & & $\begin{array}{l}\text { Outros fatores estão } \\
\text { envolvidos na disfunção } \\
\text { sexual }\end{array}$ \\
\hline
\end{tabular}

A confecção da derivação urinária não envolve inervação dos centros responsáveis pelas respostas sexuais. A ereção, com integridade neurológica, se dá por ativação do centro simpático dorso-lombar (T10-L2) ou atividade reflexa do centro sacral (S2-S4). A disfunção sexual fisiológica pode ser inerente à lesão medular, mas não relacionada à confecção da derivação urinária; o comprometimento sexual é distinto, a depender do nível neurológico acometido. As questões sexuais devem ser abordadas previamente à cirurgia ou quando se fizer necessário para desmitificar crenças existentes e propiciar satisfação com a sexualidade.

[...] o sexo diminuiu pra caramba e eu não sei porquê.

$[\ldots]$ antes de fazer a cirurgia era normal, era quase igual ao que era antes do acidente $[\ldots]$

[...] hoje pra conseguir ficar ereto é meio complicado [...]. 


\section{DISCUSSÃO}

A discussão dos resultados desta pesquisa segue a mesma ordem apresentada no capítulo precedente. Na sequência, são discutidos os dados sociodemográficos e clínicos seguidos da discussão das categorias teóricas que emergiram da avaliação qualitativa sobre a implicação da derivação urinária continente na qualidade de vida de pessoas com lesão medular.

\subsection{PERFIL SOCIODEMOGRÁFICO E CLÍNICO}

A predominância, no grupo estudado, foi de pessoas do sexo feminino, o que está em consonância com a literatura que justifica as vantagens da confecção da estomia urinária continente para essa população, haja vista que, por natureza, o acesso à uretra feminina é mais difícil (AKHAVAN et al., 2007; KARSENTY et al., 2008; TOUMA et al., 2006). A predominância das mulheres pode ser explicada pelas condições consideradas na triagem para se indicar a confecção da estomia urinária - lesão medular cervical com forte comprometimento funcional e motor, ou alterações anatômicas e dificuldades de se posicionar sentada.

A amostra foi constituída por adultos, com variação entre 16 e 48 anos, semelhantes a outros estudos nacionais e internacionais (BAMPI; GUILHEM; LIMA, 2008; VERA, 2012; GEYH et al., 2012; AKKOÇ et al., 2012). Esse fator é relevante, uma vez que essas pessoas se encontram na faixa etária produtiva e a lesão medular traz implicações pessoais, econômicas e sociais que interferem na QV (BLANES; CARMAGNANI; FERREIRA, 2009).

Os avanços no tratamento e os cuidados disponibilizados nas últimas décadas aumentaram a perspectiva de sobrevida - a população acometida por lesão medular cresce tanto em tamanho quanto em idade (THE NATIONAL SI STATISTICAL CENTER, 2013; AKKOÇ et al., 2012; MIGLIORINI; NEW; TONGE, 2010). O conhecimento das evidências sociodemográficas é um fator importante para direcionar o planejamento de políticas públicas, orçamento, estruturação dos serviços de saúde e programas de reabilitação.

Nesta pesquisa, os entrevistados tinham lesão medular de forma crônica (intervalo de 5 a 25 anos); essa evidência é significante, pois o tempo de lesão medular pode interferir na qualidade de vida percebida e no autocuidado, uma vez que quanto maior o tempo decorrido do trauma medular maiores serão as chances da utilização de estratégias mais adaptativas e de maior estabilidade (GEYH et al., 2012;VERA; ARAÚJO, 2011).

Em relação à educação formal, apenas três, entre os quinze entrevistados, concluíram o ensino superior. A baixa escolaridade da população com lesão medular é caracteristica 
comum em estudos brasileiros (MENEGUESSI, 2012; BAMPI; GUILHEM; LIMA, 2008; BLANES; CARMAGNANI; FERREIRA, 2009) e pode ser consequência tanto das condições sociais prévias quanto das dificuldades advindas com a lesão medular, a exemplo de locomoção, mobilidade urbana, barreiras arquitetônicas e de inclusão.

A variação do tempo de ensino formal irá depender do local, região e mesmo do país. Estudo multicêntrico e internacional fez a avaliação da educação em seis países e comparou o tempo médio (anos) de educação; identificou que o Brasil foi o segundo país com menor tempo de escolaridade (média de 10.7 anos), enquanto o país com maior tempo de escolaridade foi o Canadá (média de 14.8 anos). Há correlação positiva entre o tempo de estudo e a percepção sobre QV (GEYH et al., 2012). No Brasil, as pessoas com lesão medular e baixa escolaridade estão sujeitas a trabalhos de pouca rentabilidade e, na maioria das vezes, trata-se de trabalho sem vínculo empregatício e destituído dos benefícios legais destinados ao trabalhador (BLANES; CARMAGNANI; FERREIRA, 2008).

Os resultados encontrados quanto à distribuição do tipo de lesão versus confecção de estomia urinária continente vão ao encontro da literatura internacional, em que há predominância das pessoas com tetraplegia seguidas por outras etiologias da deficiência (PAZOOKI et al., 2006; ZOMMICK et al., 2003). Neste estudo, a predominância foi de pessoas com tetraplegia, sequelas de mielomeningocele e paraplegia. Acredita-se que a distribuição encontrada correlaciona-se com o perfil indicado para a confecção da estomia urinária continente. Observou-se que pessoas com paraplegia foram menos expressivas na amostra $(\mathrm{N}=3)$, pois a maioria conserva a funcionalidade e motricidade nos membros superiores; a indicação, nessa situação, está relacionada com o comprometimento da uretra para o autocateterimo vesical.

Outros estudos internacionais apontaram a heterogeniedade dos grupos submetidos à confecção de estomia urinária continente com ou sem ampliação vesical, sendo mais frequentes em grupos com lesões medulares, mielomeningocele, paralisia cerebral e esclerose múltipla (KHAVARI et al., 2012; VAN DER AA et al., 2009).

A maioria dos participantes deste estudo submeteu-se, simultanemante, à confecção de estomia urinária continente e à ampliação vesical quando necessário.

Harris et al. (2000 apud LÍARD et al., 2001, p. 2396) afirmou que: “Atualmente, na maioria das séries, a ampliação vesical é feita concomitantemente com a cistostomia continente". A ampliação vesical tem indicação quando a baixa capacidade da bexiga aliada aos fatores neurogênicos intrínsecos - bexiga contraída, hiperatividade detrusora, baixa capacidadade vesical, pressão intravesical elevada - foram riscos para a deterioração da 
função renal (KU, 2006). Na Bélgica, uma série de casos acompanhada por dois cirurgiões revelou que o aumento das cirurgias de ampliação vesical diminuiu significativamente as pequenas revisões nas estomias urinárias, e apontou a confecção da estomia urinária como uma técnica valiosa para pessoas adultas com problemas irreversíveis no trato urinário inferior (VAAN DER AA et al., 2009).

O número reduzido de pessoas submetidas à confecção de estomia urinária corrobora com os resultados encontrados em alguns estudos, que também são constituídos por série de casos. Os autores consideram que a seleção dessas pessoas deva ser criteriosa em relação às habilidades para o manuseio do cateter urinário; o mínimo de habilidade é necessário e/ou a pessoa deveria ter o apoio social de cuidador/familiar em casa (AKHAVAN, et al., 2007; ZOMMICK et al., 2003).

A indicação da confecção da derivação urinária mais evidente foi a dificuldade de acesso à genitália $(\mathrm{N}=6)$ e está relacionada com o grau de comprometimento motor e funcional. Influenciaram na indicação o tipo de anatomia lombossacra e pertencer ao sexo feminino. A estomia urinária é uma alternativa quando ocorrem dificuldades para o cateterismo transuretral, utilizada mundialmente e com várias indicações (LÍARD et al., 2001).

Outros estudos confluem para os motivos encontrados nesta pesquisa, a exemplo do desejo de realizar o autocaterismo, incapacidade de utilizar a uretra nativa devido à destreza limitada ou comprometimento da uretra, equilíbrio do tronco e posicionamento do corpo (VAN DER AA et al., 2009; TOUMA et al., 2007; PAZOOKI et al., 2006).

A ocorrência de complicações após a realização da estomia urinária continente foi expressiva, totalizando sete $(46,6 \%)$ pessoas entre os 15 entrevistados. No entanto, foi considerada aceitável quando se relacioana com o padrão reportado em alguns estudos da literatura internacional, cujas taxas variaram de $29 \%$ a 61,7\% (KHAVARI et al., 2012; VAN DER AA et al., 2009; TOUMA et al., 2007). Líard et al. (2001) fizeram uma avaliação do fallow up de 23 crianças durante o tempo médio de 20 anos, e identificaram uma taxa de complicação geral de $24 \%$. Identificaram, também, que as complicações relacionadas ao conduto urinário ocorreram com maior frequência nos primeiros anos, mas não desconsideraram a ocorrência em outro momento. Portanto, longos períodos de acompanhamento podem resultar em piores taxas de complicações.

No presente estudo, houve maior notificação de complicações nos prontuários, tanto no que se refere à frequência quanto à especificidade. Esse fato se deve ao conhecimento técnico-científico com maior precisão para identificar e descrever a complicação apresentada. 
Outro aspecto observado foi o tempo de permanência que o cateter de policrilato de vinila permanece abrigado no conduto para manter o lumen patente. Todos os entrevistados permaneceram com o cateter por 14 dias, até iniciar o treino do CIL pela estomia urinária. Outros estudos apontaram a permanência do cateter vesical por um período de 21 dias, e ainda assim ocorreram complicações no estoma (VAN DER AA et al., 2009; TOUMA et al., 2007; CHAVIANO et al., 2000). Uma possibilidade para essa situação é que o tempo de maturação do conduto urinário pode não ser determinante de uma das principais complicações da cirurgia, que é a estenose do conduto urinário.

As taxas de complicações encontradas por Van der AA et al. (2009) não identificaram correlação na análise estatística entre o sexo da pessoa, idade, índice de massa corpórea, patologia subjacente, bem como com o tipo de técnica cirúrgica empregada, nem da localização do estoma urinário.

A confecção da estomia urinária continente permitiu o autocateterismo vesical para a maioria dos participantes, sendo que 11 pessoas foram capazes de realizar o autocateteri smo com autonomia (sem a ajuda de outrem). Duas pessoas com tetraplegia consideraram que mesmo após a realização da estomia urinária não foi possível realizar o autocateterismo devido ao grau de comprometimento motor da lesão medular, mas relataram que a confecção da estomia urinária trouxe benefícios, a exemplo da facilitação para o cateterismo feito pelo cuidador (familiar ou não). Uma das participantes com mielomeningocele obteve independência parcial devido ao medo de autocateterizar-se, mas relatou fazê-lo em situações extremas. Para uma das participantes, não foi possível realizar o CIL pela estomia urinária devido à complicação, provavelmente estenose, mas ainda não tinha sido reavaliada pelo cirurgião. O sucesso para o autocateterismo vesical pelo estoma é descrito em outros estudos (KARSENTY et al., 2008; AKHAVAN et al., 2007; CHAVIANO et al., 2000) e contribui para a melhoria da QV das pessoas.

A estomia urinária continente foi correlacionada pelos entrevistados com a facilidade em autocateterizar-se, com aumento da gama de oportunidades de acesso a ambientes comuns (banheiro ou áreas reservadas), pois ambientes adaptados são escassos ou inexistentes. A estomia urinária também veio a otimizar o tempo e a independência da pessoa, no que diz respeito à necessidade de cuidador/família para realizar o esvaziamento da bexiga.

A facilidade de acesso e a praticidade em realizar o CIL emergiram no conteúdo das verbalizações. Principalmente para as mulheres, o acesso à uretra é dificultado pela anatomia feminina, o que frequentemente requer ambiente privado, onde possam passar da posição assentada para o decúbito horizontal. As mulheres podem necessitar ainda da assistência de 
um cuidador, o que compromete a privacidade, independência e a qualidade de vida (AKHAVAN et al., 2007).

Os benefícios decorrentes da confecção da estomia urinária são semelhantes aos encontrados em pesquisas prévias, nas quais os autores enfatizaram a facilidade da autocateterização (75\% a 90\%), uma vez que não havia necessidade de passar para um leito ou despir-se e o CIL poder ser realizado na posição sentada, independentemente de um cuidador/família (VAN DER AA et al., 2009; AKHAVAN et al., 2007; TOUMA et al., 2007). Outro estudo, desenvolvido na Suécia, encontrou diminuição na magnitude e frequência na síndrome de desautonomia que acomete pessoas com lesão medular alta (PAZOOKI et al., 2006). Há relatos também de diminuição das infecções do trato urinário inferior e dos episódios de incontinência urinária (AKHAVAN et al., 2007).

Um mínimo de habilidade das extremidades superiores é necessário e foi observada na maioria dos voluntários $(\mathrm{N}=13)$, o que pode ter contribuído para o sucesso da gestão do esvaziamento vesical. Não foi realizada avaliação prévia dessa condição. O estudo feito por Akhavan et al. (2007) apontou que a aplicação de um questionário funcional pode ser uma ferramenta útil na avaliação de um candidato à confeção da estomia urinária continente, uma vez que é um preditor seguro e capaz de avaliar a capacidade da pessoa para utilizar o estoma urinário.

Outro fator importante, efetuado na triagem dos candidatos à cirurgia, e que contribui para o sucesso nos resultados, é a avaliação do contexto social. Para as pessoas que são incapazes de realizar o autocateterismo, mas estão desejosas de se submeter à cirurgia para facilitar o esvaziamento da bexiga, há a necessidade do apoio social e da presença de um cuidador/familiar para a realização do CIL em intervalos regulares, a fim de evitar complicações que podem se agravar causando risco de morte (ZOMMICK et al., 2003). Essa é uma preocupação considerada pelos profissionais na realidade diária da instituição em que foi feita a pesquisa.

O sucesso da estomia urinária continente se relaciona, sobretudo, com a capacidade para realizar o CIL, e, com isso, manter preservada a função renal (MERENDA et al., 2007). A regularidade para realizar o CIL é definida de acordo com exames uroradiológicos e condições clínicas individuais.

Observou-se também nesta pesquisa que a maioria dos participantes $(\mathrm{N}=13)$ esvaziava a bexiga de forma regular, convergindo com o estudo de Meneguessi (2012), que encontrou $72 \%$ de regularidade. O intervalo de maior referência foi de quatro em quatro horas durante o dia e de seis em seis horas durante a noite. 
No protocolo de reeducação urinária, realizado no Programa de Neuroreabilitação de Lesão Medular do Hospital Sarah-Brasília, onde os dados foram coletados, é feita a orientação a respeito do controle hídrico e da ingestão de dois litros a dois e meio litros de água nas 24 horas. O volume ingerido deve ser reduzido no período noturno para maior conforto - diminuir as chances de distensão vesical e incontinência. Com isso, é possível tempo maior de sono e repouso, podendo ser esse um fator que justifique maior adesão das pessoas a esse intervalo.

$\mathrm{O}$ uso de medicamentos para diminuir a hiperatividade da bexiga foi observado na maioria das pessoas $(\mathrm{N}=9)$. Foram utilizados com maior frequência os anticolinérgicos, utilizados como tratamento coadjuvante para diminuir a incontinência urinária (MENEGUESSI, 2012).

A hiperatividade detrusora está relacionada ao nível da lesão medular (MERENDA et al., 2007); muitas vezes, apenas uma conduta frente à incontinência urinária é insuficiente e se faz necessária a associação de ações para diminuir a pressão de armazenamento da bexiga, a exemplo de: ampliação vesical, CIL e uso de medicações (KHAVARI et al., 2012; TOUMA et al., 2007).

Todos os 15 participantes submetidos à confecção de estomia urinária continente fizeram exames uroradiológicos prévios: ultrassonografia renal/vias urinárias, uretrocistografia e estudo urodinâmico. O objetivo era avaliar a função renal e as condições das vias urinárias. No entanto, apenas nove dos participantes tinham realizado os exames pós-operatórios até a finalização da coleta de dados, que tem como objetivo avaliar a repercussão cirúrgica na função renal e no trato urinário.

A litíase vesical ocorreu em apenas uma pessoa que tinha feito derivação urinária e ampliação vesical. Outro estudo com uma série de 16 pessoas indicou que quatro dos participantes haviam tido litíase vesical, mas não mencionou a presença de ampliação vesical (MERENDA et al., 2007). Já Líard et al. (2001) apontaram que cálculos vesicais podem se formar em qualquer tipo de bexiga neurogênica, e não necessariamente em bexigas que sofreram ampliação. Neste estudo, não foram encontradas evidências de que a presença de litíase se correlaciona com a derivação urinária continente.

No presente estudo, duas pessoas apresentavam, previamente, o refluxo vesicoureteral, com resolução do problema em uma. No entanto, houve incidência em um caso após a estomia urinária. Todos acometidos pelo refluxo vesico-ureteral tinham feito a estomia urinária e ampliação vesical. A evolução do refluxo vesico-ureteral permanece incerta mesmo com a ampliação vesical e com a diminuição da pressão intravesical (Líard et al., 2001). 
Nessa estratificação $(\mathrm{N}=9)$ - pessoas com exames pré e pós-operatórios -, a maioria tinha feito ampliação vesical $(n=7)$. Hiperatividade detrusora, hiperdistensão vesical, baixa capacidade e complacência vesical diminuída podem comprometer a função renal (KHAVARI et al., 2012; TOUMA et al., 2007). A ampliação vesical torna-se uma opção de tratamento quando as medidas conservadoras foram ineficazes para manter a função renal. Naqueles em que houve o incremento da capacidade vesical inicial essa variou de $28 \%$ a $88,5 \%$.

A avaliação global dos dados resultantes que envolvem os exames uroradiológicos: ultrassonografia renal/vias urinárias, uretrocistografia e estudo urodinâmico desse pequeno grupo permite inferir que a manutenção de um reservatório urinário de baixa pressão está relacionada a fatores multicausais: estomia urinária, ampliação vesical, comportamento vesical (arreflexia ou hiperatividade detrusora), uso de medicação e, também, que a capacidade de armazenamento está diretamente relacionada com a ampliação vesical.

Nesta série estudada, houve variação significativa nos episódios de infecção do trato urinário após a derivação urinária mais ampliação vesical em detrimento dessa incidência em pessoas submetidas apenas à derivação urinária, deduzindo-se que, nesse grupo, a diminuição das ocorrências de infecção urinária estaria relacionada à ampliação vesical.

Outros estudos divergem dos resultados encontrados no estudo atual, sendo que em dois deles foi encontrada diminuição importante dos episódios de infecção urinária após a derivação urinária (AKHAVAN et al., 2007; TOUMA et al., 2007). No entanto, o estudo de Touma et al. (2007) não verificou associação entre infecções do trato urinário e ampliação vesical. Já o estudo de (KHAVARI et al., 2012) apontou que a infecção do trato urinário foi uma das principais complicações após a cirurgia de derivação urinária, embora não tenha referido se a avaliação de infecção do trato urinário foi correlacionada com outros tipos de cirurgias subjacentes na amostra estudada.

\subsection{AVALIAÇÃO DA QUALIDADE DE VIDA DE PESSOAS COM DERIVAÇÃO URINÁRIA E LESÃO MEDULAR: ANÁLISE QUALITATIVA}

A subjetividade própria do construto qualidade de vida, seu caráter multidimensional, dependente da experiência vivida, dos valores individuais e coletivos, conforme apontam alguns autores (FARQUHAR, 1995; MINAYO; HARTZ; BUSS, 2000; SEIDL; ZANNON, 2004), pode ser identificada nas diferentes categorias teóricas que emergiram do estudo - "Eu tenho mais independência"; "Não ficar perdendo xixi”; "Minha lesão"; "Qualidade de vida 
pra mim é..."; "Falta acessibilidade"; "Eu tinha uma vida muito ativa"; "Nem ligo pra estética"; "Não entendem sobre isso"; "Um pouco a reclamar"; e "O sexo diminuiu".

As categorias teóricas resultantes das entrevistas permitiram inferências com relação às condições que mais afetam a qualidade de vida das pessoas com lesão medular incapazes de realizar o autocateterismo, bem como conhecer como a derivação urinária continente pode incidir de forma positiva na qualidade de vida dessas pessoas a partir do seu ponto de vista.

A qualidade de vida foi percebida como condição estabelecida após a confecção da derivação urinária continente, sendo correlacionada como o ponto de partida para as mudanças positivas ocorridas na vida de cada participante após a lesão medular. Mudanças que permitiram a simples satisfação pessoal de ingerir água ou vestir "uma roupa feminina", de sentir que é capaz do autocuidado, de trabalhar, de poder se organizar nas suas atividades diárias, de ser participativo nas variadas formas de representação social, de não se "molhar" e ficar constrangido. $\mathrm{O}$ motivo principal do manejo da bexiga neurogênica para as pessoas com derivação urinária - que é a preservação da função renal - foi considerado um objetivo secundário e sequer foi mencionado. Permaneceu ofuscado na percepção daqueles que passaram a vivenciar outras oportunidades de vida até então limitadas.

Esse conhecimento é relevante, pois possibilita traçar estratégias de reabilitação e cuidados que possam melhor contribuir para os cuidados dirigidos a essa população. As categorias teóricas serão discutidas a seguir.

A categoria teórica "Eu tenho mais independência" foi considerada a mais significativa pelos entrevistados, uma vez que a derivação urinária possibilitou a gestão do esvaziamento vesical. Esse resultado foi semelhante ao estudo feito por Merenda et al. (2007). A independência adquirida por meio da derivação urinária extrapola a realização do autocateterismo e se associa à maior autonomia e autogestão do viver; rompe com um padrão de restrições e abre um leque de oportunidades, tais como: trabalhar, estudar, mobilidade social (ir e vir) e não depender de terceiros para o esvaziamento da bexiga. Ocorre maior aproximação de um estilo de vida considerado normal (CHAVIANO et al., 2000).

Para os participantes deste estudo, a independência está diretamente relacionada à realização da derivação urinária continente, considerando-se que a pessoa passa a não requerer assistência de um cuidador/familiar para o esvaziamento da bexiga, o que permite maior privacidade e sentimentos de autossuficiência. Nas pessoas com lesão medular, a dependência é fator relevante e se relaciona às dificuldades funcionais advindas com esse tipo de lesão (VERA, 2012). 
A praticidade para a realização do autocateterismo pelo estoma na parede abdominal foi evidenciada por vários participantes do estudo $(\mathrm{N}=5)$, transformando-se em fator determinante da independência. Essa praticidade contribuiu, inclusive, para a utilização de ambientes comuns para o esvaziamento vesical e para a otimização do tempo gasto com o procedimento. No entanto, essa inferência foi feita a partir da análise do conteúdo dos discursos expressos, e não por meio da mensuração do tempo.

Alguns estudos apresentaram resultados favoráveis de pessoas incapazes para realizar o autocateterismo prévio à derivação urinária continente e que, posterioremente, foram exitosas devido ao fácil acesso para realizar o CIL (AKHAVAN et al., 2007; MERENDA et al., 2007; PAZOOKI et al., 2006).

A continência urinária alcançada com o CIL por meio da derivação urinária ocasionou impacto positivo na qualidade de vida dos participantes desta pesquisa. $\mathrm{O}$ controle da micção propiciou a convivência social, confiança para interagir e mobilidade social (ir e vir). A mobilidade social prévia à derivação urinária estava condicionada ao tempo (intervalos entre CIL) ou à acessibilidade de local/ambiente para realizar o CIL. A disfunção urinária foi considerada no estudo feito por Vera (2012) como a condição que mais interfere na qualidade de vida das pessoas com lesão medular (69\%).

O tipo de manejo da bexiga e a diminuição de perdas urinárias são importantes fatores para aumentar a qualidade de vida de pessoas com lesão medular. A disfunção vesical está associada a complicações e diminuição da qualidade de vida (AKKOÇ et al., 2012). O estudo de $\mathrm{Ku}$ (2006) apontou que as intervenções cirúrgicas para melhorar a função vesical, geralmente, aumentam a qualidade de vida.

No presente estudo, o elevado quantitativo de pessoas que avaliaram positivamente sua qualidade de vida (12) e de satisfação com a estomia urinária continente (14) nas respostas tipo Likert correlacionou-se de forma positiva com o significado dos conteúdos que emergiram da pesquisa, e corrobora com outros resultados encontrados (MERENDA et al., 2007; TOUMA et al., 2007; PAZOOKI et al., 2006).

Possuir continência urinária aumentou a satisfação pessoal e contribuiu para a melhora da autoestima nos participantes do estudo a partir do momento que foi possível eliminar o uso de dispositivos urinários externos: bolsas urinárias, cateteres urinários contínuos e fraldas, e, ainda, o fato de não perder urina nas roupas contribuiu para essa condição. A eliminação dos dispositivos, juntamente com o aumento da independência e melhor percepção da imagem corporal, tem sido citada como fator que aumenta a qualidade de vida das pessoas (ZOMMICK et al., 2003). 
Sentimentos negativos relacionados à incontinência urinária limitam a vida pessoal e produz constrangimento, vergonha, sentimento de ser desditoso, pudor por expor partes íntimas no momento do CIL. As emoções relatadas pelos participantes deixaram de ocorrer após a derivação urinária graças à eliminação dos fatores desencadeantes. A pessoa com incontinência vesical tende a evitar situações de convívio social, tais como: trabalho, passeios e viagens longas, em uma tentativa de autopreservação emocional (MENEGUESSI, 2012).

Alguns participantes apontaram em suas falas as dificuldades vivenciadas a partir da lesão medular, tais como: alteração da estrutura familiar e pessoal, comprometimento funcional, psicológico, ambiental (acessibilidade) e social, bem como sinalizaram alguns mecanismos de enfrentamento. A lesão medular é condição subjacente para que a maioria dos eventos desfavoráveis acontençam e estes requerem recursos individuais, coletivos e sociais para que ocorra adaptação às condições de vida suscitadas pela lesão medular.

Estudos sobre qualidade de vida em pessoas com lesão medular apontaram que esse comprometimento, além dos prejuízos relacionados à mobilidade, traz outras consequências que podem afetar alguns aspectos que envolvem a qualidade de vida, entre os quais a vitalidade, aspectos emocionais e o funcionamento social (BAMPI; GUILHEM, LIMA, 2008; BLANES; CARMAGNANI; FERREIRA, 2009).

Os participantes deste estudo e que tinham lesão medular alta, tetraplegia, formavam o maior subgrupo, que era composto por sete pessoas. Alguns estudos correlacionaram que quanto mais alto o nível de comprometimento neurológico, menor será a sua capacidade funcional (BLANES; CARMAGNANI; FERREIRA, 2009; AKHAVAN et al., 2007; MERENDA et al., 2007). Embora com capacidade funcional limitada, essas pessoas consideraram positiva sua qualidade de vida, com quantitativo geral elevado (seis consideraram muito boa e seis boa). Na revisão sistemática feita por Hammel (2004) há evidências de que a experiência de qualidade de vida depende de fatores qualitativos subjetivos, a exemplo do conteúdo e o contexto de vida.

Nesta pesquisa, o tempo de lesão pode estar relacionado com a alta qualidade de vida expressa pelos participantes, a exemplo das pessoas com mielomeningocele, em que o compromentimento medular existe desde o nascimento. Alguns pesquisadores, tal como Geyh et al. (2012), indicaram em seus estudos que quanto maior o tempo decorrido da lesão medular maior correlação positiva com a qualidade de vida foi encontrada. De acordo com Vera (2012), quanto maior o tempo decorrido da lesão medular maiores serão as oportunidades de vivências e enfrentamentos que levam à adaptação. 
Os mecanismos de enfrentamento observados foram: tentativa de lidar com o medo da autocateterização, permitindo-se realizá-lo em alguns momentos; busca pela aceitação individual como pessoa com lesão medular; o planejamento e ações que permitem a gestão do viver foram aspectos observados no conteúdo de algumas entrevistas.

A percepção e as respostas de pessoas sob uma mesma condição de saúde podem diferir, o que pode estar relacionado a variáveis como: idade, tempo de escolaridade, tempo de lesão, nível de lesão, vínculo empregatício e com mecanismos pessoais empregados no processamento de eventos estressores (VERA, 2012; BARONE; WATERS, 2012).

A associação feita pelos entrevistados com a qualidade de vida foi relacionada àquelas condições geradoras de insatisfação pessoal e que sofreram mudanças positivas após a derivação urinária continente, tanto as condições relacionadas à saúde e aos indicadores sociais quanto aos aspectos pessoais. Os cuidados de saúde e de tratamento das pessoas com lesão medular evoluíram no decorrer dos anos, havendo o aumento da expectativa de vida nessa população. Da mesma forma, progrediu o interesse em conhecer a repercussão desses cuidados e tratamentos na qualidade de vida (KU, 2006). A avaliação psicossocial e das condições de saúde de forma regular é um meio importante para determinar os fatores que interferem na qualidade de vida e também para subsidiar ações que possam corrigi-los (AKKOÇ et al., 2012).

Para os voluntários deste estudo, alguns aspectos que têm repercussão na qualidade de vida perecebida estão diretamente relacionados à independência para CIL: não necessitar da assistência de um cuidador continuamente; permanecer longos períodos fora de casa e com isso ter a oportunidade de maior convívio e participação social. Quer dizer, aspectos que comparados com o antes e o depois da derivação urinária tiveram mudanças significativas.

No estudo de Merenda et al. (2007), as duas principais temáticas que emergiram e contribuíram para a melhoria da QV foram independência e liberdade; condições que afetam positivamente a qualidade de vida, semelhante aos resultados encontrados no presente estudo.

A exposição íntima e a incontinência urinária foram consideradas como motivo de constrangimento e desencadeadoras de sentimentos negativos. As pessoas com lesão medular e que requerem assistência de um cuidador/familiar para o esvaziamento da bexiga têm comprometida a sua privacidade, independência, papel social e qualidade de vida (AKHAVAN et al., 2007).

A gestão do esvaziamento vesical por meio da derivação urinária operou mudanças significativas no contexto social dos voluntários, de forma que a continência urinária, a liberdade de ir e vir, foram temáticas predominantes nas falas dos entrevistados. Esses 
aspectos incidiram em maior participação social após a realização da derivação urinária continente. Para este estudo, foram utilizados como sinônimos de continência urinária e de liberdade de ir e vir os termos continência social e mobilidade social, condições que possibilitaram ou incrementaram a participação social da pessoa com lesão medular. Nessas pessoas, mesmo que as restrições físicas permaneçam evidentes, os papéis sociais, bem como as atividades sociais podem ser mantidos (KU, 2006).

Estudos como o de Vera (2012) e de Bampi, Guilhem e Lima (2008) apontam o domínio das relações sociais como estatisticamente significativo para a população com lesão medular, tendo repercussão positiva e o poder de interferir na qualidade de vida.

Esta pesquisa, que buscou avaliar as mudanças mais significativas após a confecção da derivação urinária continente, apontou os três itens mais expressivos para o grupo estudado: a independência, viajar e sair (mobilidade social) e estar com outras pessoas, confirmando que a derivação urinária favorece a autonomia e participação social.

A falta de acessibilidade foi indicada como um aspecto limitador e que interfere negativamente na qualidade de vida das pessoas com lesão medular. A falta de estrutura adaptada e as barreiras arquitetônicas impedem a locomoção em cadeira de rodas pelas ruas, em ambientes comerciais e domésticos. Estudos apontaram que a falta de acessibilidade vão além das barreiras físicas e ambientais, mas se constituem em barreiras sociais, contribuindo para aumentar o sofrimento e restringindo as oportunidades de participação social e inclusão (VERA, 2012; BAMPI; GUILHEM; LIMA, 2008; BLANES; CARMAGNANI; FERREIRA, 2009).

No grupo pesquisado, a derivação urinária constituiu-se em fator facilitador para a pessoa com lesão medular, uma vez que ambientes não adaptados tornaram-se viáveis para a realização do autocateterismo vesical. No entanto, isto não exclui a necessidade de locais e de ambientes adequados para receber essas pessoas.

Os papéis sociais foram modificados pela lesão medular, fato observado no conteúdo das falas de uma participante. Ocorreu uma desfiguração dos papéis exercidos pela pessoa no contexto familiar e social, seja por crenças disfuncionais ou por uma visão estigmatizada da sociedade em relação às pessoas com lesão medular. Com esse tipo de lesão, ocorre modificação de um padrão de independência funcional para dependência, repercutindo na capacidade de autocuidado, bem como na vida pessoal e profissional (DE SANTOMADEYA, 2009). Esse processo envolve enfrentamentos e adaptações, inclusive, adaptação frente à percepção dos outros do seu papel social (HAMMELL, 2004). 
O enfrentamento pode estar relacionado, inclusive, com a percepção positiva da estomia urinária continente na parede abdominal, mesmo após a modificação do corpo com sua criação. A imagem corporal modificada não foi considerada como fator que interferiu negativamente na qualidade de vida das pessoas com estomia urinária continente, embora duas pessoas tenham referido incômodo com a aparência. Porém, consideraram que os benefícios adquiridos foram mais significativos do que a estética. Uma terceira pessoa afirmou que: "[...] eu nem ligo pra estética! [...]”.

As estomias, na população em geral, são responsáveis por mudanças significativas para a pessoa; vão além das transformações físicas, ocasionam também transformações psicológicas e sociais decorrentes da alteração da imagem corporal (MOTA; GOMES, 2013). A literatura específica sobre estomia urinária continente em pessoas com lesão medular não aborda a percepção sobre a alteração da imagem corporal. Uma possibilidade seria que o uso dos dispositivos urinários ou a perda urinária são condições que afetam ainda mais a imagem corporal e a qualidade de vida do que a presença do estoma urinário. Estudos sobre cuidados urológicos indicam que as vantagens das estomias urinárias continentes são: preservação da imagem corporal e maior facilidade de acesso ao estoma cateterizável se comparado à uretra (FONTE, 2008).

A categoria teórica "Falta de conhecimento" emergiu na análise de conteúdo apresentando o despreparo da equipe de saúde de um hospital geral em lidar com pessoas com lesão medular; porém, apenas um dos participantes relatou o desconhecimento da equipe de saúde nos cuidados e tratamentos como elementos que podem ocasionar repercussões graves para a sua saúde, tais como: internação em unidade de cuidados intensivos, cirurgia de emergência e risco de morte. Poucos são os estudos existentes que abordam iatrogenia em pessoas com lesão medular; quando presentes estão direcionados ao tratamento das úlceras por pressão.

As ações iatrogênicas devem ser prevenidas por meio do conhecimento, da ética no viver e por mais humanidade no cuidar (MADALOSSO, 2000). A especificidade das condições clínicas da pessoa com lesão medular exige conhecimento científico e planejamento específico para o cuidado e o tratamento dessa população. O planejamento da assistência deve atender a particularidades de cada pessoa, o que possibilita melhores resultados (CAFER, et al., 2005).

$\mathrm{Na}$ categoria teórica "Um pouco a reclamar", os participantes expuseram sua insatisfação com a derivação urinária; seja pela impossibilidade do autocateterismo, devido à localização do estoma urinário, ou pela sua disfuncionalidade, devido à complicação pós- 
cirúrgica. Percebe-se que nas duas condições houve frustração das expectativas quanto à independência para o CIL pela derivação urinária. O estudo de Akkoç et al. (2012) apontou que a maneira como se realiza o manejo da bexiga pode afetar a qualidade de vida relacionada à saúde da pessoa com lesão medular.

A avaliação multiprofissional da pessoa a ser submetida à derivação urinária permite identificar alguns requisitos necessários para a efetividade do CIL pela derivação urinária, tornando maiores as chances de sucesso com a cirurgia (ZOMMICK et al., 2003). O mínimo de destreza das extremidades superiores que permita o autocateterismo pela derivação urinária, localização acessível na parede abdominal para a implantação do estoma urinário, condições de esvaziamento da bexiga em intervalos regulares por autocateterismo ou CIL assistido são aspectos observados previamente para se confeccionar uma derivação urinária continente na pessoa com lesão medular (KARSENTY et al., 2008; AKHAVAN et al., 2007; PAZOOKI et al., 2006).

No tratamento da disfunção urinária todo o contexto que envolve a pessoa com lesão medular deve ser levado em consideração, sua condição clínica, funcional e social, bem como suas expectativas futuras (AKKOÇ et al., 2012).

A categoria teórica "O sexo diminuiu" veio à tona, sendo de grande relevância para a população com lesão medular. A sexualidade é um tema complexo em pessoas com lesão medular e depende de aspectos físico-funcional, psicológico e cultural; o ato sexual é parte integrante do tema. O estudo feito por $\mathrm{Ku}$ et al. (2006) com homens coreanos com lesão medular e que realizam CIL pela uretra apontou que nessa população tanto a atividade sexual quanto a ereção estão comprometidas.

Neste estudo, o participante acredita que a piora no desempenho sexual se relacionou com a derivação urinária. Para Delavechia et al. (2010), a interferência da estomia na sexualidade pode ou não acontecer. Isso dependerá da estruturação das relações baseadas no afeto e da percepção do ser no mundo.

O estudo de Moreno et al. (1995) avaliou a qualidade de vida e sexualidade em três mulheres com tetraplegia e disfunções vesicais submetidas à cistectomia e derivação urinária continente. A pesquisa desse autor apontou que houve incremento subjetivo na qualidade percebida do prazer sexual, bem como na frequência do ato sexual naquelas mulheres sexualmente ativas.

Então, pode-se inferir que a percepção tanto da sexualidade quanto da presença da estomia urinária interferindo no ato sexual em pessoas com lesão medular é multicausal. 
As principais dificuldades ou barreiras impostas pela lesão medular que emergiram do estudo são semelhantes às apresentadas por outros estudos VERA (2012); MENEGUESSI (2012), BAMPI; GUILHEM; LIMA (2008), que envolveram lesão medular e qualidade de vida: incontinência urinária, dependência de cuidador, falta de acessibilidade, dificuldades de participação social e dificuldades psicossociais. Conhecer o significado dessas dificuldades vivenciadas pela pessoa com lesão medular permite o planejamento de ações mais eficazes pela equipe multidisciplinar e que necessitam ser trabalhadas junto a esse grupo e seus familiares, de forma a estimular os recursos mais adaptativos. 


\section{CONCLUSÃO}

Considera-se que os objetivos propostos pelo estudo foram contemplados, tendo sido possível constatar que o manejo do esvaziamento da bexiga por meio da derivação urinária continente foi decisivo para aumentar a qualidade de vida de pessoas com lesão medular e impossibilitadas de realizar o CIL pela uretra. As vantagens apresentadas pelos participantes extrapolam a dimensão do controle da micção, o que repercute na socialização, no sentimento de liberdade e independência que se traduz em gestão do viver e qualidade de vida.

Para o enfermeiro que compõe a equipe multidisciplinar de reabilitação, o conhecimento científico acerca do tema permite estabelecer novo olhar para o cuidado, com propriedade técnico-científica e consciência social da repercussão das suas ações. Para a enfermagem, o conhecimento científico proporciona maior visibilidade e credibilidade, e para aqueles cujas ações do enfermeiro são revertidas em cuidado propicia maiores possibilidades de adaptação e de inclusão social. As ações vão além do cuidado clínico que envolve a cirurgia; são ações com caráter educativo, social e humano que podem determinar maior ou menor grau de qualidade de vida para os voluntários desta pesquisa.

$\mathrm{O}$ compromisso social da equipe multidisciplinar dirigido às pessoas com lesão medular deve extrapolar o momento institucional da reabilitação. Cabe aos envolvidos lutarem pela inclusão social, seja desmistificando os estigmas de incapacidade existente na sociedade seja para lutar por políticas públicas que possam beneficiar essa população.

A derivação urinária, como procedimento cirúrgico, possui alto potencial de complicações, e sua indicação deve ser criteriosa. A alta incidência de complicações após a confecção da derivação urinária continente observada neste e em outros estudos poderia ser um elemento para tornar questionável sua realização. No entanto, a complementaridade fornecida pelos estudos qualitativos - que permitem explorar a subjetividade e experiência de vida - demonstra a alta aceitabilidade e a satisfação com a derivação urinária continente no grupo estudado e reforça a crença de que muitas outras pessoas em condições semelhantes podem se beneficiar com a sua realização.

Na condição de enfermeira de reabilitação, esta pesquisadora acredita que uma avaliação multidisciplinar pré-operatória é determinante para identificar as condições que a pessoa a ser submetida à cirurgia terá para manter o CIL pela estomia urinária continente ao longo do tempo.

As limitações encontradas neste estudo estiveram relacionadas ao fato de que é muito rara a realização de pesquisas que vinculem derivação urinária e qualidade de vida na população adulta com lesão medular. Mesmo que tenha sido ampliado o intervalo de tempo 
para a busca por publicações científicas, essa estratégia foi pouco exitosa. Outra limitação foi comparação parcial dos exames uroradiológicos dos participantes, já que alguns ainda não tinham realizado a avaliação pós-operatória, desta forma, limitando as deduções e inferências possíveis das características comparadas nesses exames.

Os poucos estudos existentes tinham como foco as complicações do procedimento cirúrgico ou a técnica cirúrgica empregada. A qualidade de vida aparecia como uma variável secundária consequente à existência da derivação urinária. A falta de pesquisas qualitativas sobre o tema, com enfoque na análise de conteúdo, não permitiu comparar as categorias teóricas que emergiram com o intuito de verificar diferenças e aproximações. No entanto, nesta investigação, foi realizada a validação das categorias teóricas por meio da participação de outro profissional enfermeiro com expertise sobre o método empregado e o tema do estudo.

O estudo serviu também para gerar hipóteses que podem ser trabalhadas com outros tipos de delineamento:

- O tempo de maturação do conduto urinário pode não ser determinante da estenose do conduto urinário.

- A manutenção de um reservatório urinário de baixa pressão está relacionada a fatores multicausais: estomia urinária, ampliação vesical, comportamento vesical (arreflexia ou hiperatividade detrusora) e ao uso de medicação.

- A capacidade de armazenamento vesical está diretamente relacionada com a ampliação vesical.

Os resultados alcançados com este estudo, embora não possam ser generalizados, podem contribuir para o conhecimento a respeito da derivação urinária continente em pessoas com lesão medular, e inspirar futuros estudos, a exemplo da realização de pesquisas que visem o desenvolvimento de um instrumento específico para avaliar a qualidade de vida em pacientes com lesão medular e bexiga neurogênica. 


\section{REFERÊNCIAS BIBLIOGRÁFICAS}

AKHAVAN, A. et al. Pilot evaluation of functional questionnaire for predicting ability of patients with tetraplegia to self-catheterize after continent diversion. Journal of Spinal Cord Medicine, Leeds, UK; v. 30, n. 5, p. 491-496, 2007.

AKKOÇ, Y. et al. Effects of diferent bladder management methods on the quality of life in patients with traumatic spinal cord injury. Spinal Cord, v.51, p. 226-231, Nov. 2012.

ALMEIDA, M. A. B. de; GUTIERREZ, G. L.; MARQUES, R. Qualidade de vida: definição, conceito e interfaces com outras áreas de pesquisa. São Paulo: EACH/USP, 2012.

ANDRADE, L. T. de et al. Papel da enfermagem na reabilitação física. Rev Bras Enferm, v. 63, n. 6, p. 1056-60, Nov-Dez, 2010.

BAMPI, L. N. da S.; GUILHEM, D.; LIMA, D. L. Qualidade de vida em pessoas com lesão medular traumática: um estudo com o WHOQOL-bref. Rev Bras Epidemiol, v.11, n. 1, p. 67-77, 2008.

BARDIN, L. Análise de conteúdo. Rio de Janeiro: Edições 70. 2001. 223p.

BARONE, S. H.; WATERS, K. Coping and adaption in adults living with spinal cord injury. American Association of Neuroscience Nurses, vol.44, n.5, p.271-283, 2012.

BLANES, L; CARMAGNANI, M. I. S.; FERREIRA, L. M. Quality of life and self-esteem of persons with paraplegia living in São Paulo, Brazil. Qual Life Res, vol. 18, p. 15-21. DOI: 10.1007/s11136-008-9411-9, 2009.

BRASIL. Ministério da Saúde. Conselho Nacional da Saúde. Comissão Nacional de Ética em Pesquisa (CONEP). Resoluçãa n. 466, de 12 dezembro de 2012. Disponível em: <http://conselh o.saude.gov.br/resolucoes/2012/Reso466.pdf>. Acesso em: 24 jul. 2013.

BUSS, P. M. Promoção da saúde e qualidade de vida. Ciência \& Saúde Coletiva, vol. 5, n. 1, p. 163-177, Jan./Mar., 2000.

CAFER, C. R. et al. Diagnósticos de enfermagem e proposta de intervenções para pacientes com lesão medular. Acta Paul Enferm., v. 18, n. 4, p. 347-53, Abr., 2005. 
CAMPOLINA, A. G.; CICONELLI, R. M. Qualidade de vida e medidas de utilidade: parâmetros clínicos para as tomadas de decisão em saúde. Rev Panam Salud Publica/Pan Am J Public Health, v.19, n. 2, p. 128-136, 2006.

CHAVIANO, A. H. et al. Mitrofanoff continent catheterizable stoma for pediatric patients with spinal cord injury. Topics in Spinal cord Injury Rehabilitation, Frederick, MD; v. 6, suppl. 1, p. 30-35, 2000.

CHEN, H. Y.; BOORE, J. R. P. Living with a spinal cord injury: a grounded theory approach. Journal compilation, doi: 10.1111/j.13652702.2007.02117.x, Mai., 2007.

CRESWELL, J. W. Research design: qualitative, quantitative, and mixed methods approaches. Thousand Oaks, CA: Sage. 4th ed. Copyright 2014 by SAGE publications, Inc.

CRESWELL, J. W.; PLANO CLARK, V. L. Designing and conducting mixed methods research. Thousand Oaks, CA: Sage. 2007.

Designing and conducting mixed methods research. Thousand Oaks, CA: Sage. 2th ed. Copyright 2011 by SAGE publications, Inc.

DANTAS, R. A. S.; SAWADA, N. O.; MALERBO, M. B. Pesquisas sobre qualidade de vida: revisão da produção científica das universidades públicas do Estado de São Paulo. Revista Latino-Americana de Enfermagem, Ribeirão Preto, v. 11, n. 4, p. 532-538, 2003.

DELAVECHIA, R. P. et al. A percepção de si como ser-estomizado: um estudo fenomenológico. Rev. enferm. UERJ, Rio de Janeiro, v. 18, n. 2, p. 223-8, Abr/Jun.,2010.

DE SANTO-MADEYA, S. Adaptation to Spinal Cord Injury for Families Post-Injury. Nurs Sci Q, v. 22, p. 57-66, Jan., 2009.

DIXON, L.; WASSON, D.; JOHNSON V. Urinary diversions: a review of nursing care. Urologic Nursing, v. 21, n. 5, p.337-343, 346-348, 2001.

DRIESSNACK, M.; SOUSA, V. D.; MENDES, I. A. C. Revisão dos desenhos de pesquisa relevantes para enfermagem: parte 3: métodos mistos e múltiplos. Rev Latino-am Enfermagem [online], v.15, n.5 pp. 1046-1047, Set./Out. 2007. 
FALLOWFIELD, L. Quality of life: the missing measure in health care. Souvenir Press, New York, 1990.

FARIAS, N.; BUCHALLA, C. M. A classificação internacional de funcionalidade, incapacidade e saúde da organização mundial da saúde: conceitos, usos e perspectivas. Rev Bras Epidemiol, v. 8, n. 2, p. 187-93, 2005.

FARQUHAR, M. Definitions quality of life: a taxonomy. Journarl Advanced Nursing, Oxford, v. 22, n. 3, p. 502-508, 1995.

FLECK, M. P. de A. et al. Desenvolvimento da versão em português do instrumento de avaliação de qualidade de vida da OMS (WHOQOL-100). Rev. Bras. Psiquiatr. [online]. 1999, vol.21, n.1, pp. 19-28. ISSN 1516-4446.

FLECK, M. P. de A. O instrumento de avaliação de qualidade de vida da Organização Mundial da Saúde (WHOQOL-100): características e perspectivas. Ciênc. saúde coletiva [online]. 2000, vol.5, n.1, pp. 33-38. ISSN 1413-8123.

FONTE, N. Urological care of the spinal cord-injured patient. Journal of wound, ostomy, and continence nursing, St. Louis; v. 35, n. 3, p. 323-331, May-Jun 2008.

GERHARZ, E. W. Is there any evidence that one continent diversion is any better than any other or than ileal conduit? Currin Opin Urol, v. 17, p. 402-407, 2007.

GEYH, S. et al. Quality of life after spinal cord injury: a comparison across six countries. Spinal Cord, p. 1-5, Sept. 2012.

HAMMELL, K. W. Exploring quality of life following high spinal cord injury: a review and critique. Spinal Cord, v.42, p.491-502, 2004.

INSTITUTO BRASILEIRO DE GEOGRAFIA E ESTATÍSTICA (IBGE). Censo Demográfico 2010: características gerais da população, religião e pessoas com deficiência. Disponível em: <http://www.ibge.gov.br/home/estatistica/populacao/censo2010/caracteristicas_religiao_defic iencia/caracteristicas_religiao_deficiencia_tab_pdf.shtm>. Acesso em: 10 out. 2013.

KARSENTY, G. et al. A novel technique to achieve cutaneous continent urinary diversion in spinal cord-injured patients unable to catheterize through native urethra. Spinal Cord, Houndmills, UK; v. 46, n. 4, p. 305-310, Aug. 2008. 
KHAVARI, R. et al. A modification to augmentation cystoplasty with catheterizable stoma for neurogenic patients: techinique and long-term results. Urology v.80, p.460-465, Mar. 2012.

KU, J. H. The management of neurogenic bladder and quality of life in spinal cord injury. BJU International. v. 98, p. 739-745, May. 2006.

LEEUWEN, C. M. C. et al. Associations between psychological factors and quality of life ratings in persons with spinal cord injury: a systematic review. Spinal Cord, n.50, pp. 174$187,2012$.

LÍARD, A. et al. The Mitrofanoff procedure: 20 yeares later. J Urol, v. 165, p. 2394-2398. Jun. 2001.

MACEDO JÚNIOR, A. M.; DAMÁZIO, E.; OTTONI, S. L. Derivação urinária continente. Urologia Contemporânea, São Paulo; v. 17, n. 2, p. 24-31, 2010.

MADALOSSO, A.R.M. Iatrogenia do cuidado de enfermagem: dialogando com o perigo no quotidiano profissional. Rev.latino-am.enfermagem, Ribeirão Preto, v. 8, n. 3, p. 11-17, jul. 2000.

MARCON, S. S. et al. Rede social e família: o olhar sensível dos enfermeiros construtores da prática. Cienc Cuid Saude, v. 8 (suplem.), p. 31-39, 2009. DOI: 10.4025/cienccuidsaude.v8i0.9715.

MENEGUESSI, G. M. Percepção sobre qualidade de vida em pessoas com lesão medular traumática: um estudo sobre incontinência urinária. 2012. 88f. Dissertação (Mestrado em Enfermagem)- Programa de Pós-graduação em Enfermagem, Faculdade de Ciências da Saúde, Departamento de Enfermagem da Universidade de Brasília, Brasília, 2012.

MERENDA, L. A. et al. Outcomes of urinary diversion in children with spinal cord injuries. The Journal of Spinal Cord Medicine, Leeds, UK; v. 30 suppl. 1, p. S 41-47, 2007.

MIGLIORINI, C. E.; NEW, P. W; TONGE, B. J. Quality of life in adults with spinal cord injury living in the community. Spinal Cord, p.1-6, 2010.

MINAYO, M. C.; HARTZ, Z. M.; BUSS, P. M. Qualidade de vida: um debate necessário. Ciência \& Saúde Coletiva, Rio de Janeiro vol. 5, n. 1, p. 7-18, 2000. 
MITROFANOFF, P. Trans-appendicular continent cystostomy in the management of the neurogenic bladder. Chir Pediatr. v. 21, n. 4, p. 297-305, 1980.

MOREIRA, D. A. Pesquisa em Administração: origens, uso e variantes do método fenomenológico. RAI - Revista de Administração e Inovação, São Paulo, v. 1, n. 1, p. 519, 2004.

MORENO, J. G. et al. Improved quality of life and sexuality with continente urinary diversion in quadriplegic women with umbilical stoma. Arch Phys Med Rehabil, v. 76, p. 758-62, Aug., 1995. (Congress of rehabilitation medicine and the american academy of physical medicine and rehabilitation).

MOTA, Marina Soares; GOMES, Giovana Calcgno. Changes in the process of living of ostomized patients after surgery. Journal of Nursing UFPE on line [JNUOL/DOI: 10.5205/01012007], v. 7, n. 12, p. 7074-7081, 2013.

NEWMAN, D. K.; WILLSON, M. M. Review of intermitente catheterization and current best practices. Urologic Nursing, v. 31, n. 1, p. 12-29, 48, 2011.

PASCHOAL, S. M. P.. Qualidade de vida do idoso: elaboração de um instrumento que privilegia sua opinião. 2000. 255f. Dissertação (Mestrado em Medicina) - Curso de Pósgraduação em Medicina, Faculdade de Medicina da Universidade de São Paulo, São Paulo, 2000.

PAZOOKI, D. et al. Continent cutaneous urinary diversion in patients with spinal cord injury. Spinal Cord, Houndmills, UK; v. 44, n. 1, p. 19-23, Jan. 2006.

PEREIRA, E. F.; TEIXEIRA, C. S.; SANTOS, A. dos. Qualidade de vida: abordagem, conceitos e avaliação. Rev. bras. educ. fís. Esporte, vol. 26, n.2, 2012. ISSN 1807-5509.

REDE SARAH DE HOSPITAIS DE REABILITAÇÃO. As internações por causas externas. Brasília, 2013. Disponível em: <http://www.sarah.br/Cvisual/Sarah/>. Acesso em: $1^{\underline{0}}$ out. $2013 \mathrm{a}$.

SARAH-Brasília. Disponível em: <http://www.sarah.br/Cvisual/Sarah/>. Acesso em: 2 out. 2013 b.

ROCHA, F. E. T.; GOMES, C. M. Bexiga Neurogênica. In: FILHO, M. Z.; JR, A. N.; SACOMANI, C. A. R. (Ed.). Urologia Fundamental. São Paulo: PlanMark, 2010. p. 239-250. 
RUNDQUIST, J. et al. Nursing bedside education and care management time during inaptient spinal cord injury rehabilitation. J Spinal Cord Med , v. 34, n.2, p. 205-215, 2011.

SAMPIERI, R. H.; COLLADO, C. F.; LUCIO, P. B. Metodologia de pesquisa. 3 ed. São Paulo: McGraw-Hill, 2006. Cap. 5, pp. 98-103.

SCHOELLER, S. D. et al. Mudanças na vida das pessoas com lesão medular adquirida. Rev. Eletr. Enf. [internet]. 2012, vol.14, n.1, pp. 95-103. ISSN 1518-1944.

SEIDL, E. M. F.; ZANNON, C. M. C. da. Qualidade de vida e saúde: aspectos conceituais e metodológicos. Cad. Saúde Pública, Rio de Janeiro, v. 20, n.2, p. 580-588, mar./abr., 2004.

THE NATIONAL SPINAL CORD INJURY STATISTICAL CENTER. Spinal Cord Injury Facts and Figures at a Glance. Birmingham, Alabama, 2013. Disponível em: <https://www.nscisc.uab.edu>. Acesso em: 25 out. 2013.

TOUMA, N. J. et al. Outcomes and quality of life of adults undergoing continente catheterizable vesicostomy for neurogenic bladder. J Urol, v. 70, p. 454-458, Apr. 2007.

VERA, R. S. Resiliência, enfrentamento e qualidade de vida na reabilitação de indivíduos com lesão medular. 2012. 220f. Tese (Doutorado em Psicologia) - Universidade de Brasília, Instituto de Psicologia, Programa de Pós- graduação Processos de Desenvolvimento e Saúde, 2012.

VERA, R. S; ARAUJO, T. C. C. F de. Enfrentamento e lesão medular: um estudo de corte transversal com pacientes em reabilitação. Com. Ciências Saúde. 2011; 22(3):211-220.

WHOQOL GROUP. The World Health Organization Quality of Life Assessment (WHOQOL): position paper from the World Health Organization, In: ORLEY, J.; KUYKEN, W. (Eds.). Quality of life assessment: international perspectives. Heidelberg: Springer Verlag; 1995. p. 41-60.

WOOD-DAUPHINEE, S. Assessing quality of life in clinical research: from where have come and where are we going? J Clin Epi, v. 52, n. 4, p. 355-363, 1999.

ZOMMICK, J. N. et al. Continent lower urinary tract reconstruction in the cervical spinal cord injured population. Journal of Urology, New York; v. 169, n. 6, p. 21842187, Jun. 2003. 


\section{APÊNDICE A - Termo de Consentimento Livre e Esclarecido}

Título do trabalho: IMPLICAÇÕES DA ESTOMIA URINÁRIA CONTINENTE NA QUALIDADE DE VIDA DA PESSOA COM LESÃO MEDULAR.

Pesquisadora Responsável: Carla Andréia Araújo - Enfermeira.

Instituição: Universidade de Brasília (UnB) / Faculdade de Ciências da Saúde (FS) / Departamento de Enfermagem (ENF).

Telefones para contato: 3319-1494 / 3319-1313 ou 3319-1295

Nome:

Idade: anos Registro Geral n.

Responsável legal (se for o caso):

Registro Geral do Responsável legal:

Você está sendo convidado para participar do estudo IMPLICAÇÕES DA ESTOMIA URINÁRIA CONTINENTE NA QUALIDADE DE VIDA DA PESSOA COM LESÃO MEDULAR.

\section{$\underline{\text { Justificativas e objetivos }}$}

A estomia urinária é um procedimento que pode ter impacto positivo na qualidade de vida das pessoas impossibilitadas de fazer o cateterismo intermitente limpo pela uretra nativa, e essa concepção despertou o interesse na realização desta pesquisa.

A execução deste estudo pretende avaliar a implicação da derivação urinária continente na qualidade de vida da pessoa com lesão medular.

Desconfortos e riscos associados: a pesquisa em si não oferecerá riscos, uma vez que busca conhecer a percepção da pessoa a respeito da implicação da confecção urinária continente na qualidade de vida. 
Benefícios esperados: maior conhecimento científico, sobretudo para os enfermeiros, no que se refere às implicações da derivação urinária continente em pessoas com lesão medular e em suas vidas.

Contribuir para traçar metas para o processo de cuidar em enfermagem antes da derivação urinária continente e após a sua realização, de forma que a pessoa obtenha resultados eficientes que interfiram de forma positiva na sua qualidade de vida. Poderá contribuir, ainda, para a maximização dos benefícios de uma assistência especializada respaldada no conhecimento advindo com a pesquisa.

Forma de assistência: nos aspectos relacionados à pesquisa, as pessoas terão esclarecimentos pertinentes ao estudo, a qualquer momento, sem nenhuma implicação que prejudique o seu tratamento e acompanhamento nesta instituição.

Formas indenizatórias: a pesquisa não agregará nenhuma situação que possa gerar prejuízo ao tratamento do participante. Como o tratamento convencional será regularmente oferecido, não é cabível a cobrança de quaisquer formas de indenização decorrente do tratamento acima proposto.

Sigilo e privacidade: em nenhum momento a pessoa será identificada, e apenas os resultados advindos da pesquisa poderão ser divulgados em eventos e artigos científicos.

Caso existam quaisquer dúvidas sobre a pesquisa ou sobre o atendimento, você poderá entrar em contato através dos telefones: 3319-1494, 3319-1313 ou 3319-1295 e pelos e-mails: comiteeticapesquisa@sarah.br; 8130@sarah.br.

Sua participação não é obrigatória. A qualquer momento, você pode desistir de participar e retirar seu consentimento, sem que haja prejuízo ao seu tratamento. Esse Termo será oferecido em duas vias nos casos presenciais e pela via virtual; será lido e explicado para a pessoa, responsável e acompanhante/cuidador. A pesquisa só ocorrerá mediante sua resposta se aceita participar ao início da entrevista.

Sua recusa não trará nenhum prejuízo em sua relação com o tratamento.

Obrigada pela atenção.

\author{
Carla Andréia Araújo
}

Pesquisadora Responsável 
$\mathrm{Eu}$, abaixoassinado, concordo participar do estudo, como sujeito. Fui devidamente informado e esclarecido pela pesquisadora Carla Andréia Araújo a respeito da pesquisa, os procedimentos nela envolvidos, assim como os possíveis riscos e benefícios decorrentes de minha participação. Foime garantido que posso retirar meu consentimento a qualquer momento, sem que isso leve a qualquer penalidade ou interrupção de meu acompanhamento/assistência/tratamento.

Participante ou seu responsável legal

Pesquisador Responsável

Data: I 


\section{APÊNDICE B - Termo de Assentimento}

Você está sendo convidado (a) como voluntário (a) para participar da pesquisa Implicações da Estomia Urinária Continente na Qualidade de Vida da Pessoa com Lesão Medular. Neste estudo pretendemos avaliar a implicação da estomia urinária continente na qualidade de vida da pessoa com lesão medular.

O motivo que nos leva a estudar esse assunto é obter maior conhecimento quanto às implicações que a confecção de um estoma urinário continente tem na qualidade de vida de uma pessoa com lesão medular.

Para este estudo, realizar-se-á entrevista, pessoalmente ou por programa de comunicação virtual, na qual será aplicado um instrumento semiestruturado para coleta de dados sociodemográficos e clínicos.

Para participar deste estudo, o responsável por você deverá autorizar e assinar um termo de consentimento; nos casos de contato virtual, será lido e explicado para você e responsável. Você não terá nenhum custo, nem receberá qualquer vantagem financeira. Você será esclarecido (a) em qualquer aspecto que desejar e estará livre para participar ou recusarse a participar. O responsável por você poderá retirar o consentimento ou interromper a sua participação a qualquer momento. A sua participação é voluntária e a recusa em participar não acarretará qualquer prejuízo no seu tratamento nem na forma de atendimento pelo pesquisador que irá tratar a sua identidade com padrões profissionais de sigilo. Você não será identificado em nenhuma publicação.

Os resultados estarão à sua disposição quando a pesquisa for finalizada. Os dados e instrumentos utilizados na pesquisa ficarão arquivados com o pesquisador responsável pelo período mínimo de cinco anos. 
$\mathrm{Eu}$, portador

(a) do documento de Identidade $n$. fui informado (a) dos objetivos do presente estudo de maneira clara e detalhada e esclareci minhas dúvidas. Sei que a qualquer momento poderei solicitar novas informações, e o meu responsável poderá modificar a decisão de participar se assim o desejar. Tendo o consentimento do meu responsável já assinado, declaro que concordo em participar desse estudo. Recebi uma cópia deste Termo de Assentimento e me foi dada a oportunidade de ler e esclarecer as minhas dúvidas.

Brasília, de de 20

Assinatura do(a) menor Assinatura do(a) pesquisador(a)

Em caso de dúvidas com respeito aos aspectos éticos deste estudo, você poderá consultar:

Pesquisadora Responsável: Carla Andréia Araújo Eenfermeira.

Instituição: Universidade de Brasília (UnB) / Faculdade de Ciências da Saúde (FS / Departamento de Enfermagem (ENF) / Comitê de Ética em Pesquisa da Associação das Pioneiras Sociais.

Telefones para contato: 3319-1494 / 3319-1313 ou 3319-1295.

E-mails: comiteeticapesquisa@sarah.br; 8130@sarah.br. 


\section{APÊNDICE C - Termo de Cessão do Uso de Imagem}

\section{Título da Pesquisa: IMPLICAÇÕES DA ESTOMIA URINÁRIA CONTINENTE NA QUALIDADE DE VIDA DA PESSOA COM LESÃO MEDULAR}

Pesquisadora Responsável: Carla Andréia Araújo - Enfermeira.

Instituição: Universidade de Brasília (UnB) / Faculdade de Ciências da Saúde (FS) / Departamento de Enfermagem (ENF).

Telefones para contato: (61) 3319-1494 / 3319-1313 ou 3319-1295

$\mathrm{Eu}$,

Idade: anos Registro Geral n.

ou seu responsável legal:

Registro Geral n. , cedo minha imagem (estoma de derivação urinária) para fins de documentação para pesquisa. Fica acordado entre pesquisadora e o participante que:

CLÁUSULA PRIMEIRA - A cessão da imagem é gratuita, não remunerada, sem comprometimento do meu tratamento e sem minha identificação.

CLÁUSULA SEGUNDA - A imagem poderá ser veiculada em revistas e apresentações científicas.

CLÁUSULA TERCEIRA - O presente Termo tem por objeto a cessão de uso de imagem/fotografia adquirida pela pesquisadora, conforme especificado abaixo:

ESPÉCIE DE MATERIAL: Fotografias.

PERÍODO DE VEICULAÇÃO: cinco anos.

LOCAL DE VEICULAÇÃO: Território Nacional e/ou Internacional.

FORMAS DE VEICULAÇÃO: Revistas científicas impressas ou virtuais, apresentações científicas.

PARÁGRAFO ÚNICO: o participante da pesquisa acima intitulada declara, neste ato, que cede gratuitamente imagens/fotografias, sem quaisquer recursos indenizatórios. 
APÊNDICE D - Questionário para Coleta de Dados Sociodemográfico e Clínico

Implicações da Estomia urinária Continente na Qualidade de Vida da Pessoa com Lesão medular.

I - Identificação:

Nome:

Número do prontuário:

Data de nascimento:

Sexo: $\square$ Feminino

$\square$ Masculino

Escolaridade:

$\square$ Ensino Fundamental

$\square$ Ensino Médio

$\square$ Superior

$\square$ Analfabeto

II - Dados referentes à lesão medular:

Data da lesão:

$\square$ Paraplegia

$\square$ Tetraplegia

III - Como você esvazia sua bexiga?

$\square$ Perdas em fraldas

$\square$ Perdas em coletor urinário externo

$\square$ Manobras de Credê ou Valsalva

$\square$ Cateterismo intermitente limpo $\square$ ssistido $\square$ Autocateterismo

$\square$ Cateter de demora 
IV - Você esvazia a bexiga de quantas em quantas horas?

$\square 6 / 6$ horas

$\square$ 4/4 horas

$\square$ 4/4 horas dia e 6/6 horas noite

3/3 horas

$\square$ Irregular/ Contínuo

V - Dados referentes aos motivos da indicação da derivação urinária:

$\square$ Alteração anatômica na uretra nativa

$\square$ Posicionamento e /ou falta de equilíbrio do tronco

$\square$ Dificuldade para o acesso à genitália. Qual a sua dificuldade?

$\square$ Outro(s) motivo(s). Qual (is)?

VI - A cirurgia indicada foi:

$\square$ Somente derivação urinária continente

$\square$ Derivação urinária continente e ampliação vesical

VII - Você usa medicação para a bexiga? $\square$ Não $\square$ Sim. Há quanto tempo?

VIII - Qual a medicação que você usa para a bexiga?

$\square$ Oxibutinina $\square$ oral $\square$ vesical

$\square$ Tolterodina

$\square$ Doxazosina

$\square$ Imipramina

IX - Atualmente é você quem faz seu cateterismo? $\square$ Sim $\square$ Não

X - Você teve ou tem alguma complicação na cirurgia de derivação urinária? Qual (is)?

XI - O quê melhorou na sua vida após a derivação urinária? Numere em ordem crescente do grau de importância:

$\square$ Independência para o cateterismo intermitente limpo

$\square$ Sexo

$\square$ Economia 

$\square$ Estar com outras pessoas
$\square$ Viajar e sair
$\square$ Estudar
$\square$ Trabalhar
$\square$ Sono

XII - Por favor, faça uma reflexão sobre sua qualidade de vida antes e depois da derivação urinária e responda.

1) O que significa para você ter qualidade de vida?

Por favor, leia a questão abaixo, veja o que você acha e faça um X no número que lhe parece a melhor resposta.

2) Como você avalia sua qualidade de vida?

$\square$ 1-muito ruim $\square$-ruim $\square$-nem ruim nem boa $\square$ boa $\square$ muito boa

3) Você está satisfeito com sua derivação urinária?

$\square$ 1-insatisfeito $\square$ 2-pouco satisfeito $\square$ 3-satisfeito $\square$ 4-muito satisfeito

4) A derivação urinária melhorou sua qualidade de vida?

XIV - Dados dos exames urológicos de acordo com laudo.

\begin{tabular}{|l|l|l|}
\hline \multicolumn{3}{|c|}{ Exames Pré-operatórios } \\
\hline Ultrassonografia urinária & $\begin{array}{l}\text { Uretrocistografia renal e de vias } \\
\text { Urinárias }\end{array}$ & Estudo Urodinâmico \\
& \multicolumn{1}{|c|}{$\begin{array}{l}\text { Refluxo vesico-ureteral: } \\
\text { Litíase: }\end{array}$} & $\begin{array}{l}\text { Capacidade: } \\
\text { Arreflexa } \square \\
\text { Sim } \square \quad \text { Não } \square\end{array}$ \\
& & Hiperativa $\square$ \\
\hline
\end{tabular}




\begin{tabular}{||l|l|l|}
\hline \multicolumn{3}{|c|}{ Exames Pós-operatórios } \\
\hline Ultrassonografia urinária & $\begin{array}{l}\text { Uretrocistografia renal e de vias } \\
\text { Urinárias }\end{array}$ & Estudo Urodinâmico \\
\hline $\begin{array}{l}\text { Litíase: } \\
\text { Sim } \square \quad \text { Não } \square\end{array}$ & $\begin{array}{l}\text { Refluxo vesico-ureteral: } \\
\text { Sim } \square \quad \text { Não } \square\end{array}$ & $\begin{array}{l}\text { Capacidade: } \\
\text { Arreflexa } \square \\
\text { Hiperativa } \square\end{array}$ \\
\hline
\end{tabular}

Se você tem mais de 1 ano de lesão medular responda:

Quantos episódios de infecção urinária você teve no último ano, antes da derivação urinária, que necessitou tratamento com antibiótico?

\section{$\square$ Nenhum \\ $\square$ Apenas 1 \\ $\square 1$ a 3 \\ $\square$ Mais de 3}

Quantos episódios de infecção urinária você teve após a derivação urinária que necessitou tratamento com antibiótico?
$\square$ Nenhum
$\square$ Apenas 1
$\square 1$ a 3
$\square$ Mais de 3

Obrigada!!! 


\section{APÊNDICE E - Entrevista com os participantes (transcrição ipsis verbis)}

\section{ENTREVISTA P1}

1.1PESQUISADORA: "Por favor, faça uma reflexão sobre sua qualidade de vida antes

1.2e depois da derivação urinária e me responda, é... o que significa pra senhora ter 1.3qualidade de vida?".

1.4ENTREVISTADA: “... Hum, o quê significa"?

1.5PESQUISADORA: “... pra senhora, o quê significa”?

1.6ENTREVISTADA: “é pra mim responder com minhas palavras?!” Sorriso

1.7PESQUISADORA: “É. O quê a senhora pensa, o que a senhora sente, por isso que

1.8eu falei: 'Óh! pensa um pouquinho!' Tudo porque é isso que a gente tá buscando é, 1.9justamente, saber o que a senhora percebe o que é qualidade de vida na percepção da 1.10senhora... e, é... depois a gente tem outros questionamentos também!"”.

1.11ENTREVISTADA: "Hum... depois da... da cirurgia, né"?

1.12PESQUISADORA: "Não! No contexto geral! o quê que a senhora percebe o quê é 1.13qualidade de vida, o quê significa para senhora? Pode envolver a cirurgia, no todo".

1.14ENTREVISTADA: “Ah! Tá! É... pra mim, é especialmente assim depois que eu fiz

1.15a cirurgia foi não ter que precisar ir mais ao pronto socorro porque antes da cirurgia

1.16eu ia ao pronto socorro sempre! Com muita febre, calafrio, era muita infecção

1.17urinária que ocorria muito por... fazer o cate rápido, não dava tempo de fazer a

1.18limpeza, né? Normal. Aí eu tinha muita febre, era um sofrimento, agora não, eu

1.19posso tomar bastante água, pra mim qualidade de vida... eu tinha muita vontade de 1.20tomar água, mas não podia porque a minha bexiga não segurava, era não sei.

1.21Mudou muito a minha vida, eu sou outra pessoa tem horas que eu falo assim:

1.22 sorriso... é! parece que eu acho que eu nem sou mais cadeirante de tão bom que foi

1.23pra mim depois que eu fiz essa cirurgia, minha vida mudou muito... sou outra

1.24pessoa, graças a Deus! Emagreci!... 17 quilos! Fiz uma dieta"!

1.25PESQUISADORA: “Óh! Que legal"!

1.26ENTREVISTADA: "Tô muito bem... sorriso... me sinto muito bem, realizada".

1.27PESQUISADORA: Sorriso... "Óh! Que bom! Fico feliz pela senhora.”

1.28PESQUISADORA: “É... em relação agora eu... eu vou tá lendo aqui algumas outras 1.29questões e falando alguns valores que a senhora vai numerar novamente. Como a 1.30senhora avalia, hoje, a sua qualidade de vida? 1 É muito ruim, 2 é ruim, 3 nem ruim 1.31e nem boa, 4 é boa e 5 é muito boa". 
1.32ENTREVISTADA: "Acho que é boa".

1.33PESQUISADORA: "Boa."

1.34ENTREVISTADA: "É..."

1.35PESQUISADORA: “... é você está satisfeito com a sua derivação urinária? 1 é 1.36insatisfeito, 2 é pouco satisfeito, 3 é satisfeito e 4 é muito satisfeito".

1.37ENTREVISTADA: “4, muito satisfeito".

1.38PESQUISADORA: “Certo. A derivação urinária melhorou a sua qualidade de 1.39vida"?

1.40ENTREVISTADA: “Muito”...

1.41PESQUISADORA: "Eu queria que a senhora falasse um pouquinho".

1.42ENTREVISTADA: “Eu já falei... foi uma mudança radical na minha vida, eu sou 1.43outra pessoa, mudou tudo... mudou tudo".

1.44PESQUISADORA: "Esse tudo quando a senhora fala tudo o quê que envolve?

1.45Porque é importante pra gente saber".

1.46ENTREVISTADA: “Ah! d'eu ter que ficar: 'gente! Vem fazer o cate tô passando 1.47muito mal!' E aqueles calafrios e usar fraldas e assar e eu ficar me sentindo muito 1.48mal com aquela fralda, né?! Porque eu sou muito vaidosa e ficar, né?! Então, eu 1.49virei... nossa, eu sou outra pessoa, agora eu posso comprar calcinha... sorrisos antes 1.50eu nem pensava em comprar... sorrisos então, eu posso usar uma calça jeans 1.51apertada, eu posso usar roupa normal, sei lá, mudou muita coisa, me arrumar, ficou 1.52melhor pra me arrumar, posso botar até um vestido porque eu sei que se eu não 1.53tomar água, muita água, eu vou ficar numa festa muitas horas sem precisar fazer 1.54cate, então, eu controlo, né?! Eu posso controlar agora, né?! E antes eu não podia". 1.55PESQUISADORA: “Agora, geralmente, o estoma da derivação urinária ele 1.56costuma ser bem pequeninho, bem discreto"...

1.57ENTREVISTADA: Sorriso... "O meu não é muito não"! Sorriso 1.58PESQUISADORA: "O quê eu ia perguntar para a senhora, interfere na imagem 1.59 corporal da senhora"?

1.60ENTREVISTADA: "Um pouco, às vezes, meu marido fica incomodado, um 1.61pouco... aí ele pediu até... ‘ Ah! amor faz uma cirurgia plástica... não sei o quê, aí tá 1.62um pouquinho feio'! Mas aí eu conversei com o Dr.X, na época, agora é o Dr. Y, eu 1.63acho, e Dr. Z, também, aí ele falou: ' não, não precisa não. Nossa! Você tá achando 
1.64que tá feio? Tem muitos piores, não, não precisa. Ah! inventa alguma coisa para 1.65tampar!' Não seio o quê. Aí eu convenci né?! Ele não reclamou mais, também não, 1.66né?! É tão bom, né?! Que não dá nem pra reclamar"... Sorriso

1.67PESQUISADORA: “Entendi”. Então, interfere um pouco também?

1.68ENTREVISTADA: "Interfere um pouco, mexeu um pouco".

\section{ENTREVISTA P2}

2.1PESQUISADORA: “Agora F., esse é o momento... assim... que você precisa refletir

2.2um pouquinho antes e tentar lembrar um pouquinho antes do procedimento e

2.3atualmente, então, eu vou pedir pra você fazer uma reflexão, né?! Sobre qualidade de

2.4vida antes e depois da derivação urinária e responder para mim... agora de uma

2.5forma geral. O quê significa para você ter qualidade de vida?

2.6ENTREVISTADO: "Hã ham, entendi, só um momento que eu vou refletir mesmo

2.7 sobre o final para te dar uma resposta completa".

2.8PESQUISADORA: "Hã ham, tranquilo, fica a vontade"!

2.9ENTREVISTADO: “Ok!”

2.10ENTREVISTADO: Alguns segundos em silêncio... "Pode responder Sorriso...

2.11Carla"?!

2.12PESQUISADORA: “Oi?! Pode”! Fica a vontade!

2.13ENTREVISTADO: “Assim... então! Pra mim, né?! qualidade de vida nesse caso

2.14relacionada a esta questão foi, primeiramente, né?! Eu ter uma vida mais... uma

2.15vida mais livre, né?! Podendo sair pra qualquer... pra qualquer local, né?! A

2.16qualquer momento... que eu quisesse, é... tive mais... uma maior, né"?!...

2.17Independência porque eu não ficava mais preso a esta questão de toda hora ter que

2.18ficar fazendo o cateter, né?! Porque agora... Eu... Né?! Agora, quando eu sinto dor,

2.19né?! Quando minha bexiga tá cheia! Então, eu sei qual é o momento de fazer o

2.20proce... O cateterismo ou não... É, conviver, né?! Com as pessoas, com... Ter, fazer 2.21mais amizades, né?! Eu, até... Soltou um pouco mais em relação ao que eu era 2.22anteriormente exatamente por eu não ter esse medo mais de vazar em todos os

2.23locais que eu tiver ter que ficar trocando a fralda toda hora, então, melhorou muito 2.24nestas questões, né?! São estas questões que eu sinto mais assim... A independência 2.25profissional, também, porque aí eu consegui né?! Porque tirando essa questão d'eu 2.26não ter mais que ficar usando a fralda, eu consegui um emprego, né?! Eu consegui 2.27ficar no emprego, então, eu não tenho mais esse problema em relação a isso. Então 
2.28pra mim... qualidade de...(Interrupção pela entrevistadora)

2.29PESQUISADORA: "Certo! Te deu uma maior ... assim... constância, uma maior

2.30tranquilidade em relação a...

2.31ENTREVISTADO: "Isso! Hã ham...”

2.32PESQUISADORA: “... a se organizar no seu tempo, também, né"?!

2.33ENTREVISTADO: "Isso!”

2.34ENTREVISTADO: "Isso! Exatamente! No meu dia a dia, ter as minhas... ter as

2.35minhas obrigações, tudo e fazer isso com mais tranquilidade sem ter o medo de

2.36ficar vazando toda hora, né?! E ficar causando constrangimento para mim e para as

2.37outras pessoas".

2.38PESQUISADORA: “Certo.”

2.39ENTREVISTADO: "No mais, qualidade de vida pra mim é isso, né?! Você ter uma 2.40maior independência, conseguir trabalhar, conseguir organizar sua rotina, ter seus 2.41momentos de lazer, tudo sem ter maiores complicações".

2.42PESQUISADORA: “Certo. Agora, eu vou tá lendo algumas questões abaixo e 2.43também, por ordem de relevância, assim... você vai me dizer o que é pra eu marcar.

2.44Como você avalia a sua qualidade de vida? 1é muito ruim, 2 é ruim, 3 nem ruim e

2.45nem boa, 4 é boa e 5 é muito boa".

2.46ENTREVISTADO: “5!”

2.47PESQUISADORA: " 5 , muito boa".

2.48ENTREVISATADO: "Hã Ham"!

2.49PESQUISADORA: "É... Você está satisfeito com a sua derivação urinária? 1 é 2.50insatisfeito, 2 é pouco satisfeito, 3 é satisfeito e 4 é muito satisfeito".

2.51ENTREVISTADO: "4! Tô muito satisfeito"!

2.52PESQUISADORA: “Certo! É... agora, essa também é uma questão de reflexão,

2.53você é... até... assim... trouxe um pouco mais é... lembra que eu falei que a primeira

2.54questão sobre a qualidade era uma abordagem mais geral, né?! Agora... A derivação

2.55urinária, especificamente, melhorou a sua qualidade de vida"?

2.56ENTREVISTADO: "Sim! Melhorou muito! Em todos os aspectos!

2.57PESQUISADORA: "Eu gostaria, assim... que você falasse, assim, um pouquinho"...

2.58ENTREVISTADO: "Hã ham"...

2.59PESQUISADORA: “... fica bem a vontade mesmo, o que você pensar, é... sentir, o

2.60quê você... é... a sua percepção mesmo".

2.61ENTREVISTADO: “Sim... É... com a derivação urinária, a principal vantagem dela 
2.62pra mim foi a questão dos vazamentos, que eu não tenho mais, então, eu não passo 2.63mais nenhum constrangimento em relação a nada! É... tem assim esta questão,

2.64também, da independência porque agora com essa derivação ficou muito mais fácil 2.65d'eu realizar o cateterismo, então, eu consigo fazer ele em qualquer local, né?!

2.66Claro! Seguindo a forma correta de fazer, mas eu consigo fazer ele em qualquer 2.67local a qualquer momento tendo os materiais em mãos, né?! E, em relação a 2.68derivação eu não sinto mais dor, também, quando eu preciso realizar o

2.69procedimento, uma coisa assim, eu passo a sonda e não sinto mais a dor que eu 2.70sentia anteriormente, então, no mais é isso mesmo.

2.71PESQUISADORA: “Certo. Então o questionário era esse, gostaria de te agradecer 2.72pela contribuição"...

\section{ENTREVISTA P3}

3.1PESQUISADORA: “Agora Senhor D, eu vou pedir para o senhor fazer uma reflexão 3.2sobre qualidade de vida antes e depois da derivação urinária e responder as perguntas 3.3que eu vou fazer para o senhor. A primeira pergunta é... O quê significa para você ter 3.4qualidade de vida"? Pergunta feita pausadamente!

3.5ENTREVISTADO: "Agora você pegou pesado! Sorrisos... A condição de vida que 3.6no momento eu tô levando, pra mim... tá sendo muito mais fácil agora que... um ano, 3.7dois anos atrás que eu fiz essa operação, por que... fica mais prático, né?! Pra eu 3.8fazer o cate, fica muito mais... tranquilo, né?! E... Então, a condição de vida 3.9melhorou outro lado assim de... timidez, esse lado assim de... ficar perto das pessoas, 3.10né?! Então melhorou bastante, então, não tem o quê reclamar não, melhorou 3.11bastante"!

3.12PESQUISADORA: "Mas por que o senhor acha que a timidez melhorou”?

3.13ENTREVISTADO: "Melhorou porque é mais prático, né?! Pensa eu perto de 3.14você... mesmo sendo no banheiro... fazendo o cate e você é minha acompanhante, aí 3.15eu fico tímido, né?! Porque, às vezes é pessoa do outro sexo, é pessoa talvez... um 3.16parente distante pode ser uma prima, um tio e tal... e pela barriga não! Eu faço perto 3.17de qualquer pessoa, não sinto vergonha, porque eu não tô mostrando parte íntima 3.18minha, né?! Então, melhorou por esse lado, né"?!

3.19PESQUISADORA: "Entendi. O senhor se sente menos... exposto"? 3.20ENTREVISTADO: “É”... menos constrangido, né?! Eu fico mais liberal, né? Até 
3.21eu faço o cate aqui perto do meu tio e ele fica arrepiado (paciente se diverte com a 3.22situação). Nesse momento o paciente imita o tio falando: ' Há eu não gosto de vê, 3.23porque você fica enfiando essa mangueira dentro, na sua própria barriga! É... é... 3.24meio, eu fico arrepiado!' Então, eu fico brincando com ele: ‘ Não, é muito mais 3.25fácil, é muito mais tranquilo por aqui, óh?! Do quê quando eu fazia pelo pênis!' 3.26Pela uretra fica muito mais difícil, né?! E vem a vergonha, né?! Porque eu sou 3.27tímido, então vem à vergonha d'eu me expor perto de outras pessoas.

3.28PESQUISADORA: "Certo. Qualidade de vida para o senhor no contexto geral, 3.29então, tá relacionada com estas questões”?

3.30ENTREVISTADO: “Tá! Acho que essas questões estão bem melhor agora”!

3.31PESQUISADORA: "Então, eu vou pedir para o senhor avaliar a pergunta que eu 3.32vou fazer e responder, óh?! Como você avalia a sua qualidade de vida? 1muito 3.33ruim, 2 é ruim, 3 não é ruim e nem boa, 4 é boa e 5 é muito boa".

3.34ENTREVISTADO: "Eu fico com a 3, não é ruim, mas não é boa também, tá aí uma 3.35coisa meio fora".

3.36PESQUISADORA: "A pergunta seguinte... Você está satisfeito é... com a sua 3.37derivação urinária? 1insatisfeito, 2 pouco satisfeito, 3 satisfeito e 4 muito

3.38satisfeito".

3.39ENTREVISTADO: "Eu vou ficar com a 3".

3.40PESQUISADORA: “Tá, satisfeito. A derivação... Agora, é sobre a derivação

3.41urinária especificamente, antes a pergunta era sobre a qualidade de vida geral num 3.42contexto geral, né?! Agora é sobre a derivação urinária. A derivação urinária

3.43melhorou a sua qualidade de vida"?

3.44ENTREVISTADO: "Sim, melhorou”.

3.45PESQUISADORA: "Sim... O senhor já trouxe um pouquinho para mim, mas eu 3.46queria que o senhor falasse mais, especificamente, o quê ficou bom em fazer o 3.47 cateterismo é, pela derivação, o quê melhorou e o quê isso interfere na sua vida que 3.48o senhor vê como melhora de qualidade"?

3.49ENTREVISTADO: "Melhorou porque ficou mais fácil de fazer, segundo, pela

3.50timidez e mostrar os órgãos genitais, a terceira, melhorou pela facilidade porque é 3.51muito mais prático de fazer e quarto, não sei se eu posso dizer, porque eu posso 3.52fazer em qualquer lugar, posso fazer num cantinho de parede, posso fazer no 3.53banheiro, eu posso fazer dentro do carro, eu posso fazer num... num lugar que eu 3.54fico mais a vontade, eu não fico com aquela vergonha com aquele"... Intervenção 
3.55da pesquisadora

3.56PESQUISADORA: "Chegou o momento de o senhor fazer o cateterismo, de

3.57esvaziar, o senhor consegue assim... ter” Interrupção do entrevistado.

3.58ENTREVISTADO: "Eu faço... numa boa sem preocupação nenhuma é mais

3.59prático, é muito bom! é muito melhor! até pela posição, né?! Porque quando você tá 3.60sentado, né?! Dentro do carro, né?! Você tá sentado dentro do carro, fica muito

3.61difícil de você fazer, porque tem que desabotoar a barguilha e, e... pra passar a

3.62sonda ali na uretra fica um pouco complicado e pela derivação não, fica tranquilo,

3.63você faz numa boa, você pode ficar sentado em qualquer posição, você não precisa

3.64ficar ali se organizando muito, a posição fica boa, ali sentado pra você passar a

3.65sonda, é beleza, é mais prático do quê pela uretra".

3.66AGRADECIMENTOS.

\section{ENTREVISTA P4}

4.1PESQUISADORA: “Agora, V. vou pedir para você fazer uma reflexão sobre

4.2qualidade de vida né?!... Antes e depois da derivação urinária; sua derivação já tem

4.3um tempinho, mas eu queria que você forçasse o pensamento e tentasse lembrar

4.4antes da derivação urinária e respondesse a pergunta: O que significa para você ter 4.5qualidade de vida"?

4.6ENTREVISTADA: "Bom, antes da cirurgia eu ficava muito com infecção urinária... 4.7ficava com febre e agora... depois, a gente tá em 2013, né?!”

4.8PESQUISADORA: "Hã, ham"...

4.9ENTREVISTADA: “Há 6 anos... 6 anos atrás?!” Expressão de dúvida.

4.10PESQUISADORA: “Óh! Foi em 2008, né?! 5"...

4.11ENTREVISTADA: “É, 2008... 2009, 2010. Há 5 anos atrás... há cinco anos depois

4.12a minha vida melhorou muita coisa! Eu não tô sentindo mais... não tô tendo, não tô 4.13tendo mais infecção urinária, mais... nem febre nem mais nada! Minha vida

4.14melhorou muito"!

4.15PESQUISADORA: “Certo. Me conta, como foi essa melhora, o quê foi bom? O

4.16quê você julga como... é... ter qualidade de vida"?

4.17ENTREVISTADA: “Áh! Melhorou porque agora eu posso passar a sonda, 4.18praticamente, sozinha... mas eu tenho um pouco de medo de passar, de me

4.19machucar"!

4.20PESQUISADORA: “Certo". 
4.21ENTREVISTADA: “... mas eu tenho medo de passar, de me machucar"!

4.22PESQUISADORA: "Entendi”.

4.23ENTREVISTADA: "Mas eu tenho que... não ter medo de me machucar... eu tenho

4.24que passar a sonda, eu tenho que tirar esse medo de mim"...

4.25PESQUISADORA: "Entendi."

4.26ENTREVISTADA: “... mas eu vou conseguir passar sonda, eu vou tirar esse medo

4.27de mim"!

4.28PESQUISADORA: “Certo e, assim, agora V. eu vou tá perguntando pra você como

4.29você avalia a sua qualidade de vida? 1é muito ruim, 2 é ruim, 3 não é ruim e nem

4.30boa, 4 é boa e 5 é muito boa".

4.31ENTREVISTADA: “A minha qualidade de vida é muito boa"!

4.32PESQUISADORA: "Muito boa e. você está satisfeita com a sua derivação urinária?

4.331 é insatisfeito, 2 é pouco satisfeito, 3 satisfeito e 4 é muito satisfeito".

4.34ENTREVISTADA: "Muito satisfeito".

4.35PESQUISADORA: "Muito satisfeito. Agora, outra pergunta, agora mais

4.36específica... antes eu tava te perguntando o quê que você acha, é... qual a ideia que 4.37você tem de qualidade de vida, né?! O que quê significa para você... agora eu vou te 4.38perguntar o quê que a derivação urinária melhorou na sua qualidade de vida? Um 4.39pouco você trouxe na pergunta anterior, né?! Você falou pra mim que diminuiu que 4.40diminuíram as infecções, mas você pode falar mais, o quê que ajudou mais pra

4.41você e que você associa com qualidade de vida"?

4.42ENTREVISTADA: “Eu posso repetir as mesmas coisas que eu disse antes de 4.43novo"?...

4.44PESQUISADORA: "Fique a vontade, você pode falar o que você pensa o que você 4.45acha".

4.46ENTREVISTADA: “Ah! Agora eu não tô tendo mais febre, nem infecção,

4.47melhorou minha qualidade de vida... agora eu posso passar a sonda sozinha, posso 4.48fazer a derivação sozinha (confusão)... posso fazer a lavagem sozinha"!

4.49PESQUISADORA: "Isso interferiu pra você, por exemplo, sair, viajar, estar com os 4.50amigos, o quê mudou nesse sentido pra você"?

4.51ENTREVISTADA: "Mudou bastante, tipo eu posso levar a sonda, é... as coisas pra 4.52eu fazer na rua, tipo no banheiro do shopping eu fazer sozinha, ou tipo eu ir 4.53almoçar, ou tipo na noiva do meu pai ou meu pai fazer em mim também... quando 4.54eu tiver dificuldade de fazer"! 
4.55PESQUISADORA: "Entendi... é, assim, em termos que... você associa que

4.56melhorou esta independência, esta facilidade que te trouxe pra sair, pra ir para os 4.57lugares, né?! Assim... a facilidade até mesmo para outras pessoas fazerem, não é 4.58isso"?

4.59ENTREVISTADA: “Isso”...

4.60PESQUISADORA: “Certo". E você consegue pensar mais em alguma coisa que 4.61possa ter reflexo na qualidade de vida... Sobre a derivação urinária?

4.62ENTREVISTADA: "Não, tem mais nada não"!

4.63AGRADECIMENTOS.

\section{ENTREVISTA P5}

5.1PESQUISADORA: “Agora, vou te perguntar assim... faça... pra você fazer uma 5.2reflexão sobre o que é qualidade de vida para você, antes do procedimento de 5.3derivação urinária, que é esse conduto por onde tira o xixi, né?! Que é o canalzinho, 5.4né?! Que tem na barriga por onde você passa a sondinha e você, então, pensar... 5.5 como era antes a sua qualidade de vida, o que você julgar que é qualidade de vida 5.6antes e depois e você me falar, o quê significa pra você ter qualidade de vida"? 5.7ENTREVISTADO: “Ah, pra mim qualidade de vida é as pessoas ser mais feliz, 5.8satisfeito do que... do que foi feito, né?! mais é... alegria mais... mais"...

5.9PESQUISADORA: “Oi”?

5.10ENTREVISTADO: “... mais independente, né?! no que foi feito".

5.11PESQUISADORA: “Certo, então, assim”...

5.12ENTREVISTADO: “... em relação, em relação à independência com as outras

5.13pessoas, conviver mais não ter mais aquela vergonha que era”.

5.14PESQUISADORA: "Mas você tinha vergonha de quê"?

5.15ENTREVISTADO: "De usar aquele jontex aquele saquinho coletor urinário, né?! 5.16Aquilo ali eu achava... muito envergonhado de vê aquilo ali, aí as pessoas vinham

5.17 me visitar e me vê com aquilo, né?! Ficava muito envergonhado".

5.18PESQUISADORA: “Certo... É... agora R. você quer complementar com mais

5.19alguma coisa sobre que é qualidade de vida pra você’?!

5.20ENTREVISTADO: "Não tenho muito assim... o que falar... acho que muitas... tem 5.21 coisas... tem coisas, tem muitos médicos aqui que não entendem sobre isso... aí 5.22complica um pouco"...

5.23PESQUISADORA: “Complica pra você ter a qualidade de vida, é... você acha que 
5.24se eles soubessem mais, em termos de maior... conhecimento sobre a situação que 5.25você tem, vivencia é... talvez eles pudessem interferir na sua qualidade de vida? É 5.26isso"?...

5.27ENTREVISTADO: "Igual, eu passei mal, dessa última vez aí eu fiquei na UTI,

5.28então, a sonda que eles colocaram entupiu, então eles não entendeu aí eles pensou 5.29que era outra... aí teve que me abri, eles não entendeu... aí foi na hora que abriu que 5.30viu que tinha perdido... abriu a bexiga e tinha muita urina perdida porque ela não 5.31pode encher muito".

5.32PESQUISADORA: "Não, não pode! Por isso, que o cateterismo é de 4 em 4 horas, 5.33 quando tem muco tem que irrigar, né?! Tudo isso... agora depois do procedimento 5.34que você fez aí o urologista daí tem que te orientar direitinho do que pode ser feito 5.35no momento, né"?!

5.36ENTREVISTADO: "Eu passei mal, não pude responder nada na hora! Que eu 5.37estava na UTI, né’?!

5.38PESQUISADORA: "Não tinha condições de explicar o que era... sua família, seus 5.39familiares sabem que você tem derivação, ampliação?’...

5.40ENTREVISTADO: “Sabia, minha mãe, minha mãe levou isso pro médico”...

5.41PESQUISADORA: "Levou o relatório”?

5.42ENTREVISTADO: “... o laudo... o relatório, aí eles disseram que foi uma infecção

5.43que eu tinha tido na bexiga, na bexiga não não! na barriga! Que essa bactéria foi 5.44na... que atingiu meu pulmão foi muito forte”.

5.45PESQUISADORA: "Foi forte, né? Então, você acha que isso tudo, esse... esse 5.46desconhecimento é... interferiu na sua qualidade de vida, foi isso"?

5.47ENTREVISTADO: “É... mais”...

5.48PESQUISADORA: “Hã”?

5.49ENTREVISTADO: “... é... toda vez que põe aquela sonda permanente tem que 5.50tomar cuidado que ela entope, se ela entupir tem que desentupir... aí, aí... foi isso". 5.51PESQUISADORA: "Entendi. R. vou te perguntar agora como você avalia, hoje, a 5.52sua qualidade de vida, no contexto geral, não só pela derivação não, é no contexto 5.53geral, como você avalia a sua qualidade de vida? 1 é muito ruim, 2 é ruim, 3 nem 5.54ruim e nem boa, 4 é boa e 5 é muito boa”.

5.55ENTREVISTADO: "Boa”!

5.56PESQUISADORA: "Boa"?!

5.57ENTREVISTADO: “A minha qualidade de vida”? 
5.58PESQUISADORA: “É... É a pergunta é como você avalia a sua qualidade de vida?

5.59Aí tem... tem 5 itens, né para você escolher 1. É... de acordo com a intensidade que

5.60você considera sua qualidade de vida, muito ruim, ruim, nem ruim e nem boa, boa e 5.61muito boa".

5.62ENTREVISTADO: "Pra mim foi”...

5.63PESQUISADORA: “Oi”?

5.64ENTREVISTADO: "Pra mim, fora esses negócio... que... complicaçãozinha, pra

5.65mim é boa".

5.66PESQUISADORA: "Você está satisfeito... hum... pode, pode falar R"...

5.67ENTREVISTADO: "Não pode falar".

5.68PESQUISADORA: "Você está satisfeito com sua derivação urinária? 1 é

5.69insatisfeito, 2 é pouco satisfeito, 3 é satisfeito e 4 é muito satisfeito”.

5.70ENTREVISTADO: "Tô satisfeito".

5.71PESQUISADORA: "Satisfeito. Agora, a pergunta é: a derivação urinária melhorou

5.72a sua qualidade de vida"?

5.73ENTREVISTADO: “Oi”?

5.74PESQUISADORA: “A derivação urinária, esse conduto por onde passa à sondinha

5.75melhorou a sua qualidade de vida"?

5.76ENTREVISTADO: "Melhorou".

5.77PESQUISADORA: "Por que"?

5.78ENTREVISTADO: "Por causa da facilidade... da praticidade de fazer o

5.79cateterismo, posso fazer sentado na cadeira, posso... é... não me sinto muito 5.80envergonhado, né"?!...

5.81PESQUISADORA: "Você se sentia envergonhado por que"?

5.82ENTREVISTADO: "Porque se for outra pessoa fazendo eu fico envergonhado,

5.83sabe? Entendeu"?

5.84PESQUISADORA: “Certo... Por exemplo, se fosse pra fazer o cateterismo é... pela 5.85uretra nativa você ficaria mais envergonhado, é isso"?

5.86ENTREVISTADO: "Verdade... sim se outra pessoa for fazer. Outra pessoa sem ser 5.87minha mãe".

5.88PESQUISADORA: “Áh! Outra pessoa que não seja sua mãe aí te dá 5.89 constrangimento"?

5.90ENTREVISTADO: "Isso"! 
5.91PESQUISADORA: "Pela, pela derivação esse constrangimento é menor ou não 5.92existe"?

\subsection{ENTREVISTADO: “Oi”?}

5.94PESQUISADORA: "Pela derivação sendo outra pessoa fora a sua mãe, esse 5.95constrangimento que você sente, essa vergonha é... é menor ou ela nem existe"?

5.96ENTREVISTADO: "Não existe vergonha".

5.97PESQUISADORA: "Não existe vergonha"!

5.98ENTREVISTADO: "Não".

5.99PESQUISADORA: "Que mais que você acha que pode ter melhorado na sua 5.100qualidade de vida que realmente interferiu... nessa derivação. Você já me falou da 5.101 praticidade, da facilidade de fazer o cateterismo, das posições”...

5.102ENTREVISTADO: "Sair pra um lugar com a minha mãe, né?! Não sinto aquela 5.103vergonha... fica mais fácil".

5.104PESQUISADORA: "Certo".

\subsection{AGRADECIMENTOS.}

\section{ENTREVISTA P6}

6.1PESQUISADORA: "V . pronto, então como a gente, você fez a resposta no 6.2formulário ontem, né?! E a gente ficou de fazer a gravação posterior que não foi 6.3possível fazer no mesmo momento é... agora eu estou entrando em contato para dar 6.4continuidade, lembrando que você já aceitou participar da pesquisa e você já

6.5respondeu e, essas são as duas perguntas referentes à qualidade de vida, então eu vou 6.6ler novamente para você responder. Então, por favor, faça uma reflexão sobre sua 6.7qualidade de vida antes e depois da derivação urinária e responda, é... O que 6.8significa pra você ter qualidade de vida"?

6.9ENTREVISTADA: "Bom, qualidade de vida depois da minha... da minha derivação 6.10é... foi a autonomia de poder ir e vir sem depender dos outros de passar a sonda". 6.11Interrupção da pesquisadora.

6.12PESQUISADORA: "Hã ham, agora nesse"...

6.13ENTREVISTADA: “... porque agora”...

6.14PESQUISADORA: “... hã, pode terminar”.

6.15ENTREVISTADA: “... porque antes eu tinha que ficar dependendo é... da minha 6.16mãe, principalmente, pra poder passar e aí agora não, né’?! 
6.17PESQUISADORA: "Mas essa primeira pergunta é... V., ela quer dizer, assim, num 6.18contexto mais geral, a. a sua ideia de... a sua percepção mesmo do que é qualidade 6.19de vida, né?! É... assim... se você tentar resgatar... o que imaginava ser, ah! isso 6.20aqui interfere na minha qualidade de vida. Vai ter a segunda questão é específica 6.21 sobre a derivação, essa primeira é referente, assim, o contexto geral de qualidade de 6.22vida. O que significa pra você esse termo, qualidade de vida"?

6.23ENTREVISTADA: "Bom, ter qualidade de vida é... você ter um... é ter uma vida 6.24saudável é... no seu dia a dia, fazer exercícios, ter, sei lá, minha moradia, meu 6.25emprego mesmo que eu tenho que me dá uma certa qualidade de vida, né?! Ou que 6.26 me proporciona uma certa qualidade de vida"...

6.27PESQUISADORA: “Certo e refletindo nesse contexto que você tá me trazendo 6.28antes e depois da derivação urinária você julga que é... existia, você já... já percebia 6.29qualidade de vida é... teve uma diferença na... na qualidade de vida nesse contexto 6.30que você está me trazendo".

6.31ENTREVISTADA: "No contexto que eu tô trazendo na... antes e depois"?

6.32PESQUISADORA: "É, antes e depois da derivação nesse contexto que você tá me 6.33trazendo, né?! Que é trabalhar, ter moradia, né?! Nesse contexto que... você julga 6.34que teve modificação na qualidade de vida ou... ou é permaneceu, como é que é"? 6.35ENTREVISTADA: “Não, é”... antes da derivação, é... eu saia é... eu tinha mais 6.36muito mais índice de infecção urinária porque eu saia eu ficava evitando beber água 6.37pra não... não fazer xixi, né?!

6.38PESQUISADORA: “Certo, hã ham”!

6.39ENTREVISTADA: “É... tinha que ficar me limitando em ir em algum local que 6.40tinha um banheiro em que tinha um acesso pra poder passar a sonda é... e aí depois 6.41 da cirurgia não, depois da cirurgia eu não tenho mais a necessidade de ficar 6.42limitando em beber água, né?! É... a qualquer momento eu mesmo passo a sonda e 6.43aí eu não preciso ficar dependendo de algum local que tenha algum banheiro então, 6.44eu tive um ganho enorme na qualidade de vida devido essa questão, né?! De... de 6.45higiene, de... de tudo eu digo".

6.46PESQUISADORA: “Certo, é, então, assim... você avaliando a derivação urinária 6.47ela melhorou sua qualidade de vida"?

6.48ENTREVISTADA: "Melhorou! Melhorou, sim! Melhorou por conta da 6.49dependência, né?! De... deu ficar... dependendo dos outros de passar a sonda e pela 6.50questão mesmo de... de infecções mesmo, eu tava mais propícia à infecção por ter 
6.51que tá usando fralda, ficava abafado, né?! E aí com a derivação, não! Com a

6.52derivação eu não, não fico mijada, né"?!

6.53PESQUISADORA: “É, assim, no contexto de trabalho, de estar com outras

6.54pessoas, de sair isso te favoreceu ou interferiu na melhora dessa qualidade de vida

6.55é... ou... como que você percebe isso"?

6.56ENTREVISTADA: "Não, é... eu percebo que... que depois que eu fiz a sonda é...

6.57que eu fiz a derivação na verdade, eu pude tá me capacitando mais no meu trabalho, 6.58fazendo os cursos porque eram cursos que eram o dia inteiro e aí eu deixava de

6.59fazer por que... porque eu não tinha como passar a sonda, então aí, eu comecei a me 6.60capacitar melhor para o meu trabalho. Os cursos, né?! Que meu trabalho oferecia eu 6.61pude, né?! Fazê-los".

6.62PESQUISADORA: "Certo, isso favoreceu no tipo de... organizar... de se organizar 6.63pra... se cuidar"...

6.64ENTREVISTADA: “Era constrangedor, né?! Você ficar mijada! E agora não”...

6.65PESQUISADORA: “Certo, agora, assim, a sensação é de bem estar”?

6.66ENTREVISTADA: "Exatamente!"

6.67AGRADECIMENTOS.

\section{ENTREVISTA P7}

7.1PESQUISADORA: "O quê significa pra ela ter qualidade de vida?! Se ela puder 7.2responder"...

7.3ENTREVISTADA (resposta por intermédio da mãe) "Se alimentar bem ela falou,

7.4fazer exercícios... Silêncio/Pausa. Na questão... oi”?!

7.5PESQUISADORA: "Certo”.

7.6PESQUISADORA: “Oi, tô ouvindo”!...

7.7ENTREVISTADA: “É, nessa questão da independência dela a pergunta... mais

7.8dirigida nesse sentido"?

7.9PESQUISADORA: "Não, no contexto geral o que é... assim, a gente pede pra pessoa 7.10fazer uma reflexão, né?! Sobre a qualidade de vida dela tanto antes quanto depois

7.11da derivação, independente se funcionou ou se não funcionou, ou seja, é pra ela ter,

7.12assim, uma ideia do que é qualidade de vida pra ela"!

7.13ENTREVISTADA: "Então, é... ela sempre fala assim pra mim que se tivesse dado 7.14certo essa cirurgia, era muito bom pra independência dela, ela poderia ter uma 7.15qualidade de vida melhor, né"?! 


\subsection{PESQUISADORA: “Certo".}

7.17ENTREVISTADA: “Acesso a mais coisas, podia passear mais, ter a independência 7.18dela, né"?!

7.19PESQUISADORA: “E... é... assim, é... em relação à nova abordagem a senhora 7.20tem... interesse foi cogitado essa possibilidade ou não"?

7.21ENTREVISTADA: “Uai, depende... tem que me convencer”! Sorriso acanhado. 7.22PESQUISADORA: “É... porque é uma cirurgia, né”?!

7.23ENTREVISTADA: “É... porque ela... é... foi bem difícil pra gente ficar aí esses

7.24dias, porque a gente mora longe é, assim, e a gente faz... assim, aquela expectativa

7.25que vai ser um sucesso e agora aí a gente faz e... assim, já é mais complicado a

7.26gente pensar nessa hipótese. Meu marido sempre foi contra em fazer, ele tem medo

7.27de cirurgia e... mais eu não sei, às vezes, eu chego assim a pensar... só que ele... eu 7.28penso assim, vai ter que tirar mais coisas ainda, fazer um canalzinho maior, mais 7.29longo, pra pegar mais acima da barriga dela porque o que foi feito ficou muito 7.30baixo, aí devido à flacidez da barriga... da barriga dela, então, ela ficou assim...

7.31muito escondido, o buraquinho ficou muito escondido".

7.32PESQUISADORA: “Ela não consegue visualizar".

7.33ENTREVISTADA: "Não, não consegue, só se for na frente de um espelho".

7.34PESQUISADORA: “Entendi. E... é... as perguntas seguintes seriam... como ela

7.35avalia a qualidade de vida dela hoje? 1muito ruim, 2 é ruim, 3 não é ruim e nem

7.36boa, 4 é boa e 5 é muito boa".

7.37ENTREVISTADA: "É boa".

7.38PESQUISADORA: "Boa, ok"!

7.39PESQUISADORA: “Agora, é, em relação à derivação urinária. 1 é pra insatisfeito,

7.402 é pouco satisfeito, 3 é pra satisfeito e 4 muito satisfeito. Como ela considera"?

7.41ENTREVISTADA: "É insatisfeita o que ela fala”.

7.42PESQUISADORA: “Certinho! Tem que ser o que ela sente mesmo! O que ela

7.43percebe. É... A pergunta seguinte seria: A derivação urinária melhorou a sua

7.44 qualidade de vida"?

7.45ENTREVISTADA: “Se tivesse funcionado tinha melhorado, né”?! Sorriso.

7.46PESQUISADORA: “Óh! Não, mais assim, é pra ela responder... Não funcionou aí 7.47ela pode responder como ela estiver pensando mesmo"!

7.48ENTREVISTADA: "Ela disse que ficaria melhor". 
7.49PESQUISADORA: "Não, a pergunta é a seguinte, é assim: A derivação urinária

7.50melhorou a sua qualidade de vida? Não é se tivesse funcionado! É se melhorou?!

7.51Eu entendi o que a senhora me trouxe até agora, mas eu queria que ela

7.52respondesse".

7.53ENTREVISTADA: “Então, mas... mesmo não tendo funcionado”?

7.54PESQUISADORA: "Se não funcionou então não teve melhora, não é isso"?

7.55ENTREVISTADA: “Então, é”!

7.56PESQUISADORA: "Então ela responderia que não melhorou né"?!

7.57ENTREVISTADA: “Isso"!

7.58PESQUISADORA: “Então pronto! É essa ideia dela mesmo”?

7.59ENTREVISTADA: “É, é sim”!

7.60PESQUISADORA: "Então pronto! Então era essa a pergunta. A derivação urinária

7.61ela não trouxe melhora na qualidade de vida dela, né?! Porque não foi funcionante... 7.62não é isso"?

7.63ENTREVISTADA: “Hã ham, isso"!

7.64AGRADECIMENTOS.

\section{ENTREVISTA P8}

8.1PESQUISADORA: “É... agora G. eu vou pedir pra você fazer uma reflexão sobre a 8.2qualidade de vida... mas antes, não especificamente, essa pergunta não é

8.3especificamente sobre a derivação não! Mas eu quero que você lembre antes da sua 8.4qualidade de vida, antes da sua cirurgia pra fazer a derivação, como era, o que você 8.5considerava como qualidade de vida e agora né?! Então, antes e depois... a qualidade

8.6de vida antes e depois da derivação urinária e aí, você vai me responder o que

8.7significa, nesse contexto, pra você a qualidade de vida, ter qualidade de vida antes e 8.8depois da derivação? Como é"?

8.9ENTREVISTADA: “Olha! Antes da derivação eu usava fraldas né?! Geriátricas,

8.10então o que acontece, é... pra gente ficar dentro de casa com a fralda geriátrica,

8.11 você pode estar trocando a hora que der entendeu? Mas na rua é complicado,

8.12vazava, sabe? Aí, não tinha onde trocar. E aí? Mesmo tempo se você tivesse na casa

8.13de um amigo, parente não tinha como você ir. Se não tiver um lugar bom assim...

8.14não tiver onde trocar, então, quer dizer, eu ficava mais presa dentro de casa sabe?

8.15Não tinha assim, assim onde trocar mas assim...depois da derivação eu posso ir ao 8.16shopping, passear, eu posso ir pra casa de amigos porque até mesmo sentada na 
8.17cadeira eu posso fazer a minha derivação"...

8.18PESQUISADORA: “E... hã? Entendi”.

8.19ENTREVISTADA: “... então eu sinto que pra mim foi muito bom”!

8.20PESQUISADORA: “Certo, então assim... a qualidade de vida você percebe como

8.21essa liberdade de ir e vir né? De ir, de estar com as pessoas... Sim pode falar".

8.22ENTREVISTADA: "Eu passei a ter menos infecção urinária, assim, não tenho

8.23assadura pra não abrir muita escara, porque a fralda ela abafa muito, entendeu? E

8.24pra mim, eu vou falar, não tenho nada... assim, eu não tenho nenhum pingo de 8.25arrependimento, eu gostei... entendeu"?

8.26PESQUISADORA: "Que bom... Como você, assim, avalia a sua qualidade de vida?

8.27 É... 1 é muito ruim, 2 é ruim, 3 nem ruim e nem boa, 4 é boa e 5 é muito boa".

8.28ENTREVISTADA: “É... falando pela, pela, pela operação, pela derivação"?

8.29PESQUISADORA: "Não, é de uma maneira geral, qualidade de vida, o que vier na

8.30sua cabeça que te leva a falar: não, isso é qualidade de vida e isso tá influenciando

8.31dessa forma, essa pergunta sobre a qualidade de vida está direcionada nesse sentido

8.32né?! O que significa pra você ter qualidade de vida? Aí você me trouxe essas

8.33informações, né"?!...

8.34ENTREVISTADA: "Foi".

8.35PESQUISADORA: “... e agora eu te pergunto também sobre a qualidade de vida

8.36nesse contexto geral é... se é muito ruim, 1 é muito ruim, 2 é ruim, 3 nem ruim e

8.37 nem boa, 4 é boa e 5 é muito boa".

8.38ENTREVISTADA: "Olha eu vou ficar na 3, a minha qualidade de vida não é muito 8.39bom, entendeu? Graças a Deus, assim... é... devido o que eu tive na minha lesão, eu 8.40tive dificuldades sim, mas se eu olhar pra traz eu também tive ganhos, então, sabe? 8.41Não foi somente assim... é lógica que voltar a ser o que eu era antes eu não vou ser 8.42mais só que eu acho o que falta pra mim é a acessibilidade, com certeza, entendeu?! 8.43Assim, um pouco... uma pessoa que tivesse do meu lado, assim... que, que pudesse

8.44me ajudar que, infelizmente, infelizmente eu não tenho, entendeu? É... isso

8.45entendeu? É isso".

8.46PESQUISADORA: “É"... agora eu questiono sobre é... a derivação urinária

8.47 melhorou a sua qualidade de vida?

8.48ENTREVISTADA: “Áh! Melhorou! Melhorou bastante, entendeu? Porque”...

8.49PESQUISADORA: "Eu queria que você falasse geral, tudo que vem, que você fala, 8.50pensa em qualidade de vida e derivação urinária o quê que melhorou"? 
8.51ENTREVISTADA: “É melhorou no fato né?! É como que eu falei da

8.52acessibilidade, também, de estar indo e vindo, é... assim, de estar precisando de

8.53pessoas pra poder estar do meu lado quando eu não... sempre precisando de alguém, 8.54melhorou nessa parte, melhorou... melhorou... é eu posso passar o dia todo dentro 8.55de casa sozinha, né?! Que... que não tem necessidade de falar... ai eu tô passando 8.56mal por que eu tenho que fazer isso, por que eu tenho que fazer a derivação, 8.57entendeu? Né"?!

8.58PESQUISADORA: “Certo, é... em relação assim... você me trouxe né?! Essa 8.59questão da facilidade e em outros contextos... da sua vida? Te ajudou em alguma 8.60coisa"?

8.61ENTREVISTADA: “O que? Não entendi, pode repetir de novo”?

8.62PESQUISADORA: "Porque assim, você me trouxe pela questão de facilidade, né?! 8.63Da praticidade né?! Que eu entendi, tem mais alguma coisa que você queira falar 8.64que... que melhorou"?

8.65ENTREVISTADA: "Melhorou?! Não, não”...

8.66PESQUISADORA: "Você percebe essas melhoras né”?!

8.67ENTREVISTADA: “É”!

8.68PESQUISADORA: "E você está satisfeita com a sua derivação urinária”?

8.69ENTREVISTADA: "Eu tô"!

8.70PESQUISADORA: "É... aí eu vou te falar também em itens, 1 é insatisfeito, 2 é

8.71pouco satisfeito, 3 é satisfeito e 4 é muito satisfeito".

8.72ENTREVISTADA: “4, muito satisfeito”...

8.73PESQUISADORA: “ 4 ”?

8.74ENTREVISTADA: "Isso, é”!

8.75AGRADECIMENTOS.

\section{ENTREVISTA P9}

9.1PESQUISADORA: "Por favor, faça uma reflexão sobre sua qualidade de vida antes

9.2e após a derivação urinária, antes e depois da derivação urinária e responda: O que 9.3significa pra você, no contexto geral, ter qualidade de vida"?

9.4ENTREVISTADO: "Bom, antes era muito ruim a qualidade de vida não era muito 9.5boa antes da derivação após deu uma melhorada bastante, deixa ver... tive, tive

9.6mais... tive mais, sei lá (sorriso), tive mais disposição, mais, mais foco... na vida! 9.7Qualidade de vida pra mim é manter a saúde em dia, manter boa alimentação, fazer 
9.8exercícios... é isso! Colocar isso em dia mais... isso que é qualidade de vida pra mim. 9.9Tem que falar mais"?

9.10PESQUISADORA: “É... como você avalia a sua qualidade de vida? 1 você até já...

9.11já tinha feito à marcação, 1 é muito ruim, 2 é ruim, 3 nem ruim e nem boa, 4 é boa e

9.125 é muito boa".

9.13ENTREVISTADO: "A minha qualidade de vida é boa".

9.14PESQUISADORA: “Boa né?! Então é a 4 né?! Em relação à derivação urinária

9.15agora, a derivação urinária melhorou a sua qualidade de vida"?

9.16ENTREVISTADO: “Melhorou, melhorou muito"!

9.17PESQUISADORA: "Eu gostaria que você falasse como? Por quê? O que mudou?

9.180 que melhorou'?

9.19ENTREVISTADO: "Em relação a tá com outras pessoas, a não ficar perdendo xixi 9.20também, saber qual o horário de esvaziar ou não e... mudou muito aí... aí também... 9.21(inaudível) saúde".

9.22PESQUISADORA: “Oi”?!

9.23ENTREVISTADO: “Ter mais saúde também! Antes dela eu tinha muitos

9.24problemas... muitos problemas com aquela bolsa lá, aquela bolsa que eu carregava

9.25de xixi, de urina... mas melhorou, bastante"!

9.26PESQUISADORA: “Ok! Você está satisfeito com a sua derivação urinária? 1 é 9.27insatisfeito, 2 é pouco satisfeito, 3 é satisfeito e 4 é muito satisfeito".

9.28ENTREVISTADO: "Tô satisfeito".

9.29PESQUISADORA: "Satisfeito, a 3, ok"!

9.30AGRADECIMENTOS.

\section{ENTREVISTA P10}

10.1PESQUISADORA: “J. eu vou pedir pra você fazer uma reflexão sobre o que é 10.2qualidade de vida pra você indiferente da derivação, mas a referência de parâmetro 10.3é antes e depois (com ênfase) da derivação né?! Urinária é... o que significa, num 10.4 contexto geral, qualidade de vida, pra você’?

10.5ENTREVISTADA: “Olha, eu acho que eu era feliz e não sabia. É a independência 10.6mesmo, viu?! Acima de tudo a independência"! Silêncio.

10.7PESQUISADORA: "Você pode falar mais um pouquinho sobre isso"?

10.8ENTREVISTADA: Sim, porque assim... É... Não poder fazer as coisas sozinha e... 10.9agora poder e agora poder sair...porque... assim minha cadeira é motorizada! Então 
10.10eu saio pra todos os lugares, assim, quando eu estou na cadeira eu sou 10.11 completamente independente é... e antes disso não, eu precisava...eu até saia, antes 10.12da derivação eu já tinha cadeira motorizada, mas eu tinha um prazo pra voltar! E 10.13assim, constrangimentos poderiam acontecer a qualquer momento, porque eu

10.14perdia né'?!

10.15PESQUISADORA: "Perdia o quê, fezes, urina"?

10.16ENTREVISTADA: "Urina eu perdia, então assim, antes da derivação é... eu até 10.17poderia ser um pouco independente, mas a minha independência era menor"...

10.18PESQUISADORA: “Entendi”.

10.19ENTREVISTADA: “... depois não, hoje eu posso sair e ficar um dia inteiro fora, 10.20porque assim, cada vez que eu precisar fazer o xixi é só ter um banheiro e o meu 10.21 material comigo".

10.22PESQUISADORA: "Entendi. E assim, no contexto de qualidade de vida você me 10.23falou: a independência! Mas o que mais você entende por qualidade de vida"?

10.24ENTREVISTADA: "Relacionado à derivação"?

10.25PESQUISADORA: "Não, indiferente, porque vai ter um momento... a pergunta 10.26seguinte é relacionada à derivação, agora é... eu queria que ter esse parâmetro com 10.27 você do significado, num contexto geral de qualidade de vida pra depois

10.28especificar sobre a derivação... aí eu queria que você falasse primeiro dessa sua 10.29percepção sobre qualidade de vida e tentasse que você, assim... já tem muito

10.30tempo né?! Mas que você se lembrasse do que você considerava como qualidade 10.31 de vida pra você"?

10.32ENTREVISTADA: “Ah! acho que eu continuo arraigada na independência, 10.33porque assim, eu trabalhava, eu tinha uma vida muito ativa antes da lesão, eu 10.34trabalhava, eu tinha dois filhos pequenos, casada, saia, fazia um monte de coisa e 10.35de repente tudo isso parou $\mathrm{e} . .$. eu fiquei nesse... nesse tempo parada muito tempo, 10.36assim, durante muito tempo eu fiquei totalmente parada isso foi um baque pra 10.37mim?!. Então assim, não só parada mais fisicamente parada. né?! Então assim, a 10.38independência é tudo, qualidade de vida é a gente ter independência, poder fazer 10.39as coisas, sair, fazer por si né?! e...assim... hoje eu não tenho essa total 10.40independência mas eu já conquistei bastante".

10.41PESQUISADORA: "Certo. Agora eu vou te perguntar é... como você avalia a sua 10.42qualidade de vida? 1 é muito ruim, 2 é ruim, 3 não é ruim nem boa, 4 é boa e 5 é 10.43muito boa". 
10.44ENTREVISTADA: “4, é boa, porque assim, uma questão de... tem a parte do 10.45intestino, mas é um pouco constrangedor assim... às vezes acontece! Ter uns piriri 10.46também né’?!

10.47PESQUISADORA: "Hã ham, você faz estímulo? Massagem"?

10.48ENTREVISTADA: “Faço... é... ponho supositório né?! Que estimula, vou no 10.49banheiro".

10.50PESQUISADORA: "Mas quando você veio nós orientamos massagem, estímulo? 10.51Fizemos a orientação pra você"?

10.52ENTREVISTADA: “Sim, mas o que mais me”... Interrupção da pesquisadora.

10.53PESQUISADORA: “O que foi mais efetivo foi o supositório”?

10.54ENTREVISTADA: "Foi o supositório de glicerina e não aquele não o que... o que 10.55usa aí o. o"...

10.56PESQUISADORA: “Minilax”...

10.57ENTREVISTADA: “... o minilax é aquele outro, o que coloca e espera um 10.58pouquinho e depois vai pro banheiro. Coloco deitada ainda e depois vou pro 10.59banheiro".

10.60PESQUISADORA: “Ok”!

10.61ENTREVISTADA: "Esse foi o mais fácil pra mim. Mas, às vezes, acontece de ter 10.62diarreia, sabe? ter que fazer fora de hora. Nossa! Quando isso acontece, assim... é 10.63 um dos poucos momentos que eu me sinto muito mal! muito mal mesmo"!

10.64PESQUISADORA: “Entendi”.

10.65ENTREVISTADA: "Nem pro banho, assim, ter que depender de outra pessoa pra 10.66tomar banho, pra sair da cama pra voltar, pra deitar não é tão ruim assim, mas 10.67quando isso acontece, nossa! O meu munda cai”.

10.68PESQUISADORA: "Entendo. É... agora, eu vou fazer a pergunta sobre: A 10.69derivação urinária, ela melhorou sua qualidade de vida? Aí eu queria que você 10.70falasse é... tudo sobre... se melhorou se não melhorou e se tiver melhorado como?

10.71E se não melhorou também, porque"?

10.72ENTREVISTADA: "Melhorou muito! Muito, muito, muito! Melhorou muito. 10.73Assim, hoje... é antes eu ficava... minha mãe vem pra cá todos os dias me ajudar, 10.74na minha casa, aí assim, antes eu precisava que ela ficasse aqui um tempo muito 10.75maior do que ela fica hoje. Hoje, assim, tem dias que ela nem vem, antes quando 10.76acontecia dela não poder vir, tinha que vir outra pessoa ou eu ir na casa de outra 10.77pessoa pra pessoa passar a sonda né?! agora não! Agora eu fico sozinha é... se eu 
10.78tiver que sair, se eu tiver que demorar, não tem problema! Eu posso ficar a 10.79 vontade, é... aqui a gente tem ônibus coletivo, eu saio fico fora o dia inteiro vou 10.80pra faculdade, volto, melhorou muito, muito mesmo"!

10.81PESQUISADORA: "Nessa questão que você preza né?! A respeito da qualidade 10.82 de vida sobre a independência, você acha que te deu uma maior independência"? 10.83ENTREVISTADA: "Muito maior! muito mesmo"!

10.84PESQUISADORA: “A próxima pergunta é: Você está satisfeito com sua 10.85derivação urinária? 1 é insatisfeito, 2 é pouco satisfeito, 3 é satisfeito e 4 é muito 10.86satisfeito".

10.87ENTREVISTADA: “4, muito satisfeito”. 10.88AGRADECIMENTOS.

\section{ENTREVISTA P11}

11.1PESQUISADORA: "Agora, R. eu vou pedir pra você fazer uma reflexão sobre 11.2qualidade de vida antes da derivação urinária, né?! E me responder, o que significa

11.3pra você ter qualidade de vida"?

11.4ENTREVISTADO: “O que significa pra mim”?

11.5PESQUISADORA: "Hã ham”.

11.6ENTREVISTADO: “Eu só tenho um pouco a reclamar dessa derivação que foi

11.7feita"!

11.8PESQUISADORA: "Não... mais olha só, a pergunta é assim... sobre a derivação 11.9urinária né assim"...

11.10ENTREVISTADO: “Assim... a tá! Só pra você é... frisar na sua pesquisa né?! Um 11.11item que isso tá me atrapalhando muito e não me atrapalhava antes".

11.12PESQUISADORA: "Pode dizer"!

11.13ENTREVISTADO: “Eu não tinha dor de cabeça é... dislexia que eles falam”?

11.14PESQUISADORA: "Disreflexia"!

11.15ENTREVISTADO: "Eu não tinha dor de cabeça e nem arrepios, antes da cirurgia! 11.16Depois que eu fiz, nossa! Isso me atrapalha e muito! Né"?!

11.17PESQUISADORA: “A disreflexia”?

11.18ENTREVISTADO: "É... atrapalha e muito, eu sinto muita dor de cabeça, às vezes, 11.19eu chego a ficar o dia inteiro com dor de cabeça"... 
11.20PESQUISADORA: "Mas aí você fazendo o cateterismo, mudando de posição, 11.21intestino, essa coisa toda porque são vários fatores que podem desencadear a 11.22disreflexia".

11.23ENTREVISTADO: "Mesmo, mesmo eu fazendo tudo isso... digamos, começa 11.24com a dor de cabeça, tá, então vou, faço o cateterismo, mudo de posição, o

11.25intestino trabalhando normal né?! mesmo assim, eu passo o dia inteiro com dor de 11.26cabeça"!

11.27PESQUISADORA: "Entendi... agora, me diga, antes da derivação, antes de fazer 11.280 procedimento, o que você significa, significava pra você ter qualidade de vida"? 11.29ENTREVISTADO: "Significava eu ter mais independência, né?! Eu depender 11.30menos da minha mãe, né?! Coisa que obrigava muito ela mexer comigo, né?!

11.31Hoje, aqui a história... antes eu só dependia da minha mãe pra fazer o cateterismo; 11.32hoje, através da derivação que foi feita eu já tenho confiança de outras pessoas 11.33fazer pra mim, então, essa qualidade melhorou bastante, né’?!

11.34PESQUISADORA: "Certo! Mas antes... digamos assim, o R. ainda não tem a 11.35derivação e o R., o quê que o R. pensava sobre qualidade de vida”, sem a 11.36derivação"?

11.37ENTREVISTADO: "Você quer que eu fale"?

11.38PESQUISADORA: "É. O quê significava pra você qualidade de vida"?

11.39ENTREVISTADO: “Qualidade de vida pra mim... significava não ser dependente 11.40de ninguém, o menos possível! Né, né"?! Silêncio.

11.41PESQUISADORA: "Mais alguma coisa que você queira falar”?

11.42ENTREVISTADO: "não, não, só isso mesmo".

11.43PESQUISADORA: "R. agora eu vou perguntar como você avalia a sua qualidade 11.44de vida? lé muito ruim, 2 é ruim, 3 não é ruim e nem boa, 4 é boa e 5 é muito 11.45boa".

11.46ENTREVISTADO: "Eu avalio como 3”.

11.47PESQUISADORA: “3 ok! nem ruim e nem boa. E... é, agora, a pergunta é

11.48referente à qualidade de vida, mas após a derivação urinária. A derivação urinária 11.49 melhorou a sua qualidade de vida"?

11.50ENTREVISTADO: "Melhorou! Mesmo dependendo da minha mãe ainda pra 11.51 fazer, melhorou"!

11.52PESQUISADORA: "Você diz que pode outras pessoas fazer por você né?! 11.53Quando ela não está. Que facilitou mais". 
11.54ENTREVISTADO: "Hã ham. Não preciso ficar me expondo mais, o meu órgão,

11.55 pra pessoa fazer o cateterismo, né’?!

11.56PESQUISADORA: “Quer falar mais alguma coisa”?

11.57ENTREVISTADO: "Não, não”!

11.58PESQUISADORA: "Você, hoje, está satisfeito com sua derivação urinária? 1 é 11.59insatisfeito, 2 é pouco satisfeito, 3 é satisfeito, 4 é muito satisfeito".

11.60ENTREVISTADO: “4”!

11.61PESQUISADORA: “4”?

11.62ENTREVISTADO: “4”!

11.63PESQUISADORA: "Mesmo com essas alterações que teve e que você me falou”?

11.64ENTREVISTADO: "Mesmo com as alterações. Como eu falei me facilitou fazer o 11.65cateterismo mesmo dependendo de outras pessoas, então, teve uma melhora

11.66enorme, né"?!

11.67PESQUISADORA: "E você percebe que se a derivação tivesse num

11.68posicionamento melhor poderia estar te ajudando mais não é"? (Ele mencionou

11.69esse fato em outro momento da entrevista.).

11.70ENTREVISTADO: “Eu creio que sim! Né?! Com um pequeno esforço meu

11.71tudinho né?! eu conseguiria fazer sozinho né?! mas onde ficou é impossível”.

11.72PESQUISADORA: "E ela... é... ficou mais ou menos onde... abaixo do umbigo"?

11.73ENTREVISTADO: "Ela ficou bem... ficou, digamos no, como eu posso dizer,

11.74ficou como na dobra da barriga! Digamos, se eu engordar muito é como se a

11.75barriga fosse tampar ela".

11.76PESQUISADORA: “Entendi”.

11.77ENTREVISTADO: “Até sentado, até sentado eu já tenho um pouco de dificuldade 11.78de fazer, outra pessoa fazer”.

11.79PESQUISADORA: "Hã ham. Você é... Seu peso é qual, atualmente”?

11.80ENTREVISTADO: "Bom, vou colocar aí uns 72 porque devido eu ter emagrecido 11.81quando eu fiz a cirurgia e depois os outros 13 dias que eu fiquei aqui também eu 11.82emagreci muito né"?!

11.83PESQUISADORA: “Certo”.

11.84ENTREVISTADO: "Vou colocar que eu estou com 72 quilos mais ou menos".

11.85PESQUISADORA: "Não é gordinho né?! Porque poderia falar assim, as dobras 11.86estão atrapalhando ver, mas não é sobrepeso".

11.87ENTREVISTADO: "Não, não porque pela minha altura eu tô no peso ideal 
11.88ainda".

11.89AGRADECIMENTOS e ESCLARECIMENTOS.

\section{ENTREVISTA P12}

12.1PESQUISADORA: "Então eu tô ligando pra gente é... fazer aquelas questões que 12.2precisavam ser gravadas, não deu pra gravar no momento, é... então eu vou te 12.3perguntar. Vou pedir, por favor, pra você fazer uma reflexão sobre sua qualidade de 12.4vida antes e depois da derivação urinária e responder: 'O que significa, num

12.5primeiro momento é antes da derivação tá?! Então, o que significa pra você é... ter 12.6qualidade de vida"?

12.7ENTREVISTADA: “Antes da derivação, né”?!

12.8PESQUISADORA: "É... é você avaliar o antes e o depois, mas no contexto geral, o 12.9que é ter qualidade de vida pra você"?

12.10ENTREVISTADA: "Ah, tá! Ah! Qualidade de vida pra mim é tá bem comigo 12.11 mesma, me aceitando do jeito que eu sou não é?! Do jeito que eu estou... ter uma 12.12boa saúde, tá bem com as pessoas, né?! E comigo, com meus amigos, vizinhos...

12.13que mais?! Eu acho fundamental ter um horário assim, pra mim meditar, orar”...

12.14PESQUISADORA: "Certo”.

12.15ENTREVISTADA: “... ir à igreja... ah! poder viajar, sair, ter um tempo assim, pra 12.16praticar um exercício não como se fosse com aquela obrigação mais uma coisa 12.17mais natural, fisioterapia... e... é... ter acessibilidade”.

12.18PESQUISADORA: “De ter”?

12.19ENTREVISTADA: “Acessibilidade”.

12.20PESQUISADORA: “Acessibilidade, certo”!

12.21ENTREVISTADA: “e ter ambientes agradáveis, boa alimentação, pra mim, é 12.22 fundamental".

12.23PESQUISADORA: “Certo. Como você avalia a sua qualidade de vida? 1 é muito 12.24ruim, 2 é ruim, 3 nem ruim e nem boa, 4 é boa e 5 é muito boa”.

12.25ENTREVISTADA: "A minha qualidade de vida eu avalio como boa”. 12.26PESQUISADORA: “Ok”!

12.27ENTREVISTADA: "Não chega a ser muito boa porque eu ainda preciso assim é... 12.28que falta acessibilidade! Na minha cidade, por exemplo, é muito difícil sair aqui, 
12.29não tem... é difícil chegar numa loja, ir ao banco, não tem acessibilidade, então... 12.30eu"...

12.31PESQUISADORA: "Dificulta o dia a dia".

12.32ENTREVISTADA: "É! Porque imagina se tivesse mais acesso eu mesma poderia

12.33ir sozinha, qualquer horário".

12.34PESQUISADORA: “Certo”.

12.35ENTREVISTADA: "Sem depender de carro, de outras pessoas. Aí, é isso".

12.36PESQUISADORA: "Hoje, a derivação urinária melhorou sua qualidade de vida?

12.37Eu gostaria que você falasse assim, no contexto geral, se melhorou, o quê

12.38melhorou se não melhorou o quê que não melhorou o que poderia ter sido melhor,

12.39então assim, é... a pergunta é: 'A derivação urinária melhorou a sua qualidade de 12.40vida"'?

12.41ENTREVISTADA: “Ah! Bastante mesmo! Olha, eu acho assim 99 por cento”! 12.42PESQUISADORA: "Foi bastante".

12.43ENTREVISTADA: "Melhorou bastante, porque antes eu tinha receio de sair, 12.44ficava até difícil de ir a um lugar, era tudo aquele tempo certinho e, às vezes, eu 12.45não tinha acesso a um banheiro e alguma coisa assim, agora não, eu tô tranquila...

12.46é bem mais fácil, não tenho mais aquela ansiedade: 'ah! eu vou sair, vou passar 12.47mal e o que vai acontecer?', agora não, é bem tranquilo mesmo! Em casa, minha 12.48mãe pode sair à vontade, demorar, eu fico, eu fico bem"!

12.49PESQUISADORA: "Você sentiu mais liberdade"?

12.50ENTREVISTADA: "Nossa muito! Muito mesmo”!

12.51PESQUISADORA: "É a... a... você está satisfeito com a sua derivação urinária? 1

12.52é insatisfeito, 2 é pouco satisfeito, 3 é satisfeito e 4 é muito satisfeito".

12.53ENTREVISTADA: "Muito satisfeito. Muito, muito satisfeito mesmo"!

12.54PESQUISADORA: “Então, pelo que eu percebi foi muito positivo pra você né"?!

12.55ENTREVISTADA: "Foi. É... igual eu te falei né?! Eu antes não sabia que existia 12.56essa cirurgia, no momento em que me falaram eu já... eu falei: 'é isso mesmo que

12.57 eu quero! ' pra mim ia ser tudo mais fácil. Ia facilitar bastante a minha vida".

12.58PESQUISADORA: "Não tá aqui no questionário não, mas eu vou te perguntar a 12.59título de curiosidade! É... como foi a sensação pra você de você mesmo fazer seu 12.60 cateterismo"?

12.61ENTREVISTADA: "Eu já falei isso pra algumas pessoas e elas até duvidam, mas 12.62a sensação que eu tenho é como se... quando eu não era cadeirante eu sentia 
12.63vontade de ir ao sanitário e ia né?! Sentia aquele alívio; eu sinto isso agora! Minha 12.64bexiga enche, eu tenho aquela necessidade de fazer o esvaziamento e uma vez que 12.65faço eu sinto alívio, é essa a minha sensação".

12.66PESQUISADORA: “Certo. Assim, do alívio fisiológico né?! E pessoal, o que

12.67você sentiu"?

12.68ENTREVISTADA: "Fisiológico, emocional, quando eu falo assim é”...

12.69PESQUISADORA: "É porque tá envolvido tudo"!

12.70ENTREVISTADA: "É, envolvido tudo mesmo! É tanto que eu nem ligo pra

12.71 estética! Tem gente que fala: 'oh! É estranho, é esquisito! Sinceramente, eu não

12.72me incomodo"!

12.73PESQUISADORA: “É... a sua estomia ela é muito delicada, mas cada pessoa

12.74reage de uma forma a qualquer... às vezes, até um sinal de nascença, né?! Isso vai 12.75depender de cada um, né?! Você tá me falando que pra você isso não foi 12.76significante, né"?!

12.77ENTREVISTADA: “Não. Pro lado estético, não”!

12.78PESQUISADORA: “Certo”.

12.79ENTREVISTADA: "Pra mim o benefício foi tanto que pra mim é tranquilo".

12.80PESQUISADORA: "Suplanta qualquer outra situação”?

12.81ENTREVISTADA: "Isso"!

12.82AGRADECIMENTOS.

\section{ENTREVISTA P13}

13.1PESQUISADORA: "Eu vou pedir, por favor, para você fazer uma reflexão sobre 13.2qualidade de vida tanto antes quanto depois da derivação urinária e responder a 13.3pergunta para mim. O que significa para você ter qualidade de vida"?

13.4ENTREVISTADA: “É... sei lá, ter condições de suprir necessidades de forma a 13.5viver bem, englobando todos os aspectos assim é... psicológicos, físico e mental". 13.6PESQUISADORA: “O que você julga que é necessário para suprir essas 13.7necessidades"?

13.8ENTREVISTADA: "Como assim"? Sorriso.

13.9PESQUISADORA: "Você tá me dizendo que pra ter qualidade de vida precisa

13.10suprir as necessidades é... fisiológicas, psicológicas... não é?! Mas aí, mais 13.11 especificamente. O que seria isso pra você’’?

13.12ENTREVISTADA: "Não sei como responder! Sorriso. Eu fui pega de surpresa". 
13.13PESQUISADORA: "Não, fica a vontade, é tranquilo"!

13.14ENTREVISTADA: "Eu posso responder depois"? Sorriso.

13.15PESQUISADORA: "Pode, tranquilo! Depois a gente volta nessa".

13.16PESQUISADORA: "Hoje como você avalia a sua qualidade de vida? É

13.17relacionada com a pergunta anterior, você julga a sua qualidade de vida: 1 muito 13.18ruim, 2 ruim, 3 nem ruim e nem boa, 4 boa e 5 muito boa".

13.19ENTREVISTADA: "Muito boa, melhorou bastante depois da cirurgia".

13.20PESQUISADORA: “Agora a pergunta é a seguinte, é parecida com aquela, a 13.21 derivação urinária melhorou a sua qualidade de vida"?

13.22ENTREVISTADA: "Sim".

13.23PESQUISADORA: “Ai eu queria que você falasse porque"?

13.24ENTREVISTADA: "É... porque"? Porque me proporcionou mais independência, 13.25mais bem estar, sei lá, minha autoestima melhorou, acho que são questões que 13.26estão relacionadas, assim, com a cirurgia... com o que melhorou depois".

13.27PESQUISADORA: “Tenta fazer uma comparação com o que você consegue

13.28devido à derivação, na sua vida, que te dá esta sensação de qualidade de vida e que 13.29não tinha antes da derivação"?

13.30ENTREVISTADA: "Acho que na questão de estudar e de sair, sei lá, acho que 13.31ficava apreensiva antes por causa da fralda, às vezes, eu tinha que sair antes dos 13.32lugares porque molhava e tal, dormir... eu posso dormir melhor! Sem preocupar se 13.33eu vou acordar molhada".

13.34PESQUISADORA: "Hoje, você não tem mais perda"?

13.35ENTREVISTADA: “Oi”?

13.36PESQUISADORA: “Tem perdas ainda ou não"?

13.37ENTREVISTADA: "Não"!

13.38PESQUISADORA: "Não tem perdas então você acha que na questão de

13.39segurança, de independência, seria isso"?

13.40ENTREVISTADA: “Isso"!

13.41PESQUISADORA: "Porque você me disse, também, que antes precisava de ajuda, 13.42né?! Hoje você precisa ainda"?

13.43ENTREVISTADA: "Não, não”!

13.44PESQUISADORA: “Hoje, assim, onde você estiver você consegue fazer”?

13.45ENTREVISTADA: “Isso".

13.46PESQUISADORA: “Consegue”? 
13.47ENTREVISTADA: "Consigo".

13.48PESQUISADORA: "Em relação à derivação urinária, você está satisfeito com sua 13.49derivação urinária? 1 é insatisfeito, 2 é pouco satisfeito, 3 satisfeito e 4 é muito 13.50satisfeito".

13.51ENTREVISTADA: "Muito satisfeito."

13.52PESQUISADORA: “Agora voltando naquela primeira pergunta, né?! Assim, você

13.53já começou a responder mas eu queria que você falasse mais porque o objetivo do 13.54trabalho é saber o que a pessoa percebe como qualidade de vida, agora eu queria 13.55compreender o que é qualidade de vida para você”?

13.56ENTREVISTADA: "Então, como eu já falei antes é ter bem estar em vários 13.57aspectos da vida... assim... no biológico, no psicológico, na vida social".

13.58PESQUISADORA: “Entendi”.

13.59AGRADECIMENTOS.

\section{ENTREVISTA P14}

14.1PESQUISADORA: “Agora eu vou pedir para você fazer uma reflexão, pra você

14.2pensar na sua qualidade de vida, tanto antes quanto depois da derivação urinária e 14.3responder: 'O que significa para você ter qualidade de vida"'?

14.4ENTREVISTADO: “Uai! Ter qualidade de vida é, sei lá, é estar bem comigo

14.5mesmo, é estar bem de saúde é, nada me atrapalhando, alguma coisa, essas coisas 14.6assim!

14.7PESQUISADORA: "Eu queria que você falasse mais".

14.8ENTREVISTADO: "Sei lá, acho que não tem mais o que falar assim, sei lá, eu sou 14.9tranquilo, folgado e hoje eu não trabalho, fico em casa, sei lá, sou tranquilo, está

14.10bom assim! Antes era mais perturbante, às vezes, a gente preocupava mais, até por 14.11 sair por causa da urina mais... hoje não é bem mais tranquilo".

14.12PESQUISADORA: "Em relação a sua qualidade de vida você considera: 1 muito 14.13ruim, 2 ruim, 3 nem ruim e nem boa, 4 boa e 5 muito boa".

14.14ENTREVISTADO: "Vou dizer assim, 4 boa, tá boa”!

14.15PESQUISADORA: "Boa”.

14.16ENTREVISTADO: "Não tá muito boa, como se diz, tem os probleminhas de

14.17 sempre mas tá bem, graças à Deus tá bom”.

14.18PESQUISADORA: “O que são os probleminhas de sempre”? 
14.19ENTREVISTADO: "Não é... por isso, porque é esse negócio de passando sonda, 14.20isso aí, dois, três meses aí, infecçãozinha de urina, alguma coisa, esses

14.21 probleminhas que perturba a gente! Mas do contrário tá tudo bem e a questão do 14.22sexo, o sexo diminuiu pra caramba e eu não sei por que. Porque antes de fazer a 14.23cirurgia era normal, era quase igual ao que era antes do acidente. Hoje bagunçou 14.24bastante, hoje pra conseguir ficar ereto e meio complicado, sabe"?

14.25PESQUISADORA: “Certo, de fato, pela cirurgia não interfere não! Quando você 14.26vier procura conversar com o urologista que ele pode estar te orientando, também,

14.27há outras pessoas que podem estar te orientando. Agora vou te perguntar: 'A 14.28derivação urinária melhorou a sua qualidade de vida"”?

14.29ENTREVISTADO: "Melhorou, vichi! Nossa senhora! Melhorou bastante"!

14.30PESQUISADORA: "Eu queria saber, porque isso é importante para mim, como 14.31melhorou, o que melhorou"?

14.32ENTREVISTADO: "Melhorou porque antes eu não tinha paz com essa urina 14.33vazando, essas coisas, hoje eu não tenho mais esse tipo de problema, né?! Hoje, eu 14.34tenho a bexiga, não preciso ficar com sonda direto, porque antes eu tinha uma 14.35cistostomia, a sonda ficava direto, então, hoje não, hoje eu coloco a sonda para 14.36urinar, de 4 em 4 horas, melhorou bastante. Hoje não, hoje eu não preciso estar 14.37carregando bolsa, antes se eu fosse descer da cadeira tinha que descer eu com a

14.38bolsa e tudo! Hoje eu não ando assim, hoje eu não saio com aquela bolsa, até evita 14.39das pessoas tá perguntando pra que serve aquilo, porque eu estava com aquilo, eu 14.40tinha que explicar até para os cachorros na rua, então, melhorou bastante, 100 por 14.41 cento, no caso".

14.42PESQUISADORA: “Ok. Você está satisfeito com a sua derivação? 1 é

14.43insatisfeito, 2 é pouco satisfeito, 3 é satisfeito e 4 muito satisfeito".

14.44ENTREVISTADO: "Não é 3, satisfeito"!

14.45PESQUISADORA: “Satisfeito, ok”!

14.46AGRADECIMENTOS.

\section{ENTREVISTA P15}

15.1PESQUISADORA: “O que é qualidade de vida para você? O que significa para 15.2 você ter qualidade de vida"?

15.3ENTREVISTADA: "Olha, minha qualidade de vida que eu tenho é simples porque 15.4eu tenho minha vida e eu gosto. É... não sei como te explicar mas pra mim é a 
15.5melhor coisa".

15.6PESQUISADORA: “Tá mas o que é a melhor coisa para você”?

15.7ENTREVISTADA: “Só de poder estar com família, com os amigos é... todos os

15.8meus irmãos e ter uma vida boa, pra mim, já é tudo"!

15.9PESQUISADORA: "Entendi. S. como você avalia a sua qualidade de vida? 1 muito 15.10ruim, 2 ruim, 3 nem ruim e nem boa, 4 boa e 5 muito boa".

15.11ENTREVISTADA: “5”!

15.12PESQUISADORA: "Muito boa. Agora a pergunta é a seguinte: 'A derivação 15.13urinária, por onde você passa a sonda, melhorou a sua qualidade de vida"'?

15.14ENTREVISTADA: "Melhorou. Porque eu me tornei uma pessoa mais

15.15independente, entendeu? Eu não precisar tanto assim da minha mãe pra poder me 15.16ajudar, entendeu? Melhorou, também, porque eu posso sair, levar o kitizinho pra 15.17poder cuidar de mim aonde eu estiver, entendeu?! Melhorou bastante”.

15.18PESQUISADORA: “Certo. Na escola você mesmo consegue, como é”?

15.19ENTREVISTADA: "Eu mesmo consigo na escola".

15.20PESQUISADORA: “certo. Antes tinha dificuldade”?

15.21ENTREVISTADA: "Tinha".

15.22PESQUISADORA: "Então você acha que esta parte da independência, de você 15.23 mesmo cuidar de você melhorou"?

15.24ENTREVISTADA: "Melhorou".

15.25PESQUISADORA: “Certo. Isso foi bom pra você”?

15.26ENTREVISTADA: “Foi”.

15.27PESQUISADORA: “Qual a sensação que você tem”?

15.28ENTREVISTADA: “Ah a sensação... a melhor! De poder fazer tudo, de sair.”

15.29PESQUISADORA: "S. você está satisfeita com a sua derivação urinária? 1 15.30insatisfeito, 2 é pouco satisfeito, 3 é satisfeito e 4 é muito satisfeito".

15.31ENTREVISTADA: "Eu estou muito satisfeita". 15.32AGRADECIMENTOS E ESCLARECIMENTOS. 


\section{APÊNDICE F - Entrevista com os participantes (tratamento do material)}

\section{Entrevista (1)}

\begin{tabular}{|c|c|c|c|c|}
\hline Observações & Sequência & Unidades textuais de análise & Temática & Observações Conclusivas \\
\hline \multirow[t]{2}{*}{$\begin{array}{l}\text { Não ir ao pronto-socorro por causa } \\
\text { da bexiga. }\end{array}$} & $1.14 / 1.13$ & $\begin{array}{l}\text { "Ah! Tá! É... pra mim, é especialmente } \\
\text { assim depois que eu fiz a cirurgia foi não } \\
\text { ter que precisar ir mais ao pronto- } \\
\text { socorro..." }\end{array}$ & $\begin{array}{l}\text { Não ir ao pronto- } \\
\text { socorro }\end{array}$ & \multirow[t]{2}{*}{$\begin{array}{l}\text { Aspecto negativo anterior à cirurgia que } \\
\text { deixou de ocorrer. }\end{array}$} \\
\hline & $1.16 / 1.17$ & $\begin{array}{l}\text { “...eu ia ao pronto-socorro sempre! Com } \\
\text { muita febre, calafrio, era muita infecção } \\
\text { urinária que ocorria..." }\end{array}$ & Infecção urinária & \\
\hline $\begin{array}{l}\text { Qualidade de vida é não ter mais } \\
\text { infecção urinária. }\end{array}$ & $1.19 / 1.20$ & $\begin{array}{l}\text { "...eu posso tomar bastante água, pra } \\
\text { mim qualidade de vida... eu tinha muita } \\
\text { vontade de tomar água, mas não podia } \\
\text { porque a minha bexiga não segurava..." }\end{array}$ & \multirow[t]{2}{*}{ Mudança de vida } & \multirow[t]{2}{*}{$\begin{array}{l}\text { Comparando o antes com o depois da } \\
\text { derivação urinária houve uma mudança } \\
\text { significativa. }\end{array}$} \\
\hline $\begin{array}{l}\text { Não precisar de higiene íntima- não } \\
\text { dá para realizar rapidamente para } \\
\text { fazer o cateterismo. }\end{array}$ & 1.21 & $\begin{array}{l}\text { "Mudou muito a minha vida, eu sou } \\
\text { outra pessoa..." }\end{array}$ & & \\
\hline
\end{tabular}


Entrevista (1) - continuação

\begin{tabular}{|c|c|c|c|c|}
\hline Observações & Sequência & Unidades textuais de análise & Temática & Observações Conclusivas \\
\hline $\begin{array}{l}\text { Mudança: O quê mudou? } \\
\text { Temas: }\end{array}$ & 1.22 & $\begin{array}{l}\text { "...é! parece que eu acho que eu nem sou } \\
\text { mais cadeirante de tão bom que foi ..." }\end{array}$ & $\begin{array}{l}\text { Deixar de ser } \\
\text { cadeirante }\end{array}$ & $\begin{array}{l}\text { O resultado foi tão bom que compara com o } \\
\text { deixar de ser cadeirante (alcançar o normal } \\
\text { ou uma dita normalidade). }\end{array}$ \\
\hline \multirow{2}{*}{$\begin{array}{l}\text { Não depender dos outros para fazer } \\
\text { o cateterismo. }\end{array}$} & & & & \\
\hline & 1.24 & "Emagreci!... 17 quilos! Fiz uma dieta!” & Autoestima & Emagrecimento. \\
\hline $\begin{array}{l}\text { Poder fazer o cateterismo tão logo } \\
\text { se inicie os sintomas de disrreflexia. }\end{array}$ & $1.46 / 1.47$ & $\begin{array}{l}\text { "Ah! d'eu ter que ficar: 'gente! Vem } \\
\text { fazer o cate tô passando muito mal!'”, }\end{array}$ & $\begin{array}{l}\text { Independência para } \\
\text { o cateterismo }\end{array}$ & $\begin{array}{l}\text { Controle e autonomia para o cateterismo sem } \\
\text { a dependência de outras pessoas como } \\
\text { acontecia anteriormente. }\end{array}$ \\
\hline Não ter que usar fraldas. & $1.47 / 1.48$ & $\begin{array}{l}\text { "E aqueles calafrios e usar fraldas e assar } \\
\text { e eu ficar me sentindo muito mal com } \\
\text { aquela fralda, né?! Porque eu sou muito } \\
\text { vaidosa..." }\end{array}$ & Sofrimento & $\begin{array}{l}\text { Assaduras e constrangimento com o uso de } \\
\text { fraldas }\end{array}$ \\
\hline $\begin{array}{l}\text { Poder usar roupas normais } \\
\text { (calcinha, jeans e vestido). }\end{array}$ & $\begin{array}{l}1.49 / 1.50 / 1 \\
51\end{array}$ & $\begin{array}{l}\text { “...eu posso comprar calcinha... antes eu } \\
\text { nem pensava em comprar... então, eu } \\
\text { posso usar." }\end{array}$ & \multirow[t]{2}{*}{ Vaidade } & \multirow[t]{2}{*}{$\begin{array}{l}\text { Satisfação pessoal com o uso de roupas } \\
\text { femininas }\end{array}$} \\
\hline $\begin{array}{l}\text { Modificação do estilo de vida } \\
\text { (perdeu peso). }\end{array}$ & & $\begin{array}{l}\text { "...uma calça jeans apertada, eu posso } \\
\text { usar roupa normal..." }\end{array}$ & & \\
\hline $\begin{array}{l}\text { A percepção do marido da imagem } \\
\text { corporal devido a presença do } \\
\text { estoma na parede abdominal. }\end{array}$ & $\begin{array}{l}1.60 / 1.61 / 1 \\
62\end{array}$ & $\begin{array}{l}\text { “...meu marido fica incomodado um } \\
\text { pouco... aí ele pediu até... "Ah! amor faz } \\
\text { uma cirurgia plástica'..." }\end{array}$ & $\begin{array}{l}\text { Alteração da } \\
\text { imagem corporal }\end{array}$ & $\begin{array}{l}\text { O marido acha feio e pede para fazer uma } \\
\text { cirurgia plástica. }\end{array}$ \\
\hline
\end{tabular}




\begin{tabular}{|c|c|c|}
\hline Classificação Temática & Categorias Empíricas & Categorias teóricas \\
\hline Não ir ao pronto socorro & \multirow[t]{2}{*}{ Melhoria das complicações urinárias } & \multirow[t]{4}{*}{ "Qualidade de vida pra mim é...” } \\
\hline Infecção do trato urinário & & \\
\hline Sofrimento & Melhoria dos sintomas físicos e psicológicos & \\
\hline Mudança de vida & Mudança de vida & \\
\hline Deixar de ser cadeirante & \multirow[t]{3}{*}{ Melhoria da autoestima } & \multirow[t]{3}{*}{ "Não ficar perdendo xixi" } \\
\hline Autoestima & & \\
\hline Vaidade & & \\
\hline Independência para o cateterismo & Melhoria da independência para o cateterismo & "Eu tenho mais independência" \\
\hline Alteração da imagem corporal & Percepção pelo outro da imagem corporal & "Nem ligo pra estética" \\
\hline
\end{tabular}

Pesquisa de Opinião:

1. Como você avalia a sua qualidade de vida? (4 - boa)

2. Você está satisfeito com a sua derivação urinária? (4 - Muito Satisfeito)

Fatores que interferiam negativamente na qualidade de vida relacionados ao período anterior à derivação:

a) Incontinência urinária;

b) Dependência de outras pessoas para fazer o cateterismo;

c) Infecção urinária;

d) Necessidade frequente de ir ao pronto socorro;

e) Uso de fraldas;

f) Não poder ingerir bastante água;

g) Baixa autoestima;

h) Não poder usar roupas "normais". 


\section{Entrevista (2)}

\begin{tabular}{|c|c|c|c|c|}
\hline Observações & Sequência & Unidades textuais de análise & Temática & Observações Conclusivas \\
\hline Liberdade de ir e vir & $\begin{array}{l}2.14 / 2.15 / 2 \\
16\end{array}$ & $\begin{array}{l}\text { "Eu ter uma vida mais... uma vida mais } \\
\text { livre, né?! Podendo sair pra qualquer... } \\
\text { pra qualquer local, né?! A qualquer } \\
\text { momento..." }\end{array}$ & \multirow[t]{2}{*}{$\begin{array}{l}\text { Independência } \\
\text { pessoal }\end{array}$} & Restrições antes da cirurgia \\
\hline $\begin{array}{l}\text { Planejamento da vida diária } \\
\text { Lazer }\end{array}$ & $2.40 / 2.41$ & $\begin{array}{l}\text { "...conseguir organizar sua rotina, ter } \\
\text { seus momentos de lazer, tudo sem ter } \\
\text { maiores complicações." }\end{array}$ & & $\begin{array}{l}\text { Devido às perdas não estabelecia uma } \\
\text { regularidade na rotina diária. }\end{array}$ \\
\hline $\begin{array}{l}\text { Regularidade para o cateterismo em } \\
\text { um intervalo de tempo maior }\end{array}$ & $2.17 / 2.18$ & $\begin{array}{l}\text { “...eu não ficava mais preso a esta } \\
\text { questão de toda hora ter que ficar } \\
\text { fazendo o cateter, né?!" }\end{array}$ & Controle da micção & A continência favoreceu a autonomia. \\
\hline Medo de perdas urinárias & $2.20 / 2.21$ & $\begin{array}{l}\text { "É, conviver, né?! Com as pessoas, } \\
\text { com... Ter, fazer mais amizades, né?!" }\end{array}$ & Socialização & Convivência social. \\
\hline Trocas de fralda frequente & 2.21 & & Autoestima & Maior confiança para interagir \\
\hline Ter amigos & $2.25 / 2.26$ & $\begin{array}{l}\text { "Porque tirando essa questão d'eu não ter } \\
\text { mais que ficar usando a fralda, eu } \\
\text { consegui um emprego, né?!" }\end{array}$ & $\begin{array}{l}\text { Independência } \\
\text { profissional }\end{array}$ & $\begin{array}{l}\text { A continência libertou da fralda e deu } \\
\text { independência profissional. }\end{array}$ \\
\hline \multirow[t]{2}{*}{$\begin{array}{l}\text { Ter um emprego } \\
\text { Mudança no comportamento }\end{array}$} & $\begin{array}{l}2.61 / 2.62 / 2 \\
63\end{array}$ & $\begin{array}{l}\text { “...a principal vantagem dela pra mim foi } \\
\text { a questão dos vazamentos, que eu não } \\
\text { tenho mais, então, eu não passo mais } \\
\text { nenhum constrangimento em relação a } \\
\text { nada!” }\end{array}$ & \multirow[t]{3}{*}{ Vergonha } & \multirow[t]{3}{*}{$\begin{array}{l}\text { Antes da derivação tinha perdas que limitava } \\
\text { as relações sociais. }\end{array}$} \\
\hline & $2.36 / 2.37$ & & & \\
\hline Sentir seguro & & & & \\
\hline
\end{tabular}


Entrevista (2) - continuação

\begin{tabular}{|l|l|l|l|l|}
\hline \multicolumn{1}{|c|}{ Observações } & \multicolumn{1}{|c|}{ Sequência } & \multicolumn{1}{c|}{ Unidades textuais de análise } & \multicolumn{1}{c|}{ Temática } & \multicolumn{1}{c|}{ Observações conclusivas } \\
\hline Facilitou o cateterismo vesical & $2.64 / 2.65$ & $\begin{array}{l}\text { “..ficou muito mais fácil d’eu realizar o } \\
\text { cateterismo...” }\end{array}$ & Praticidade \\
\hline $\begin{array}{l}\text { Ambiente/espaço físico } \\
\text { comum }\end{array}$ & 2.65 & $\begin{array}{l}\text { “..eu consigo fazer ele em qualquer } \\
\text { lugar, né?!” }\end{array}$ & $\begin{array}{l}\text { Acessibilidade de } \\
\text { local/ambiente }\end{array}$ & $\begin{array}{l}\text { Não depende de local específico e faz seu } \\
\text { próprio cateterismo. }\end{array}$ \\
\hline $\begin{array}{l}\text { Não se sente for com o } \\
\text { cateterismo }\end{array}$ & 2.68 & “...e não sinto mais dor...” & Sofrimento & $\begin{array}{l}\text { Aspecto negativo anterior à cirurgia (que } \\
\text { deixou de ocorrer). }\end{array}$ \\
\hline
\end{tabular}

\begin{tabular}{|c|c|c|}
\hline Classificação Temática & Categorias Empíricas & Categorias teóricas \\
\hline Controle da micção & Melhoria da incontinência urinária & "Não ficar perdendo xixi" \\
\hline Vergonha & Sofrimento psicológico & \multirow[t]{3}{*}{ "Não ficar perdendo xixi" } \\
\hline Socialização & \multirow[t]{2}{*}{ Melhoria da autoestima } & \\
\hline Autoestima & & \\
\hline Independência pessoal & \multirow[t]{3}{*}{ Melhoria da independência } & \multirow[t]{3}{*}{ "Eu tenho mais independência" } \\
\hline Independência profissional & & \\
\hline Praticidade & & \\
\hline Sofrimento & Melhoria dos sintomas físicos & "Qualidade de vida pra mim é..." \\
\hline Acessibilidade local/ambiente & Aumento das oportunidades de ambientes & "Falta acessibilidade" \\
\hline
\end{tabular}

Pesquisa de Opinião:

3. Como você avalia a sua qualidade de vida? 5 ( Muito boa)

4. Você está satisfeito com a sua derivação urinária? 4 (Muito Satisfeito)

Fatores que interferiam negativamente na qualidade de vida relacionados ao período anterior à derivação:

a) Restrição devido às perdas urinárias;

b) Dor; 
c) Usar fraldas;

d) Incontinência urinária;

e) Desemprego;

f) Falta de controle sobre a vida.

\section{Entrevista (3)}

\begin{tabular}{|c|c|c|c|c|}
\hline Observações & Sequência & Unidades textuais de análise & Temática & Observações Conclusivas \\
\hline \multirow[t]{5}{*}{ Facilidade para fazer o cateterismo } & $3.6 / 3.7$ & $\begin{array}{l}\text { “...tá sendo muito mais fácil agora que... } \\
\text { um ano, dois anos atrás que eu fiz essa } \\
\text { operação, por que... fica mais prático, né?!" }\end{array}$ & \multirow[t]{5}{*}{ Praticidade } & \multirow[t]{3}{*}{$\begin{array}{l}\text { Passar o cateter pelo estoma é mais prático e } \\
\text { pode ser feito em qualquer lugar. }\end{array}$} \\
\hline & $3.24 / 3.25$ & & & \\
\hline & 3.49 & & & \\
\hline & 3.59 & & & Posicionamento do corpo ( assentado). \\
\hline & 3.65 & & & \\
\hline \multirow[t]{2}{*}{ Qualquer espaço físico } & 3.51 & "eu posso fazer em qualquer lugar..." & \multirow{2}{*}{$\begin{array}{l}\text { Acessibilidade de } \\
\text { local/ambiente }\end{array}$} & \multirow{2}{*}{$\begin{array}{l}\text { Pode fazer o cateterismo sem necessidade de } \\
\text { local específico. }\end{array}$} \\
\hline & $3.52 / 3.53$ & & & \\
\hline \multirow[t]{2}{*}{$\begin{array}{l}\text { Timidez } \\
\text { Interação social }\end{array}$} & $3.8 / 3.9$ & $\begin{array}{l}\text { “...a condição de vida melhorou outro } \\
\text { lado assim de... timidez, }\end{array}$ & \multirow[t]{2}{*}{ Socialização } & $\begin{array}{l}\text { A incontinência atrapalhava as interações } \\
\text { sociais causando }\end{array}$ \\
\hline & & $\begin{array}{l}\text { esse lado assim de... ficar perto das } \\
\text { pessoas, né?!" }\end{array}$ & & Constrangimento. \\
\hline \multirow[t]{4}{*}{$\begin{array}{l}\text { Exposição de partes íntimas do } \\
\text { corpo }\end{array}$} & $3.13 / 3.14$ & $\begin{array}{l}\text { "Pensa eu perto de você... mesmo sendo } \\
\text { no banheiro..." }\end{array}$ & \multirow[t]{4}{*}{ Vergonha } & $\begin{array}{l}\text { Aspecto negativo anterior à cirurgia (que } \\
\text { deixou de ocorrer). }\end{array}$ \\
\hline & 3.15 & & & $\begin{array}{l}\text { Dependência de outras pessoas para o } \\
\text { cateterismo uretral }\end{array}$ \\
\hline & 3.17 & & & \multirow[t]{2}{*}{ Constrangimento } \\
\hline & $3.26 / 3.27$ & & & \\
\hline $\begin{array}{l}\text { Faz o cateterismo perto de outras } \\
\text { pessoas sem inibição }\end{array}$ & $3.20 / 3.21$ & $\begin{array}{l}\text { "Eu fico mais liberal, né? Até eu faço o } \\
\text { cate aqui perto do meu tio e ele fica } \\
\text { arrepiado..." }\end{array}$ & Comportamento & Mudança de atitude \\
\hline
\end{tabular}




\begin{tabular}{|l|l|l|}
\hline \multicolumn{1}{|c|}{ Classificação Temática } & \multicolumn{1}{c|}{ Categorias Empíricas } & \multicolumn{1}{c|}{ Categorias teóricas } \\
\hline Praticidade & Autogestão no esvaziamento vesical & "Eu tenho mais independência" \\
\hline Acessibilidade de local/ambiente & Aumento das oportunidades de ambientes & "Falta acessibilidade" \\
\hline Socialização & Melhoria da autoestima & "Não ficar perdendo xixi” \\
\cline { 1 - 1 } Vergonha & Sofrimento psicológico & \\
\hline Comportamento & Comportamento & \\
\hline
\end{tabular}

Pesquisa de Opinião:

1. Como você avalia a sua qualidade de vida? (3 não é ruim e nem boa)

2. Você está satisfeito com a sua derivação urinária? (3 satisfeito)

Fatores que interferiam negativamente na qualidade de vida relacionados ao período anterior à derivação:

a) Dificuldade para o cateterização (divertículo) com posterior necessidade de cateter contínuo por cistostomia;

b) Incontinência urinária;

c) Exposição do corpo (genitália) a outras pessoas durante o cateterismo;

d) Timidez;

e) Necessidade de ajuda para fazer o cateterismo vesical. 


\section{Entrevista (4)}

\begin{tabular}{|c|c|c|c|c|}
\hline Observações & Sequência & Unidades textuais de análise & Temática & Observações Conclusivas \\
\hline \multirow[t]{5}{*}{$\begin{array}{l}\text { Apresentava infecções urinárias } \\
\text { constantes }\end{array}$} & 4.6 & $\begin{array}{l}\text { "Bom, antes da cirurgia eu ficava muito } \\
\text { com infecção urinária..." }\end{array}$ & \multirow[t]{3}{*}{ Infecção urinária } & \multirow[t]{3}{*}{$\begin{array}{l}\text { Aspecto negativo anterior à cirurgia } \\
\text { (diminuiu ou deixou de ocorrer) }\end{array}$} \\
\hline & $4.12 / 4.13$ & $\begin{array}{l}\text { "não tô tendo mais infecção urinária, } \\
\text { mais... nem febre nem mais nada!" }\end{array}$ & & \\
\hline & 4.46 & & & \\
\hline & 4.12 & “...a minha vida melhorou muita coisa!” & \multirow[t]{2}{*}{ Mudança de vida } & \multirow{2}{*}{$\begin{array}{l}\text { Comparando o antes com o depois da } \\
\text { derivação urinária }\end{array}$} \\
\hline & 4.47 & & & \\
\hline \multirow[t]{3}{*}{ Independência relativa } & $4.17 / 4.18$ & $\begin{array}{l}\text { "Melhorou porque agora eu posso passar } \\
\text { a sonda, praticamente, sozinha..." }\end{array}$ & \multirow[t]{3}{*}{$\begin{array}{l}\text { Independência para } \\
\text { o cateterismo }\end{array}$} & \multirow[t]{3}{*}{ Consegue fazer o cateterismo algumas vezes } \\
\hline & 4.48 & & & \\
\hline & 4.52 & & & \\
\hline
\end{tabular}


Entrevista (4) - continuação

\begin{tabular}{|c|c|c|c|c|}
\hline Observações & Sequência & Unidades textuais de análise & Temática & Observações Conclusivas \\
\hline \multirow[t]{3}{*}{$\begin{array}{l}\text { Acredita que ao passar o cateter } \\
\text { pode se machucar }\end{array}$} & $4.18 / 4.19$ & $\begin{array}{l}\text { "...eu tenho um pouco de medo de } \\
\text { passar, de me machucar!" }\end{array}$ & \multirow[t]{3}{*}{ Medo } & \multirow[t]{3}{*}{$\begin{array}{l}\text { Não realiza todos os cateterismos } \\
\text { Depende da presença dos pais }\end{array}$} \\
\hline & 4.21 & & & \\
\hline & 4.53 & & & \\
\hline \multirow[t]{2}{*}{ Dualismo de opinião } & $4.23 / 4.24$ & $\begin{array}{l}\text { "eu tenho que passar a sonda, eu tenho } \\
\text { que tirar esse medo..." }\end{array}$ & \multirow[t]{2}{*}{ Autoafirmação } & \multirow[t]{2}{*}{$\begin{array}{l}\text { Sente medo de fazer o cateterismo, mas não } \\
\text { quer depender de outras pessoas. }\end{array}$} \\
\hline & $4.26 / 4.27$ & & & \\
\hline $\begin{array}{l}\text { Encontra com facilidade locais para } \\
\text { o autocateterismo }\end{array}$ & 4.52 & $\begin{array}{l}\text { "eu fazer na rua, tipo no banheiro do } \\
\text { shopping..." }\end{array}$ & $\begin{array}{l}\text { Acessibilidade } \\
\text { local/ambiente }\end{array}$ & $\begin{array}{l}\text { Cita lugares públicos que pode estar fazendo } \\
\text { o cateterismo }\end{array}$ \\
\hline
\end{tabular}

\begin{tabular}{|c|c|c|}
\hline Classificação Temática & Categorias Empíricas & Categorias teóricas \\
\hline Infecção urinária & Melhoria das infecções urinárias & \multirow[t]{2}{*}{ “Qualidade de vida pra mim é...” } \\
\hline Mudança de vida & Mudança de vida & \\
\hline Independência para o cateterismo & Melhora da independência & "Eu tenho mais independência" \\
\hline Autoafirmação & Adaptação ao cateterismo pela derivação & \multirow[t]{2}{*}{ "Minha lesão" } \\
\hline Medo & Medo da manipulação do corpo & \\
\hline Acessibilidade de local/Ambiente & $\begin{array}{l}\text { Aumento das oportunidades de locais para o } \\
\text { cateterismo }\end{array}$ & "Falta acessibilidade" \\
\hline
\end{tabular}

Pesquisa de Opinião:

1. Como você avalia a sua qualidade de vida? ( 5 - muito boa)

2. Você está satisfeito com a sua derivação urinária? (4 - muito satisfeito) 
Fatores que interferiam negativamente na qualidade de vida relacionados ao período anterior à derivação:

a) Infecções urinárias;

b) Dependência de outras pessoas para realizar o cateterismo vesical;

c) Restrição dos locais para realizar o esvaziamento da bexiga.

\section{Entrevista (5)}

\begin{tabular}{|c|c|c|c|c|}
\hline Observações & Sequência & Unidades textuais de análise & Temática & Observações Conclusivas \\
\hline \multirow[t]{4}{*}{$\begin{array}{l}\text { Ser agradecido aos benefícios da } \\
\text { derivação urinária }\end{array}$} & $5.7 / 5.8$ & $\begin{array}{l}\text { "qualidade de vida é as pessoas ser mais } \\
\text { feliz, satisfeito do que... do que foi feito, } \\
\text { né?!" }\end{array}$ & \multirow[t]{4}{*}{ Satisfação } & \multirow[t]{4}{*}{$\begin{array}{l}\text { Os benefícios da derivação urinária } \\
\text { influenciam na satisfação com a vida. }\end{array}$} \\
\hline & 5.15 & & & \\
\hline & 5.16 & & & \\
\hline & 5.17 & & & \\
\hline \multirow{3}{*}{$\begin{array}{l}\text { A sonda obstruiu por muco } \\
\text { Desconhecimento das condições do } \\
\text { paciente }\end{array}$} & 5.21 & $\begin{array}{l}\text { "...tem muitos médicos aqui que não } \\
\text { entendem sobre isso..." }\end{array}$ & \multirow[t]{6}{*}{ Conhecimento } & \multirow{6}{*}{$\begin{array}{l}\text { A falta de conhecimento da equipe de saúde } \\
\text { sobre as condições urológicas do paciente } \\
\text { com lesão medular contribuiu para } \\
\text { complicações graves. }\end{array}$} \\
\hline & 5.28 & & & \\
\hline & 5.29 & & & \\
\hline \multirow{3}{*}{$\begin{array}{l}\text { Ficou UTI } \\
\text { Necessidade de cirurgia }\end{array}$} & 5.30 & & & \\
\hline & 5.31 & & & \\
\hline & $5.49 / 5.50$ & & & \\
\hline $\begin{array}{l}\text { Facilitou fazer o cateterismo e a } \\
\text { viabilidade }\end{array}$ & $5.78 / 5.79$ & $\begin{array}{l}\text { "Por causa da facilidade... da praticidade } \\
\text { de fazer o cateterismo..." }\end{array}$ & Praticidade & $\begin{array}{l}\text { Pode fazer o cateterismo sentado, sem } \\
\text { necessidade de passar para uma cama. }\end{array}$ \\
\hline
\end{tabular}


Entrevista (5) - continuação

\begin{tabular}{|c|c|c|c|c|}
\hline Observações & Sequência & Unidades textuais de análise & Temática & Observações Conclusivas \\
\hline \multirow[t]{5}{*}{$\begin{array}{l}\text { Expor partes íntimas do corpo a } \\
\text { outras pessoas que não a mãe. }\end{array}$} & $5.79 / 5.80$ & "não me sinto muito envergonhado..." & \multirow[t]{5}{*}{ Vergonha } & $\begin{array}{l}\text { Outro cuidador (sem ser a mãe) pode fazer o } \\
\text { cateterismo pela derivação sem } \\
\text { constrangimentos. }\end{array}$ \\
\hline & & & & Privacidade com o corpo. \\
\hline & 5.82 & & & \\
\hline & $5.86 / 5.87$ & & & \\
\hline & 5.96 & & & \\
\hline Sai de casa com a mãe & 5.102 & "Sair pra um lugar com a minha mãe..." & $\begin{array}{l}\text { Independência } \\
\text { pessoal }\end{array}$ & Não usa dispositivo urinário \\
\hline
\end{tabular}

\begin{tabular}{|l|l|l|}
\hline \multicolumn{1}{|c|}{ Classificação Temática } & \multicolumn{1}{c|}{ Categorias Empíricas } & \multicolumn{1}{c|}{ Categorias teóricas } \\
\hline Satisfação & Satisfação com o viver & "Qualidade de vida pra mim é..." \\
\hline Conhecimento & Qualificação profissional & "Não entendem sobre isso" \\
\hline Praticidade & Posicionamento do corpo & "Eu tenho mais independência”" \\
\hline Independência pessoal & Melhoria da independência & \\
\hline Vergonha & Sofrimento psicológico & "Não ficar perdendo xixi”" \\
\hline
\end{tabular}

Pesquisa de Opinião:

1. Como você avalia a sua qualidade de vida? $(4-$ boa)

2. Você está satisfeito com a sua derivação urinária? (3 - satisfeito) 
Fatores que interferiam negativamente na qualidade de vida relacionados ao período anterior à derivação:

a) Equipe de saúde não tinha domínio de como cuidar da pessoa com lesão medular e ampliação vesical;

b) Uso de dispositivos externos;

c) Exposição do corpo a outras pessoas ( sem ser o cuidador habitual);

d) Complicações clínicas.

\section{Entrevista (6)}

\begin{tabular}{|c|c|c|c|c|}
\hline Observações & Sequência & Unidades textuais de análise & Temática & Observações Conclusivas \\
\hline \multirow[t]{3}{*}{$\begin{array}{l}\text { Autonomia para sair de casa } \\
\text { Autossuficiência para o cateterismo }\end{array}$} & 6.10 & $\begin{array}{l}\text { "autonomia de poder ir e vir sem } \\
\text { depender dos outros de passar a sonda". }\end{array}$ & \multirow{3}{*}{$\begin{array}{l}\text { Independência para } \\
\text { or cateterismo } \\
\text { vesical }\end{array}$} & \multirow{3}{*}{$\begin{array}{l}\text { Não depende de um cuidador para esvaziar a } \\
\text { bexiga } \\
\text { Sai do ambiente doméstico }\end{array}$} \\
\hline & $6.15 / 6.16$ & & & \\
\hline & 6.49 & & & \\
\hline Praticar exercícios & $6.23 / 6.24$ & $\begin{array}{l}\text { "ter uma vida saudável é... no seu dia a } \\
\text { dia, fazer exercícios..." }\end{array}$ & $\begin{array}{l}\text { Saúde e estilo de } \\
\text { vida }\end{array}$ & $\begin{array}{l}\text { Associa a qualidade de vida com atividades } \\
\text { físicas e saúde }\end{array}$ \\
\hline $\begin{array}{l}\text { Ter moradia } \\
\text { Trabalhar }\end{array}$ & $6.24 / 6.25$ & $\begin{array}{l}\text { “...ter, sei lá, minha moradia, meu } \\
\text { emprego..." }\end{array}$ & $\begin{array}{l}\text { Determinantes } \\
\text { sociais de qualidade } \\
\text { de vida }\end{array}$ & $\begin{array}{l}\text { Ter onde morar } \\
\text { Ser autossuficiente financeiramente }\end{array}$ \\
\hline \multirow[t]{2}{*}{$\begin{array}{l}\text { Ocorrência de infecções urinária } \\
\text { repetitivas }\end{array}$} & 6.36 & $\begin{array}{l}\text { "...muito mais índice de infecção } \\
\text { urinária..." }\end{array}$ & \multirow[t]{2}{*}{ Infecção urinária } & \multirow[t]{2}{*}{$\begin{array}{l}\text { Aspecto negativo anterior à cirurgia } \\
\text { (diminuiu ou deixou de ocorrer) }\end{array}$} \\
\hline & 6.50 & & & \\
\hline
\end{tabular}


Entrevista (6) - continuação

\begin{tabular}{|c|c|c|c|c|}
\hline Observações & Sequência & Unidades textuais de análise & Temática & Observações Conclusivas \\
\hline Necessidade de local específico & $6.39 / 6.40$ & $\begin{array}{l}\text { "...tinha que ficar me limitando em ir em } \\
\text { algum local que tinha }\end{array}$ & Mudança de vida & $\begin{array}{l}\text { Compara o antes com o depois da derivação } \\
\text { ( mudança) }\end{array}$ \\
\hline & $6.39 / 6.40$ & "...um banheiro..." & \multirow[t]{5}{*}{ Mudança de vida } & \multirow{5}{*}{$\begin{array}{l}\text { Comparando o antes com o depois houve } \\
\text { uma mudança significativa. }\end{array}$} \\
\hline & $\begin{array}{l}6.41 / 6.42 / 6 \\
43\end{array}$ & $\begin{array}{l}\text { “...depois da cirurgia eu não tenho mais a } \\
\text { necessidade de ficar limitando em beber } \\
\text { água, né?! É... a qualquer momento eu } \\
\text { mesmo passo a sonda e aí eu não preciso } \\
\text { ficar dependendo de algum local que } \\
\text { tenha algum banheiro...” }\end{array}$ & & \\
\hline & 6.51 & & & \\
\hline & 6.52 & & & \\
\hline & 6.64 & & & \\
\hline $\begin{array}{l}\text { Pode passar o dia todo fora } \\
\text { Capacitação profissional }\end{array}$ & $6.57 / 6.58$ & $\begin{array}{l}\text { "...eu pude tá me capacitando mais no } \\
\text { meu trabalho, fazendo os cursos porque } \\
\text { eram cursos que eram o dia inteiro..." }\end{array}$ & $\begin{array}{l}\text { Independência para } \\
\text { o cateterismo }\end{array}$ & $\begin{array}{l}\text { Aumentou as oportunidades de qualificação } \\
\text { profissional }\end{array}$ \\
\hline Constrangimento & 6.64 & $\begin{array}{l}\text { "Era constrangedor né?! Você ficar } \\
\text { mijada!" }\end{array}$ & Perdas urinárias & $\begin{array}{l}\text { Constrangimento por estar molhada com } \\
\text { urina }\end{array}$ \\
\hline
\end{tabular}




\begin{tabular}{|l|l|l|}
\hline \multicolumn{1}{|c|}{ Classificação Temática } & \multicolumn{1}{c|}{ Categorias Empíricas } & \multicolumn{1}{c|}{ Categorias teóricas } \\
\hline Independência para o cateterismo & Melhoria da independência & "Eu tenho mais independência" \\
\hline Saúde e estilo de vida & Saúde e estilo de vida & \multirow{3}{*}{ "Qualidade de vida pra mim é...” } \\
\hline Determinantes sociais de qualidade de vida & Determinantes sociais de qualidade de vida & \\
\hline Mudança de vida & Mudança de vida & \\
\hline Infeção urinária & Melhoria das complicações urinárias & "Não ficar perdendo xixi”" \\
\hline Perdas urinárias & Melhoria da incontinência urinária & \\
\hline
\end{tabular}

\section{Pesquisa de Opinião:}

1. Como você avalia a sua qualidade de vida? (5 - muito boa)

2. Você está satisfeito com a sua derivação urinária? (4 - muito satisfeito)

Fatores que interferiam negativamente na qualidade de vida relacionados ao período anterior à derivação:

a) Infecções urinárias de repetição;

b) Não beber água;

c) Incontinência urinária;

d) Dificuldade de local/ambiente para fazer o cateterismo vesical.

\section{Entrevista (7)}

\begin{tabular}{|c|c|c|c|c|}
\hline Observações & Sequência & Unidades textuais de análise & Temática & Observações Conclusivas \\
\hline Alimentação saudável & $7.3 / 7.4$ & $\begin{array}{l}\text { "Se alimentar bem ela falou, fazer } \\
\text { exercícios..." }\end{array}$ & $\begin{array}{l}\text { Saúde e estilo de } \\
\text { vida }\end{array}$ & $\begin{array}{l}\text { Alimentação e exercícios estão relacionados } \\
\text { com qualidade de vida. }\end{array}$ \\
\hline \multirow[t]{2}{*}{$\begin{array}{l}\text { Imagina se a cirurgia tivesse sido } \\
\text { exitosa } \\
\text { Lazer }\end{array}$} & 7.14 & $\begin{array}{l}\text { "...ela sempre fala assim pra mim que se } \\
\text { tivesse dado certo essa cirurgia, era } \\
\text { muito bom pra independência dela..." }\end{array}$ & \multirow[t]{2}{*}{$\begin{array}{l}\text { Independência } \\
\text { pessoal }\end{array}$} & \multirow{2}{*}{$\begin{array}{l}\text { Independência. } \\
\text { O cateterismo pela derivação permitiria } \\
\text { maior mobilidade social (ir para outros } \\
\text { locais). } \\
\text { O autocateterismo daria mais independência. }\end{array}$} \\
\hline & 7.17 & $\begin{array}{l}\text { "Acesso a mais coisas, podia passear } \\
\text { mais, ter a independência..." }\end{array}$ & & \\
\hline
\end{tabular}


Entrevista (7) - continuação

\begin{tabular}{|c|c|c|c|c|}
\hline Observações & Sequência & Unidades textuais de análise & Temática & Observações Conclusivas \\
\hline Insucesso com a derivação & $7.24 / 7.25$ & $\begin{array}{l}\text { "...aquela expectativa que vai ser um sucesso } \\
\text { e agora aí a gente faz e..." }\end{array}$ & \multirow[t]{3}{*}{$\begin{array}{l}\text { Insatisfação com a } \\
\text { derivação }\end{array}$} & Não realiza o cateterismo pela derivação \\
\hline \multirow[t]{2}{*}{ Posição do estoma } & $7.29 / 7.30$ & $\begin{array}{l}\text { "...o que foi feito ficou muito baixo, aí } \\
\text { devido à flacidez da barriga..." }\end{array}$ & & A posição do estoma ficou inadequada \\
\hline & 7.31 & & & \\
\hline
\end{tabular}

\begin{tabular}{|l|l|l|}
\hline \multicolumn{1}{|c|}{ Classificação Temática } & \multicolumn{1}{c|}{ Categorias Empíricas } & \multicolumn{1}{c|}{ Categorias teóricas } \\
\hline Saúde e estilo de vida & Saúde e estilo de vida & "Qualidade de vida pra mim é..." \\
\hline Independência pessoal & Melhoria da independência & "Eu tenho mais independência" \\
\hline Insatisfação com a derivação urinária & Impossibilidade de cateterização do estoma & "Um pouco a reclamar" \\
\hline
\end{tabular}

Pesquisa de Opinião:

1. Como você avalia a sua qualidade de vida? (4 - boa)

2. Você está satisfeito com a sua derivação urinária? (1 - insatisfeito)

Fatores que interferiam negativamente na qualidade de vida relacionados ao período anterior à derivação:

a) Dependência;

b) Restrição social (limitação para sair de casa). 


\section{Entrevista (8)}

\begin{tabular}{|c|c|c|c|c|}
\hline Observações & Sequência & Unidades textuais de análise & Temática & Observações Conclusivas \\
\hline Necessidade de fraldas & 8.9 & "...Antes da derivação eu usava & \multirow[t]{3}{*}{ Perdas urinárias } & \multirow{3}{*}{$\begin{array}{l}\text { Perda de urina } \\
\text { Necessidade de local apropriado para trocar } \\
\text { a fralda } \\
\text { Restrição da mobilidade social (sair de casa) } \\
\text { Sem assaduras (dermatite de contato) }\end{array}$} \\
\hline \multirow{2}{*}{$\begin{array}{l}\text { Vazamento } \\
\text { Dificuldade para trocar a fralda }\end{array}$} & $8.11 / 8.12$ & & & \\
\hline & $8.22 / 8.23$ & & & \\
\hline $\begin{array}{l}\text { Diminuiu episódios de infecção } \\
\text { urinária }\end{array}$ & 8.22 & $\begin{array}{l}\text { "Eu passei a ter menos infecção } \\
\text { urinária..." }\end{array}$ & Infecção urinária & $\begin{array}{l}\text { Percebeu que houve diminuição dos } \\
\text { episódios de infecção urinária }\end{array}$ \\
\hline \multirow{5}{*}{$\begin{array}{l}\text { Mudanças após a derivação } \\
\text { urinária: } \\
\text { Passou a sair mais de casa } \\
\text { Fica sozinha em casa } \\
\text { Autonomia para sair }\end{array}$} & $8.15 / 8.16$ & $\begin{array}{l}\text { “...depois da derivação eu posso ir ao } \\
\text { shopping, passear, eu posso ir pra casa de }\end{array}$ & \multirow[t]{3}{*}{ Mudança de vida } & \multirow{3}{*}{$\begin{array}{l}\text { Aumentaram as possibilidades de } \\
\text { socialização } \\
\text { Comparando o antes com o depois houve } \\
\text { mudanças significativas }\end{array}$} \\
\hline & & amigos..." & & \\
\hline & $8.54 / 8.55$ & $\begin{array}{l}\text { "...eu posso passar o dia todo dentro de } \\
\text { casa sozinha..." }\end{array}$ & & \\
\hline & 8.52 & “...estar indo e vindo..." & \multirow{2}{*}{$\begin{array}{l}\text { Independência } \\
\text { pessoal }\end{array}$} & \multirow[t]{2}{*}{ Poder sair } \\
\hline & 8.53 & & & \\
\hline Faz o cateterismo sentada & $8.16 / 8.17$ & $\begin{array}{l}\text { "até mesmo sentada na cadeira eu posso } \\
\text { fazer a minha derivação..." }\end{array}$ & Praticidade & Faz o cateterismo na cadeira de rodas \\
\hline A lesão medular trouxe dificuldades & $8.39 / 8.40$ & $\begin{array}{l}\text { "...eu tive na minha lesão, eu tive } \\
\text { dificuldades sim..." }\end{array}$ & Enfrentamento & $\begin{array}{l}\text { Vivenciou dificuldades por ter uma lesão } \\
\text { medular }\end{array}$ \\
\hline $\begin{array}{l}\text { Dificuldade de acesso físico para } \\
\text { cadeirantes }\end{array}$ & 8.42 & falta pra mim é a acessibilidade & Acessibilidade & $\begin{array}{l}\text { Aspecto negativo relacionado a qualidade de } \\
\text { vida }\end{array}$ \\
\hline Sente falta de ajuda & $8.43 / 8.44$ & $\begin{array}{l}\text { "...uma pessoa que tivesse do meu } \\
\text { lado...que pudesse me ajudar..." }\end{array}$ & Desamparo & Não tem uma pessoa para ajudar \\
\hline
\end{tabular}




\begin{tabular}{|l|l|l|}
\hline \multicolumn{1}{|c|}{ Classificação Temática } & \multicolumn{1}{c|}{ Categorias Empíricas } \\
\hline Perdas urinárias & Melhoria da incontinência urinária & "Não ficar perdendo xixi”" \\
\hline Mudança de vida & Mudança de vida & "Qualidade de vida pra mim é..." \\
\hline Infecção urinária & Melhoria das complicações urinárias & \\
\hline Acessibilidade & Déficit de acessibilidade & "Falta acessibilidade" \\
\hline Enfrentamento & Lesão medular & "Minha lesão" \\
\hline Desamparo & & \\
\hline Praticidade & Posicionamento do corpo & \\
\hline Independência pessoal & Melhoria da independência & \\
\hline
\end{tabular}

Pesquisa de Opinião:

1. Como você avalia a sua qualidade de vida? (3 - nem ruim e nem boa)

2. Você está satisfeito com a sua derivação urinária? (4 - muito satisfeito)

Fatores que interferiam negativamente na qualidade de vida relacionados ao período anterior à derivação:

a) Restrição da mobilidade social (passeio);

b) Infecção urinária;

c) Incontinência urinária;

d) Dependência de um cuidador;

e) Uso de fralda;

f) Lesão medular. 


\section{Entrevista (9)}

\begin{tabular}{|c|c|c|c|c|}
\hline Observações & Sequência & Unidades textuais de análise & Temática & Observações Conclusivas \\
\hline $\begin{array}{l}\text { Percepção de uma qualidade de } \\
\text { vida ruim }\end{array}$ & $9.4 / 9.5$ & $\begin{array}{l}\text { "...a qualidade de vida não era muito boa } \\
\text { antes da derivação..." }\end{array}$ & \multirow[t]{2}{*}{ Mudança de vida } & \multirow[t]{2}{*}{$\begin{array}{l}\text { Comparando o antes com o depois houve } \\
\text { mudanças significativas }\end{array}$} \\
\hline Com energia e meta para viver & 9.6 & $\begin{array}{l}\text { "...tive mais disposição, mais, mais } \\
\text { foco... na vida!" }\end{array}$ & & \\
\hline \multirow[t]{3}{*}{$\begin{array}{l}\text { Alimentação } \\
\text { Fazer atividade física } \\
\text { Não ter complicações de saúde }\end{array}$} & $9.7 / 9.8$ & $\begin{array}{l}\text { "Qualidade de vida pra mim é manter a } \\
\text { saúde em dia, manter boa alimentação, } \\
\text { fazer exercícios..." }\end{array}$ & \multirow[t]{3}{*}{$\begin{array}{l}\text { Saúde e estilo de } \\
\text { vida }\end{array}$} & \multirow[t]{3}{*}{$\begin{array}{l}\text { Boa saúde, alimentação e fazer atividade } \\
\text { física é qualidade de vida }\end{array}$} \\
\hline & 9.21 & & & \\
\hline & 9.23 & & & \\
\hline $\begin{array}{l}\text { Não perder urina perto de outras } \\
\text { pessoas é positivo }\end{array}$ & 9.19 & $\begin{array}{l}\text { "Em relação a tá com outras pessoas, a não } \\
\text { ficar perdendo xixi..." }\end{array}$ & Perdas urinárias & Não perde urina perto de outras pessoas \\
\hline $\begin{array}{l}\text { Controla o horário de esvaziar a } \\
\text { bexiga }\end{array}$ & 9.20 & $\begin{array}{l}\text { “...saber qual o horário de esvaziar ou } \\
\text { não..." }\end{array}$ & Controle da micção & Esvazia a bexiga em intervalos regulares \\
\hline Usa bolsa coletora de urina & $9.23 / 9.24$ & $\begin{array}{l}\text { "Antes dela eu tinha muitos problemas... } \\
\text { muitos problemas com aquela bolsa..." }\end{array}$ & $\begin{array}{l}\text { Dispositivos } \\
\text { urinários externos }\end{array}$ & $\begin{array}{l}\text { O uso do coletor urinário era considerado } \\
\text { um problema }\end{array}$ \\
\hline
\end{tabular}

\begin{tabular}{|c|c|c|}
\hline Classificação Temática & Categorias Empíricas & Categorias teóricas \\
\hline Mudança de vida & Mudança de vida & \multirow[t]{2}{*}{ "Qualidade de vida pra mim é..." } \\
\hline Saúde e estilo de vida & Saúde e estilo de vida & \\
\hline Perdas urinárias & \multirow[t]{2}{*}{ Melhoria da incontinência urinária } & \multirow[t]{3}{*}{ "Não ficar perdendo xixi" } \\
\hline Controle da micção & & \\
\hline Dispositivos urinários externos & Deixar de usar dispositivos urinários externos & \\
\hline
\end{tabular}




\section{Pesquisa de Opinião:}

1. Como você avalia a sua qualidade de vida? (4 - boa)

2. Você está satisfeito com a sua derivação urinária? (3 - satisfeito)

Fatores que interferiam negativamente na qualidade de vida relacionados ao período anterior à derivação:

a) Incontinência urinária;

b) Uso de dispositivo urinário externo.

\section{Entrevista (10)}

\begin{tabular}{|c|c|c|c|c|}
\hline Observações & Sequência & Unidades textuais de análise & Temática & Observações Conclusivas \\
\hline \multirow[t]{6}{*}{ Ser independente } & 10.5 & $\begin{array}{l}\text { "...eu acho que eu era feliz e não sabia. É } \\
\text { a independência..." }\end{array}$ & \multirow[t]{6}{*}{ Independência } & \multirow{6}{*}{$\begin{array}{l}\text { Antes da lesão não dependia de outras } \\
\text { pessoas } \\
\text { Autocuidar-se }\end{array}$} \\
\hline & 10.8 & "fazer as coisas sozinha..." & & \\
\hline & 10.32 & & & \\
\hline & $\begin{array}{l}10.38 / \\
10.39\end{array}$ & & & \\
\hline & 10.82 & & & \\
\hline & 10.83 & & & \\
\hline \multirow{2}{*}{$\begin{array}{l}\text { Emprego, mãe, esposa } \\
\text { Vida conjugal e social }\end{array}$} & 10.33 & $\begin{array}{l}\text { "eu trabalhava, eu tinha uma vida muito } \\
\text { ativa antes da lesão..." }\end{array}$ & \multirow[t]{2}{*}{ Papéis sociais } & \multirow{2}{*}{$\begin{array}{l}\text { Vinculo com um emprego } \\
\text { Cuidados com os filhos } \\
\text { Saia para encontros sociais }\end{array}$} \\
\hline & 10.34 & & & \\
\hline
\end{tabular}


Entrevista (10) - continuação

\begin{tabular}{|c|c|c|c|c|}
\hline Observações & Sequência & Unidades textuais de análise & Temática & Observações Conclusivas \\
\hline \multirow{3}{*}{$\begin{array}{l}\text { Saia com horário programado de } \\
\text { volta } \\
\text { Independência parcial } \\
\text { Depois da derivação pôde } \\
\text { permanecer longos períodos fora de } \\
\text { casa }\end{array}$} & $\begin{array}{l}10.11 / \\
10.12\end{array}$ & $\begin{array}{l}\text { “eu até saia antes da derivação eu já } \\
\text { tinha cadeira motorizada, mas eu tinha } \\
\text { um prazo pra voltar..." }\end{array}$ & \multirow[t]{5}{*}{ Mudança de vida } & $\begin{array}{l}\text { Saia com horário para voltar } \\
\text { Percebe que a independência atual (depois } \\
\text { da derivação) é maior }\end{array}$ \\
\hline & 10.17 & & & Fica períodos longos fora de casa \\
\hline & 10.19 & & & $\begin{array}{l}\text { A mãe não necessita ficar o dia todo para } \\
\text { prestar cuidados }\end{array}$ \\
\hline \multirow[t]{2}{*}{$\begin{array}{l}\text { Requer menos ajuda da mãe nos } \\
\text { cuidados }\end{array}$} & $\begin{array}{l}10.73 / \\
10.74 / \\
10.75\end{array}$ & $\begin{array}{l}\text { “...minha mãe vem pra cá todos os dias } \\
\text { me ajudar, na minha casa, aí assim, antes } \\
\text { eu precisava que ela ficasse aqui um } \\
\text { tempo muito maior do que ela fica hoje." }\end{array}$ & & \multirow[t]{2}{*}{ Mobilidade social (pode sair) } \\
\hline & $\begin{array}{l}10.76 / \\
10.77 / \\
10.78 / \\
10.79 / \\
10.80\end{array}$ & & & \\
\hline \multirow[t]{4}{*}{ Perda fecal } & $\begin{array}{l}10.61 / \\
10.62\end{array}$ & $\begin{array}{l}\text { "...às vezes, acontece de ter diarreia, } \\
\text { sabe?" }\end{array}$ & \multirow[t]{4}{*}{ Incontinência fecal } & \multirow{4}{*}{$\begin{array}{l}\text { Evacua fora de hora (perdas) } \\
\text { Compara como a situação mais } \\
\text { Negativa entre outras que envolve a lesão } \\
\text { medular }\end{array}$} \\
\hline & 10.63 & & & \\
\hline & 10.65 & & & \\
\hline & 10.66 & & & \\
\hline Perda de urina & $\begin{array}{l}10.13 / \\
10.14\end{array}$ & $\begin{array}{l}\text { “...constrangimentos poderiam acontecer } \\
\text { a qualquer momento, porque eu perdia } \\
\text { né?!" }\end{array}$ & Perdas urinárias & Ficava constrangida quando perdia urina \\
\hline $\begin{array}{l}\text { Não precisa de uma pessoa para } \\
\text { esvaziar a bexiga }\end{array}$ & $\begin{array}{l}10.20 / \\
10.21\end{array}$ & $\begin{array}{l}\text { "...cada vez que eu precisar fazer o xixi é } \\
\text { só ter um banheiro..." }\end{array}$ & Controle da micção & $\begin{array}{l}\text { Para esvaziar a bexiga requer apenas o } \\
\text { banheiro e o material. }\end{array}$ \\
\hline
\end{tabular}




\begin{tabular}{|l|l|l|}
\hline \multicolumn{1}{|c|}{ Classificação Temática } & \multicolumn{1}{c|}{ Categorias Empíricas } & \multicolumn{1}{c|}{ Categorias teóricas } \\
\hline Mudança de vida & Mudança de vida & "Qualidade de vida pra mim é..." \\
\hline Independência & Melhoria da independência & "Eu tenho mais independência" \\
\hline Papéis sociais & Papéis sociais & "Eu tinha uma vida muito ativa” \\
\hline Incontinência fecal & Incontinência fecal & "Não ficar perdendo xixi” \\
\hline Perdas urinárias & Melhoria da incontinência urinária & \\
\hline Controle da micção & & \\
\hline
\end{tabular}

\section{Pesquisa de Opinião:}

1. Como você avalia a sua qualidade de vida? (4 - boa)

2. Você está satisfeito com a sua derivação urinária? (4 - muito satisfeito)

Fatores que interferiam negativamente na qualidade de vida relacionados ao período anterior à derivação:

a) Dependência de um cuidador/familiar para as atividades de vida diária (transferências, banho, higiene, etc.);

b) Limitação imposta pela lesão medular (trabalho, vida social, ser mãe, esposa);

c) Tempo controlado para estar fora de casa;

d) Incontinências: urinária e fecal. 


\section{Entrevista (11)}

\begin{tabular}{|c|c|c|c|c|}
\hline Observações & Sequência & Unidades textuais de análise & Temática & Observações Conclusivas \\
\hline \multirow{9}{*}{$\begin{array}{l}\text { Deseja reclamar sobre a derivação } \\
\text { Apresenta cefaléia e arrepios } \\
\text { Local do estoma }\end{array}$} & 11.6/11.7 & $\begin{array}{l}\text { "Eu só tenho um pouco a reclamar dessa } \\
\text { derivação que foi feita"! }\end{array}$ & \multirow[t]{9}{*}{$\begin{array}{l}\text { Insatisfação com a } \\
\text { derivação }\end{array}$} & \multirow[t]{5}{*}{$\begin{array}{l}\text { Reclama da derivação urinária feita } \\
\text { Queixa de sintomas de disrreflexia }\end{array}$} \\
\hline & $\begin{array}{l}11.10 / \\
11.11\end{array}$ & & & \\
\hline & 11.13 & "Eu não tinha dor de cabeça..." & & \\
\hline & $\begin{array}{l}11.15 / \\
11.16\end{array}$ & & & \\
\hline & $\begin{array}{l}11.18 / \\
11.19\end{array}$ & & & \\
\hline & $\begin{array}{l}11.67 / \\
11.68\end{array}$ & $\begin{array}{l}\text { "...se a derivação tivesse num } \\
\text { posicionamento melhor poderia estar te } \\
\text { ajudando mais não é?" }\end{array}$ & & Insatisfação com a localização do estoma \\
\hline & 11.71 & “...onde ficou é impossível." & & \multirow[t]{3}{*}{ Não consegue fazer o autocateterismo } \\
\hline & 11.74 & & & \\
\hline & 11.77 & & & \\
\hline
\end{tabular}


Entrevista (11) - continuação

\begin{tabular}{|c|c|c|c|c|}
\hline Observações & Sequência & Unidades textuais de análise & Temática & Observações Conclusivas \\
\hline \multirow{4}{*}{$\begin{array}{l}\text { Diminuir o grau de dependência da } \\
\text { mãe para os cuidados } \\
\text { Confia em outra pessoa nos } \\
\text { cuidados }\end{array}$} & $\begin{array}{l}11.29 / \\
11.30\end{array}$ & $\begin{array}{l}\text { "...eu ter mais independência, né?! Eu } \\
\text { depender menos da minha mãe..." }\end{array}$ & \multirow[t]{3}{*}{$\begin{array}{l}\text { Dependência da } \\
\text { mãe }\end{array}$} & \multirow{3}{*}{$\begin{array}{l}\text { Depende menos da presença da mãe para os } \\
\text { cuidados } \\
\text { Confia em outra pessoa (diferente da mãe) } \\
\text { para fazer o cateterismo } \\
\text { Vesical }\end{array}$} \\
\hline & 11.31 & & & \\
\hline & $\begin{array}{l}11.39 / \\
11.40\end{array}$ & & & \\
\hline & $\begin{array}{l}11.32 / \\
11.33\end{array}$ & $\begin{array}{l}\text { "...eu já tenho confiança de outras } \\
\text { pessoas fazer pra mim..." }\end{array}$ & Confiança & $\begin{array}{l}\text { Confia em outra pessoa diferente da mãe } \\
\text { fazer o cateterismo } \\
\text { Não ficará com a genitália exposta }\end{array}$ \\
\hline $\begin{array}{l}\text { Sem exposição de partes íntimas do } \\
\text { corpo (genitália) }\end{array}$ & $\begin{array}{l}11.54 / \\
11.55\end{array}$ & $\begin{array}{l}\text { "Não preciso ficar me expondo mais, o } \\
\text { meu órgão, pra pessoa fazer o } \\
\text { cateterismo..." }\end{array}$ & Vergonha & Não é preciso expor a genitália. \\
\hline $\begin{array}{l}\text { Facilidade para fazer o cateterismo } \\
\text { vesical }\end{array}$ & $\begin{array}{l}11.64 / \\
11.65\end{array}$ & $\begin{array}{l}\text { "...facilitou fazer o cateterismo mesmo } \\
\text { dependendo de outras pessoas..." }\end{array}$ & Praticidade & O cateterismo ficou mais fácil de ser feito \\
\hline
\end{tabular}

\begin{tabular}{|l|l|l|}
\hline \multicolumn{1}{|c|}{ Classificação Temática } & \multicolumn{1}{c|}{ Categorias Empíricas } & \multicolumn{2}{c|}{ Categorias teóricas } \\
\hline Insatisfação com a derivação urinária & Insatisfação com a derivação & "Qualidade de vida pra mim é..." \\
\hline Dependência da mãe & Mudança de vida & \multirow{2}{*}{ "Não ficar perdendo xixi”" } \\
\hline Confiança & Confiança & "Eu tenho mais independência” \\
\hline Vergonha & Sofrimento psicológico & Posicionamento do corpo \\
\hline Praticidade & & \\
\hline
\end{tabular}




\section{Pesquisa de Opinião:}

1. Como você avalia a sua qualidade de vida? (3 - nem ruim e nem boa)

2. Você está satisfeito com a sua derivação urinária? (4 - muito satisfeito)

Fatores que interferiam negativamente na qualidade de vida relacionados ao período anterior à derivação:

a) Dependência da mãe para os cuidados;

b) Exposição do corpo (genitália).

\section{Entrevista (12)}

\begin{tabular}{|c|c|c|c|c|}
\hline Observações & Sequência & Unidades textuais de análise & Temática & Observações Conclusivas \\
\hline $\begin{array}{l}\text { Aceita as condições de uma pessoa } \\
\text { com lesão medular }\end{array}$ & $\begin{array}{l}12.10 / \\
12.11\end{array}$ & $\begin{array}{l}\text { "Qualidade de vida pra mim é tá bem } \\
\text { comigo mesma, me aceitando do jeito } \\
\text { que eu sou não é?! Do jeito que eu } \\
\text { estou..." }\end{array}$ & Resiliência & $\begin{array}{l}\text { Se aceita com uma lesão medular, ser } \\
\text { resiliente }\end{array}$ \\
\hline \multirow{3}{*}{$\begin{array}{l}\text { Saúde } \\
\text { Atividade física } \\
\text { Alimentação }\end{array}$} & $\begin{array}{l}12.11 / \\
12.12\end{array}$ & $\begin{array}{l}\text { "...ter uma boa saúde, tá bem com as } \\
\text { pessoas..." }\end{array}$ & \multirow[t]{3}{*}{$\begin{array}{l}\text { Saúde e estilo de } \\
\text { vida }\end{array}$} & \multirow[t]{3}{*}{$\begin{array}{l}\text { Boa saúde, alimentação e fazer atividade } \\
\text { física é qualidade de vida }\end{array}$} \\
\hline & 12.16 & & & \\
\hline & 12.21 & & & \\
\hline Liberdade para ir e vir & 12.15 & "...ir à igreja... ah! poder viajar..." & $\begin{array}{l}\text { Independência } \\
\text { pessoal }\end{array}$ & Restrições antes da cirurgia \\
\hline
\end{tabular}


Entrevista (12) - continuação

\begin{tabular}{|c|c|c|c|c|}
\hline Observações & Sequência & Unidades textuais de análise & Temática & Observações Conclusivas \\
\hline \multirow[t]{2}{*}{$\begin{array}{l}\text { Falta acessibilidade nos ambientes } \\
\text { físicos }\end{array}$} & 12.17 & “...ter acessibilidade." & Acessibilidade & $\begin{array}{l}\text { Dificulta: } \\
\text { o acesso a ambientes agradáveis; } \\
\text { a locomoção pela cidade. }\end{array}$ \\
\hline & $\begin{array}{l}12.28 / \\
12.29\end{array}$ & & \multirow[t]{3}{*}{ Acessibilidade } & Necessita estar acompanhada para sair. \\
\hline \multirow[t]{2}{*}{ Depende de outra pessoa para sair } & $\begin{array}{l}12.32 / \\
12.33\end{array}$ & & & \multirow[t]{2}{*}{$\begin{array}{l}\text { A falta de acessibilidade requer um } \\
\text { automóvel. }\end{array}$} \\
\hline & 12.35 & & & \\
\hline \multirow[t]{2}{*}{$\begin{array}{l}\text { Ansiedade ao sair } \\
\text { Saia com tempo programado para } \\
\text { voltar }\end{array}$} & $\begin{array}{l}12.43 / \\
12.44\end{array}$ & $\begin{array}{l}\text { “...antes eu tinha receio de sair, } \\
\text { ficava até difícil de ir a um lugar, era } \\
\text { tudo aquele tempo certinho..." }\end{array}$ & \multirow[t]{2}{*}{ Mudança de vida } & \multirow[t]{2}{*}{$\begin{array}{l}\text { Comparando o antes com o depois houve } \\
\text { uma mudança significativa } \\
\text { Dependia de local adequado para fazer o } \\
\text { cateterismo. }\end{array}$} \\
\hline & 12.45 & & & \\
\hline \multirow{3}{*}{$\begin{array}{l}\text { Mudança: o que mudou? } \\
\text { Temas: } \\
\text { Não depender de outros para } \\
\text { fazer o cateterismo }\end{array}$} & 12.62 & $\begin{array}{l}\text { "...a sensação que eu tenho é como } \\
\text { se... quando eu não era cadeirante..." }\end{array}$ & \multirow[t]{3}{*}{$\begin{array}{l}\text { Deixar de ser } \\
\text { cadeirante }\end{array}$} & \multirow{2}{*}{$\begin{array}{l}\text { O resultado foi tão bom que compara } \\
\text { com o deixar de ser cadeirante (alcançar } \\
\text { o normal, ou uma dita normalidade). } \\
\text { Tem sensação de bexiga cheia, faz o } \\
\text { autocateterismo e sente alívio. } \\
\text { Como se não tivesse lesão medular }\end{array}$} \\
\hline & $\begin{array}{l}12.64 / \\
12.65\end{array}$ & $\begin{array}{l}\text { "Minha bexiga enche, eu tenho } \\
\text { aquela necessidade de fazer o } \\
\text { esvaziamento e uma vez que faço eu } \\
\text { sinto alívio..." }\end{array}$ & & \\
\hline & $\begin{array}{l}12.47 / \\
12.48\end{array}$ & $\begin{array}{l}\text { “...minha mãe pode sair à vontade, } \\
\text { demorar, eu fico, eu fico bem!" }\end{array}$ & & \\
\hline $\begin{array}{l}\text { Outras pessoas consideram a } \\
\text { estomia estranha, esquisita. }\end{array}$ & $\begin{array}{l}12.71 / \\
12.72\end{array}$ & $\begin{array}{l}\text { "...nem ligo pra estética!" } \\
\text { "Sinceramente, eu não me } \\
\text { incomodo!" }\end{array}$ & $\begin{array}{l}\text { Alteração da } \\
\text { imagem corporal }\end{array}$ & $\begin{array}{l}\text { Considera o benefício da derivação } \\
\text { superior a alteração na imagem corporal. }\end{array}$ \\
\hline
\end{tabular}




\begin{tabular}{|l|l|l|}
\hline \multicolumn{1}{|c|}{ Classificação Temática } & \multicolumn{1}{c|}{ Categorias Empíricas } & \multicolumn{1}{c|}{ Categorias teóricas } \\
\hline Resiliência & Lesão Medular & "Minha lesão" \\
\hline Acessibilidade & Déficit de acessibilidade & "Falta acessibilidade" \\
\hline Saúde e estilo de vida & Saúde e estilo de vida & "Qualidade de vida pra mim é...” \\
\hline Mudança de vida & Mudançade vida & \\
\hline Independência & Melhoria da independência & "Eu tenho mais independência" \\
\hline Deixar de ser cadeirante & Melhoria da incontinência urinária & "Não ficar perdendo xixi”" \\
\hline Alteração da imagem corporal & Autopercepção do corpo & "Nem ligo pra estética" \\
\hline
\end{tabular}

Pesquisa de Opinião:

1. Como você avalia a sua qualidade de vida? (4 - Boa)

2. Você está satisfeito com a sua derivação urinária? (4 - muito satisfeito)

Fatores que interferiam negativamente na qualidade de vida relacionados ao período anterior à derivação:

a) Disrreflexia;

b) Necessidade de acompanhamento constante da mãe;

c) Restrição da mobilidade social ( saia com tempo predeterminado de voltar);

d) Falta de acessibilidade para realizar o cateterismo assistido. 


\section{Entrevista (13)}

\begin{tabular}{|c|c|c|c|c|}
\hline Observações & Sequência & Unidades textuais de análise & Temática & Observações Conclusivas \\
\hline $\begin{array}{l}\text { Possuir condições psicossociais que } \\
\text { favoreçam o viver bem }\end{array}$ & $13.4 / 13.5$ & $\begin{array}{l}\text { “...ter condições de suprir necessidades } \\
\text { de forma a viver bem, englobando todos } \\
\text { os aspectos assim é... psicológicos, físico } \\
\text { e mental." }\end{array}$ & Viver bem & Suprir necessidades para viver bem \\
\hline \multirow[t]{4}{*}{$\begin{array}{l}\text { Não precisa mais de ajuda para } \\
\text { fazer o cateterismo }\end{array}$} & 13.24 & $\begin{array}{l}\text { “...me proporcionou mais } \\
\text { independência..." }\end{array}$ & \multirow[t]{4}{*}{ Independência } & \multirow[t]{4}{*}{$\begin{array}{l}\text { Pode sair para estudar } \\
\text { Faz o autocateterismo }\end{array}$} \\
\hline & $13.41 /$ & & & \\
\hline & 13.42 & & & \\
\hline & 13.43 & & & \\
\hline $\begin{array}{l}\begin{array}{l}\text { Percepção de melhora da } \\
\text { autoestima }\end{array} \\
\text { a d }\end{array}$ & 13.25 & "...minha autoestima melhorou..." & Autoestima & $\begin{array}{l}\text { Compara a autoestima antes com depois da } \\
\text { derivação }\end{array}$ \\
\hline $\begin{array}{l}\text { Necessidade de fralda } \\
\text { Perdas urinárias }\end{array}$ & $\begin{array}{l}13.31 / \\
13.32\end{array}$ & $\begin{array}{l}\text { “...ficava apreensiva antes por causa da } \\
\text { fralda, às vezes, eu tinha que sair antes } \\
\text { dos lugares porque molhava...” }\end{array}$ & Perdas urinárias & $\begin{array}{l}\text { Apreensão pelo uso da fralda } \\
\text { Perda de urina antecipava seu retorno }\end{array}$ \\
\hline
\end{tabular}

\begin{tabular}{|l|l|l|}
\hline \multicolumn{1}{|c|}{ Classificação Temática } & \multicolumn{1}{c|}{ Categorias Empíricas } & \multirow{2}{*}{ Categorias teóricas } \\
\hline Viver bem & Determinantes sociais de qualidade de vida & \\
\hline Autoestima & Autoestima & "Não ficar perdendo xixi...” \\
\hline Perdas urinárias & Melhoria da incontinência urinária & "Eu tenho mais independência” pra mim é...” \\
\hline Independência & Melhoria da independência & "Eua \\
\hline
\end{tabular}


Pesquisa de Opinião:

1. Como você avalia a sua qualidade de vida? (5 - Muito boa)

2. Você está satisfeito com a sua derivação urinária? (4 - muito satisfeito)

Fatores que interferiam negativamente na qualidade de vida relacionados ao período anterior à derivação:

a) Perdas urinárias;

b) Uso de fraldas;

c) Dependência de outra pessoa para fazer o cateterismo;

d) Baixa autoestima.

\section{Entrevista (14)}

\begin{tabular}{|c|c|c|c|c|}
\hline Observações & Sequência & Unidades textuais de análise & Temática & Observações Conclusivas \\
\hline \multirow[t]{4}{*}{$\begin{array}{l}\text { Bem-estar psicológico } \\
\text { Saúde }\end{array}$} & 14.4 & $\begin{array}{l}\text { "...estar bem comigo mesmo..." é estar } \\
\text { bem de saúde..." }\end{array}$ & \multirow[t]{3}{*}{ Autoestima } & \multirow[t]{3}{*}{ Estar bem consigo } \\
\hline & $14.8 / 14.9$ & & & \\
\hline & 14.10 & & & \\
\hline & 14.5 & “...é estar bem de saúde...” & $\begin{array}{l}\text { Saúde e estilo de } \\
\text { vida }\end{array}$ & Não estar doente \\
\hline $\begin{array}{l}\text { Maior preocupação devida à perda } \\
\text { de urina }\end{array}$ & $\begin{array}{l}14.10 / \\
14.11\end{array}$ & $\begin{array}{l}\text { "Antes era mais perturbante, às vezes, a } \\
\text { gente preocupava mais, até por sair por } \\
\text { causa da urina..." }\end{array}$ & \multirow[t]{2}{*}{ Perdas urinárias } & $\begin{array}{l}\text { A perda urinária perturbava antes da } \\
\text { derivação }\end{array}$ \\
\hline $\begin{array}{l}\text { Perda de urina contínua pela } \\
\text { cistostomia }\end{array}$ & $\begin{array}{l}14.32 / \\
14.33\end{array}$ & $\begin{array}{l}\text { "...antes eu não tinha paz com essa urina } \\
\text { vazando..." }\end{array}$ & & Desditoso pela perda urinária \\
\hline
\end{tabular}


Entrevista (14) - continuação

\begin{tabular}{|c|c|c|c|c|}
\hline Observações & Sequência & Unidades textuais de análise & Temática & Observações Conclusivas \\
\hline \multirow[t]{3}{*}{ Uso de bolsa coletora de urina } & $\begin{array}{l}14.34 / \\
14.35\end{array}$ & $\begin{array}{l}\text { “...porque antes eu tinha uma } \\
\text { cistostomia, a sonda ficava direto..." }\end{array}$ & \multirow[t]{3}{*}{$\begin{array}{l}\text { Uso de dispositivo } \\
\text { urinário }\end{array}$} & \multirow{3}{*}{$\begin{array}{l}\text { Presença de cistostomia } \\
\text { Satisfação por não necessitar de coletor } \\
\text { urinário externo }\end{array}$} \\
\hline & $\begin{array}{l}14.36 / \\
14.37\end{array}$ & “...não preciso estar carregando bolsa..." & & \\
\hline & $\begin{array}{l}14.38 / \\
14.39\end{array}$ & & & \\
\hline $\begin{array}{l}\text { Apresenta infecção de urina } \\
\text { recorrente }\end{array}$ & $\begin{array}{l}14.19 / \\
14.20\end{array}$ & $\begin{array}{l}\text { “...esse negócio de passando sonda...isso } \\
\text { aí, dois, três meses aí, } \\
\text {...infecçãozinha de urina...” }\end{array}$ & Infecção urinária & $\begin{array}{l}\text { Infecções urinárias frequentes (aspecto } \\
\text { negativo anterior à cirurgia) }\end{array}$ \\
\hline \multirow[t]{3}{*}{ Sexualidade } & 14.22 & $\begin{array}{l}\text { "... sexo diminuiu pra caramba e eu não } \\
\text { sei porquê." }\end{array}$ & \multirow[t]{3}{*}{ Sexo } & \multirow[t]{3}{*}{$\begin{array}{l}\text { Disfunção sexual (crença que a piora advém } \\
\text { com a derivação) }\end{array}$} \\
\hline & 14.23 & & & \\
\hline & 14.24 & & & \\
\hline
\end{tabular}

\begin{tabular}{|l|l|l|}
\hline \multicolumn{1}{|c|}{ Classificação Temática } & \multicolumn{1}{c|}{ Categorias Empíricas } & \multirow{2}{*}{ "Qualegorias teóricas } \\
\hline Autoestima & Autoestima & \\
\hline Saúde e estilo de vida & Saúde e estilo de vida & \multirow{2}{*}{ "Não ficar perdendo xida pra mim é...” } \\
\hline Infecção urinária & Infecções urinárias recorrentes & \\
\hline Perdas urinárias & Melhoria da incontinência urinária & "O sexo diminuiu" \\
\hline Dispositivos urinários externos & Deixar de usar dispositivos urinários & \\
\hline Sexo & Atividade sexual & \\
\hline
\end{tabular}

Pesquisa de Opinião:

1. Como você avalia a sua qualidade de vida? (4 - boa) 
2. Você está satisfeito com a sua derivação urinária? (3 - satisfeito)

Fatores que interferiam negativamente na qualidade de vida relacionados ao período anterior à derivação:

a) Necessidade de cistostomia;

b) Uso de dispositivo urinário externo;

c) Perdas urinárias contínuas.

\section{Entrevista (15)}

\begin{tabular}{|c|c|c|c|c|}
\hline Observações & Sequência & Unidades textuais de análise & Temática & Observações Conclusivas \\
\hline $\begin{array}{l}\text { Qualidade de vida é estar com a } \\
\text { família e amigos }\end{array}$ & $15.7 / 15.8$ & $\begin{array}{l}\text { "Só de poder estar com família, com os } \\
\text { amigos é... todos os meus irmãos e ter } \\
\text { uma vida boa..." }\end{array}$ & Rede de apoio & $\begin{array}{l}\text { Estar (conviver) com outras pessoas } \\
\text { significativas }\end{array}$ \\
\hline $\begin{array}{l}\text { Depende menos da mãe para os } \\
\text { cuidados }\end{array}$ & $\begin{array}{l}15.14 / \\
15.15\end{array}$ & $\begin{array}{l}\text { "...eu me tornei uma pessoa mais } \\
\text { independente... }\end{array}$ & \multirow[t]{3}{*}{ Independência } & \multirow[t]{2}{*}{$\begin{array}{l}\text { Não depende da mãe para fazer o } \\
\text { cateterismo }\end{array}$} \\
\hline Pode sair e fazer o autocateterismo & $\begin{array}{l}15.16 / \\
15.17\end{array}$ & & & \\
\hline Liberdade para ir e vir & & “...poder fazer tudo, de sair.” & & Autonomia para sair após a derivação \\
\hline
\end{tabular}

\begin{tabular}{|l|l|l|}
\hline \multicolumn{1}{|c|}{ Classificação Temática } & \multicolumn{1}{|c|}{ Categorias Empíricas } & \multicolumn{1}{c|}{ Categorias teóricas } \\
\hline Rede de apoio & Rede de apoio & "Qualidade de vida pra mim é...” \\
\hline Independência & Melhoria da independência & "Eu tenho mais independência" \\
\hline
\end{tabular}

Pesquisa de Opinião:

1. Como você avalia a sua qualidade de vida? (5 - muito boa)

2. Você está satisfeito com a sua derivação urinária? (4 - muito satisfeita)

Fatores que interferiam negativamente na qualidade de vida relacionados ao período anterior à derivação: 
a) Dependência da mãe para o cateterismo vesical;

b) Restrição da mobilidade social (sair).

Emergiram as dez Categorias Teóricas a seguir:

1. "Qualidade de vida pra mim é..."

2. "Não ficar perdendo xixi."

3. "Eu tenho mais independência."

4. "Falta Acessibilidade."

5. "Não entendem sobre isso."

6. "Um pouco a reclamar."

7. "Minha lesão."

8. "Eu tinha uma vida muito ativa."

9. "Nem ligo pra estética."

10. "O sexo diminuiu.". 


\section{APÊNDICE G - Fotos}

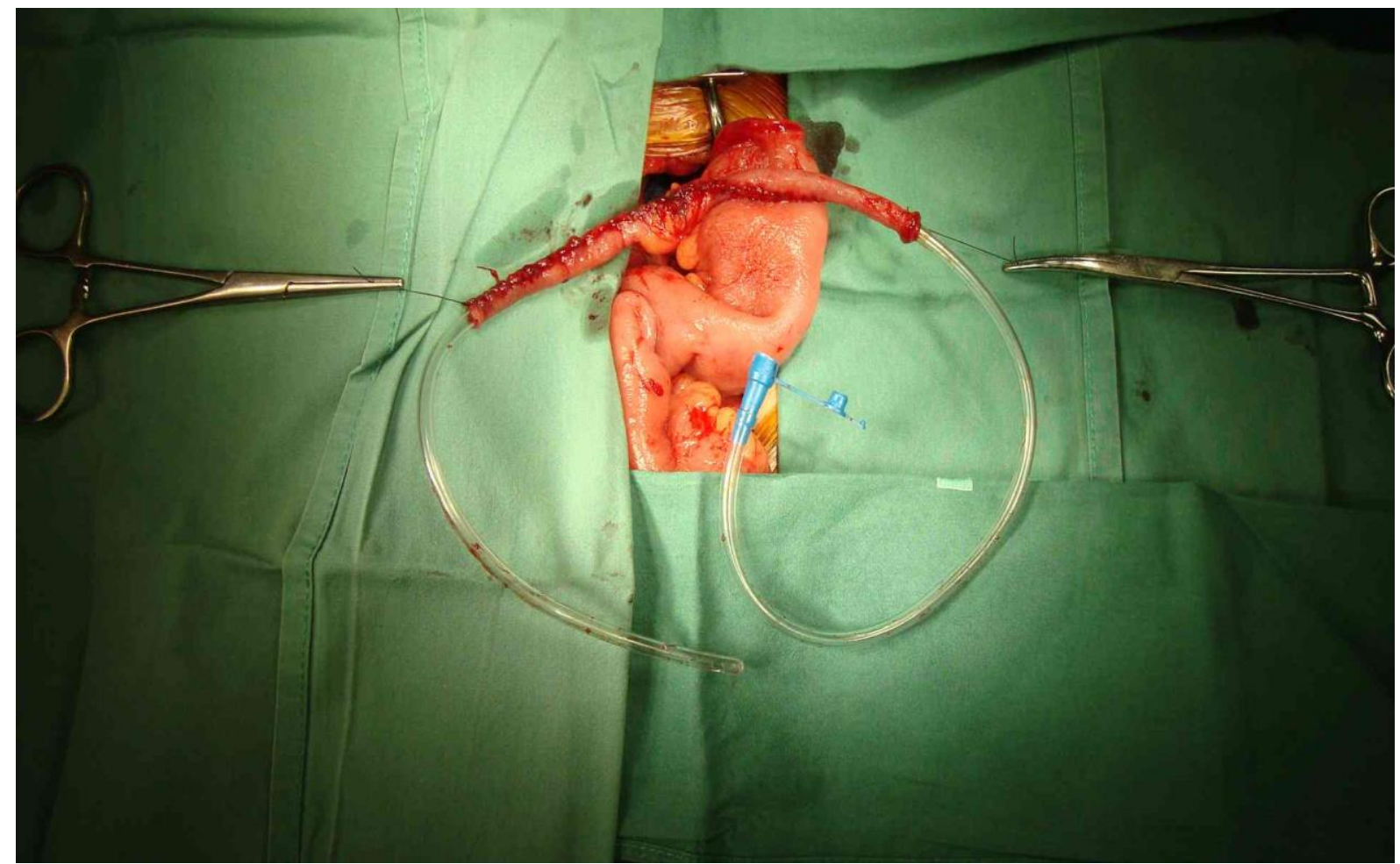

Foto 1 - Confecção cirúrgica do conduto utilizando a técnica de Monti.

Nota 1: Imagem documentada no prontuário do participante.

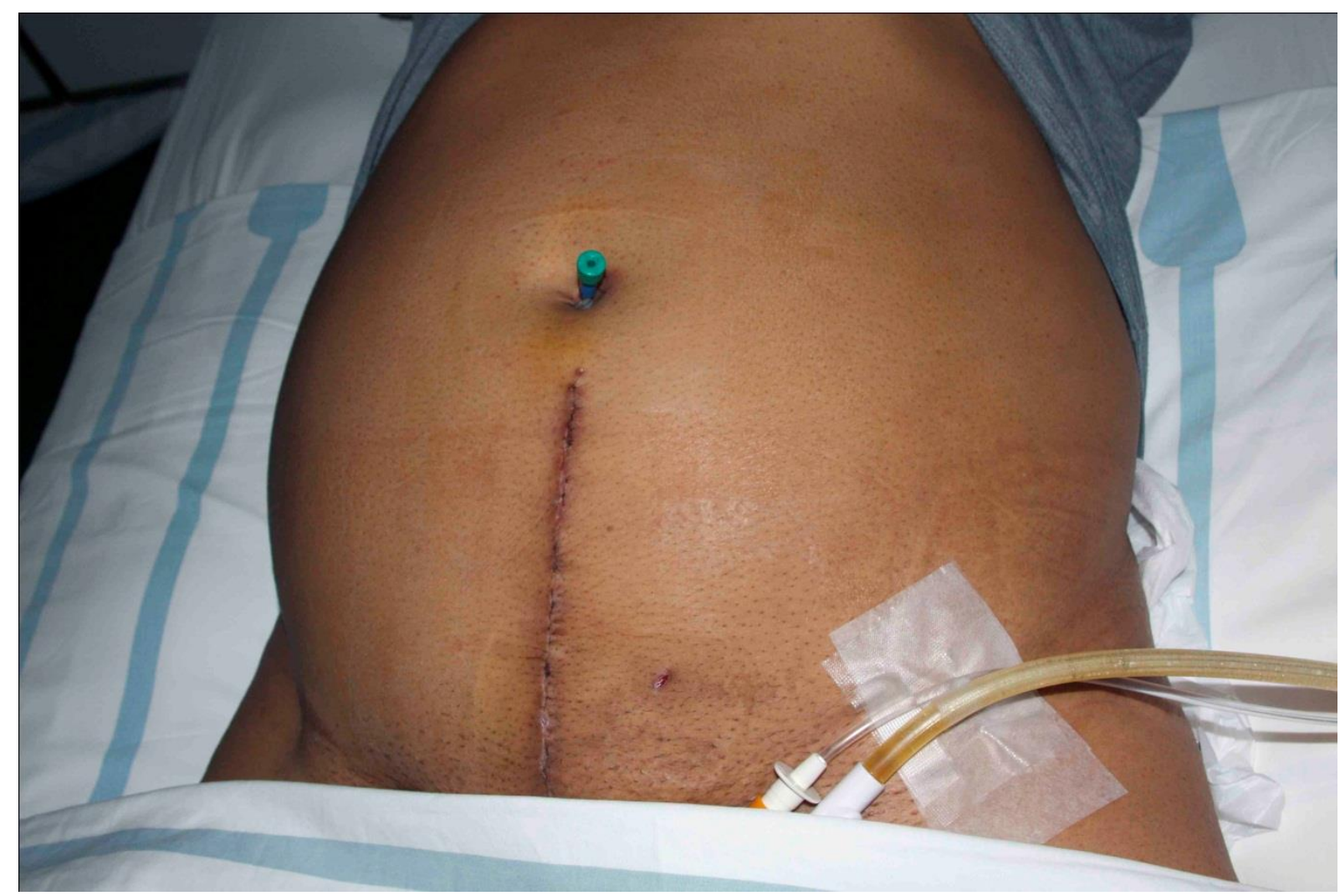

Foto 2 - Pós-operatório tardio de derivação urinária continente (maturação do conduto urinário).

Nota: Imagem documentada no prontuário de não participante da pesquisa, mas devidamente autorizada a utilização e veiculação. 


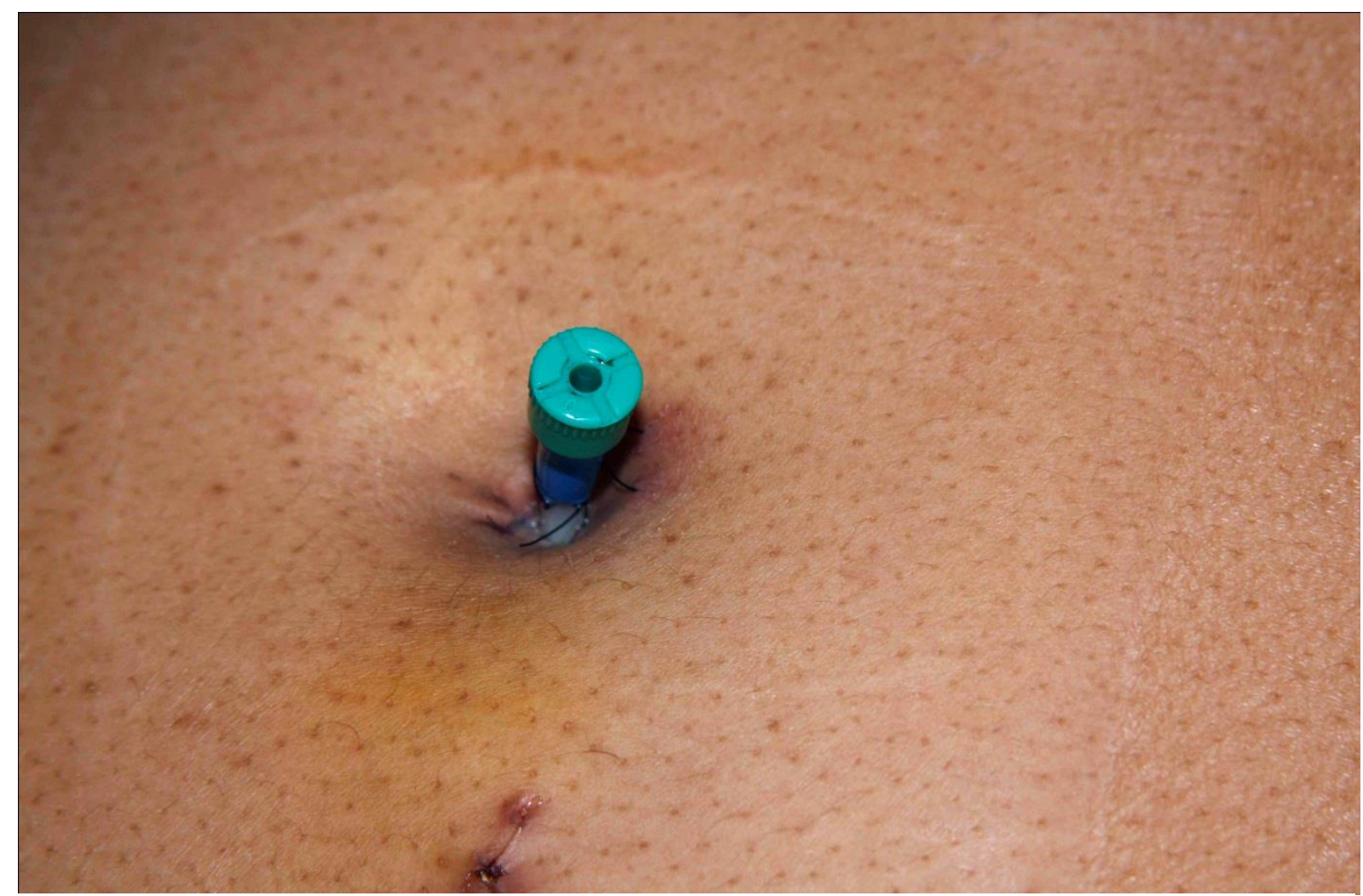

Foto 3 - Pós-operatório tardio de derivação urinária continente (presença de cateter vesical no estoma). Imagem documentada em prontuário.

Nota: Imagem documentada no prontuário de não participante da pesquisa, mas devidamente autorizada a utilização e veiculação.

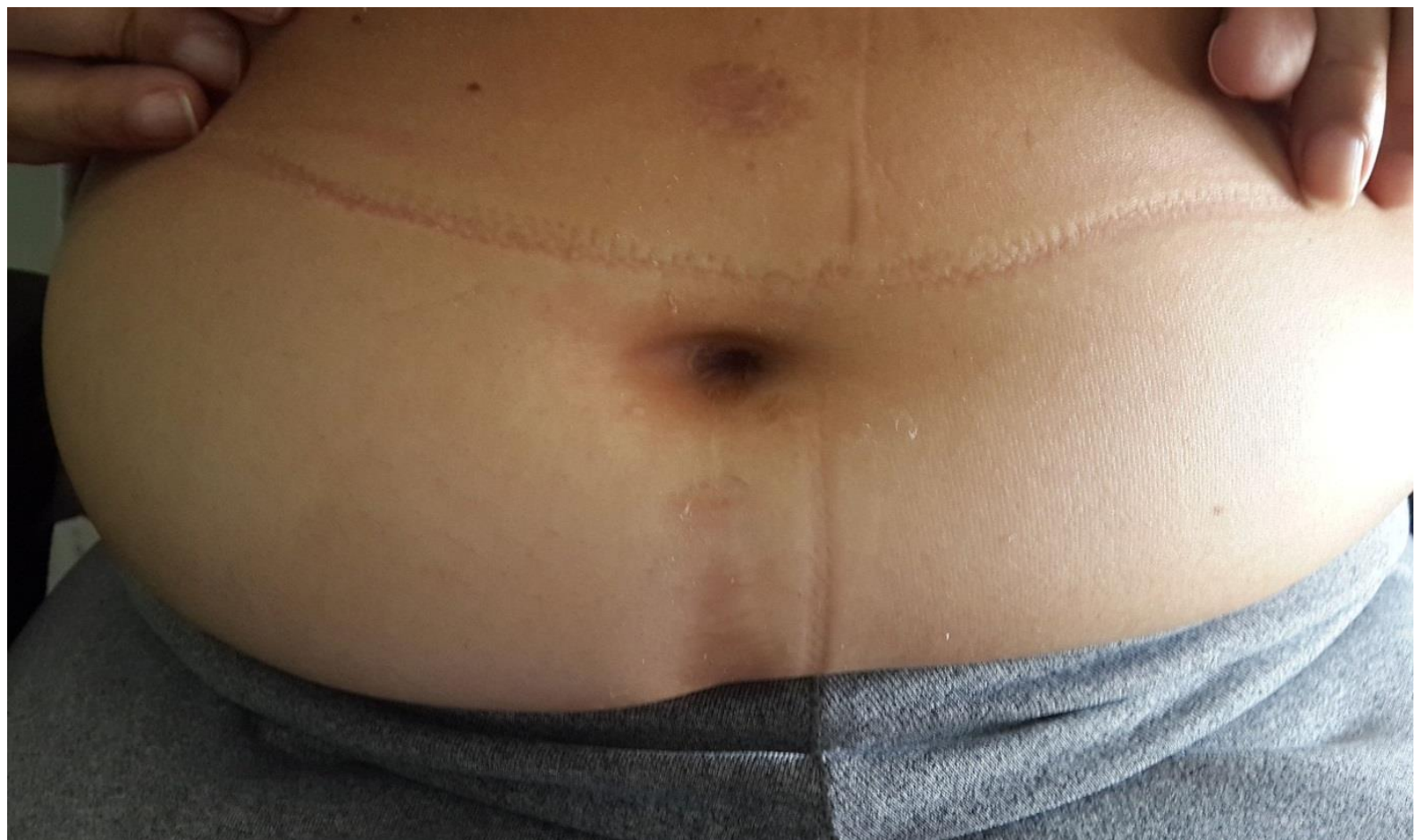

Foto 4 - Estoma urinário localizado na cicatriz umbilical.

Nota: Arquivo pessoal. Foto cedida pela participante. 


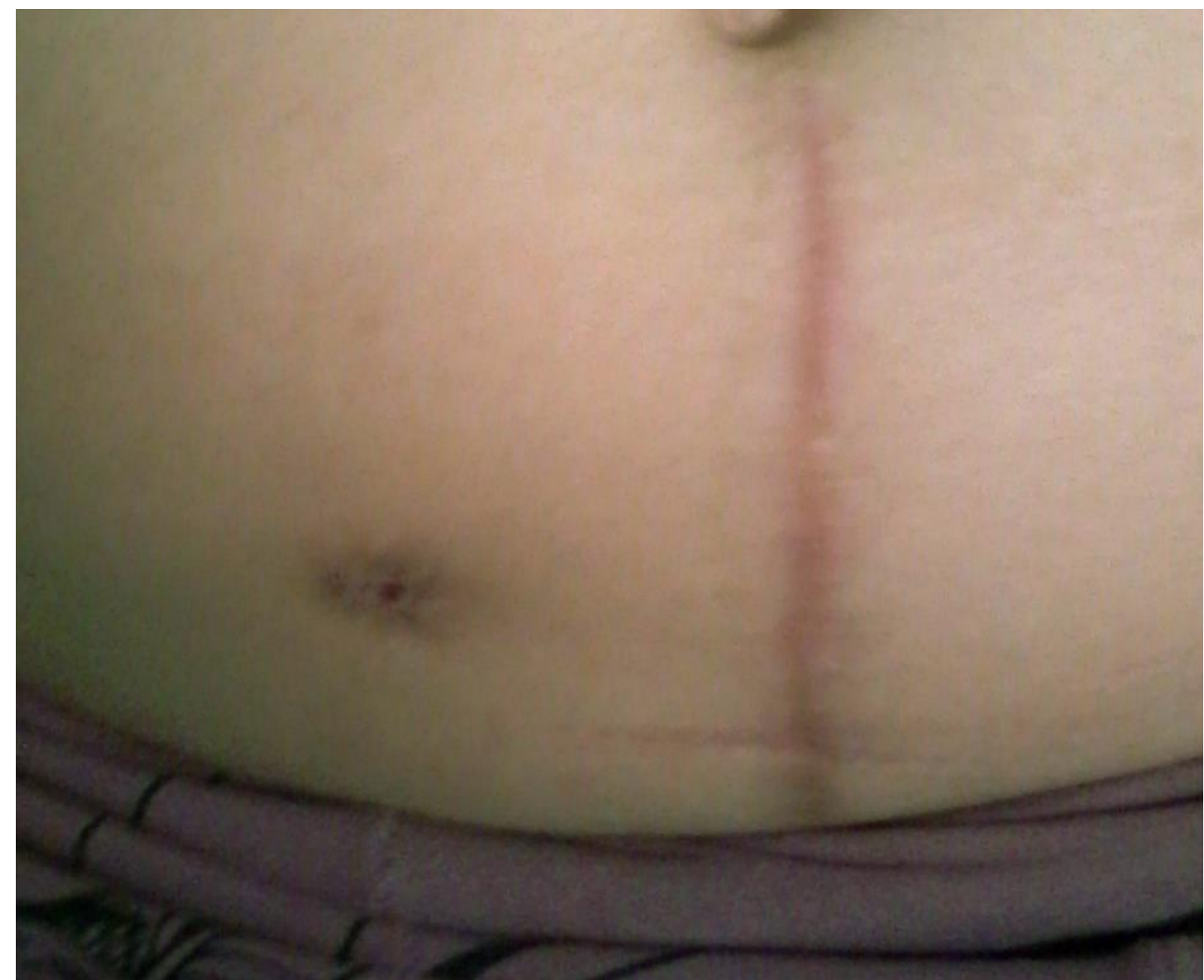

Foto5 - Derivação urinária continente, localizada no hipocôndrio direito.

Nota: Arquivo pessoal. Foto cedida pela participante. 


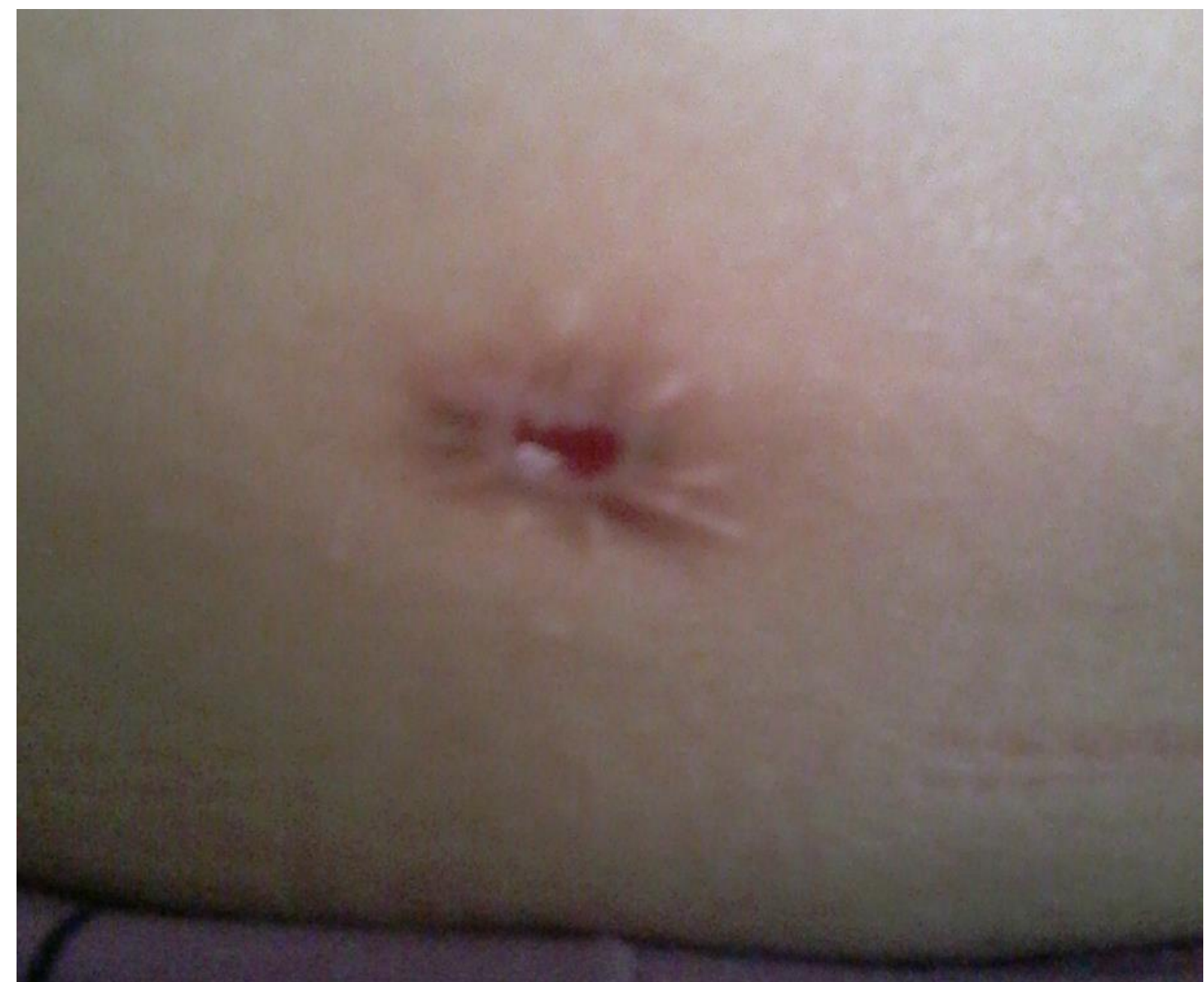

Foto 6 - Derivação urinária continente (foto evidenciando o estoma).

Nota: Arquivo pessoal. Foto cedida pela participante. 


\title{
ANEXO A - Parecer consubstanciado do CEP/SARAH-Brasília
}

\author{
ASSOCIACYAO DAS PIONEIRAS \\ SOCIAIS-DF/REDE SARAH

\section{Cistoraforma}

\section{PARECER CONSUBSTANCIADO DO CEP}

\section{DADOS DO PROJETO DE PESQUISA}

Titulo da Pesquisa: impliçaçâo da Estoma Urinaria Continente na Qualidade de Vida do Paciente com Lesabo Medular

Pesquisador Carla Andreia Araujo

Área Tematica

Versào: 3

CAAE: $16932713,1,0000.0022$

Instituição Proponente: Associayajo das Poneras Sociais-DF / Rede Sarah

Patrocinador Principal: Financamento Proprio

\section{DADOS DO PARECER}

Numero do Parecer: 405.685

Data da Relatoria: $12 / 09 / 2013$

Apresentaça do Projeto:

Apresentaçao do Projeto. Avaliaçało da repercussão do procedimento de derivaçào urinaria continente através da estamia urinaria na qualidade de vida de pacientes com lesão medular.

\section{Objetive da Pesquisa:}

Objettvo da Pesquisa. Primário Avaliar a implicaç̧o da estomia urinária continente na qualidade de vida do paciente com lesăo medular .

Secundario identificar as caracteristicas sociodemograficas e o perfil clinica dos participantes. Conhecer a porcepçao sobre qualidade de vida das pessoas com lesao medular e derivaçăo uninaria continente.

\section{Avaliaçâo dos Riscos e Beneficios:}

Avalıaçẫo dos Riscos e Beneficios Riscos: A pesquisa em si não oferece riscos uma vez que busca conhecer a percepçáo do paciente sobre a implicacào da confeçào urinária continente na qualidade de vida.

Beneficios: Maicr conhecimento cientifico, sobretudo para os enfermairos, no que se refere as imglicaçōes da denvação urınatna contınente em pessoas com lesāo medular. Contribuir para traçar metas para o processo de cuidar em enfermagem antes e após a derivação urinaria de forma

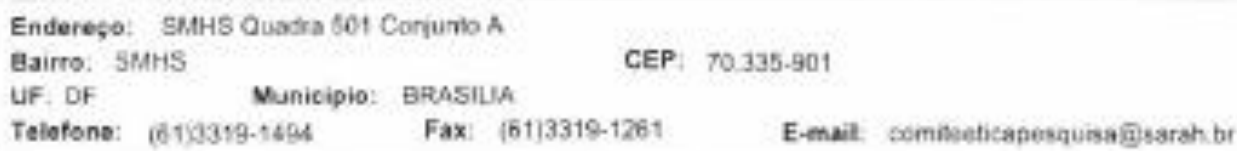

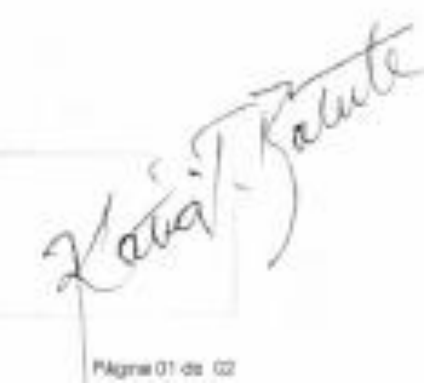




\section{ASSOCIAÇÃO DAS PIONEIRAS Plotoforma SOCIAIS-DF/ REDE SARAH}

Continuapao do Parecer 405.685

que o paciente obtenha resultados eficientes que interfiram de forma positiva na qualidade de vida. Podera contribuir ainda para a maximizaçāo de beneficios de assistência especializada respaldada em conhecimento advindo da pesquisa.

\section{Comentários e Consideraçōes sobre a Pesquisa:}

Comentários e Consideraçōes sobre a Pesquisa.

A pesquisadora atendeu as solicitaçōes, colocando os tipos de questōes que serāo abordadas no questionário, tornando mais claro o desenvolvimento metodológico. O cronograma r orçamento foram explicitados. Foi mencionado que as duas perguntas abertas e as duas questōes com itens tipo Likert sobre qualidade de vida estăo contidas na questão XII do questionário.

Consideraçōes sobre os Termos de apresentaçăo obrigatória:

apresentou TCLE adequado

Recomendaçōes:

Conclusōes ou Pendências e Lista de Inadequaçōes:

aprovado

Situaçāo do Parecer:

Aprovado

Necessita Apreciação da CONEP:

Não

Consideraçōes Finais a critério do CEP:

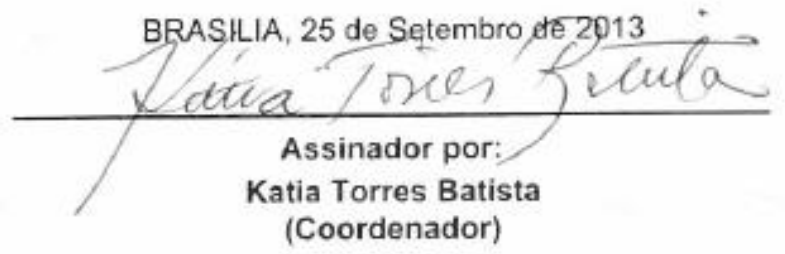

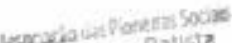

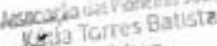

turedico

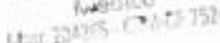

(Coordenador)

Endereço: SMHS Ouadra 501 Conjunto A

Bairro: SMHS

UF DF Municipio: BRASILIA

CEP: $70.335-901$

Telefone: (61)3319-1494

Fax: (61)3319-1261

E-mail: comiteeticapesquisa@sarah br 